\title{
INCLUSIVE HOUSING
}

EXPLORING CULTURALLY INCLUSIVE + ACCESSIBLE DESIGN IN THE CONTEMPORARY NEW ZEALAND STATE HOUSE

LYDIA POWRIE

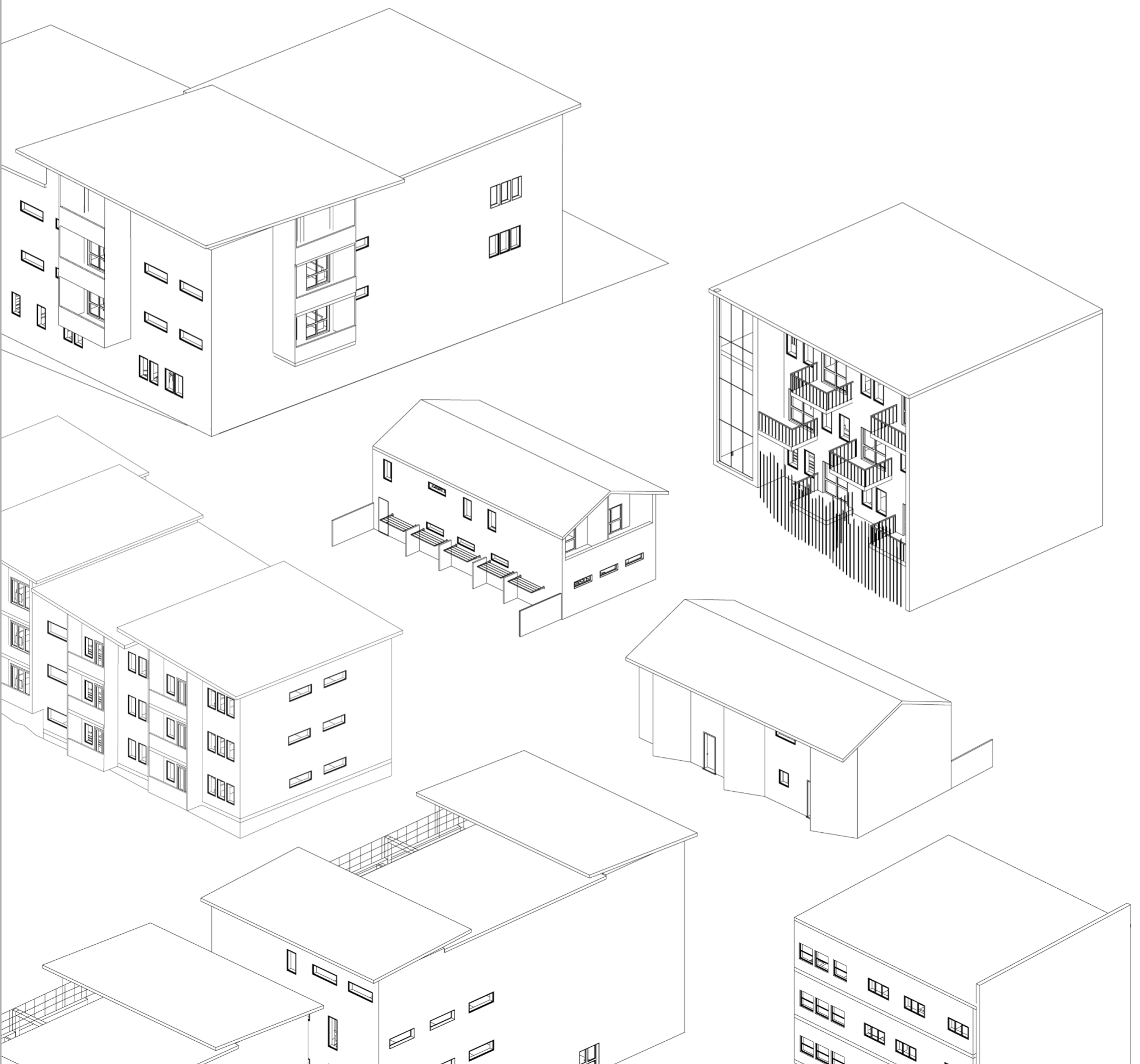


Inclusive Housing: Exploring Culturally Inclusive + Accessible

Design in the Contemporary New Zealand State House

Lydia Powrie

Supervisor: Nilesh Bakshi \& Joanna Merwood-Salisbury

A thesis submitted to Victoria University of Wellington in partial fulfilment of the requirements for the degree of Master of Architecture (Professional).

Victoria University of Wellington 


\section{Abstract}

The aim of this research is to establish and apply design methods that define an appropriate dwelling for New Zealand's state housing. The central criteria for this is accessibility and cultural inclusivity. New Zealand's current state housing scheme is struggling to provide for an ever-growing waitlist of eligible households. Furthermore, the size and design of state homes have remained relatively stagnant, while the average occupant has significantly deviated from the nuclear family it once was. Not only is density but it is alng stock predominantly low in bi-cultural society. However, state home occupants are no longer comprised of two parents + child(ren) from Pakeha or Maori backgrounds. Instead, single-person households, couples with no children or only one child from all ranges of ethnicities make up the majority of the state housing register.

This change suggests there is a potential need for a paradigm shift from three-four bedroom dwellings to one-two bedroom and five+ bedroom dwellings becoming the majority of the housing stock. Not only are the homes incorrect in bedroom size, but many are also inaccessible to New Zealand's diverse range of cultures, there is 'no one size fits all' home type for each cultural group.
The findings of this thesis identify a lack of consideration in Housing NZ's design guides demographics of its residents. Intention domestic case studies are comparatively analysed to identify spatial features that con inform the way state houses should be designed for New Zealand residents. This research has been used to create a design guidelines that provides flexible and inclusive dwellings. Finally these guidelines are tested on a specific site in inner-city Wellington proposing a range of dwelling typologies designed for accessibility and inclusivity that are explored at three key scales - the urban landscape, the building envelope and the interior. 
Thank you to my supervisors, family and friends. Your feedback and support was invaluable.

To my partner, thank you for your unwavering encouragement and kindness throughout this process. 


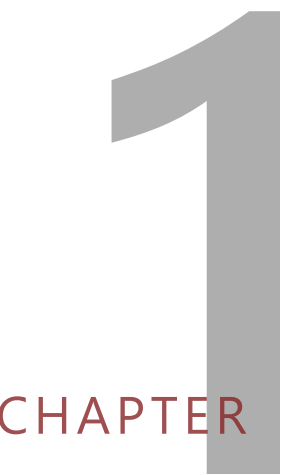

Theory

Research Question.......................02

Introduction................................. 03

Literature Review.......... History of New Zealand's State Housing...................... Current Issues of New

Zealand's State Housing.......10

to State Housing...

Recent Additions..

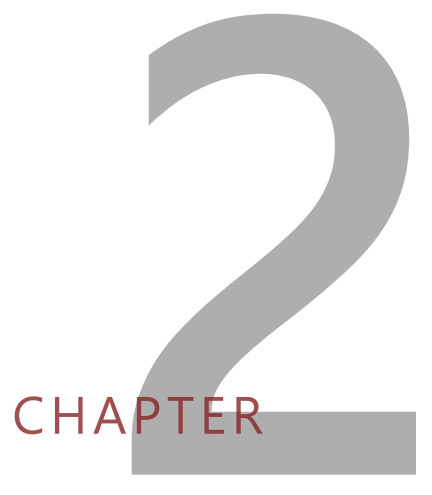

Demographics

Why .......................................................2

Social Housing Register...………......26

Māori Considerations........................28

Pasifika Considerations......................30

Refugee Considerations....................32

Religious Considerations....................34

Universal Design..................................

Spatial Relationships

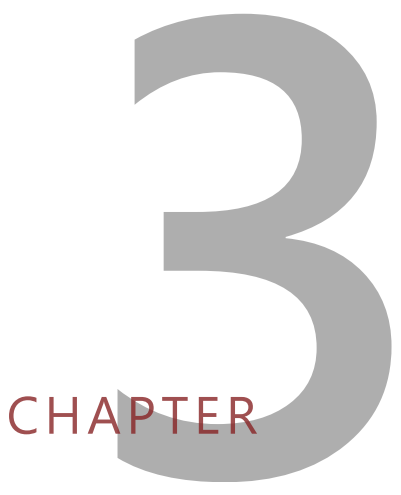

Assessing Appropriate

Contemporary Dwelling Analysis.... 44

Testing "Appropriate" Design.............54

A s.

Assessing Arlington..........................68

Reflection. $\cdots \cdots \cdots \cdot 72$

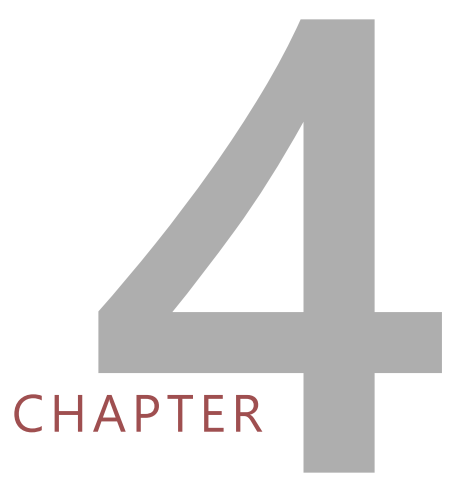

Initial Design

Exploring The Alternative Home.......76

Building Typologies............................ 78

Plan Exploration.........

Urban Scale......................... 90

Communal Space................................98

Reflection

CHAPTER

Developed Design

Developing State Housing....................106

Masterplanning.............................108

Internal Street Units........

Type A.......................................... 132

Type B..................................................... 146

Full Scheme........................................156

North East Courtyard........................158

North East Courtyard Units...............162

Type C............................................164

Type D...…………………………....170

Type E..................................................174

Full Scheme.

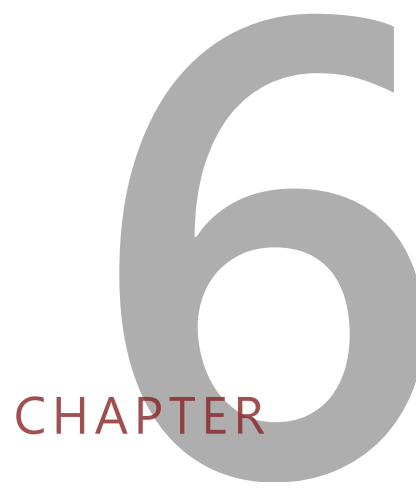

Summary

Conclusion..

Future Research....

List of Figures....................................204 


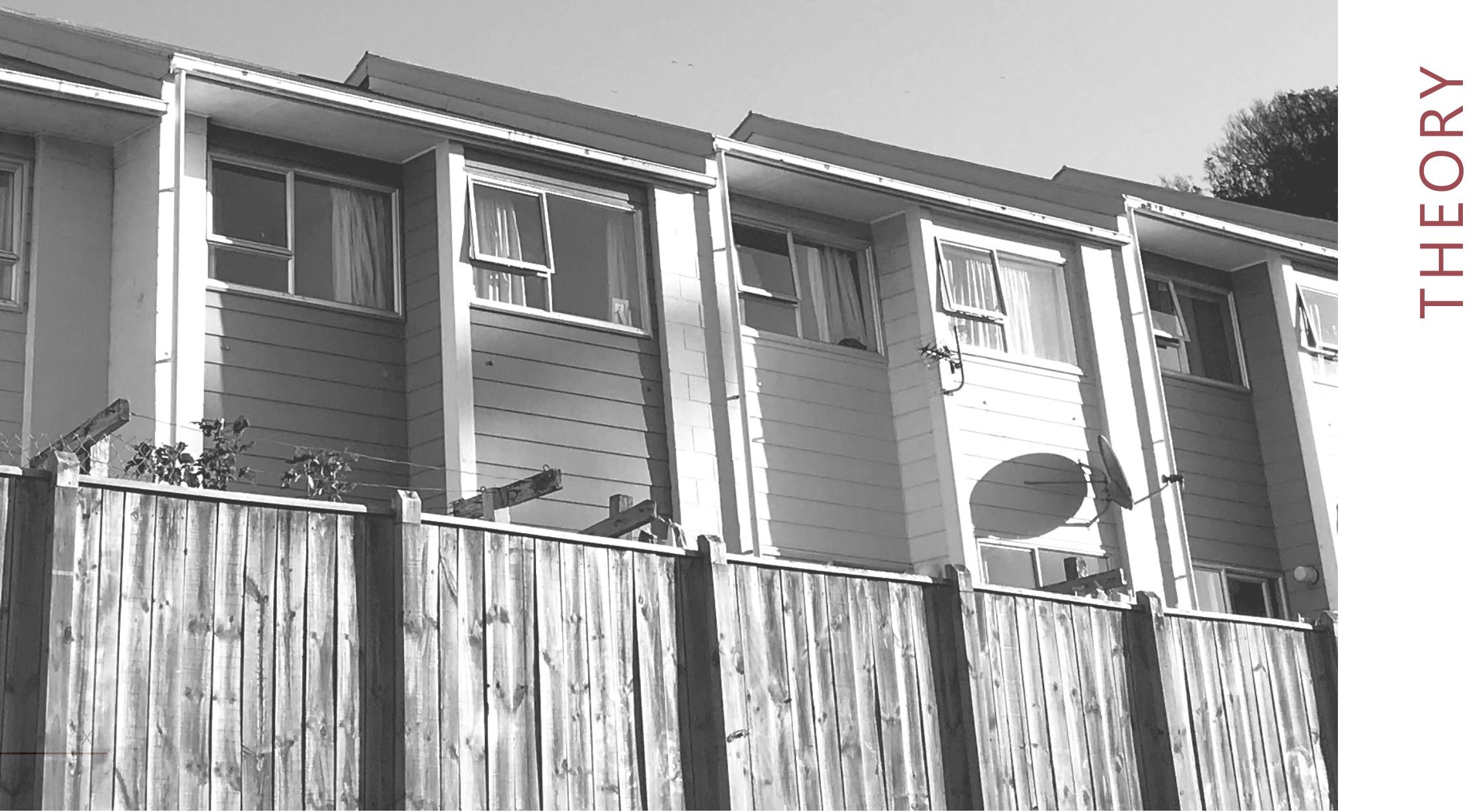




\section{Research Question:}

Can design-led research help define more appropriate and inclusive social housing for New Zealand?

This thesis aims to develop a deeper understanding of the role that architecture can play in the spatial needs of New Zealand's social housing residents.

\section{Introduction}

New Zealand state housing has taken a "one size fits all" approach since its inception just over 100 years ago. While it was once a benchmark for quality housing in the 1950s, it is now a typology that is failing its residents. Over its lifetime, cultural representatives have worked with Housing New Zealand and other housing providers to propose more suitable dwellings for those of Māori and Pasifika background (Hoskins, 2014; Faumina \& Associates, 2002). These groups have produced general rules of thumb when designing for Mãori or Pasifika families. While this is a step in the right direction, this still implies that each culture requires its own type of housing, which can be short-sighted. New Zealand is only increasing in diversity as the refugee crisis is worsening, globalisation continues and New Zealand's social housing provides for short and long term residents from around the world. Dwellings should be flexible enough to provide sufficient and appropriate homes for everyone who requires them. Currently, the housing stock is made up of standard European orientated dwellings, when only $21 \%$ of state housing applicants are of European descent (MHUD, 2019). According to the Ministry of Housing and Urban Development (MHUD) 16\% of the state housing register is comprised of people of "other" and "unspecified" ethnicity, which includes those who identify as Asian, MELAA (Middle Eastern, Latin America and Africa) or a huge variety of mixed cultural backgrounds which are not clearly defined. Those in these groups may also have strong preferences about the dwellings that they live in and are currently not being provided for.
In the same way different cultures have been treated separately, the issue of accessibility has had a similar history in state housing. For example, the typical 1950's state house was built with a sub-basement, raising the entire house above the ground, making the entryway accessible by small, steep stairs. In recent years, a few accessible social housing developments such as Galway Street complex in Onehunga, Auckland, and Hanson Street in Newtown, Wellington, have been built. In many cases, they are only for those with physical disabilities, or only the ground floo units are accessible (Housing New Zealand, 2018). Along with this, these developments are usually made up of one-bedroom dwellings and no communal space is provided for the residents. This segregates those in these groups from living in diverse communities that would range in age groups and have opportunities to connect with their neighbours. Those who feel isolated in their surroundings will be at higher risk of mental health illness (Pearson, Griffin, Davies \& Kingham, 2013). Rather than focusing on accessibility requirements, a universal design approach can be taken to ensure that environments are designed to be "useable by all people, to the greatest extent possible, without the need for adaptation or specialised design" (Mace, 1985, 18). By focusing on universal design approaches rather than individual requirements, an inclusive and flexible dwelling can be proposed that can be suitable or adaptable to most state housing residents. 


\section{Methodology}

This thesis has utilised design led research to define and design an inclusive and appropriate contemporary New Zealand state home. As established through a review of relevant literature, a new design approach to state housing requires an in-depth analysis of those who are occupying the dwellings and what their preferences are in order to enrich the design outcome. The methodology supports a depth of research to establish clear guidelines for design tested at multiple scales. It balanced quantitative and qualitative data to efficiently and effectively question the design. The research involved four phases:

\section{Literature review}

2. Demographic analysis of state/social housing occupants

3. Evaluation of contemporary New Zealand social housing developments to develop criteria that defines "appropriate" and inclusive social housing.

4. Proposal of design solutions at a range of scales that meet the criteria set out, which will be tested on a specific site and critically reflected upon at each design stage (initial, developed and final).

Phase One comprised a literature review to establish the history of New Zealand state housing, the current state of affairs and international examples of social housing. The history of state housing is important to understand why New Zealand first began to provide state housing to those who needed it and how government policy and politics have changed the design of state housing over time. Equally as important, the literature review established the current status of state housing in New Zealand, and gave an overview of international social housing methods. Government involvement in each country was also discussed so that inappropriate direct comparisons were not made.

Phase Two established who state occupants are and what their needs are in detail. These were then specified into specific spatial requirements.

Phase Three evaluated contemporary New Zealand state dwellings against requirements specified in Phase Two. Both successful and unsuccessful homes were evaluated in detail so that the design outcome could be optimised.

Phase Four comprised the design phase where appropriate and inclusive homes are proposed in the context of a specific site. Upon consideration, Arlington One/Arlington Apartments in the Te Aro area of Wellington was explored. Initial design proposed design solutions at three scales - masterplan, building envelope and interior. Developed design began to integrate all three scales and involved greater consideration to surrounding context to propose possible building typologies, communal spaces and approaches to privacy and accessibility concerns. The final design outcome is a development with a range of building typologies that provided for the diverse needs of those who occupy state housing in an urban context.

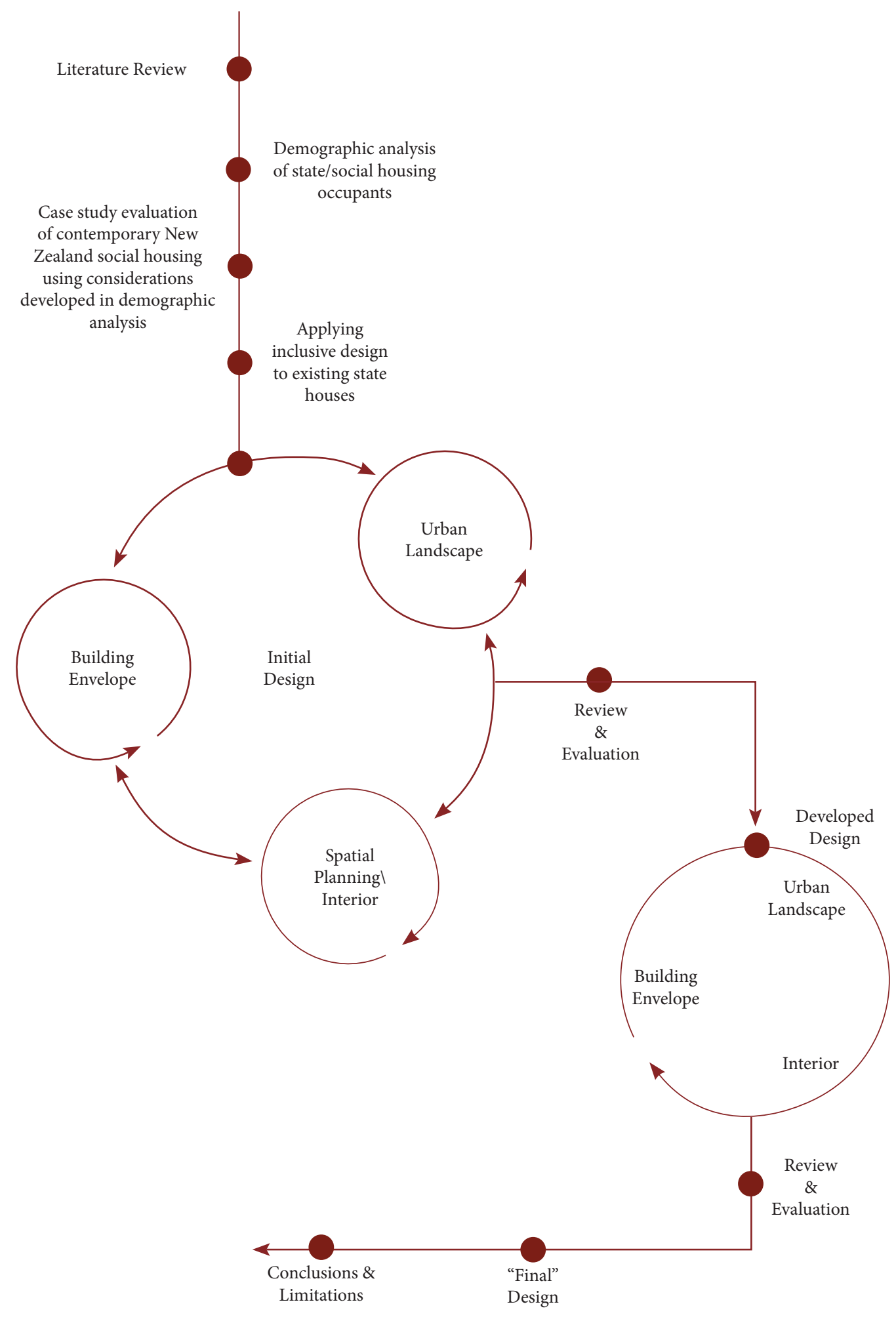




\section{Literature Review}

This chapter provides an overview to state housing in New Zealand by exploring its history, current issues and recent examples of successful state housing in New Zealand. International approaches to state housing will also be researched to present and evaluate

History of New Zealand's State Housing

At the end of the 19th Century, New Zealand was in a housing crisis due to its rising population. At the same time, New Zealand was rapidly expanding its railway network and the informal settlements were not sufficient housing for the workers and their families. In response to this, the New Zealand Railways Department built the first example of state housing - Railways cottages (Schrader, 2007). These were built between 1880 and 1923 .

In 1906, the Labour government trialled state housing in Petone as an inner-city area with low-quality housing (Schrader, 2007). In the early 20th century, New Zealand cities were predominantly comprised of industrial areas and ports, with the majority of houses being built in the outer suburbs. Two key factors limited a worker's home ownership ability: the distance required to travel between the suburbs and city; and the cost of buying a house. As a result of this, informal settlements arose in the inner city due to insufficient housing. alternative ways state-provided housing has been implemented. From this evaluation, it can be established how the design of New Zealand' state housing could be improved. This will aid in defining what "appropriate" and inclusive state housing is through design.
These settlements did not have adequate sewage, fresh water or power (Schrader, 2007). Labour's solution to this issue was to provide cottages for workers. These cottages were located in the suburbs and gained popularity while only addressing one of the two issues. However, in 1910 a new political party was elected and piorities shifted away from stateowned housing and these properties were sold.

The production of state housing ceased, resulting in overcrowding steadily increasing until 1936 when the Labour government was re-elected. The Labour government used what had been learned from the successful trial in Petone to inform what the nationwide state-provided housing program became. The government agreed to build 5,000 homes and set the rent of each household relative to the occupant's salary (Schrader, 2007). By February 1939, the applicant waiting list had risen to 10,000 and the government were building 57 homes a week to combat the

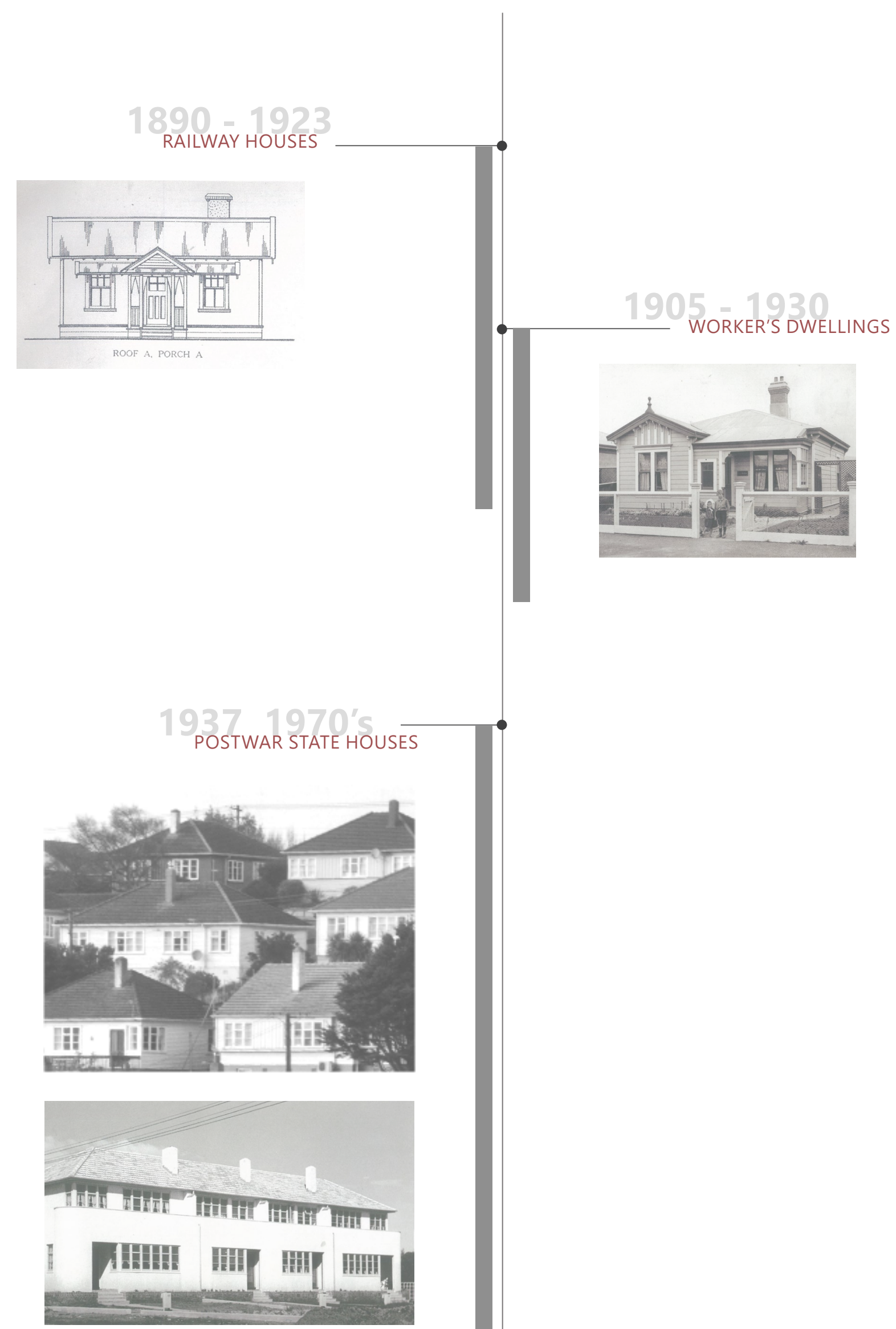


demand. During World War II, production of state housing was halted. As the war ended, Labour introduced legislation that aimed to make state housing "as close as possible to

the owner-occupied tenure status" through increasing rental rights (Boyce, 2009, p.2). These dwellings were built with quality materials and were regarded as the benchmark for quality housing at the time.

When a National government was elected in 1949, home ownership was a priority and residents of state homes were offered to own their home for a subsidised value (Schrader, 2007). Due to their high quality, state housing was popular and many residents accepted the offer to purchase. However, as of 1953 the Housing Construction Division (HCD, now known as Housing New Zealand) were required to meet a budget. This budget restricted the construction of state housing and economies of scale could no longer be maintained. Additionally, houses were still being sold at the same rate while production decreased.

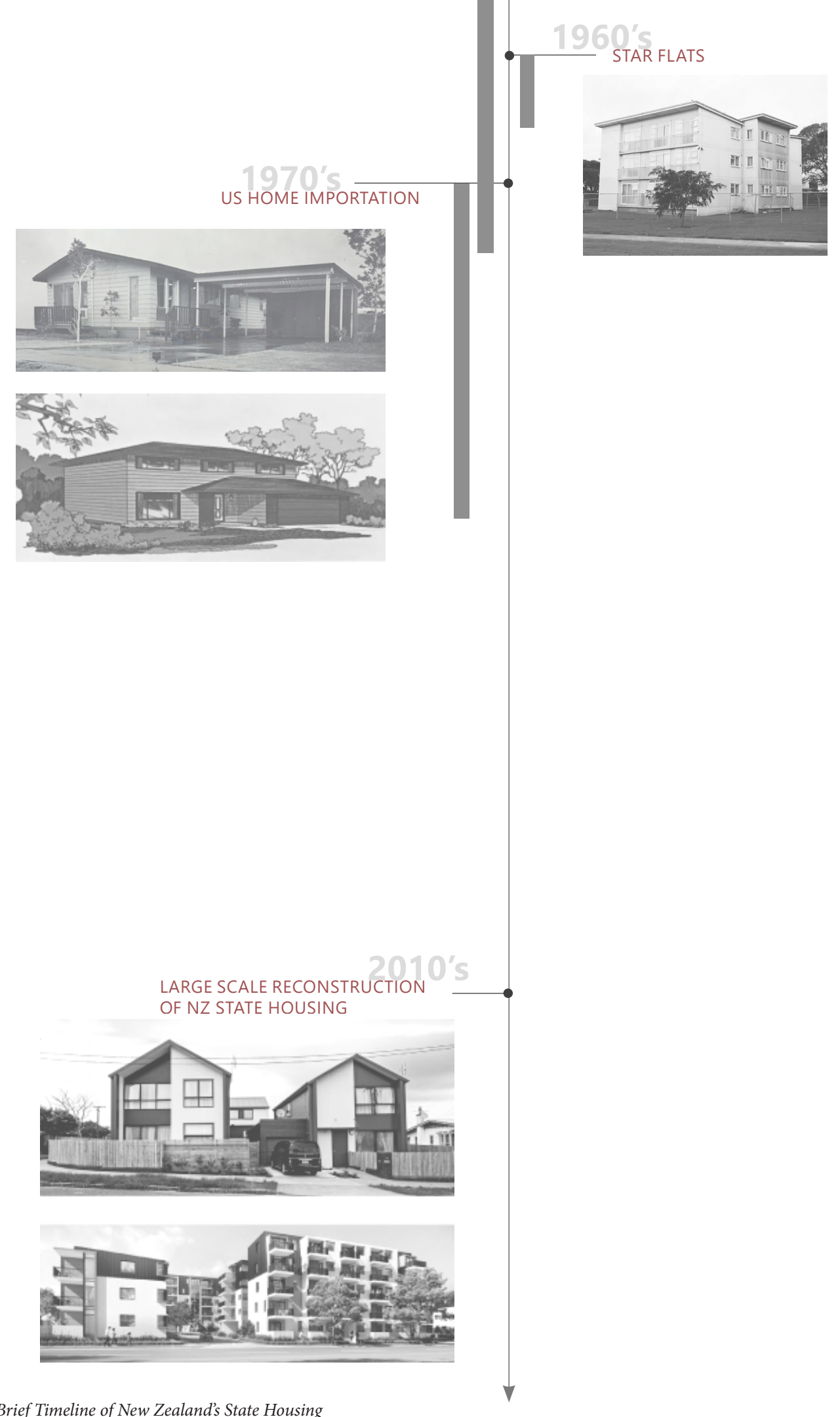


Current State of New Zealand's Social Housing

In recent years, state housing has more popularly been referred to as social housing due to the growing number of council and Non-Government Organisations (NGOs) provided social housing (Johnson, 2017). Housing providers have to balance between supply and demand, the correct size homes with an adequate number of bedrooms and being located in appropriate locations for the occupants. The typical state housing occupant was originally a family with children. However, the demand has increasingly shifted towards single adults and couples with no children (MSD, 2018). This demographic change should have resulted in a shift in the design of the social housing stock, however, this did not occur.

A report released by the Salvation Army in 2017 highlights the complexities at play when trying to propose the dream solution for social housing. As identified by Johnson (2017), there is a perception that state housing occupants will eventually be able to move out as their circumstances improve. However, this is not occuring. The economic discord between rental prices rising and stagnating minimum wages, has made it difficult for those in state housing to enter into the private rental market. Additionally, many tenants require state housing continuously due to their age, disability or health status (including mental health).

The Salvation Army report identified two key groups who may require long term social housing. The first consists of approximately 150,000 people who are in poor health or are less able and will most likely be heavily reliant on state support for the rest of their lives (Johnson, 2017, pp 3-7). The second is approximately 190,000 elderly who do not own their own home and will soon, or already do rely on New Zealand Superannuation for thei main source of income. However, due to a disproportionately high ageing population, this group is estimated to grow to 270,000 by 2030 if house prices and rents continue to rise at a consistent rate. While these two groups have remained fairly consistent over the last 50 years, there has been a large shift in diversity acros New Zealand in this time. This has resulted in new demographics with different requirements. Johnson observed that the current housing stock of New Zealand fails to provide for these different needs. This is equally, if not more, prevalent in social housing with an increase in the diversity of applicants alongside larger levels of migration to New Zealand. Due to the large diversity, this has meant that state housing groups may be larger or smaller than the average New Zealand family.

As identified by Statistics New Zealand (2013), the average household size for immigran cultures, such as Pasifika and MELAA, is larger than the average household size for Europeans and Asians. However, the average household size across all cultures has decreased. This is reflected in the current state housing applications, where $74 \%$ of applications are requesting one-two bedroom dwellings. While there has been a consistent shift towards smaller dwellings throughout New Zealand, these requirements differ between each region around New Zealand due to different financial, cultural and social circumstances. However, the currrent social housing stock still

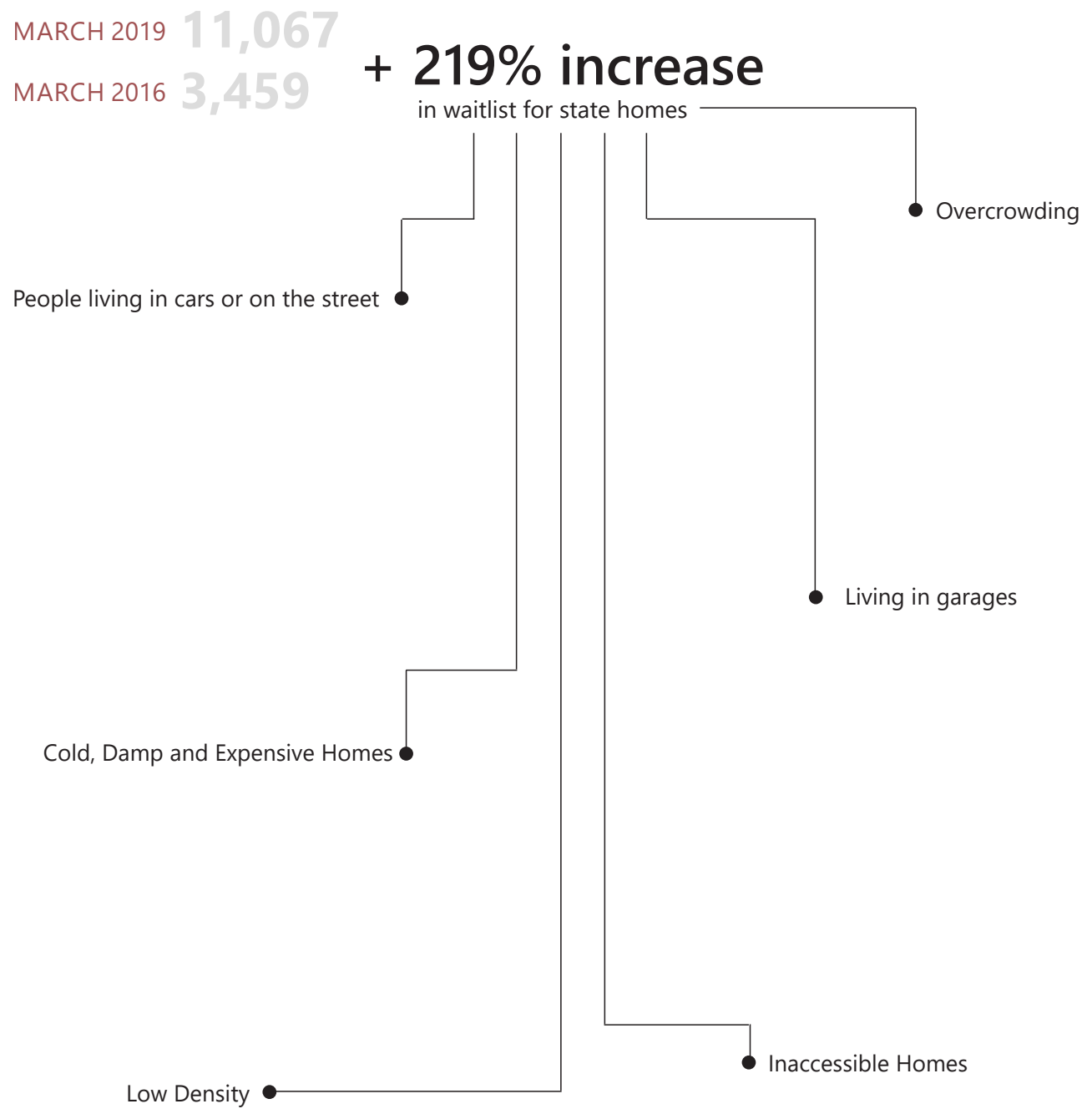

Figure 1.02. Main concerns for Social Housing in New Zealent 
reflects the demographics of 1960's New Zealand, with three to four bedrooms being the majority. Along with this, there is a significant housing shortage, with the state housing wait-list tripling in the last five years (MHUD, 2019). Johnson, Howden-Chapman and Eaqub completed a stocktake of New Zealand housing in 2018 which highlighted the failure of the current Housing system. In Auckland alone, the housing shortage has reached 45,000 units and will continue to rise (Johnson, Howden-Chapman \& Eaqub, 2018).

In the next 20-30 years, Housing New Zealand and Wellington City Council are aiming to replace or renew their entire housing stock (WCC, 2018). They have acknowledged that the stock does meet the requirements of current occupants and those waiting for state housing. This plan includes adding an estimated 30,000 new homes to the housing stock in the Wellington Council's housing portfolio alone, which excludes the Hutt Valley, Porirua and Kapiti Coast. In both cases, more concern should be taken when designing state/social housing so that they provide appropriate housing for current and future residents. A 'one size fits all' approach to state housing that once worked when New Zealand was less ethnically diverse in the 1930s will no longer suffice. This thesis will address the changing needs of state housing occupants through design. While architecture cannot change the political landscape and perception of those in state housing, it can address their spatial requirements and improve the perception of statehouses. 
International Approaches to State Housing

Social housing has been provided to those who require it in almost every country in the world (Arrigoitia, Scanlon and Whitehead, 2014). However, different levels of government involvement and economic support has resulted in a wide variety of social housing models. After World War II, Europe was in a housing crisis due to the mass destruction of cities, along with a widespread displacement of people and as a result, the construction of social housing rapidly increased. In Eastern Europe, social housing was based on the state providing a social wage, with those who were in need having their rent paid by the central government. In Northern Europe, it was a key responsibility of the welfare-state contract, meaning they would provide dwellings for everyone who required them based upon the individual criteria of each nation (Arrigoitia, Scanlon and Whitehead, 2014). In Southern Europe, the policy emphasis was home ownership for families who could not access adequate housing. Given the context of this thesis, it was decided that the Netherlands model of social housing would be analysed as their social housing is of high quality, inclusive to the diverse population and as a result is destigmatised (Hoekstra, 2013). By proposing a more appropriate housing solution, New Zealand's state housing could also be perceived in a positive light in the future.

The Netherlands is unique for its large social housing sector, which is $32 \%$ of the national housing stock. Any rental property in Holland is rent controlled by the government, which allows social and private rentals to be affordable and removes the stigma of social housing that can occur when the difference in quality is significant (Arrigoitia, Scanlon and Whitehead, 2014). Additionally, any 'profit' that is made is reinvested back into more social housing and the upkeep of dwellings (Hoekstra, 2013). In contrast, many European countries prioritised profitability and have since sold significant portions of their socia housing stock that was built post-war. This has resulted in a housing shortage which has been amplified in recent years by the refugee crisis. In these countries, NGO's have been relied on to provide social housing (Arrigoitia, Scanlon and Whitehead, 2014). This has only been successful when there are incentives from the government for these organisations to compete against each other resulting in lower costs and high-quality housing.

Alongside different levels of government involvement, a range of housing typologies have been used around the world. Increasing populations and urban density, led to most modern social housing typologies being multi-storey. There are five key housing typologies; tenement blocks, tower blocks, slab blocks, linked slabs and deck accessed estates (Towers, 2000).

Tenement blocks are typically threefive storeys high and are only accessible via stairs. They originated in the 19th Century and were built predominantly until the 1940s. Each block has a small number of units to allow a medium density level of density and familiarity between neighbours (Towers, 2000). Tenement blocks were constructed worldwide although many
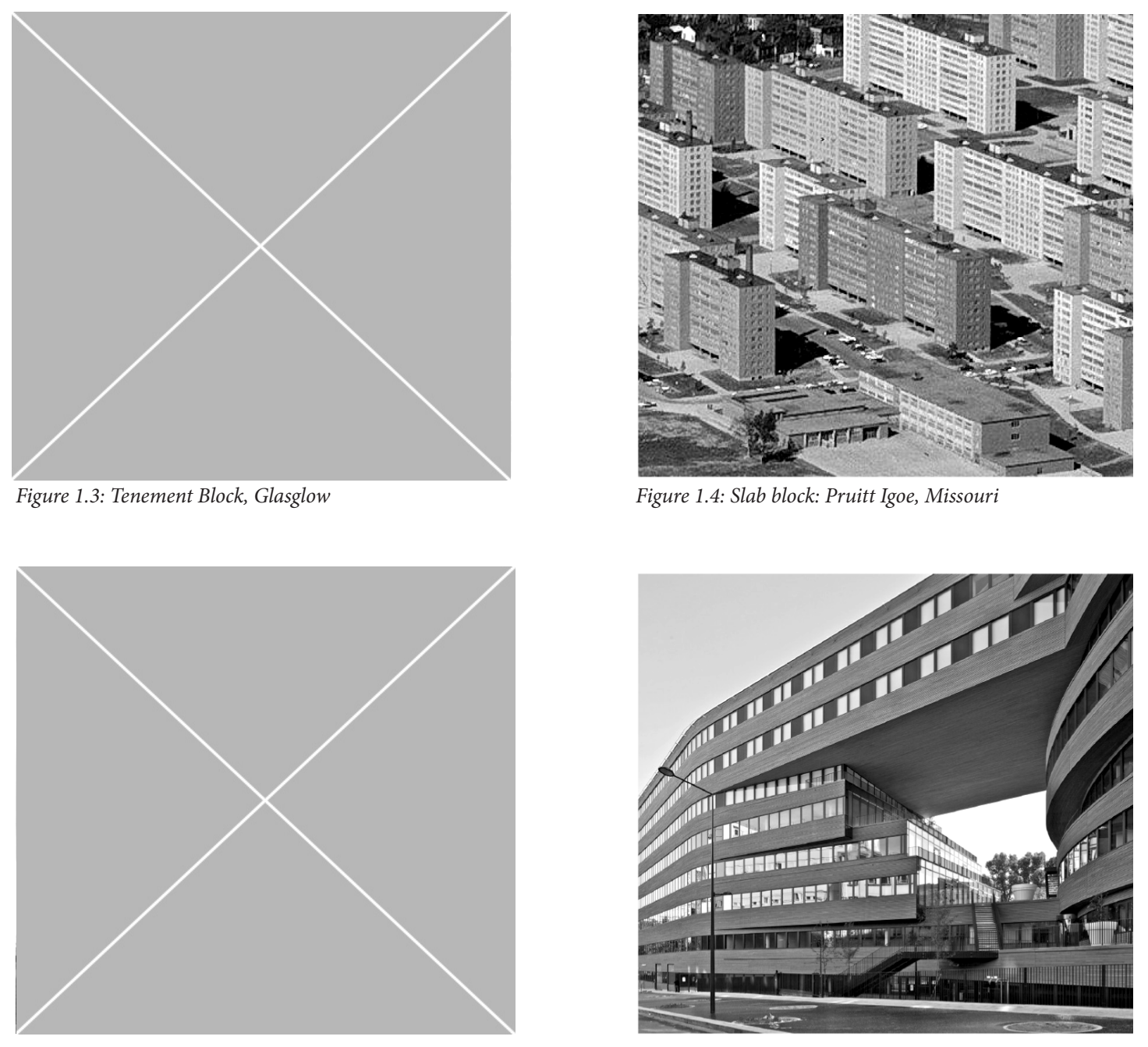

Figure 1.5: Block Tower, UK

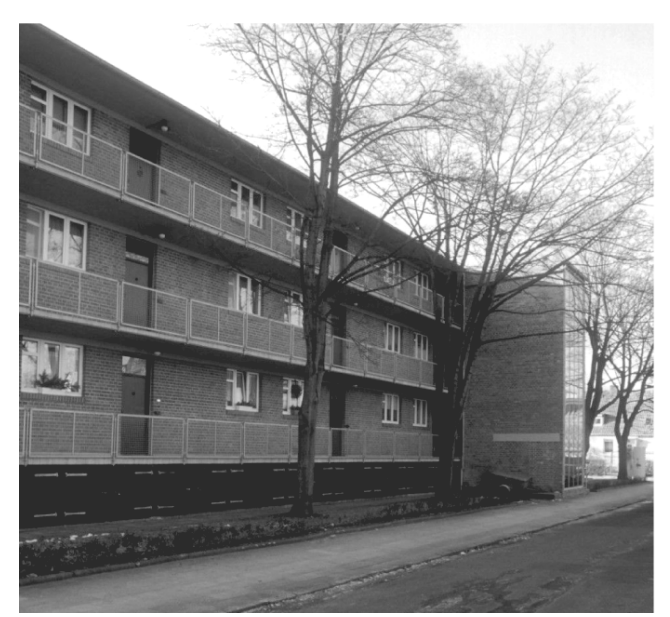

Figure 1.7: Deck Access Estate, Germany
Slab block: Pruitt Igoe, Misoron
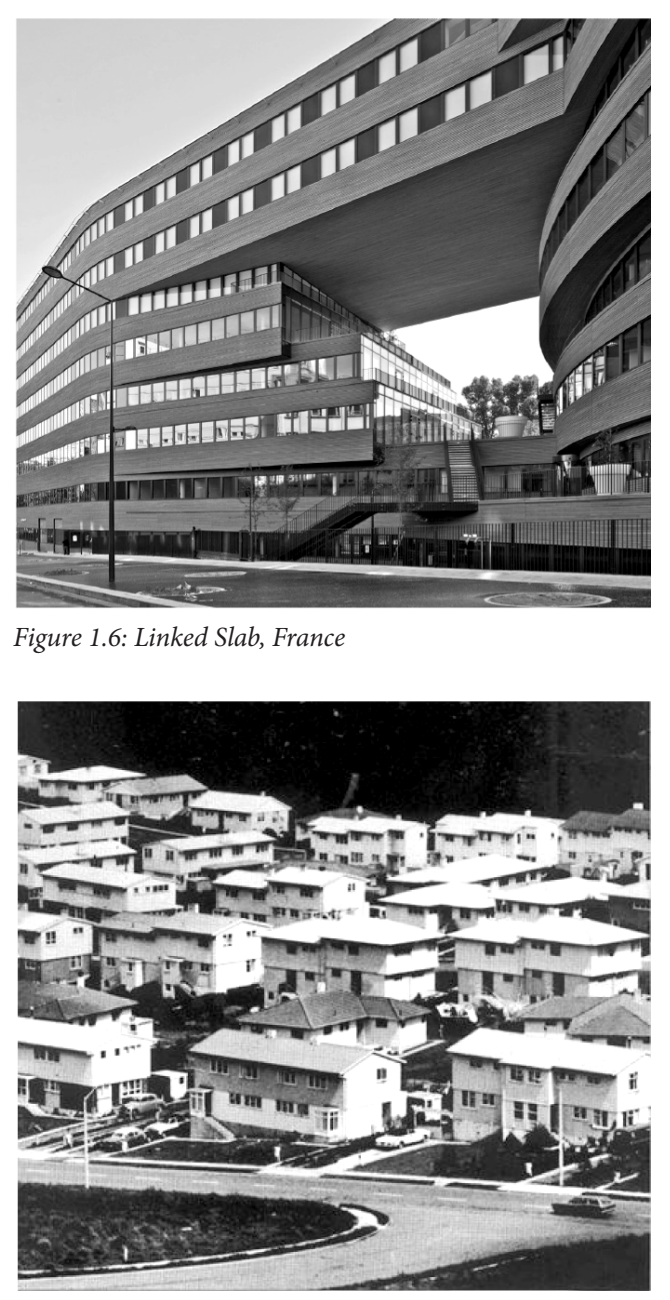

Figure 1.8: Post War State Housing, Porirua, NZ 
have since been demolished in favour of typologies with greater density and accessibility. In comparison, Tower blocks have a single entrance with a single elevator and staircase that generally spanned 10-11 storeys. The success or failure of this model often depends on the level of government involvement, building upkeep and rental/occupant rights (Urban, 2012). As they were designed for mass social housing, the size of units were often limited and the poorest or most vulnerable of that nation occupied them. These people generally had little to no disposable income to furnish their apartment or contribute to the maintenance of common areas. In the USA they were notorious for acting as gang watch towers, informally known as "the projects" (Urban, 2012). Newman identifies several factors that often caused this building type to fail: a lack of green space, insufficient maintenance, and occupants feeling unstable in their living arrangements.

Slab blocks are housing structures where the width exceeded the height, typically between three-eight storeys high (Towers, 2000). They were only considered successful if there was; consistent support from the state/government, each unit was of an adequate size, there was sufficient outdoor space and the design encouraged community interaction and a sense of community (Newman, 1973). Furthermore, Linked slabs are two or more slab blocks joined together via bridges (Towers, 2000). Open gallery spaces or enclosed corridors connect the blocks at several levels to link access routes together. This led onto the design of Deck Access Estates where these corridors were extended further to act as 'streets in the sky'.
This was a response to growing urbanisation and the issue of high rise buildings not providing spaces to connect in the same way people on the sidewalk did (Modi, 2014). Horizontal access ways were open to the air and aimed to act as pedestrian streets. Open access ways also allow for greater transparency between residents and visitors, allowing for a greater sense of security. This was achieved when the access system consisted of multiple open areas, allowing free flow of movement. These estates typically ranged from five-six storeys high (Towers, 2000).

These five approaches to multi-storey housing provide potential alternatives to New Zealand's lower density state housing. These approaches could be utilised in urban areas where the location and context of each typology is built would affect their success. 
Wellington City Council and Housing New Zealand have been replacing and adding to their housing stock over the last 10 years. They have worked with Novak + Middleton to explore housing alternatives in Wellington which go against traditional and contemporary state housing models. Two examples of this are Arlington Two completed in 2018 and the Central Park Apartments completed in 2012.

Arlington Two, now known as Te Mara Apartments, is a development made up of ten, three-storey buildings which encircle a central courtyard and opened in 2018 (Figure 1.9). Initially, the project was funded by Wellington City Council with Housing New Zealand assuming responsibility during the construction phase and then management of the development. Each building has a maximum of 12 units that are currently configured as a mix of one-four bedroom dwellings. However, are designed to be adaptable to the changing needs of residents. A single floor can be configured as four individual one-bedroom dwellings, a dwelling of four bedrooms or a dwelling with up to seven bedrooms. This is achieved through a modular design that is pre-wired and plumbed for these changes to occur over the 100-year life span. This modular design is successful in its ability to simplify the construction of social housing in New Zealand to a prefabricated form. Pre-fabrication reduces cost and could allow for economies of scale if it were to be mass implemented, just as post-war state homes were mass constructed in the housing crisis that followed the war. The development has also tried to address the origina of safety at Arlington by integrating Crime Prevention Through Environmental Design (CPTED) into the planning and design process. The initial design for Te Mara had several shared living spaces, however, these were later re-designed and built as three additional apartments (Novak \& Rangiwhetu, 2019). Simon Novak is critical of this decision as the residents of Arlington utilised and appreciated the communal spaces provided in the original scheme.

Central Park Apartments were opened in 2012 as the first significant update to Wellington City Council's housing stock in partnership with Novak+Middleton. In contrast to working with Housing New Zealand, Novak celebrated Wellington City Council's willingness to provide a range of communal facilities to those in their housing developments (Novak \& Rangiwhetu, 2019). Lara Rangiwhetu highlights the importance of communal spaces, particularly with contemporary developments focusing on one-two bedroom dwellings to meet the demand. Developments which isolate their residents will put at risk of mental illness. Community spaces will encourage residents to connect with one another. Secure developments with flexible communal spaces that encourage wellbeing are the key to having successful housing stock. While neither development meets the cultural and accessibility criteria which are outlined in Chapter 2, the design acknowledges the potential needs of the current and future residents. These developments both provide an accessible site and accessible units to accomodate for a range of residents.
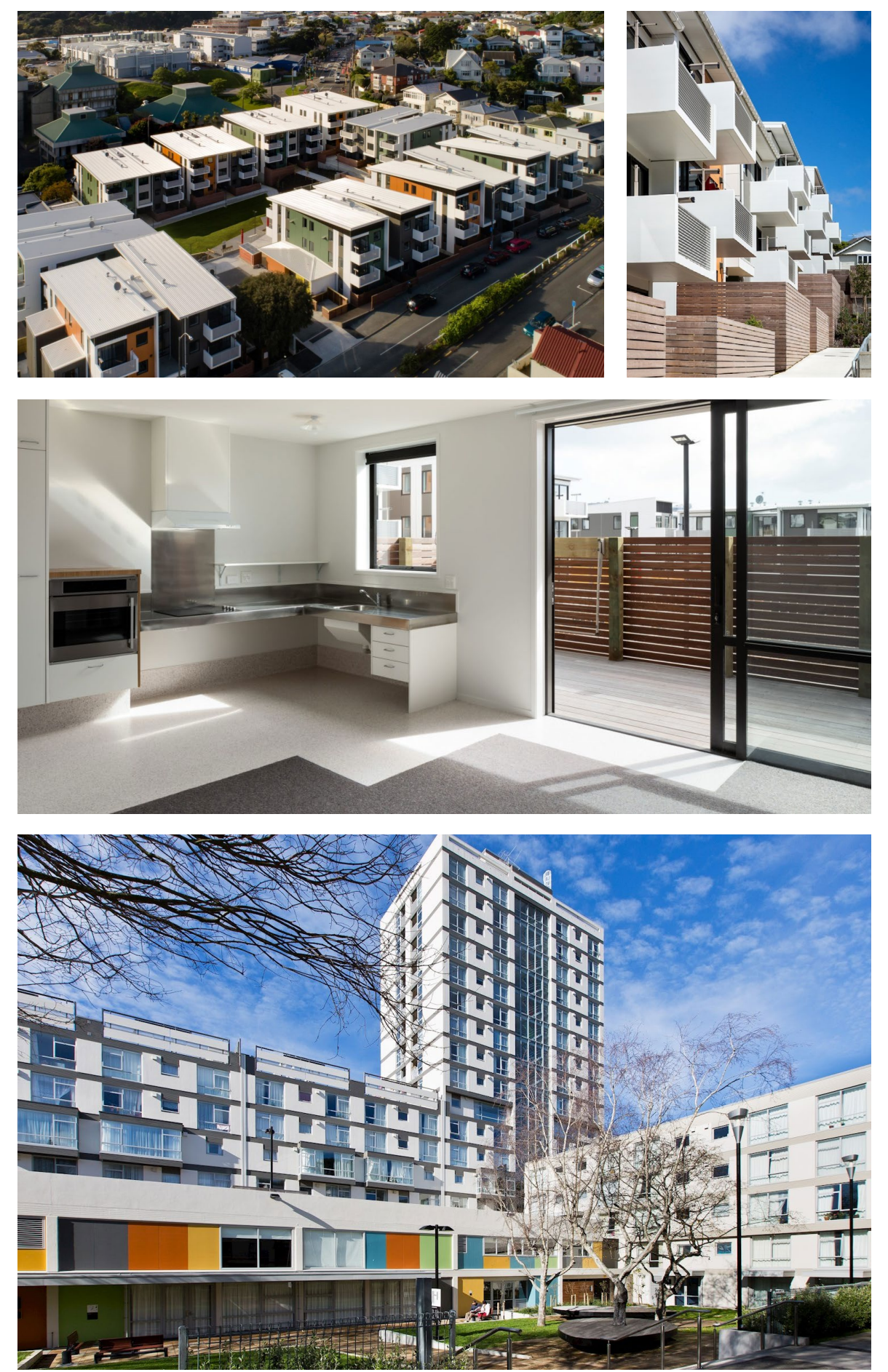

Figure 1.9: Top to bottom. Full stev view from George Porter Tower, Changing levels and balconies along the facade, An accessible apart ment, Exterior view of Central Park Apartments and the colourful central communal spaces 
Central Park also provides a range of communal spaces for its residents. The design solutions presented in this thesis can support the lack of community facilities provided at Te Mara and improve upon the inclusivity of both developments.

New Zealand's social housing has changed significantly since the 1950 s and is currently insufficient for the growing needs of those that require it. There is a wide variety in how social housing is provided, supported and designed in other countries which can inform the way it is implemented in New Zealand. These ideas will influence how "appropriate" is defined through design in this thesis. Through the exploration of these various options and their issues, each state housing development in New Zealand must address the needs of those who currently occupy it, along with those who will occupy it in the future. As demonstrated, there are successful contemporary state housing developments, however, they do not address the diverse needs of their residents entirely. The next step in this thesis will be to outline exactly who state housing occupants are and what their needs may be to propose architectural solutions. These solutions will address the needs of current and future state housing residents to provide an "appropriate" housing model. 


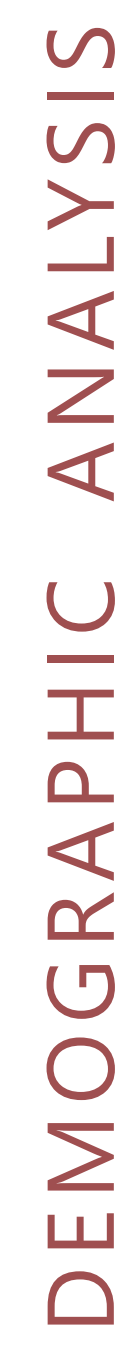

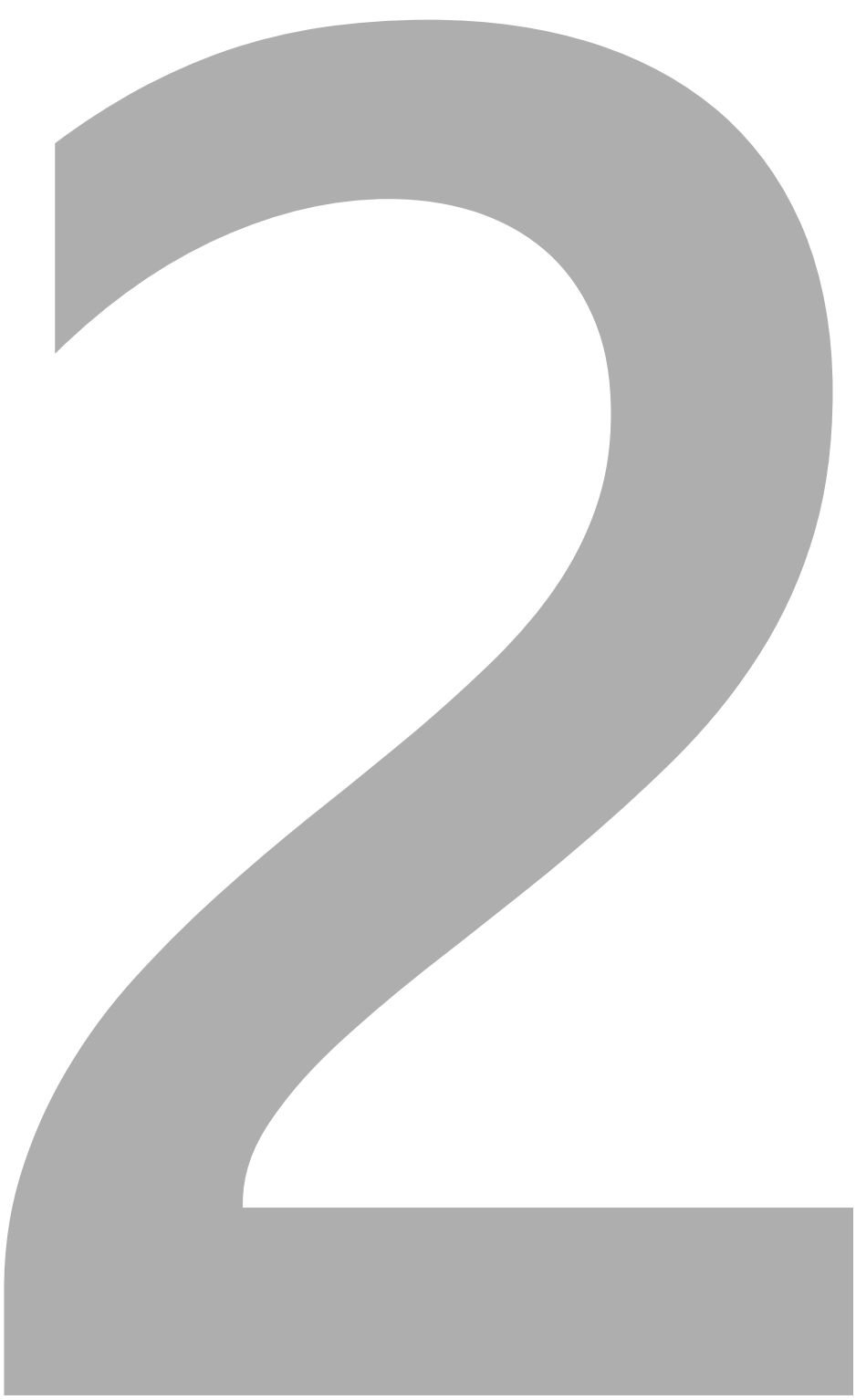




\section{Why Inclusive and Accessible?}

This thesis defines an "appropriate dwelling" as a place of residence that is suitable for the occupant's needs and considers their social, cultural and political circumstance. This is due to the direct influence politics has on social housing, but also the importance of acknowledging cultural differences and the social circumstance which leads to people requiring social housing. For example, a social housing applicant may have just arrived in New Zealand and have no possessions or little to no money. This person will not be in a position to purchase furniture for the state house they have been provided. Another scenario: A woman with two children is unable to work due to a physical disability requires social housing. The house she is given to occupy may not be accessible, therefore she has to wait months for an accessible dwelling to become available. The benefits of designing appropriate homes that provide for the needs of each user is critical to social housing. Neither of these scenarios are an unknown to social housing providers and each social house should be 'appropriate' to provide for the needs of the residents. Not only should the homes be appropriate inside, but the exterior envelope and surrounding development should also be considered too.

'Appropriate' design can be defined through 'Universal Design' which is defined as "a process that enables and empowers a diverse population by improving human performance, health and wellness, and social participation" (Steinfeld, Maisel, 2012, p. xi). By not providing universally designed homes, housing providers create barriers for their residents and themselves. Universal homes are designed to be flexible to occupant's needs, rather than trying to design specific homes for specific groups of people. The state housing register is diverse and therefore, a universal design approach would be the most appropriate solution for social housing. Particularly if these homes are meant to provide for fluctuation in occupants who will all have different requirements, along with these requirements changing in the future. A potential issue with universal design is that it may lead to larger homes, which may be more expensive. However, focusing on cost may restrict the exploration of appropriate design and will, therefore, be left out of the scope of this thesis. Additionally, constructing homes are universal will increase each user's independence will result in less expenses for mental healthcare and in-home aids, along with any in home additions to allow for accessibility

Accessible developments have often been completed in isolated contemporary social housing developments in New Zealand. These developments are entirely accessible, and therefore the residents who are placed there are those with accessibility requirements. Due to the connection between age and accessibility, this results in accessible developments being comprised of mostly older residents. Younger residents may be placed in these developments, causing them to feel isolated as they have nothing in common with other residents. Universal design would allow for any development to be diverse and allow residents to connect with those they may relate to.
Universal design is culturally inclusive by definition, but design guides were developed in Europe and North America (Steinfeld, Maisel, 2012). In New Zealand, we have a mix of indigenous and migrant peoples, all with vastly different cultural ideals. Some of these ideals are unique to New Zealand and therefore need to be further explored to define Universal design within the context of New Zealand. This will include spatial requirements that inform the design of this thesis and provide criteria which contemporary state housing can be analysed against. The criteria created will then be used to determine whether new models of state housing are necessary or if current housing can be adapted. 


\section{Social Housing Register}

To define an 'appropriate' contemporary New Zealand state house, spatial relationships between private, semi-private and public space must be understood. Research has shown that New Zealand's current social housing occupants are from a wide range of cultures, ages, and varying levels of ability (MSD, 2018). Many of these residents have spatial requirements that are not currently catered for by existing state houses, or contemporary social housing currently being built. The Ministry of Social Development's 2018 December report found that $42 \%$ of the state housing register is Māori, 22\% European, 19\% Pasifika, and 17\% Other (Figure 2.1). These groups have unique spatial requirements, which will be explored further in this chapter. A range of cultural requirements, age and ability should be considered in the design of an appropriate housing solution. Additionally, the scale and accessibility of a contemporary state house should be considerate of any who may occupy them and not discriminate towards the residents as those who occupy state housing are widely diverse (Figure 2.1-2.4). The increase in single-person households is a concern for social housing providers building one-two bedroom dwellings in quick succession without providing communal space because if large groups of vulnerable people are living alone, this may cause isolation and lead to further anti-social behaviour.

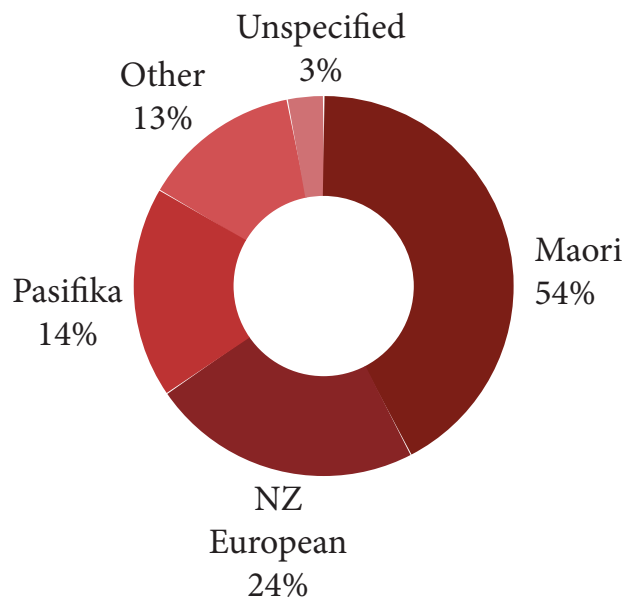

Figure 2.1: Ethnicity of social housing applicants (\%)

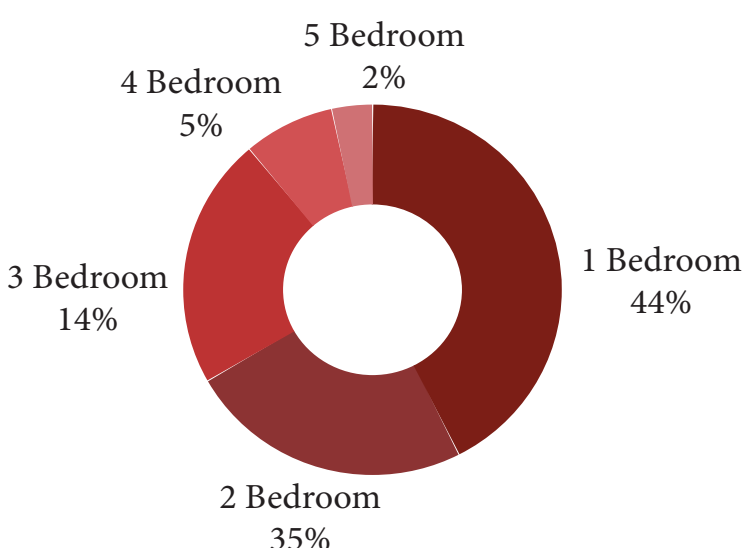

$35 \%$ Figure 2.3: Bedrooms required by social housing
applicants $(\%)$

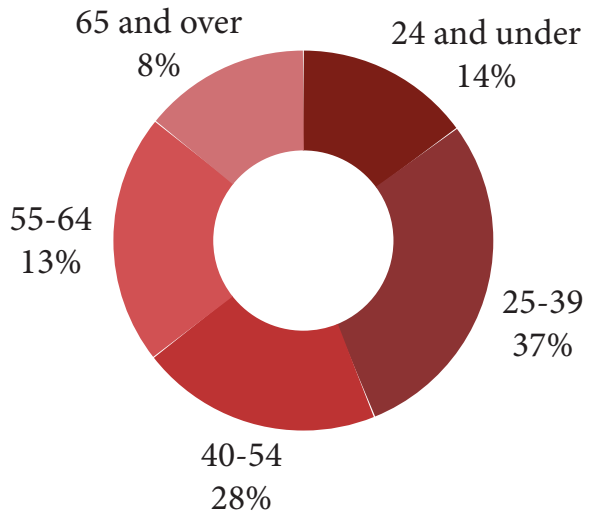

Figure 2.2: Age of social housing applicants(\%)

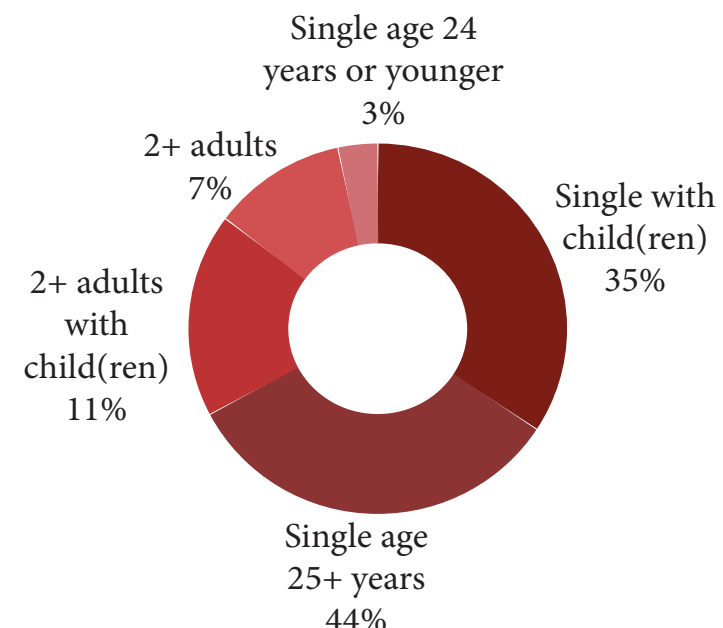

Figure 2.4: Household composition of social 


\section{Māori Considerations}

As of September 2018, Māori make up $42 \%$ of the state housing register, making them the main ethnic group that state housing currently provides for (MSD, 2018). In Mãori society, the spatial assignment of certain household functions is key to preserving Tapu. The concept of Tapu is used in multiple ways and describes the state of being sacred. According to Mead (2016, p 20) "it is like a personal life force which supports the mauri (spark of life)". To increase or preserve Tapu is to preserve the spark of life as it is in people, places and buildings, In contrast, "Noa" is common or safe. Tapu and Noa should always in balance with one another, particularly in architecture (Hoskins, 2014). This results in areas related to food and cleaning being kept separate bathrooms must not open out onto the kitchen or dining area, along with not opening out onto the living room (whanau room) (Hoskins, 2014). These spatial relationships can be seen in Figure 2.5 where a spatial matrix has simplified this to aid in spatial planning.

Several requirements help to balance Tapu and Noa throughout room is the heart of the Māori home. Guests will occasionally sleep in this space, or during a period of mourning, a tupāpāku (deceased family member) will lie in the living space. This can be accommodated for by larger hallways and wider/double door access to allow for a coffin to be transported easily. To accommodate this, it is recommended the living room provides space up to 20 people (Hoskins, 2014, p 11). Due to the living space accommodating these types of events, the kitchen and dining space would be able to be separate from the living space. Bodily functions must also be kept separate from cleaning/washing areas therefore a separate WC from the bathroom should be provided. There should also be an outdoor space for cooking/hangi provided, for family gatherings or events. There are also actions which those entering the home must do, such as removing footwear. This would require space outside which is covered or an intermediate entry space before entering the home

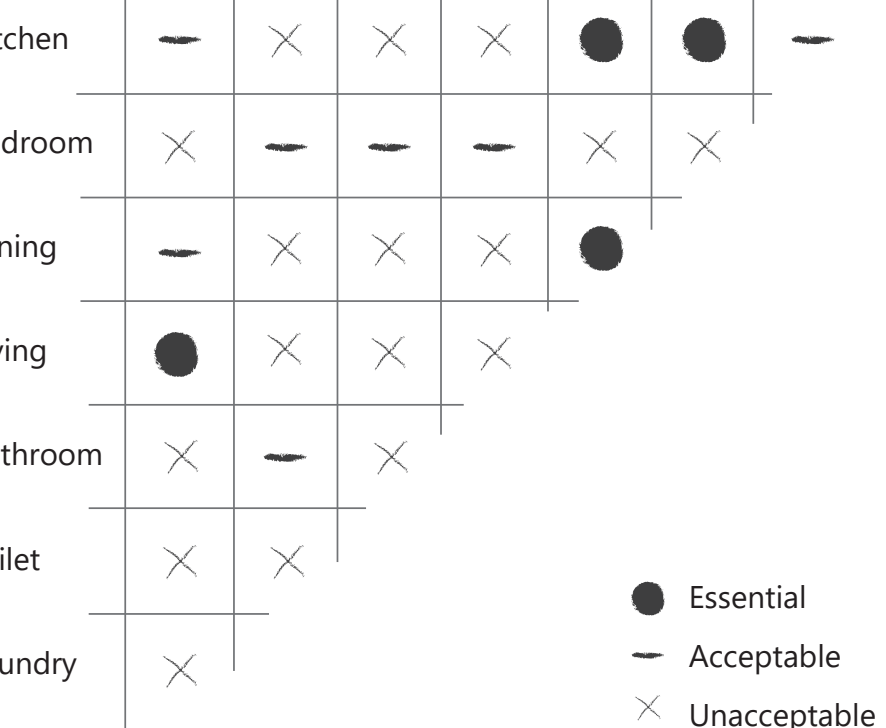

Figure 2.5: Maori spatial relationship matrix 


\section{Pasifika Considerations}

In Pasifika society, homes should allow for fluctuating family size, along with higher occupancy than the traditional New Zealand dwelling of two people per bedroom

(Faumina \& Associates, 2002). While there are differences between Pasifika cultures, the spatial requirements of each country do not vary significantly (Lal, 1992). Within Pasifika culture, there is a deep respect for elders and multi-generational households are normal as children and grandchildren care for their parents and grandparents. This results in large family gatherings where a living room may need to house $20+$ people at a time. These are for celebrations, but similarly to Māori, mourning will also occur within the home. Typically, this results in homes having two living spaces

- an informal and a formal. These can be connected, but need to be able to be closed off using sliding doors, screening or a curtain for different occasions. This is not essential, but in larger families, this will reduce pressure if only a single living area is provided (Faumina \& Associates, 2002). Open plan living helps to reduce pressure also and allow for flexible use of space. The size of the kitchen must allow for two-three people working in the space at a time in larger homes, as these are more likely to be used for family gatherings.

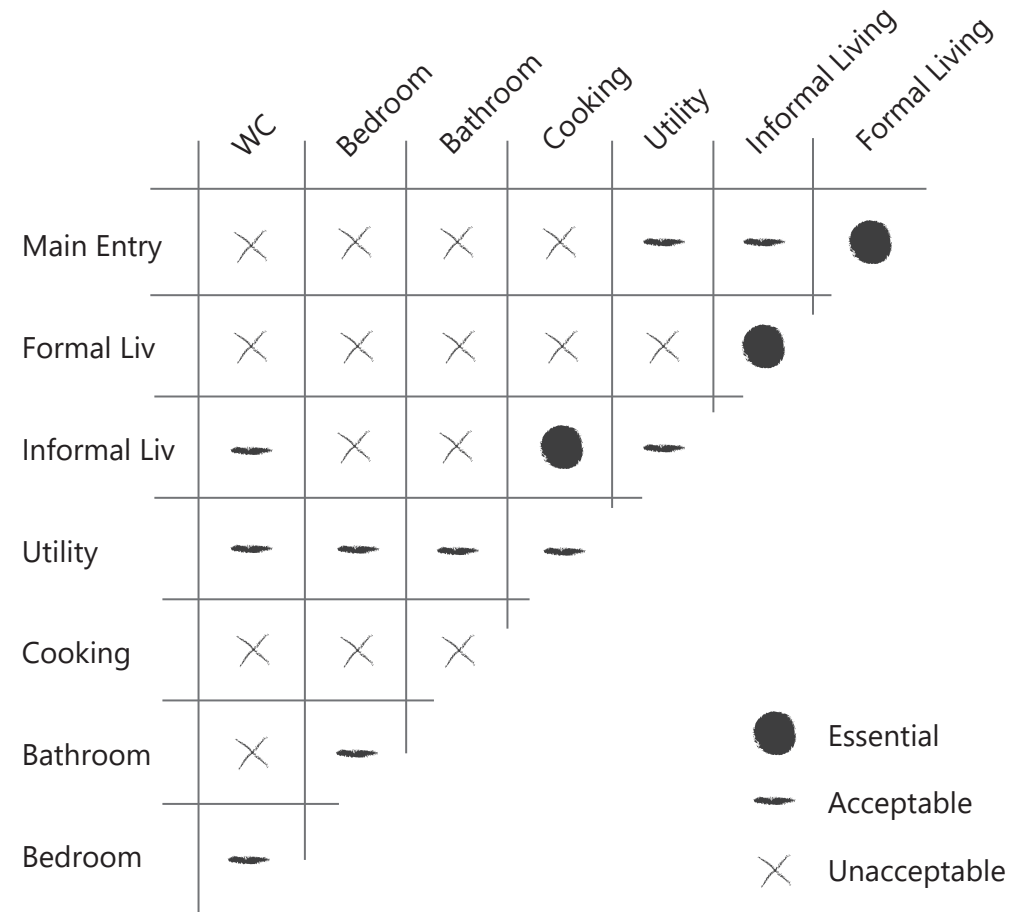

Figure 2.6: Pasifika spatial relationship matrix 


\section{"Other" Considerations}

Within the MSD's 2018 report, 17\% of their register is categorised as "Other". This category includes any other ethnicity or those who did not disclose their background in the census. Minority ethnic groups that may be included in this "Other" group are Asian (comprised mainly of Indian and Chinese, but also includes Japanese, Korean, Filipino, Vietnamese and Pakistani) or MELAA - Middle Eastern Latin American and African. Ethnicity is not always clear, as an individual may be of multiple ethnicities, but identify with only one within the confines of a questionnaire. While this data is indicative, it can provide insight and suggestions to what groups may have potential spatial requirements.

\section{Refugee Considerations}

For social housing to be inclusive towards refugees, a large range of religious and cultural beliefs need to be explored. According to MBIE data, there are 5 key groups of refugees; Refugee Quota recipients, Convention Refugees and Protected persons, Samoan Quota Scheme, Pacific Access Category and Special residence policies (MBIE, 2017). These groups constitute a total of 4,021 people who are entering New Zealand to seek refuge. While any member of this group qualifies for state housing, there is no clear data for how many receive housing. The key countries that these refugees come from are Samoa, Tonga, Fiji, Syria, Myanmar, Columbia, Pakistan and Sri Lanka.
Syria has been in a state of Civil War since 2011, therefore population data has not been officially gathered in the period that has followed. However, a survey completed in 2017 held results that were indicative of previous census data and migration patterns. This found that $71.9 \%$ of the population followed Islam, 16.1\% Christian and 9.8\% Secularist (Takaoka et al., 2017).

Myanmar (or Burma) is $87.9 \%$ Buddhist, $6.2 \%$ Christian and 4.3\% Islam (BDHRL, 2017).

Myanmar is governed by an authoritarian military regime that restricts religious freedom. This government has encouraged Buddhism strongly and attempted to make it the state religion numerous times. This coincided with harsh punishments for those who were not Buddist. This has resulted in many Muslim and Christian Myanmar to seek refuge in New Zealand.

Columbia’s refugees are escaping instability resulting from the war on narcotics (RCUSA, 2011). Columbia's religious demographic is 70.9\% Catholic, 16.7\% Protestant, 4.7\% atheist and 3.5\% agnostic (Beltrán, 2011, p 210). Those entering New Zealand can be assumed to be from any of these beliefs as their reason for seeking refuge is not religious persecution.

Afghanistan and Pakistan are Islamic republics with $96-99 \%$ of their populations declaring Muslim beliefs (Karim et al, 2004, p 85). Both countries have been engaged in long-standing military conflicts over the control of territory that is led by terrorist groups, not specifically against the religious minority so their refugees could be of any religion, however, they have mostly been Muslim in the past (Ewans, 2004). Sri Lanka has had multiple periods of colonisation which has created a wide variety of ethnic groups. The main is the Sinhalese, who are typically Buddhist and Tamils, who are mostly Hindu. The majority of Sri Lanka's population is Buddhist at $70.2 \%$, however $12.6 \%$ is Hindu $9.7 \%$ is Musim and $6.1 \%$ is Roman Catholic (DCS, 2012). Sri Lanka was in a state of civil war between 1983-2009 driven by the LTTE (Liberation Tigers of Tamil Eelam) and the Sri Lankan government (ICJ, 2012). While the official conflict has ended, Tamils continue to be a vulnerable minority in Sri Lanka as the country is favouring Buddhism. Tamils are statistically Hindu and due to their vulnerability, seek refuge in other countries.

As outlined above, there is a wide range of religious beliefs of those who are seeking refuge in New Zealand. These religions will be explored to understand any spatial requirements that may affect social housing design 


\section{Religious Considerations}

Based upon MSD and MBIE data, those who occupy state dwellings are Christian, atheist, Muslim, Buddhist and Hindu. The spatial requirements of these groups will be outlined below. Christianity has a variety of denominations that will each have different levels of orthodoxy. More conservative Christians will prefer separate bedrooms for male and female children. However there are no other clear spatial requirements, instead, any spatial requirements would be cultural. Similarly, Atheist's may have spatial requirements but these would come from cultural views rather than views based upon religion.

Islamic dwellings have strict rules which separate the private, semi-private and public areas of a dwelling. These zones translate into privacy between neighbour's dwellings, privacy between male and female/privacy between family members (individual privacy) (Othman et. al, 2011). The main entrance is visually isolated from the rest of the home (Oman, 2004). It is also very common to have central courtyards to allow the occupants of a home to be able to see outside but still be in the privacy of the family home ( $p$ 151). Inside the home, there are typically at least two living areas, one which is strictly for the family, and one which accommodates guests, this arrangement also allows for the separation of women and men. Women can move between the two spaces as they wish, or separate themselves from male intrusion. Similarly to Māori culture, bathrooms are to be visually separated from the eating and living area. Open plan livingkitchen-dining is also preferred so the semi- private space can accommodate fluctuation of guests. This is important during religious festivals such as the end of Ramadan, where family and friends may celebrate together in the home. A musallah is a space for prayer meditation or other religious activities that can be opened up or closed off to be used by the individual or a group (Campo, 1991). This can easily be accommodated in a home and when not in use by an Islamic family, can be utilised as storage space or a study/workspace. This could also be provided for in a communal sense or simply occur in a private space such as a bedroom. Spatial diagrams shown in Figure 2.7 demonstrate many of these design considerations.

Buddhist spatial requirements are specific in places of worship, but flexible in the homes which Buddhists in habit (Soper, 1978). Overall, Buddhist architecture is simple but tends to vary based upon the country it is in with traditional construction techniques being used as much as possible (USDS, 2017) (Herrle \& Wozniak, 2017). Minimalism and modernism would be in line with Buddhist values of selfcontrol and meditation, however, this is not a rule (Gellner \& Gombrich, 2015). There are eight precepts that Buddhists can adhere to, two of them being "not to adorn oneself or go to entertainments, and not to use luxurious beds (i.e. sleep on the floor)" (p 890). This would imply a home that is not wasting space and is simplistic in its inclusion would be favourable to Buddhists. The users may sleep on the floor and may not own a television.

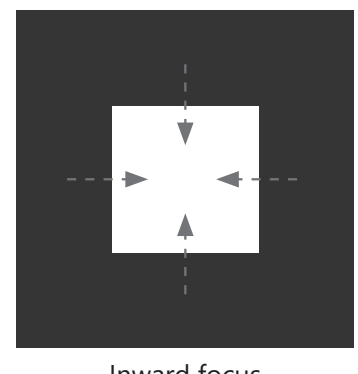

Inward focus

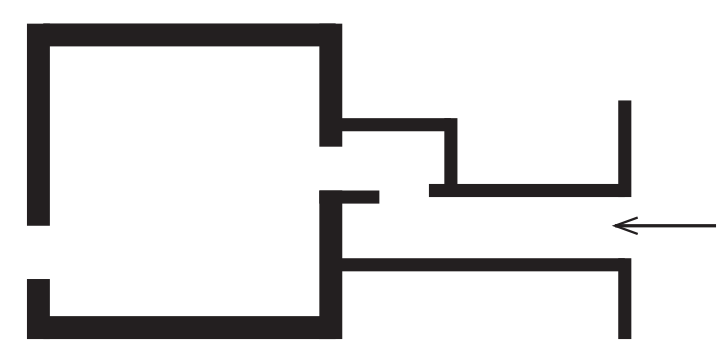

Isolated entrance

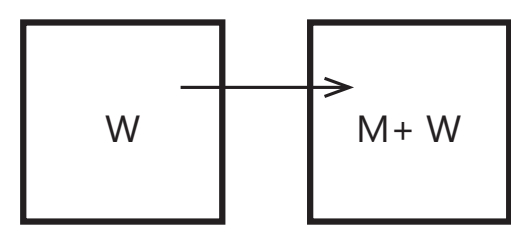

Separate living spaces

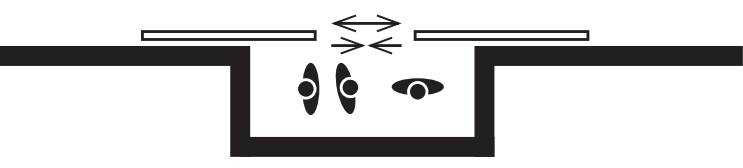

Musallah 

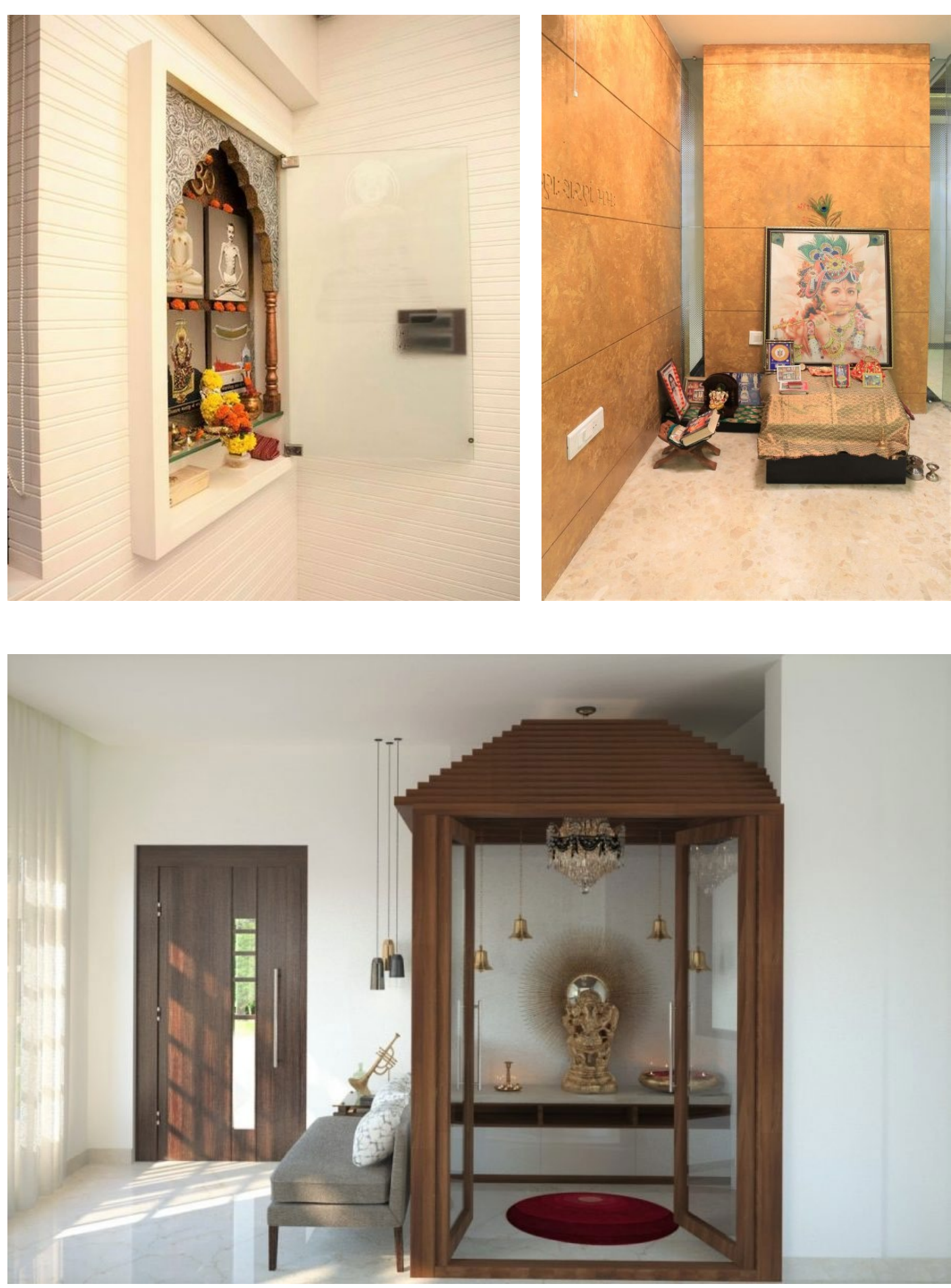

Figure 2.8: A series of different mandir widt the home
As Sahney (2010, p. 39) outlines, "Hindus often say that there can be no town or city without a temple". This is translated into the home in the form of a "mandir" or temple. The mandir can be unnoticeable to non-Hindus or visitors as it is a small altar or shrine located in the home (Prorok, 2014). In countries with higher Hindu populations, mandir are often built into homes as can be seen in Figure 2.8. However, in nations that do not have a significant Hindu population, these shrines are these shrines are placed anywhere in the house - typically at the end of a kitchen counter or in the corner of a lounge. Many Hindu rituals will be performed inside and outside the home by the residents, however, these do not have a direct effect on the spatial configuration or design of the home. 


\section{Universal Design}

Accessibility affects people of all ages, however, as people age, the more likely they are to have a physical impairment that will affect their mobility. According to New Zealand Census

data, out of the estimated 632,000 people who have a physical impairment which limits their everyday activities, $49 \%$ are 65 years old or over (MacPherson, 2014). With New Zealand's ageing population increasing rents increasing and superannuation not currently set to increase significantly, this percentage will rise. The issue of catering to the elderly is significant in New Zealand, however, as the Census indicates, there is also $51 \%$ of those with a physical disability being below the age of 65 (Statistics NZ, 2013). 25\% of state housing applicants listed medical/special needs as their reason for requiring state housing (MSD, 2018, p 14). While this may not mean all of these people require accessibility features throughout their homes, it indicates a need for architects and designers to accept that accessibility should be considered. A large number of state homes in the 1950s were elevated from the ground, which has later on needed to be modified by ACC to include ramps so that residents could easily access their home (Enable, 2018).

Retrofitting a contemporary state house is a costly design solution, which could be avoided by providing universal homes. Design guides such as Lifemark or Universal Design provide simple and appropriate design solutions. Both design guides aim to encourage the design of accessible homes that adapt with age and stage. They provide a wide range of suggestions and solutions to making homes more accessible which could be integrated within the design strategies later in the design process. Additionally, Universal design is not just about accessibility, it is also culturally inclusive by definition (Enable, 2018). In providing universal homes, both accessibility and cultural inclusivity can be defined through design.
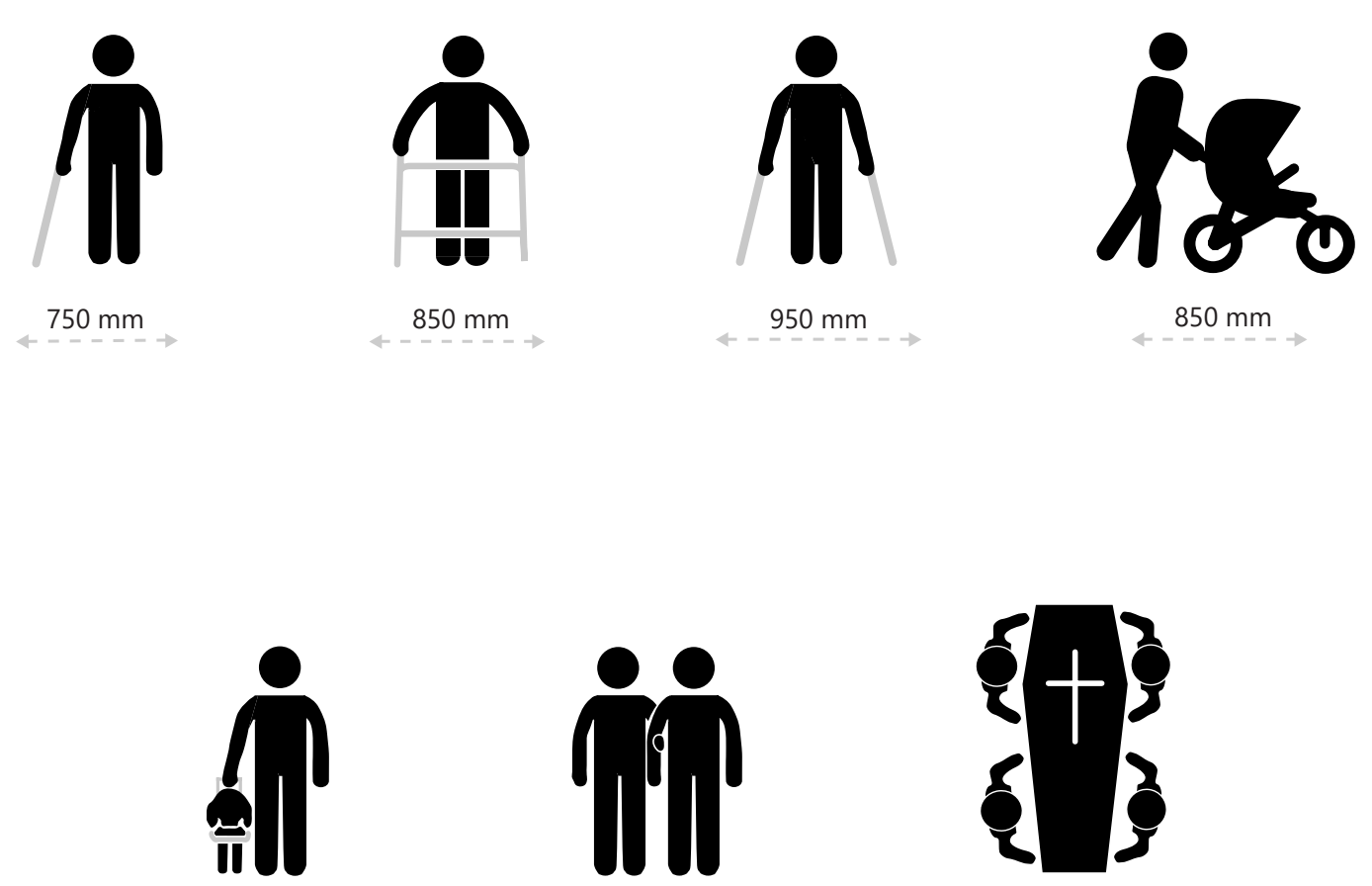

$1200 \mathrm{~mm}$
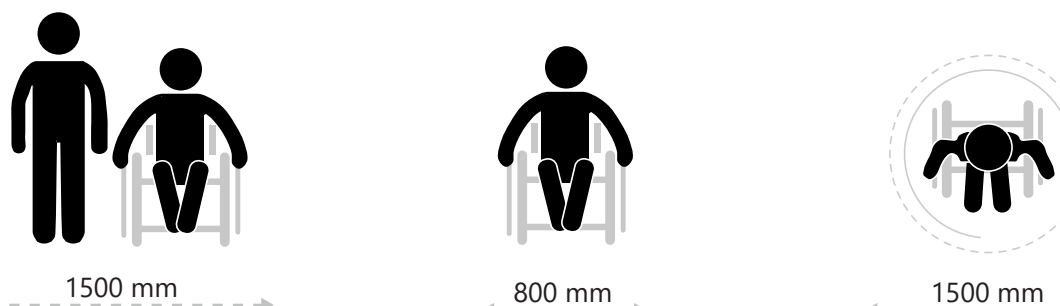


\section{Spatial Relationships}

When designing inclusive social housing, it is important to consider all groups that may occupy the dwellings. An argument could

be made for designing homes which cater

to individual cultures and to build a certain amount to cater for these different groups. However, this is not a sustainable opinion as these needs and requirements will change overtime, just as they have in the last 50 years of social housing. Social housing in New Zealand needs to be built for adaptability and an interchange of occupants that have diverse needs.

This chapter identified key groups which have spatial relationships that do not align with the standard New Zealand social housing model. These groups are Māori, Pasifika, Islamic and those with accessibility concerns. Figure 2.10 outlines the spatial relationships within each culture along with the current New Zealand European model. Private, semi-private and public spaces have different significance within a home for different cultures, along with a different level of separation between these spaces. Chapter 3 will utilise these spatial requirements and relationships to analyse contemporary state dwellings to determine how 'appropriate' they are. The outcome of this will determine how inclusive and appropriate social housing can be designed in the New Zealand context.

Maori

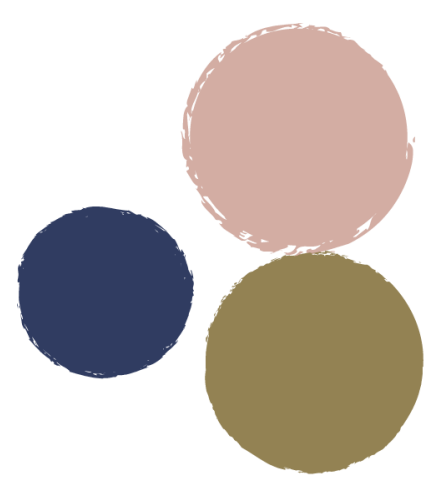

NZ European

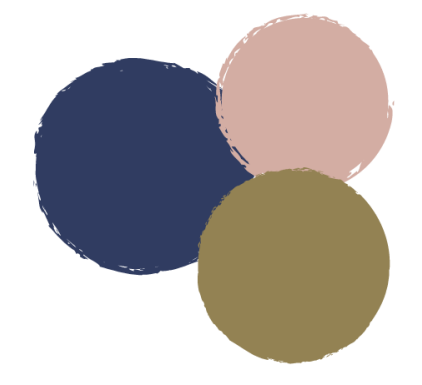

Pacifica

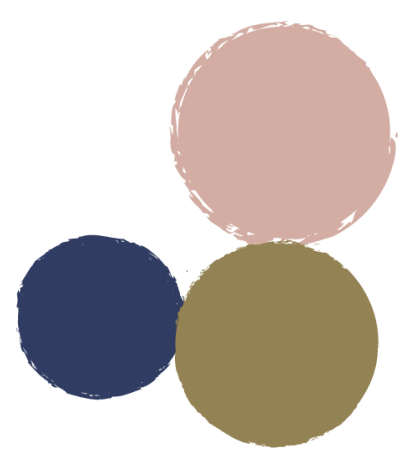

Muslim

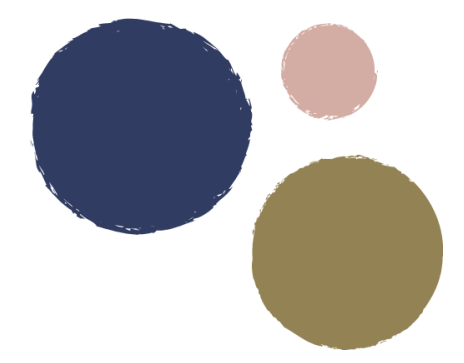

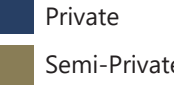

Public 


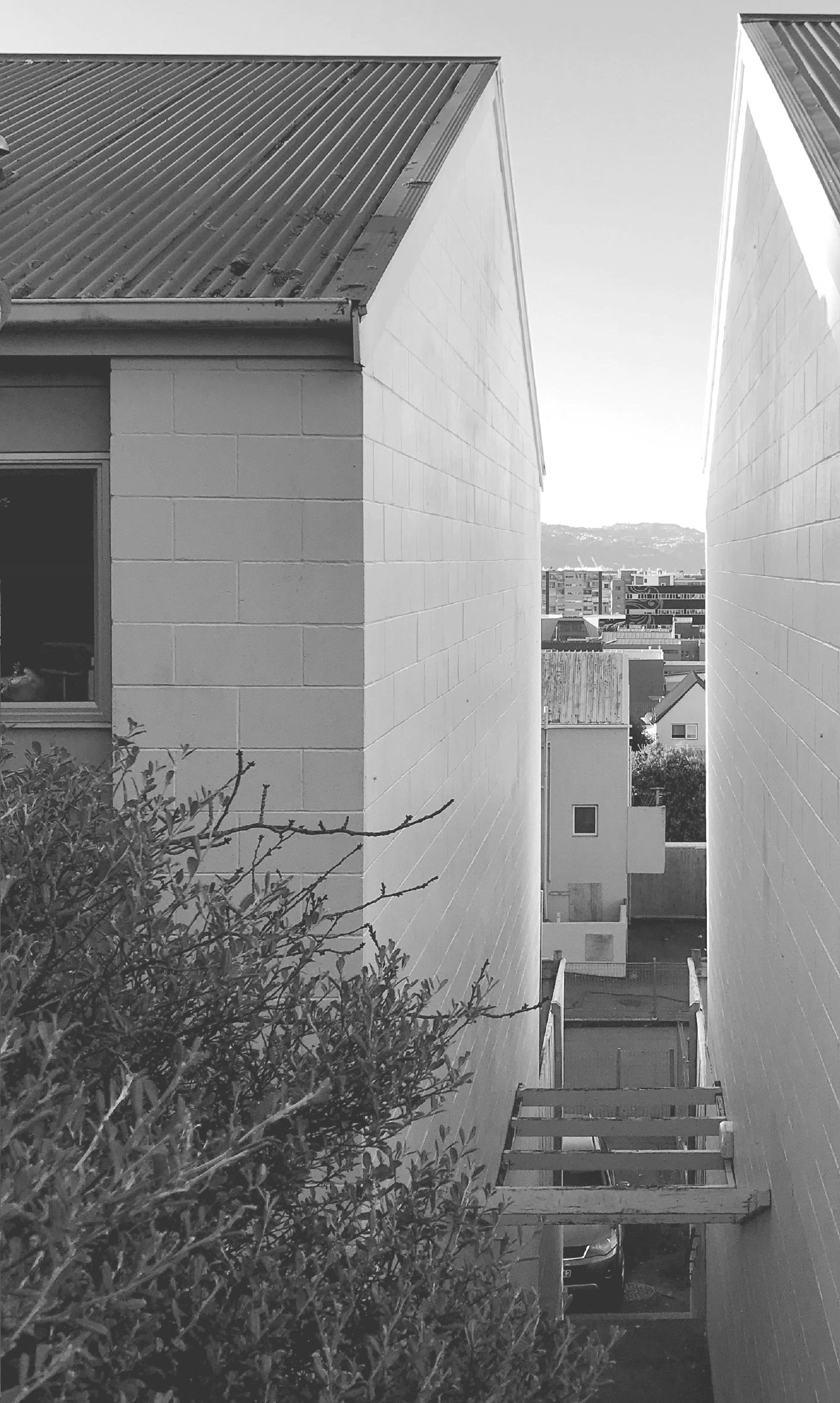

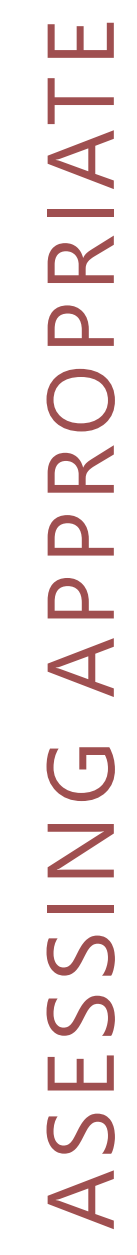

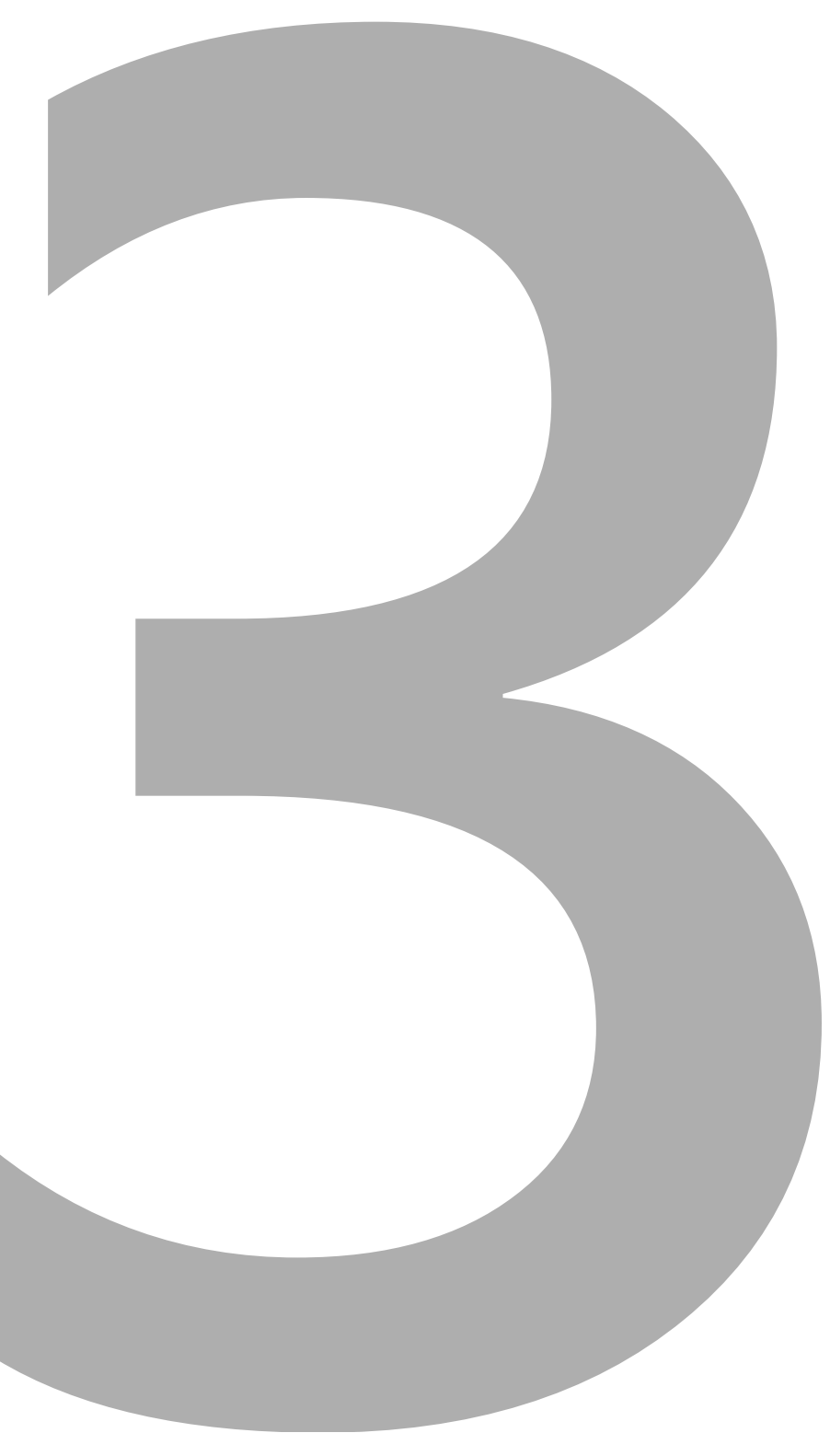


Contemporary Dwelling Analysis

To establish an understanding of how appropriate contemporary New Zealand social housing is, five recent social housing and private developments will be analysed. These developments are Greys Ave and Sunderland in Auckland, Regent Park, Marshall Court and Britomart in Wellington (Figure 3.13.5). They are analysed against the individual cultural considerations for Māori, Pasifika and Muslim people as defined in Chapter 2. This is combined in an "inclusive" overview to identify where there may be clashes or consensus in spatial requirements. This was done in plan to quickly and identify spatial configuration issues. Many of these floor plans were not available to scale, universal design has only been mentioned when there was a clear issue e.g. no bedroom on the ground floor.

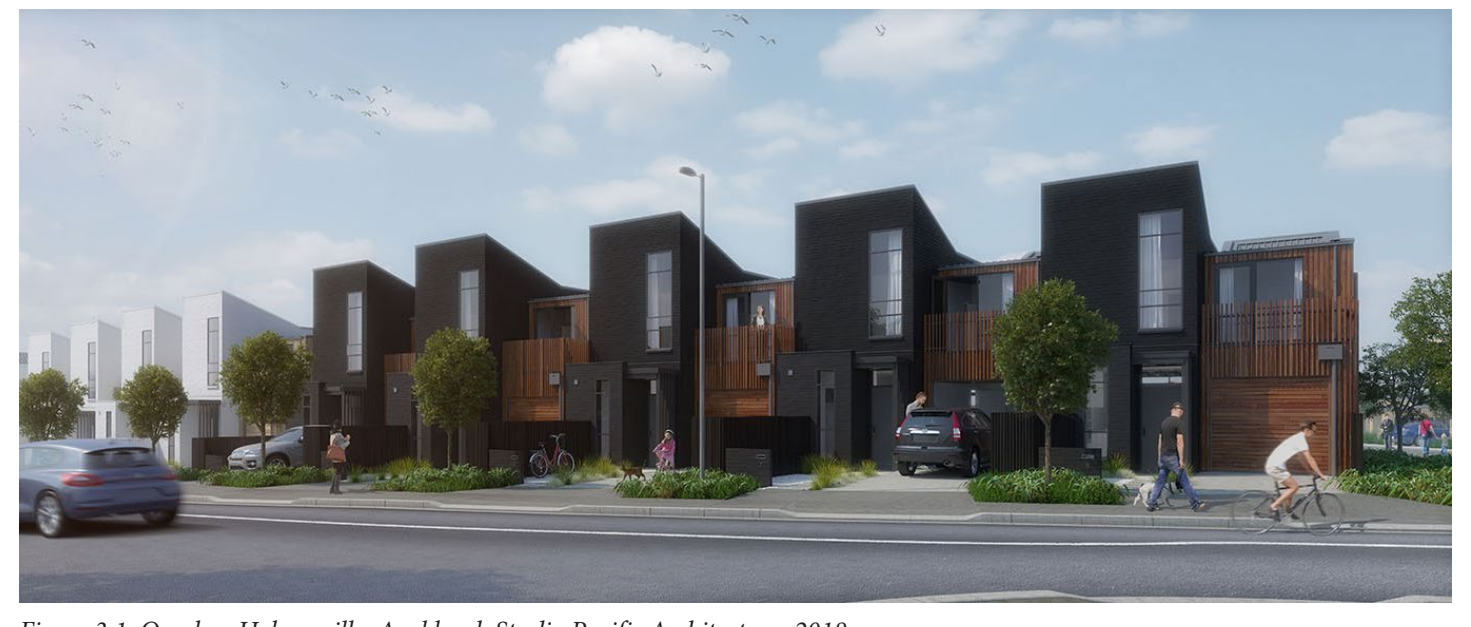

Figure 3.1: Overlea, Hobsonville, Auckland. Studio Pacific Architecture, 2018

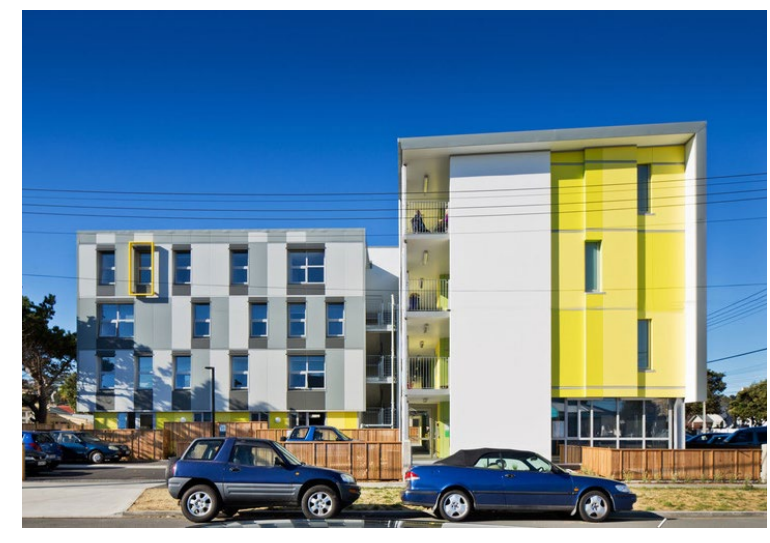
igure 3.2: Marshall $\mathrm{C}$.

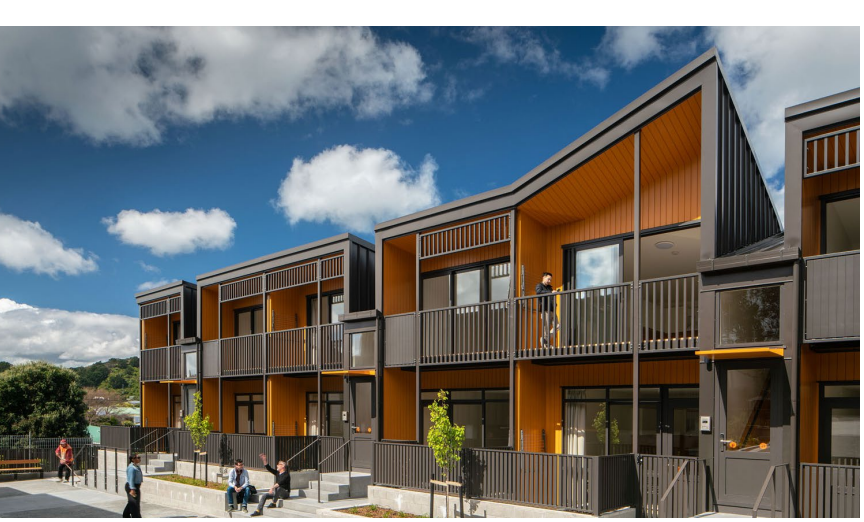

Figure 3.4: Te Maru o Tawatawa, Britomart SS
Wellington. Studio Pacific Architecture, 2018

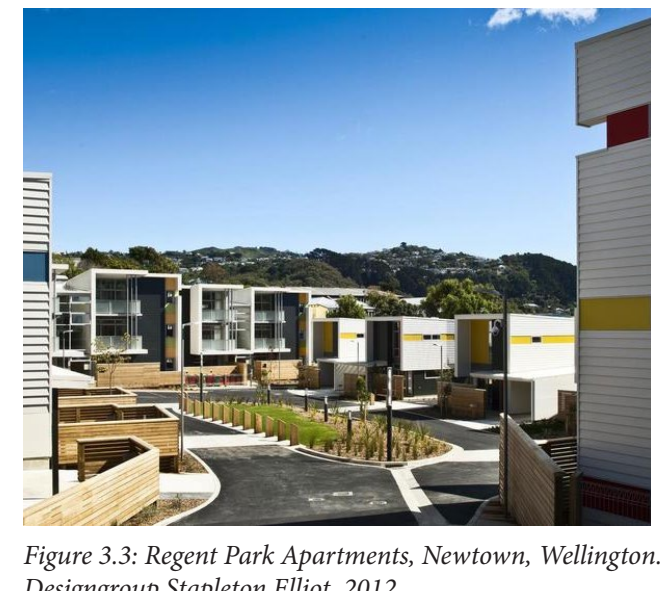

Figure 3.3: Regent Park Apartments, Newtown, Wellington.
Designgroup Stapleton Elliot 2012

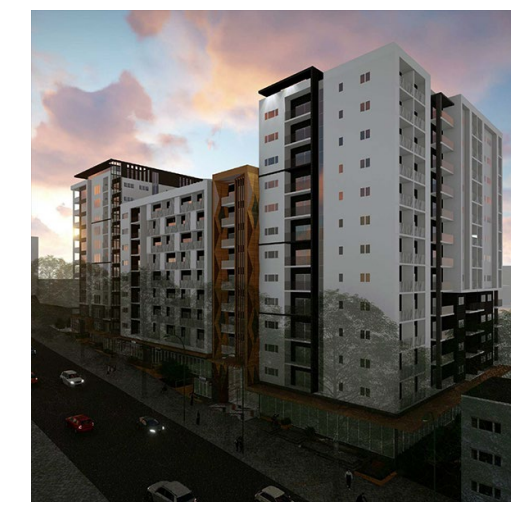

Figure 3.5: Greys Ave, Auckland CBD. Housing New Zealand, under construction 


\section{One Bedroom Analysis}

One bedroom dwellings included bedsits/ studios to show a range of residences which would be assumed to have one-two people occupying them. Marshall Court is comprised of studio dwellings, while Greys Ave and Britomart are defined as one bedroom. Both dwelling types have many cultural conflicts due to the proximity of rooms to save space. Unsurprisingly, Marshall Court's studio dwelling is the least successful spatial arrangement due to the overlap in private and public space. However, this raises an issue in defining "appropriate" housing. A studio dwelling is more likely to be occupied by a single person who doesn't mind an overlap of spaces as the entire apartment is their private space. In contrast, one-bedroom dwellings are larger and have defined rooms. This allows for a range of configurations. From a religious/ cultural perspective, it will still be important to maintain a separation of cooking, cleaning and bodily functions with the dwelling. However, a bedroom being in the living area may not be a significant issue as it would be in a larger household. This is a question that may only be answered through interviewing those of the cultures in question, which is out of the scope of this thesis. Instead, a range of different configurations of one-bedroom dwellings will be tested in this thesis. Additionally, a communal living space could be included in the development for residents in smaller dwellings to host larger gatherings.
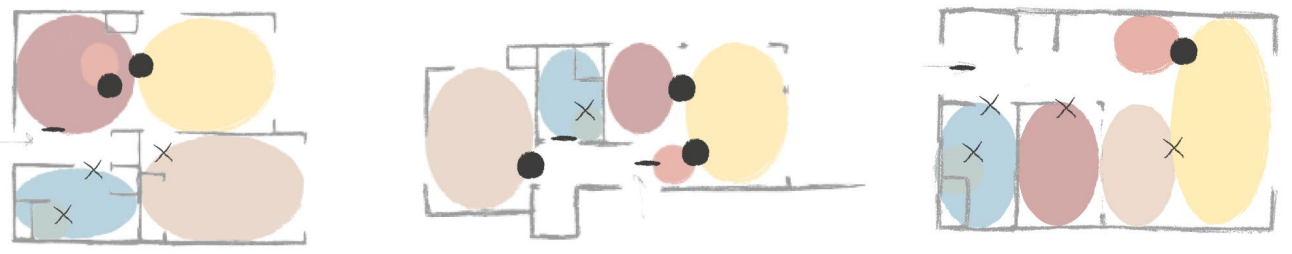

Pasifika
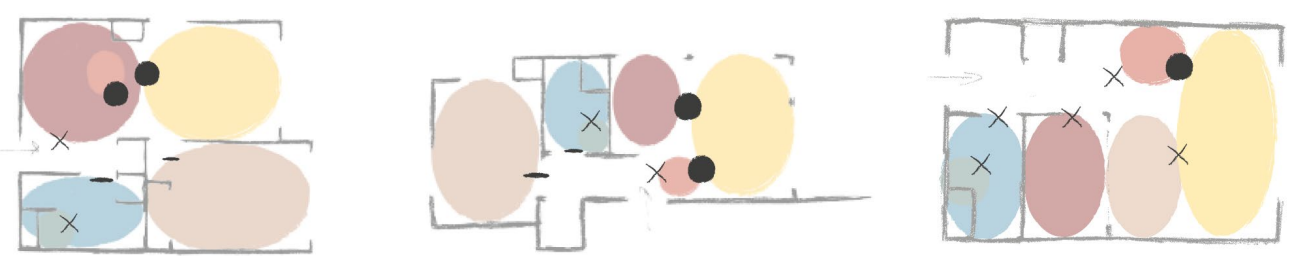

Muslim
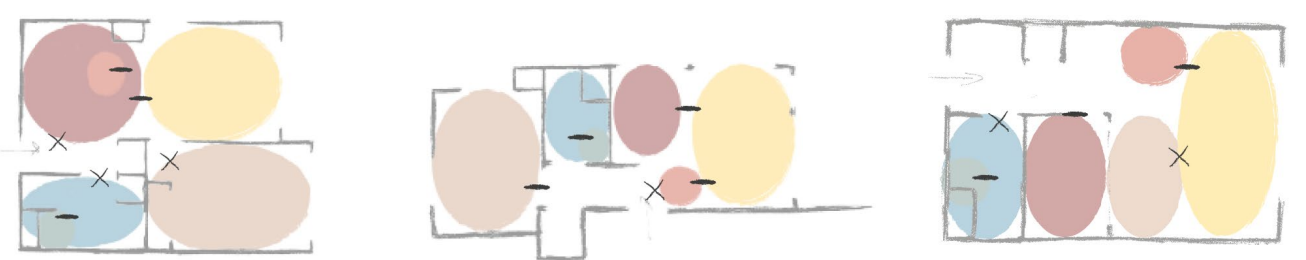

Inclusive
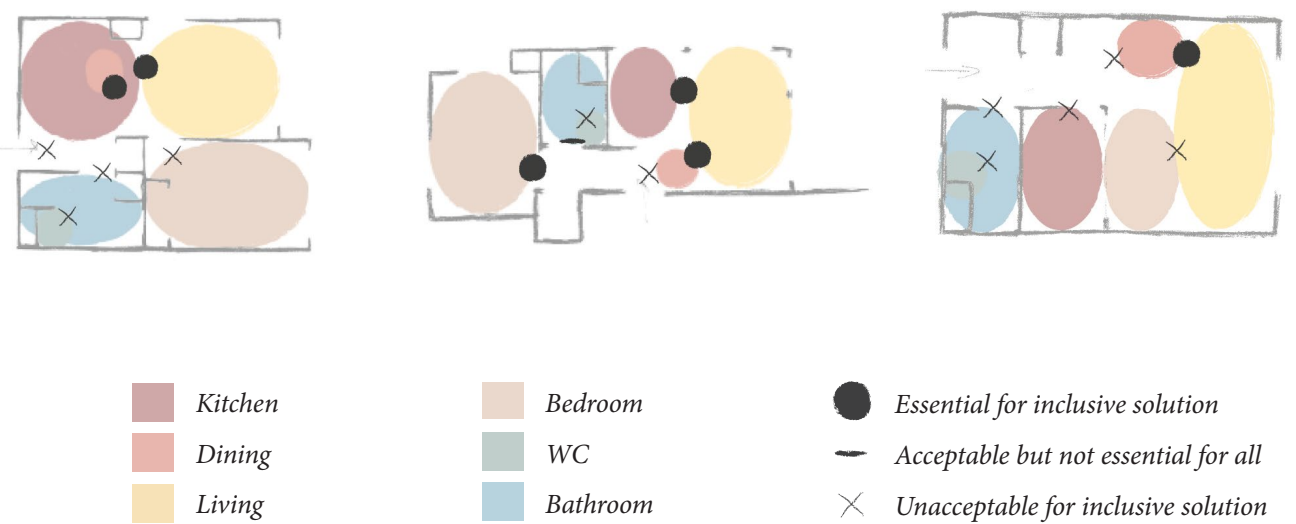

Bedroom
WC
Betroom

Essential for inclusive solution

Acceptable but not essential for all

Unacceptable for inclusive solution 
Two Bedroom Analysis

The two-bedroom dwelling examples were drawn from Regent Park and Hobsonville. Hobsonville, being designed to maximise density in private suburban development, has utilised two levels in its design. When observing this with the considerations of a Muslim family, this allows for greater privacy as bedrooms (private spaces) are placed upstairs and therefore visually and audibly separated from the living areas. However, similar to other case study examples, the main entryway is near the living/kitchen/dining area. In Pasifika culture, having eating/cooking areas being seen from the main entrance is not acceptable. Preparing food is a sacred activity and the disruption of entry and exit space negatively affects this activity (Faumina \& Associates, 2002). The Hobsonville design also separates the kitchen from living and dining, a connection in Pasifika and Māori culture that is essential. This is where the Regent Park two-bedroom design has been successful. It allows for a flow of living kitchen and dining space, while still keeping bedrooms and bathrooms reasonably separate, both visually and physically. The entryway is still too open to be ideal for a Muslim family. Additionally, the bathroom and WC should be separate spaces, which will occupy a greater area. While accessibility is not evaluated specifically for these case studies, having a bedroom on the ground floor would allow for greater accessibility.
Two bedroom - Regents Park

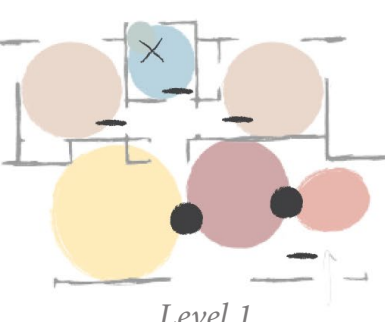

Level 1

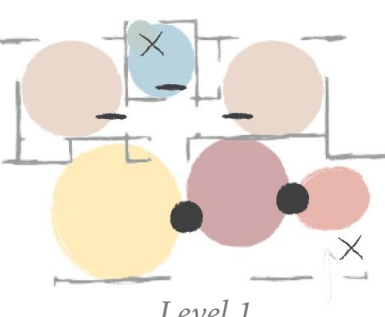

Level

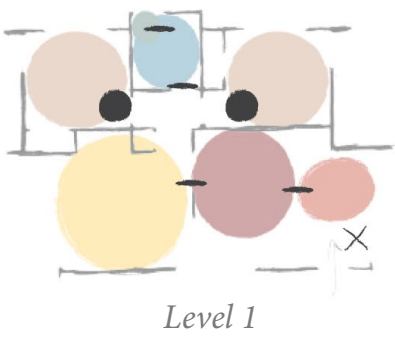

Level

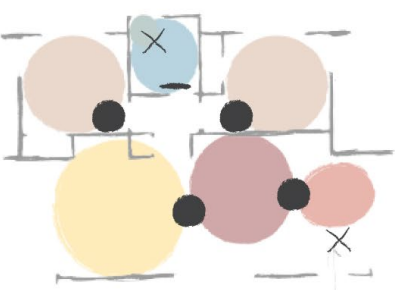

Level
Two bedroom - Hobsonville

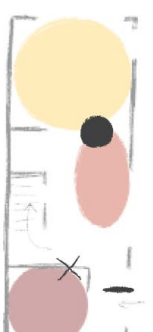

Level 1

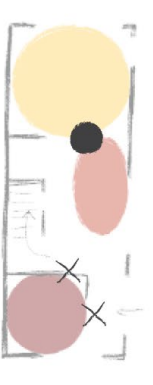

Level 1

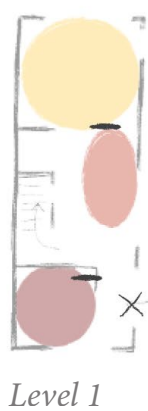

Level 1

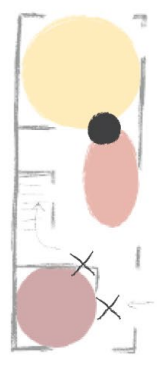

Level

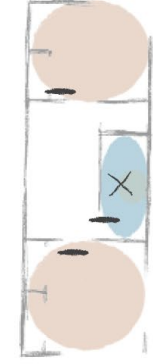

Level 2

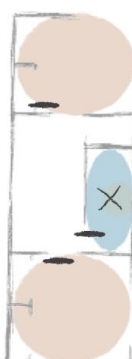

Level 2

Level 2

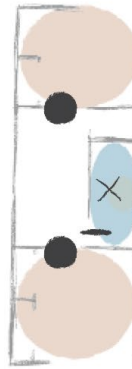

Level 2

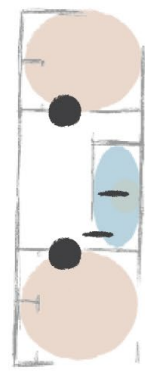

Two bedroom - Hobsonville

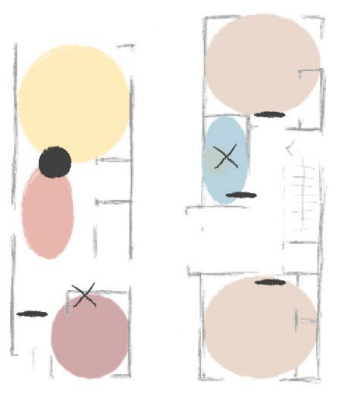

Level 1

Level 2
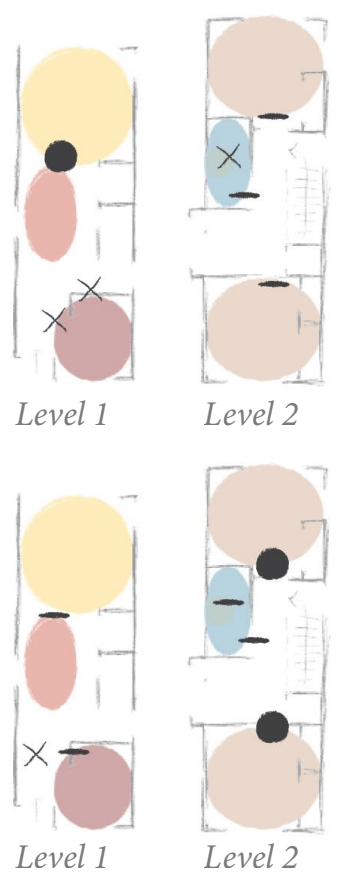

Level 1

Level 2

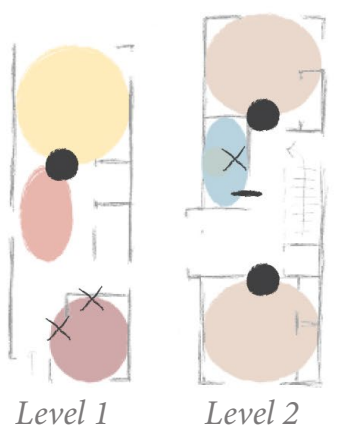




\section{Three Bedroom Analysis}

Regent Park and Hobsonville also presented two case studies of three-bedroom dwellings, both of which are multi-storey. The Regent Park dwelling design is successful in providing living, kitchen and dining space which flows together to allow for flexible space of any gathering. Additionally, there is a bedroom on the ground floor for accessibility. However, there is no visual barrier from the living space to the bedroom - an unacceptable design for Muslim families. In both the Regent Park and the Hobsonville dwellings, the access way and bathroom design are not acceptable as they link directly to the living space and have the toilet in the bathroom. However, in the Hobsonville case study, the entryway could have been easily reoriented or shifted to be culturally acceptable. There is also no bedroom located on the ground floor of the Hobsonville three-bedroom dwelling - a failure of accessible design.

Many of the Hobsonville dwellings included garages in the home. From the demographic analysis, a garage does not have clear cultural specifications but it is a space which Housing New Zealand encourages to be excluded from home design in favour of a carport. This is because it can often be used in an inappropriate capacity for bedrooms or extra living space as a response to the housing crisis. Garages by New Zealand Code standards are not watertight and this can cause many health issues when those occupying the space for long periods are consistently breathing in damp and cold air. This causes respiratory illness and other more serious health risks (Mendell, Mirer, Cheung, Tong \& Douwes, 2011). This could also be in response to a lack of adequate living space

within the dwelling itself. Different groups and even different families within a culture will use a dwelling differently, requiring different space. Due to this large variation, compromise in design may need to be made along with a basic rule of thumb based upon the occupancy of a household as to how much living space is needed. Homes in New Zealand could instead be defined in a European way, by rooms in place of bedrooms. This could then be utilized by the family occupying a dwelling as they need, rather than having a defined use.

Pasifika

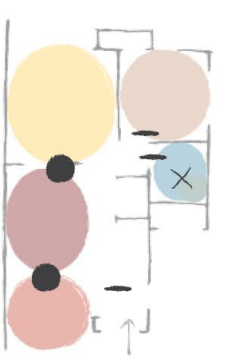

Level 1

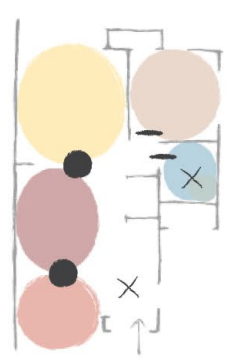

Level

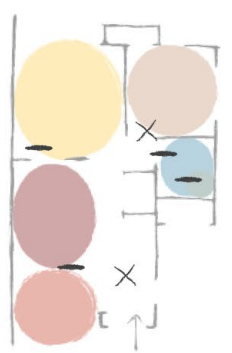

Level 1

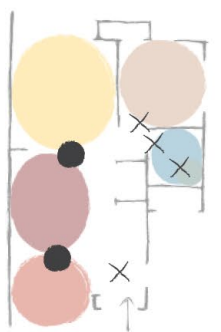

Level

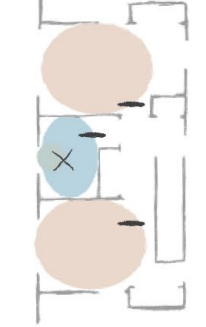

Level

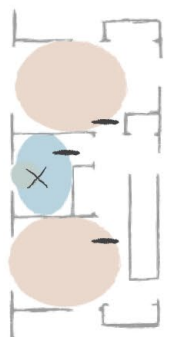

Level 2

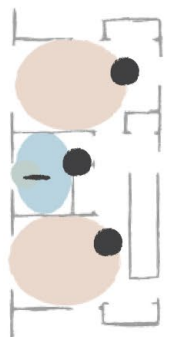

Level

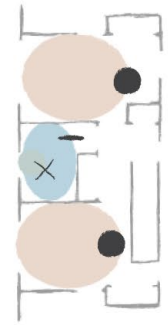

Level 2

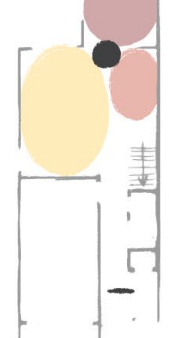

Level 1

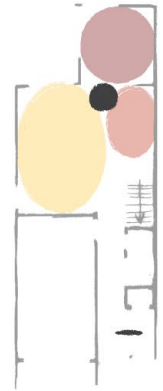

Level 1

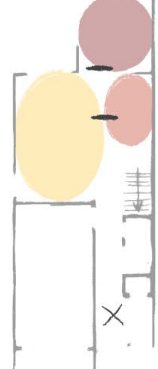

Level 1

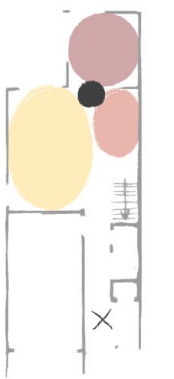

Level 1

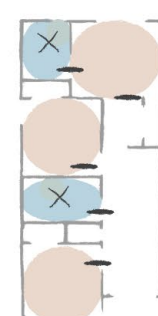

Level 2

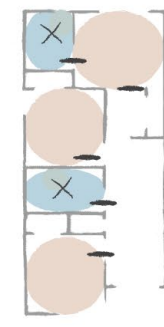

Level 2
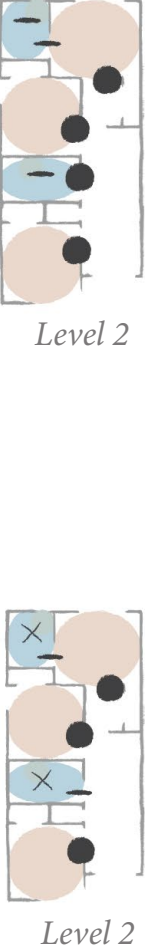
Four Bedroom Analysis

The larger a dwelling is, the easier it is for the design to allow for greater areas of privacy as levels can be split. This can be seen in the fourbedroom case studies where the "inclusive"

criteria have demonstrated that each dwelling almost meets the cultural criteria. However, the WC and bathroom are combined and many entryways are not acceptable. These are reoccurring issues throughout this analysis of contemporary dwellings. In the last Hobsonville case study, an isolated entrance has been created, however, there is no bedroom on the ground level - an issue of accessibility. The compact design of many of the case study homes would indicate that an accessible stair has not been included either, making the dwellings truly unliveable for anyone with restrictions on their movement.

Māori
Four bedroom - Regents Park
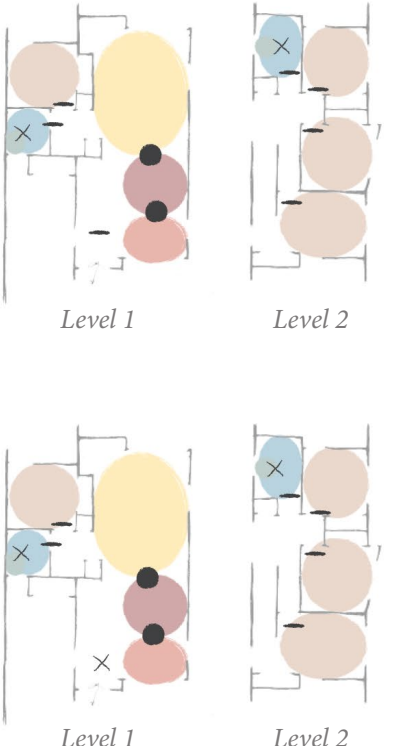

Level 1

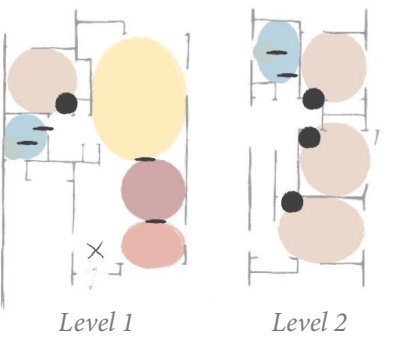

evel 2

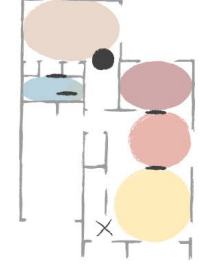

Level
Four bedroom - Hobsonville

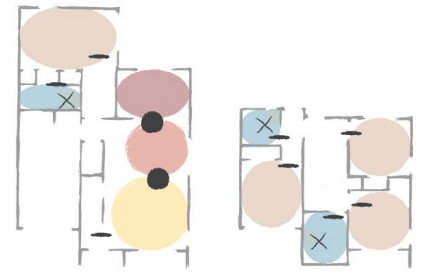

Level 1

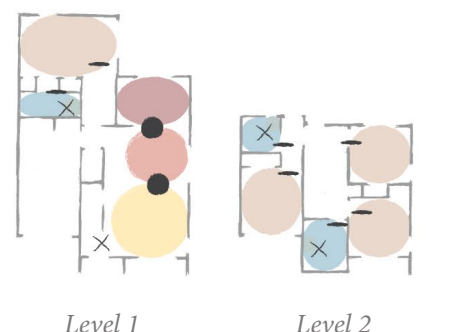

Level 2

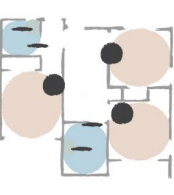

Level 2

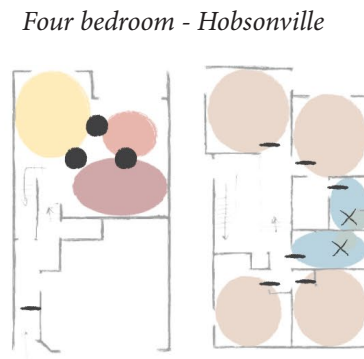

Level
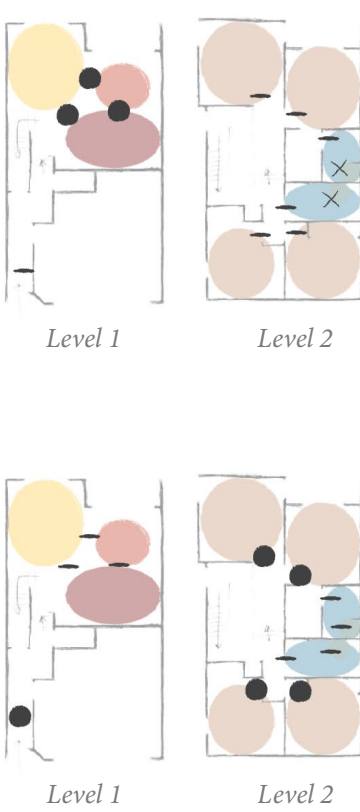

evel 2
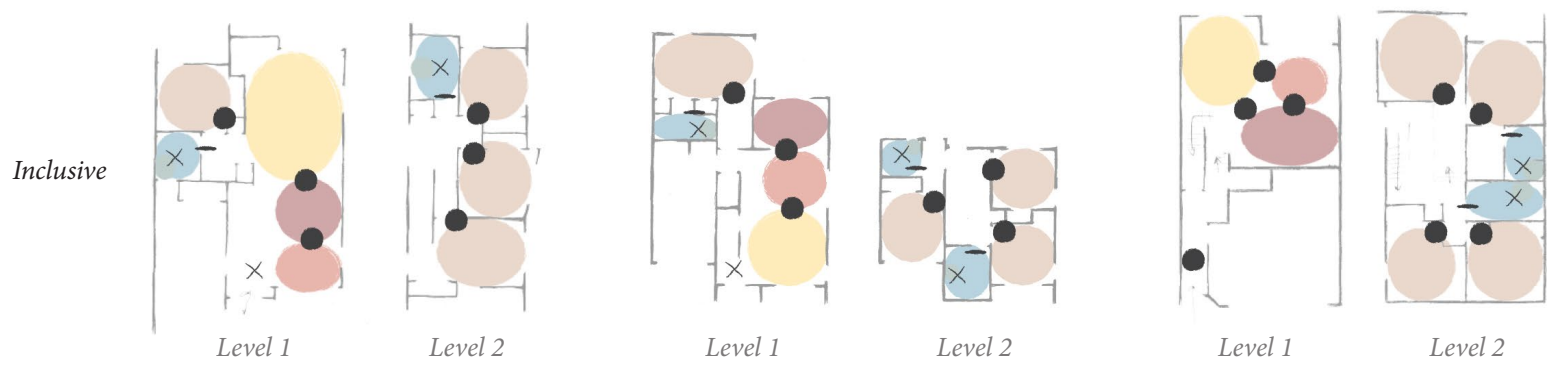
Testing Appropriate Design

As the previous tests indicate, New Zealand's social housing is not meeting the needs of its occupants based upon the criteria discovered.

The Overlea development was chosen to see if

modifications could be made in order for each

dwelling to be appropriate. This was difficult to successfully achieve, as many dwellings were too compact to add visual barriers or walls to isolate conflicting spaces from one another without infringing upon other areas.

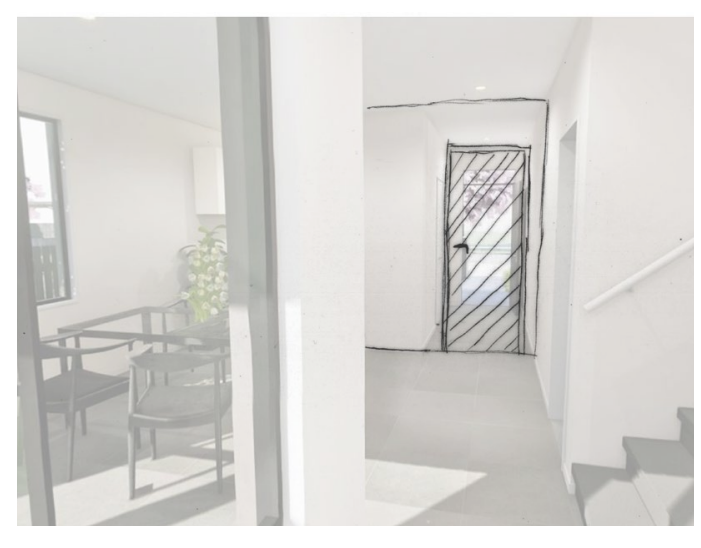

Isolating semi private from public space

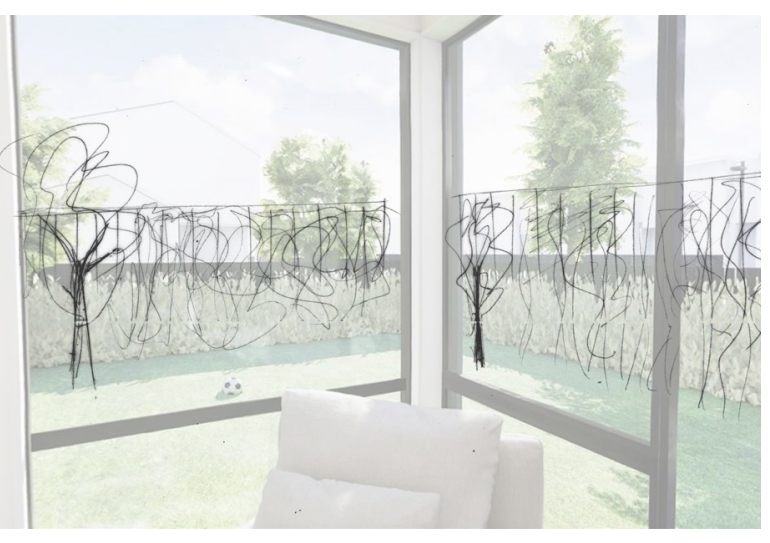

Privatise the living space (semi private) from public (neighbours)

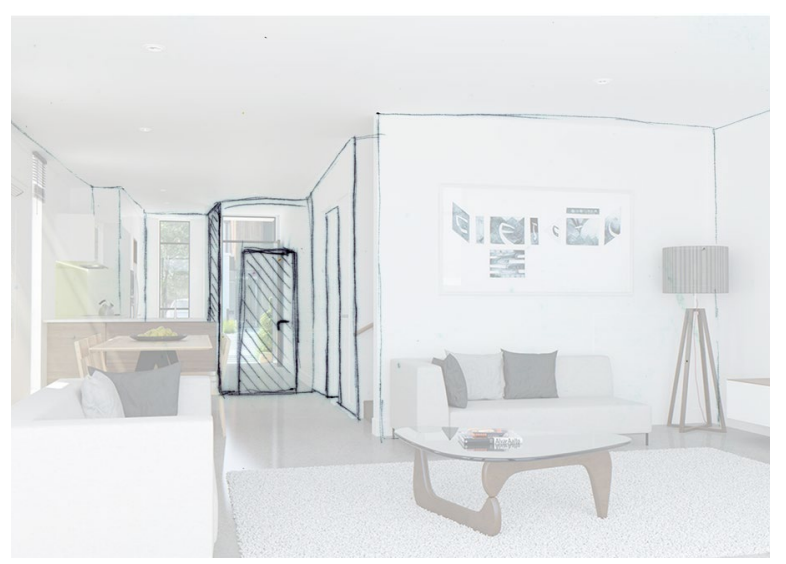

Isolate entryway as living/kitchen/dining area is too close to use angled entry

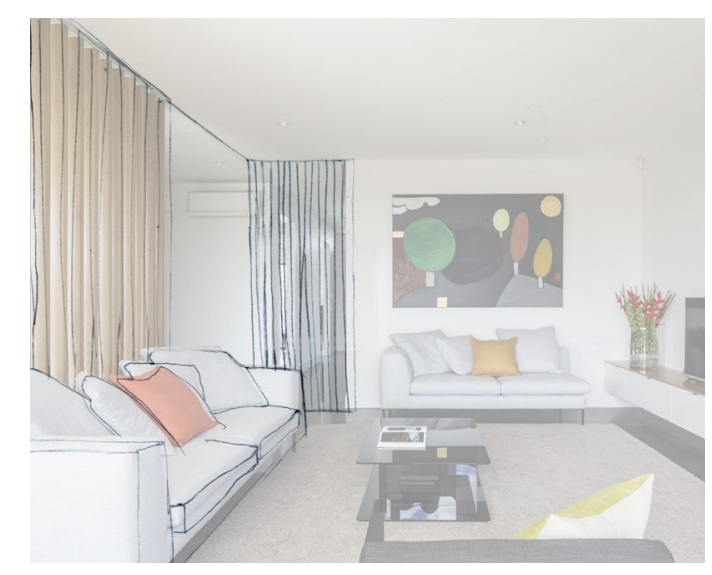

Use existing method of screening to protect the living area from main entryway view
These plans have been made culturally appropriate, however, many of these dwellings did not have a bedroom on the ground floor. This is not 'appropriate' and would require significant change to meet the criteria defined.

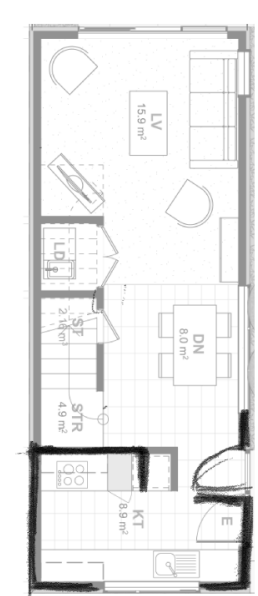

Level 1

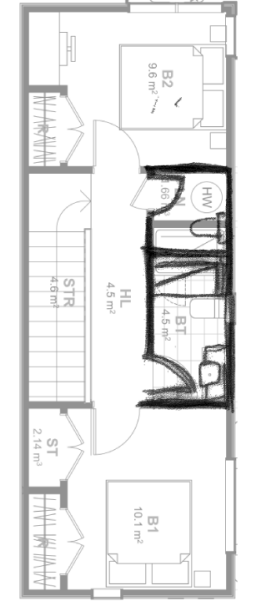

Level 2
Many of these solutions would make the dwellings feel even more compact and be undesirable homes.
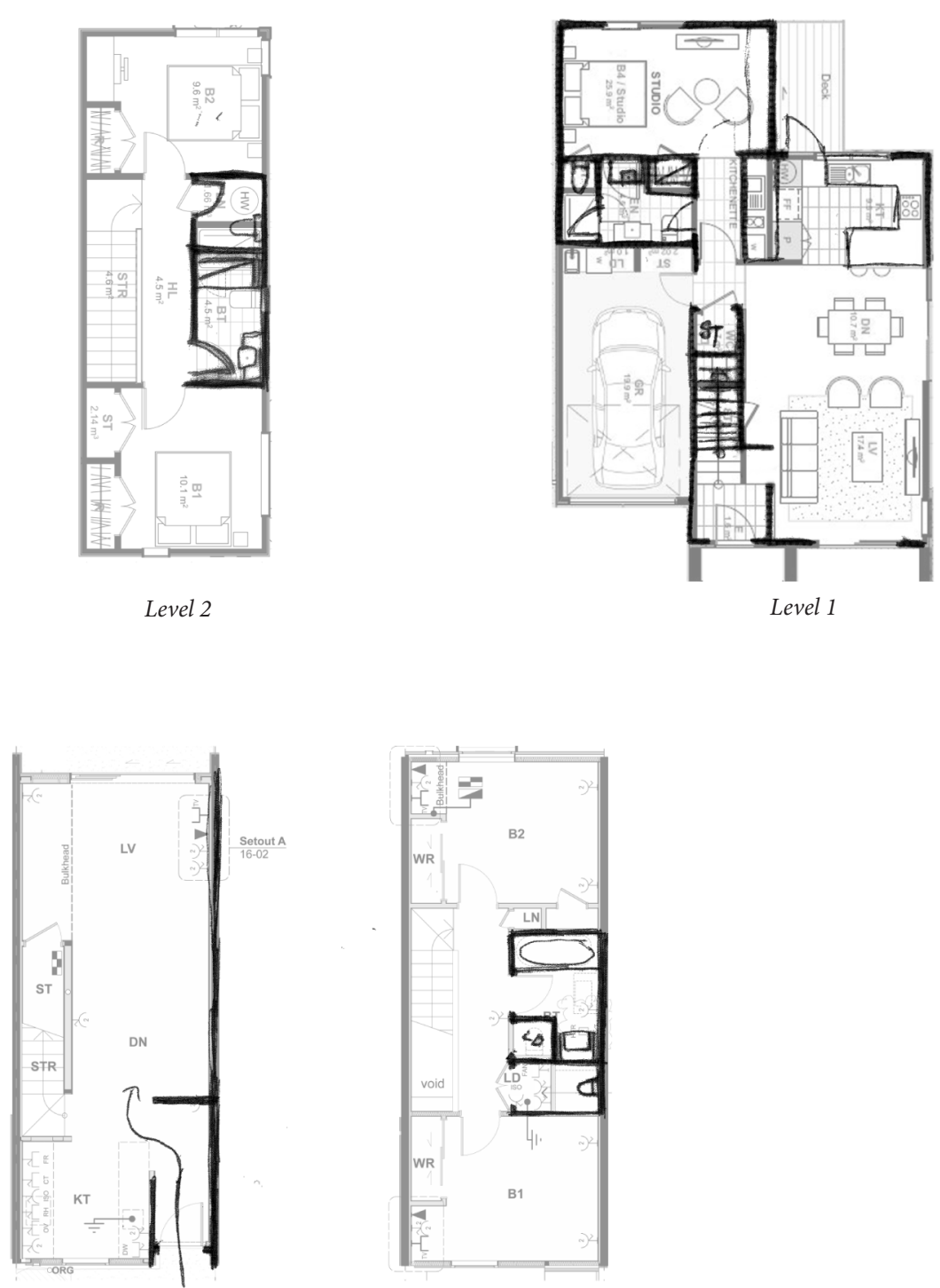

Level 2 
Upon analyzing a range of contemporary New Zealand state dwellings, there were two common issues. Those were combined bathroom and WC, and an unisolated entrance.

These have simple design solutions such as having separate WC to the bathroom, or using screens or walls to block views within a dwelling. These solutions may require the homes to be slightly larger to allow for this. However, this may be seen as "unnecessary" to some due to cost. However, as previously mentioned, these dwellings could be efficiently designed and will require less expense adapting the homes if they are not appropriate. This case study analysis made it clear that the individual spatial requirements of each group can be provided for, but that is not currently being achieved. A selection of these dwellings was then attempted to be made "appropriate" in interior perspective and plan. While in some cases, this was an easy fix, many required a lot of renovation/reorganization to be made appropriate. The next step is to apply this knowledge to a specific site and test those dwellings against spatial needs to determine how these criteria can be explored through design. 


\section{Site Selection}

Over the next 20-30 years, Housing New Zealand and other housing providers such as Wellington City Council are aiming to replace or restore their housing stock. This is in favour of lowering maintenance costs by taking a large initial cost to significantly update social housing. Three recent developments that are being considered/constructed are Arlington, Ōwairaka and Overlea.

Arlington is located in Mt Cook, Wellington and is the largest development that Wellington City Council has. It was constructed in the 1970s in stages and designed by King \& Dawson Architects and Ian Athfield. It was designed to encourage greater community in housing developments, something that was revolutionary for the time. It is no longer providing for its residents and is below modern living standards. It is on the border of suburban and central Wellington, providing an opportunity to explore a range of dwelling typologies in one site.

The Ōwairaka development is part of a rejuvenation of Mt Roskill in Auckland, which contains a huge number of the 1940s/50's state houses on large sites. The goal of this redevelopment is to at least double the density of dwellings in the area. This site would give ease of experimentation of housing, however, the context would limit the type of housing that is available to be "appropriated" as a three-four storey dwelling of any kind may look out of place in the suburban context.

Overlea is located in Tamaki, Auckland. The Tamaki Regeneration Company (TRC) has been regenerating the Tamaki area since 2013.
The regeneration intended to be for state or private ownership based upon demand. It is still unclear what has occurred, as the area is already home to other state housing developments. This site would allow for a range of dwelling types as it is varied in design already. Similar to Ōwairaka it is suburban and this may mean enforcement on cars/parking in preference of pedestrian-only and accessible spaces.

Ultimately, a site which will allow for maximum exploration of design ideas will be the best option going forward. Arlington will meet these criteria due to its suburban/urban overlap. Along with this, due to the site being under construction, there is a wealth of information available such as detailed proposals for the site and documentation on its history. The intention of the original design aligns with the intentions of this thesis - to encourage individualism but also community (Gatley, 2008). Assessing Arlington for "appropriateness" will enrich this research of state housing as it is from a different period (1960s/70's) and has been lived in for many decades. It will also determine what can be done on the site as there is historic value to the dwellings, which could be renovated to be appropriate.

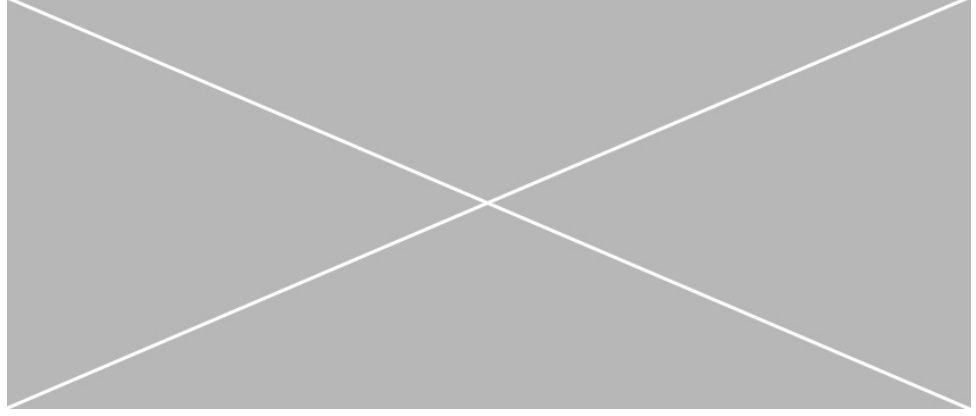

igure 3.12: Arlington One from the George Porter Tower, Wellington

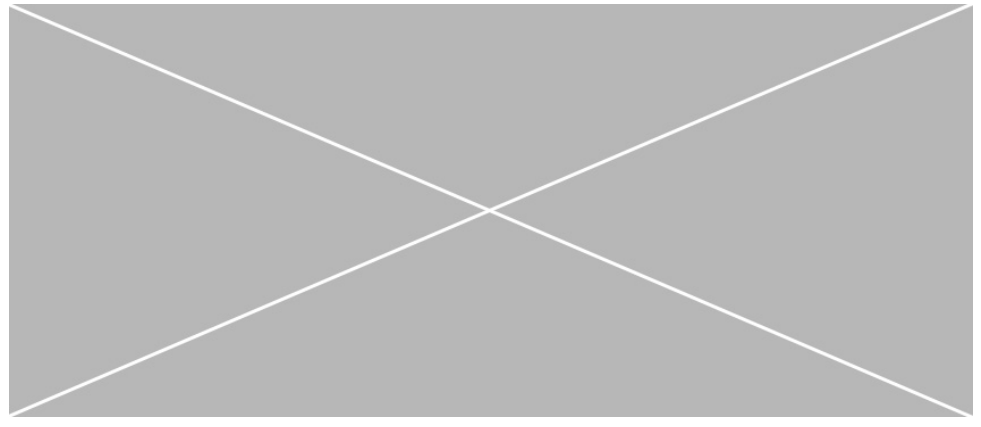

Figure 3.13: Owairaka Development, Mt Roskil, Auckland

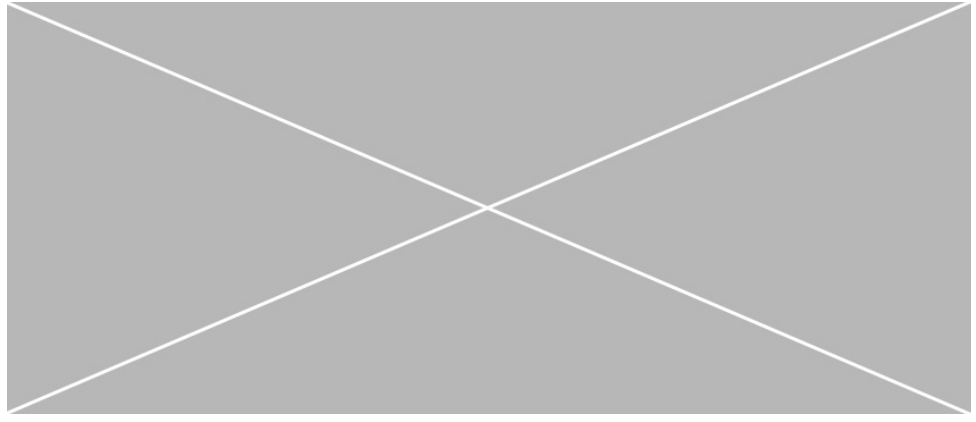

Figure 3.14: Tamaki State Housing, Auckland 


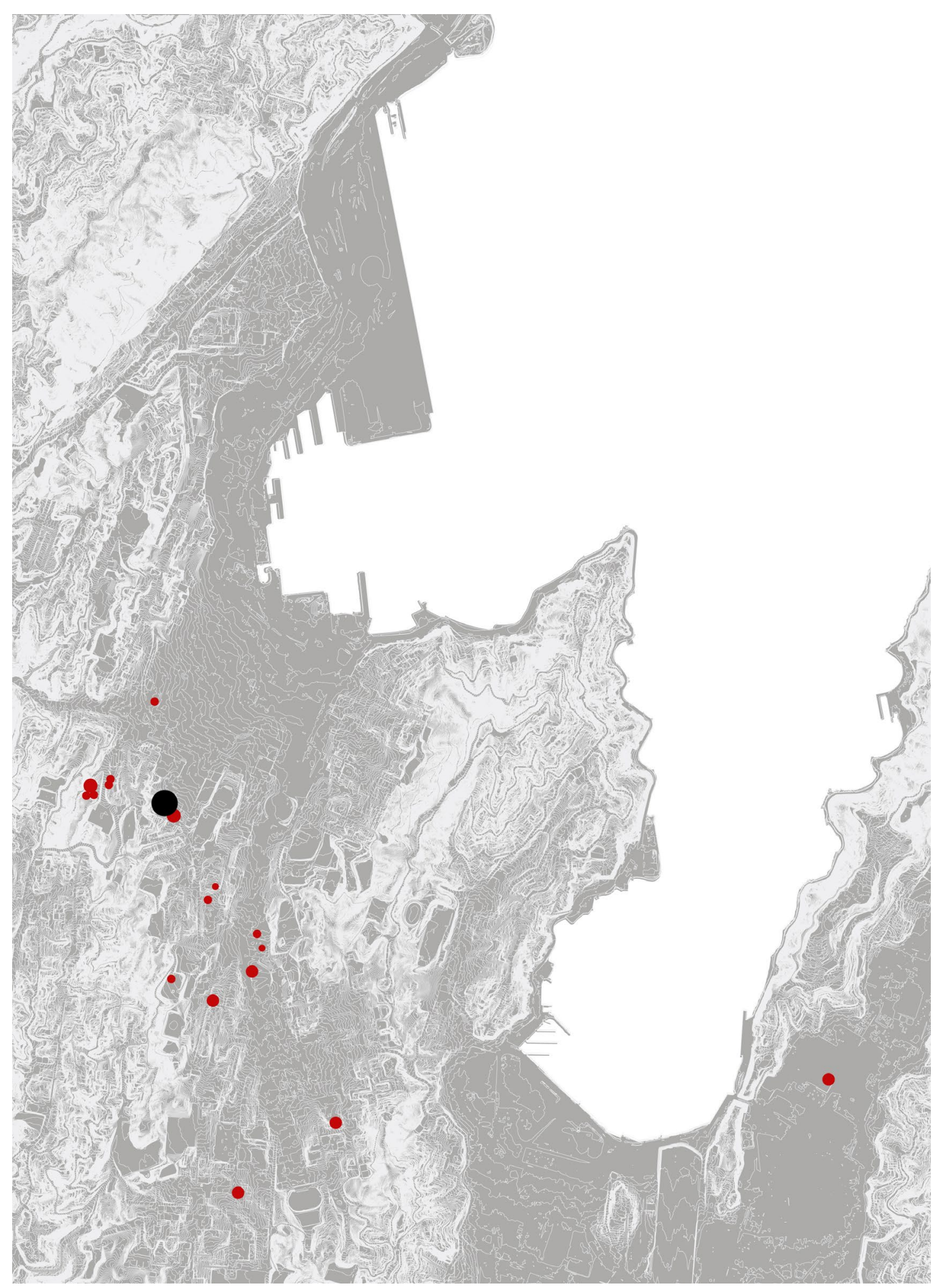

Figure 3.15: Wellington City plan showing surrounding social housing developments and Arlington One

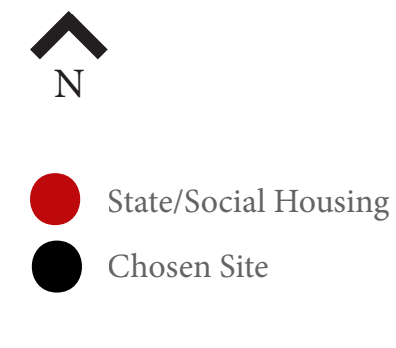

$\stackrel{\vdash}{\stackrel{1}{1}}$ 


\section{Arlington}

Arlington was designed by King \& Dawson Architects and Ian Athfield in the 1970s. It was groundbreaking for the time by providing three-four storey dwellings with communal amenities as a solution for state/social housing (Gatley, 2008). The vision behind Arlington was that of Ian Athfield. Athfield has played a significant role in shifting traditional conventions of design in New Zealand by giving it "a healthy and personalised kick in the pants" (Walden, 1981, p 30). Architecture to Athfield was ever-changing and he carried a strong opposition to heritage-listed buildings (Huynh, 2017). Any building which was not providing for the needs of its users would be under contention to be redesigned, reconstructed or refurbished. As Athfield said, "Architecture has a social responsibility beyond the building, client and architect" (Gatley, 2008, 28). This was demonstrated in the design of Arlington as Athfield was able to bring in his concepts of fostering community living in the four-stage development. In 1972, Stage One combined medium-density housing that was one-three storeys, with an 11 storey tower - the George Porter Tower. They were made up of studio dwellings, one, two and three-bedroom dwellings. Stage Two was a repetition of the one-three storey dwellings in Stage One. Stage One and Two provided outdoor laundries and a court that could be used by all residents. Stage Three presented three types of dwellings, three, four and five bedrooms in order to cater for larger households, however, no additional communal facilities were included. Stage Four, which is located across the road in between Hooper, Hankey and Taranaki Street was built last and was made up of one- three bedroom dwellings. Stage One \& Two are currently unoccupied while Stage Three is occupied by WCC residents and Stage Four has recently been rebuilt as discussed in Chapter 1. All of the apartments were constructed with uninsulated concrete block and currently do not meet New Zealand's building standards. The sites were also referred to as mazes with the change in levels creating unsafe corridors and blind corners. These levels are broken up by stairs, making the majority of the site inaccessible to the elderly, parents with prams and those with accessibility requirements.

In recent years, Arlington Apartments ha been a discussion point for many published works. Three Architectural theses have analysed Arlington's design from differing perspectives and scales (Cahill, 2017), (Huynh, 2017) (Holmes, 2012). In 2017, Cahill was critical of Arlington's design from a planning/ landscape architecture perspective, stating "it seems like the Wellington City Council, at the time, wanted an innovative design... but were held back by regulations. Therefore Arlington is left lacking that inspiring design, but with a thin mask of 'Athfield-ness' that doesn't quite hide its realities" (Cahill, 2017, 40). While it is correct that the council restricted the scheme by standardised design between the units and fixtures to cut costs, this did not leave development with only a little 'Athfield-ness'. Athfield's ideas are presented in the dwellings and throughout the site, as there are communal laundries, green space, a playground, a basketball court and a continuous connection between differen blocks of units. All of these design decisions
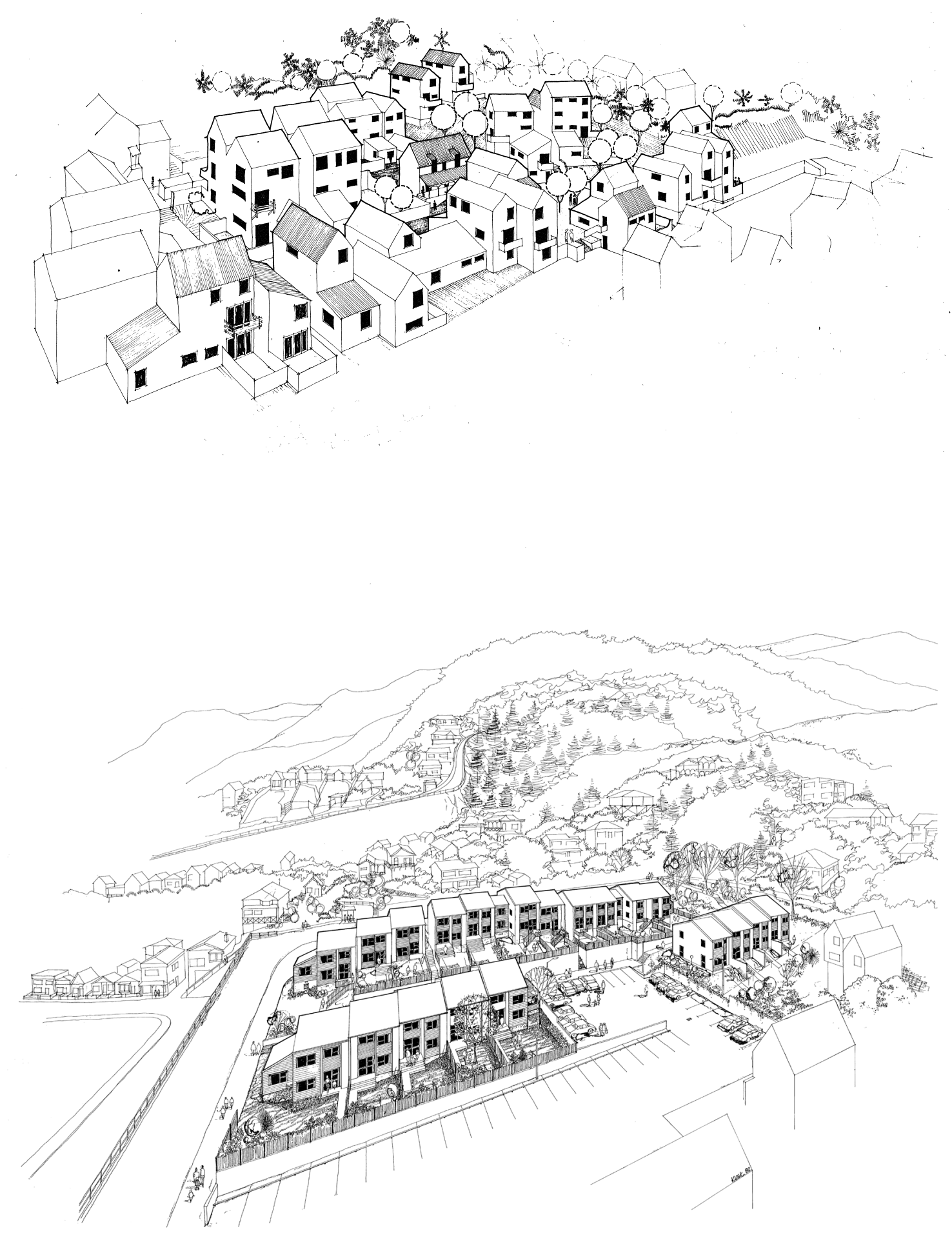

Figure 3.16: Original Arlington Stage One and Three perspectives 

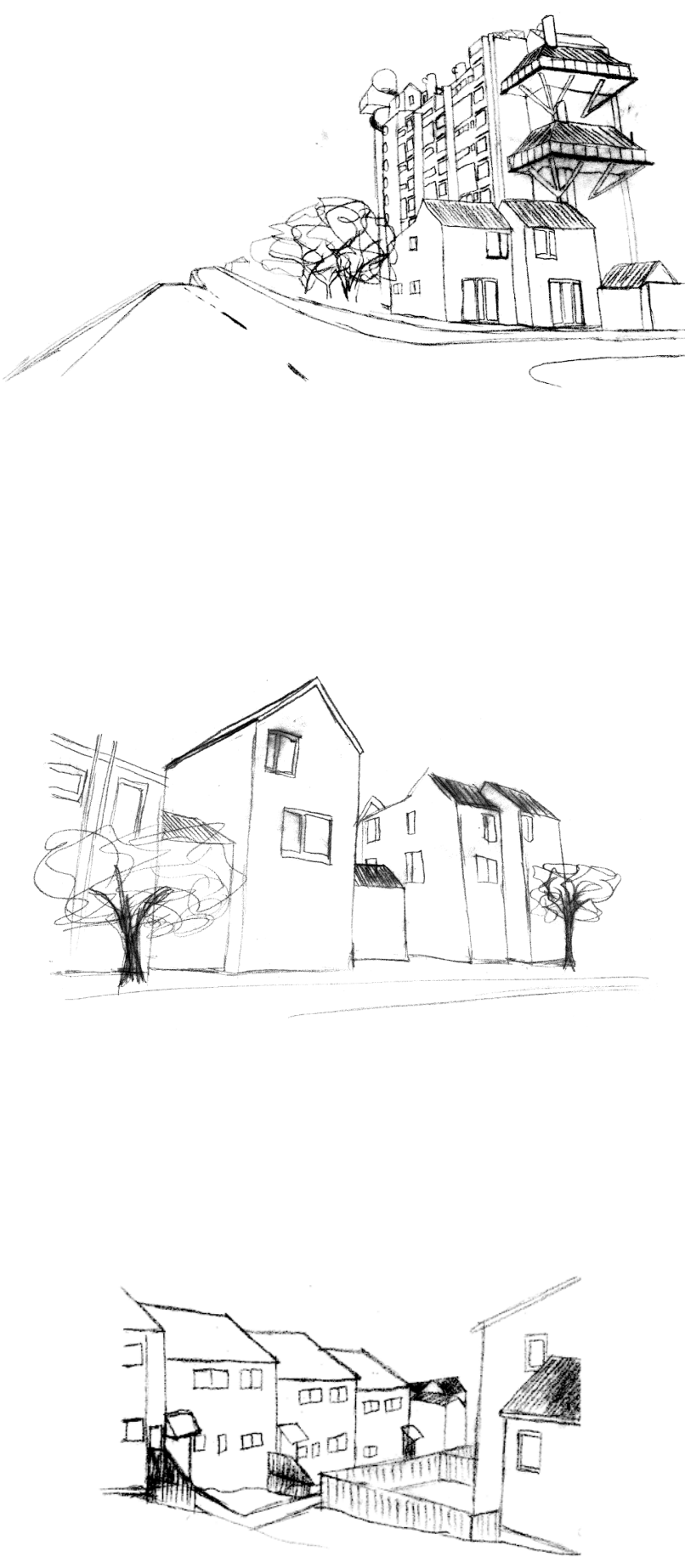

were made to encourage community between residents of the site as Athfield had intended. In 2017, Huynh focused on the George Porter Tower. This thesis compared historic and contemporary high-density housing designs that were constructed for social housing to analyse the intentions, weaknesses and strengths of George Porter Tower. The re-design of the tower: added green space to community areas, added to the roof of the tower to provide communal space, restructured the building to provide greater earthquake resistance and placed winter gardens to the exterior of each dwelling to make each space feel larger. In 2012, Holmes utilised Arlington Apartments as a case study of immigrant housing in Wellington, while the rest of the thesis explored social housing that catered for immigrants. It explored similar themes of inclusivity of minorities, flexibility and adaptability that are being explored in this thesis, however, it did not acknowledge Māori design concepts which are essential to any social housing solution as Mãori currently make up $46 \%$ of the state housing register (MSD, 2018). Statements from this thesis can be expanded upon as there was a highlight of Japanese architectural values but no other key cultural groups that social housing provides for. 

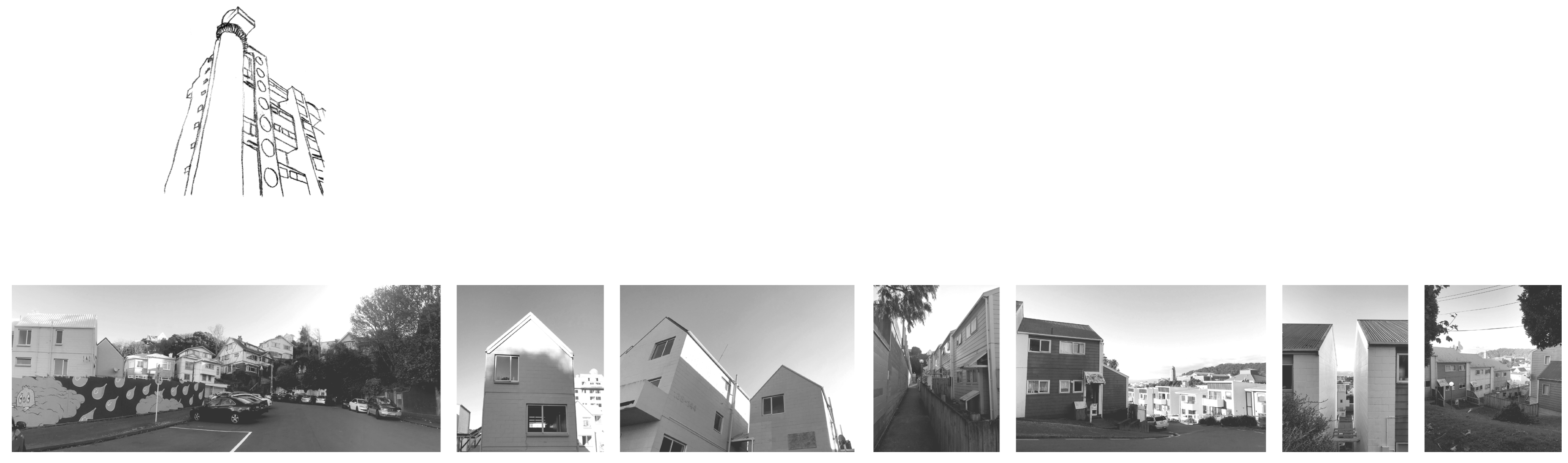

Figure 3.19: Site Photographs. Left to Right: Arlington Street, Stage One D welling I Block". Stage One Dwelling "H Block". Stage 3

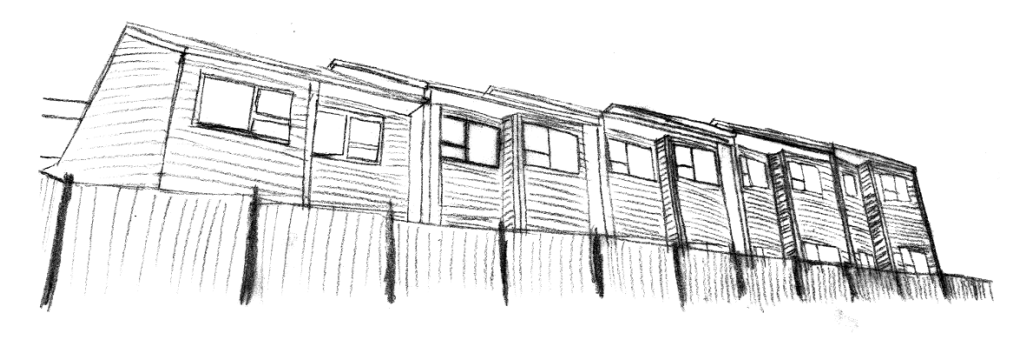




\section{Assessing Arlington's Appropriateness}

Arlington had similar issues to contemporary state homes in terms of cultural requirements such as tight units creating direct connection of private and semi-private spaces such as living room and dining. In analysing accessibility in plan, there is a huge variation in levels and many of these developments are not accessible. Arlington's dwellings are not accessible,

culturally inappropriate and below New Zealand modern building standards and are currently being demolished. Acknowledging Arlington's past and original design intention will help to better design its future. Those key ideas being encouraging interaction through communal space and increasing density without sacrificing light.

Currently Arlington's design provides 372 bedrooms, whereas the current proposed design by WCC has suggested 459 beds. In order to be "appropriate", the design needs to provide 372 beds at minimum, however exceeding that without losing natural light and providing privacy would be a better response. The diagrams in Figures 3.20-3.22 assess Ian Athfield's original design in relation to the spatial considerations of diverse social housing tenants discussed earlier.

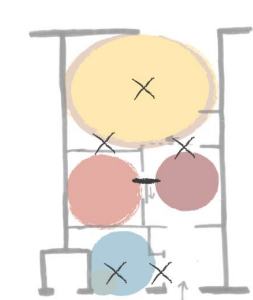

Level 3-9

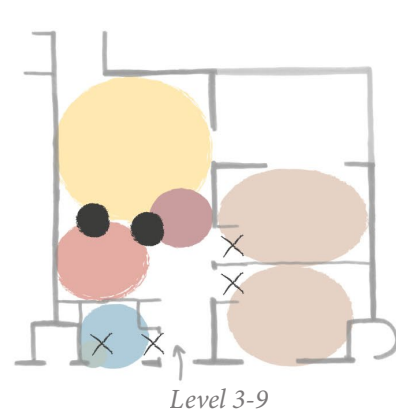

evel 3-9
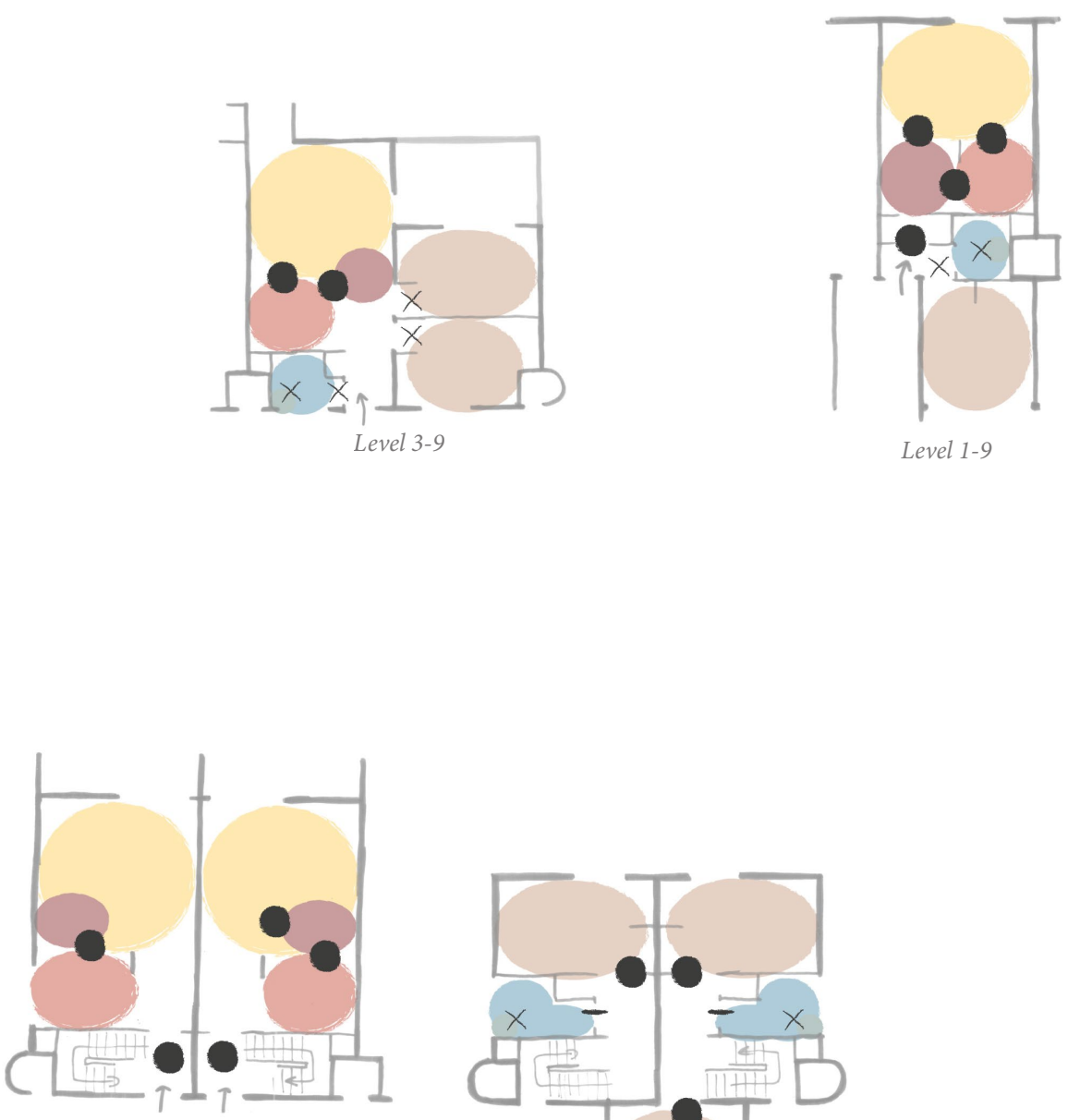

Level 10

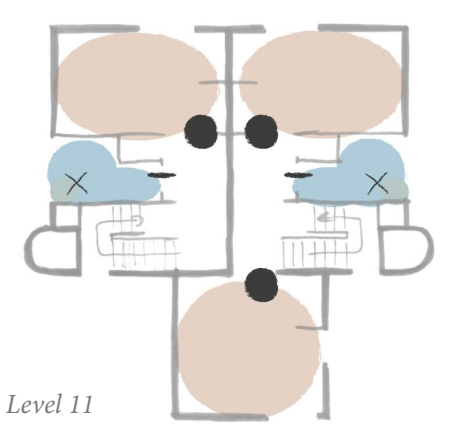

Level 11

\begin{tabular}{|c|c|c|}
\hline Kitchen & Bedroom & Essential for inclusive solution \\
\hline Dining & $W C$ & - Acceptable but not essential for all \\
\hline Living & Bathroom & $\times$ Unacceptable for $i$ \\
\hline
\end{tabular}




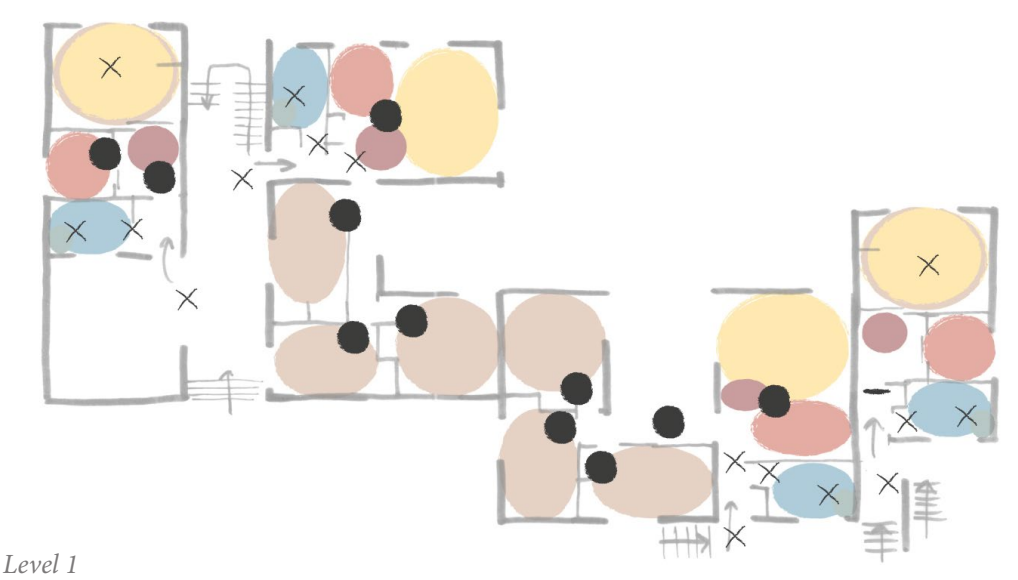

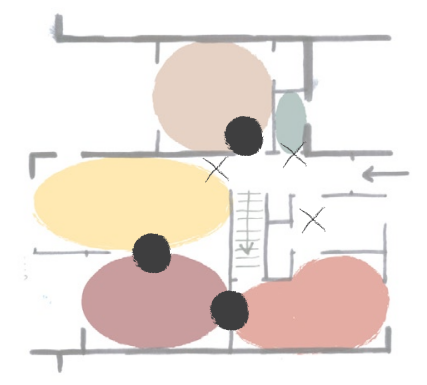

Level 1
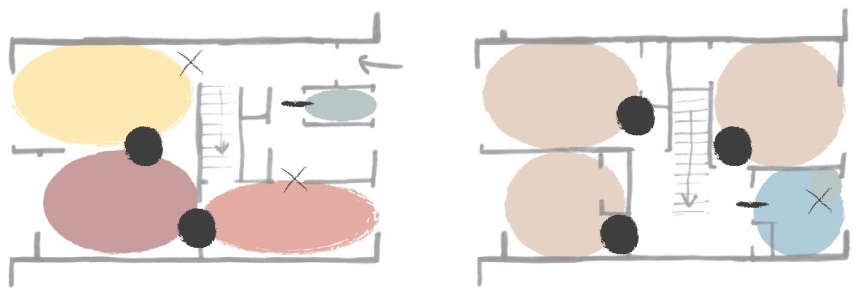

Level 1

Level
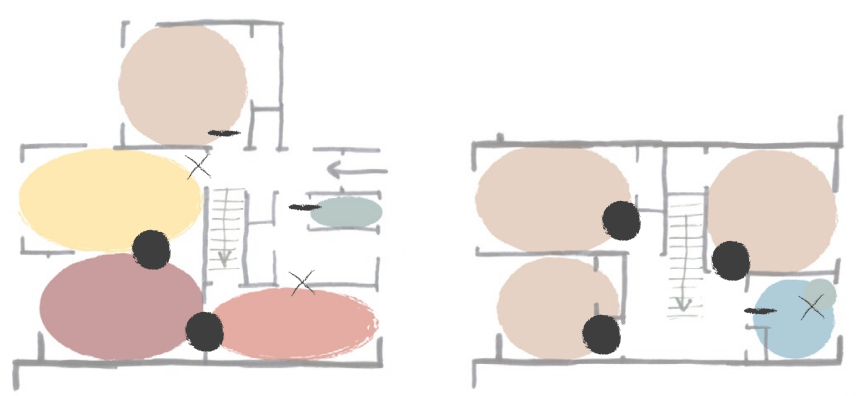

Level 1

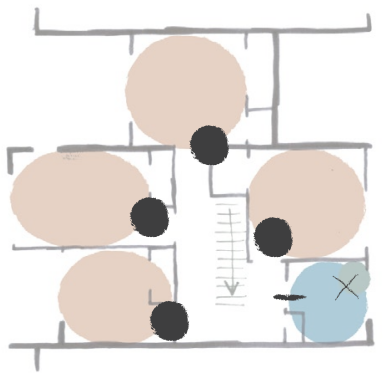

Level 2 


\section{Reflection}

Throughout this chapter, appropriateness has been defined further and tested against contemporary social homes to assess the need for appropriate housing.

By testing each cultural need individually in plan, it was found that housing which is inclusive of all cultures is achievable as many spatial requirements either overlapped or could be provided for. When touching on accessible design, further research can be done into universal design guides and utilising NZS4121, to design to meet this code, along with any novel design suggestions found through universal design guides. By testing the criteria defined in Chapter 2 against contemporary

Arlington is a site that has many issues such as privacy, community and security that will align with the explorations of this thesis as often cultural requirements can be dealt with through managing privacy. Located in the city fringe, the site has the option to be relatively dense and challenge conventional housing in New Zealand based upon what will appear appropriate for the area. The original complex was not up to modern standards and is being demolished, which provides a design opportunity. The original intentions and successful qualities of the development such as encouraging community interaction will be taken into account in the proposed development.

When the Labour government originally began mass-producing state housing in 1937, there was not the same stigma being put on social housing as it has currently. Instead, it set a precedent for quality and challenged what affordable housing looked like in New Zealand. The same approach could be taken now as the country steps into a new stage of social housing in which the housing stock is being replaced. These criteria will now be explored in the initial design phase to answer the following questions:

At what size does a dwelling require an extra living? Is this required in every large home?

What kind of dwelling is appropriate? 


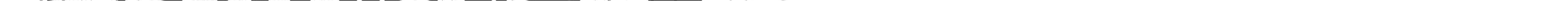


Exploring the Alternative Home - Inside and Out

From assessing state houses over time,

Arlington's 70 s and 80 s dwellings and a range of

contemporary state houses from both Housing

New Zealand and Councils, it can be concluded

that while they may have been appropriate for

the time, there is currently not an appropriate

architectural response to the diverse needs of

those requiring state housing.

The next phase in this thesis will be to examine appropriate design solutions for these dwellings according to the criteria explored in the

literature review.

Appropriate design solutions for these dwellings have been examined at three scales -

the building envelope; interior spatial planning

and the masterplan.
1. BUILDING

- ENVELOPE

Page 78

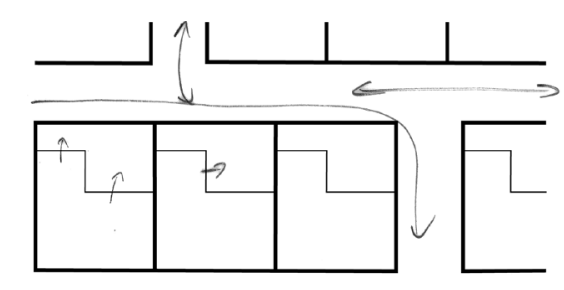
2. INTERIOR SPATIAL

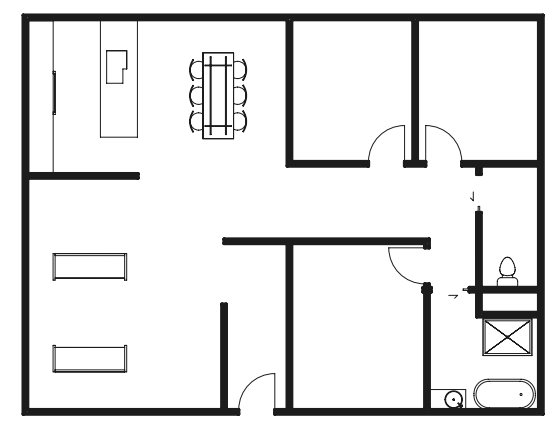

3 MASTERPLAN

Page 88

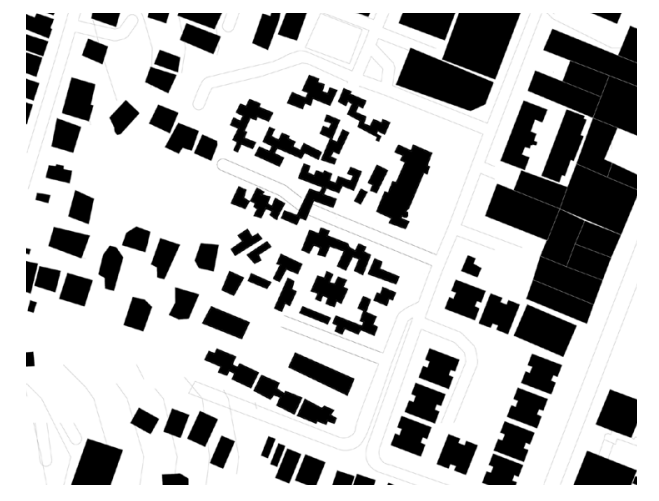




\section{Building Typologies}

In Chapter 2 dwellings were tested in plan, however, their relationship to each other was not able to be considered. This test proposes different dwelling shapes, orientations and their relationships to each other through opaque

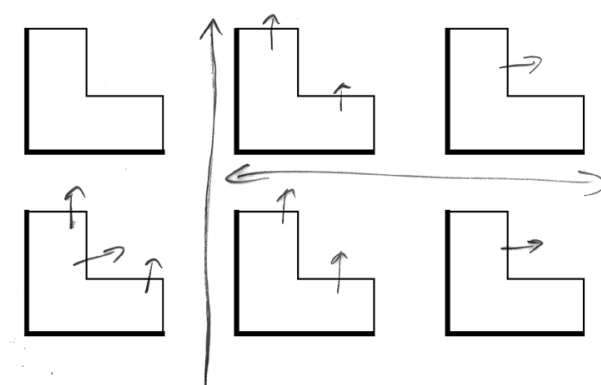

Figure 4.1: L-shaped blocks which face outwards and never into another block. Plausible at small scale

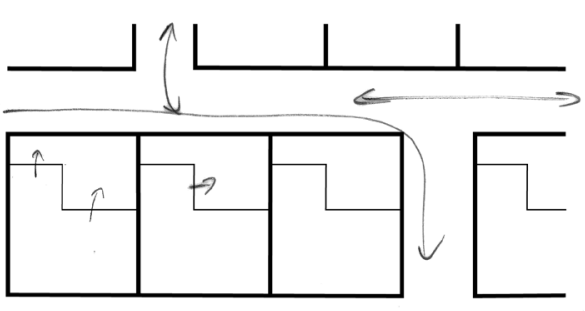

Figure 4.3: Considering both solid walls and fence lines to enclose each a welling. Does not take into consideration ablock and transparent boundaries to address privacy between dwellings or buildings. Fencing partitions, walls and courtyards can be utilised to increase or decrease privacy.

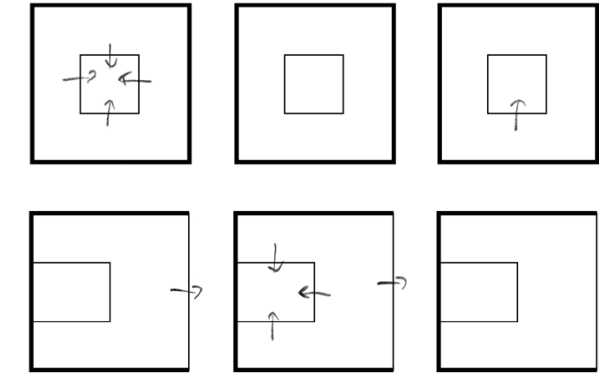

Figure 4.2: Variations of courtyard blocks, a typical home for Islamic culture. Allows for total privacy but
only at small scale

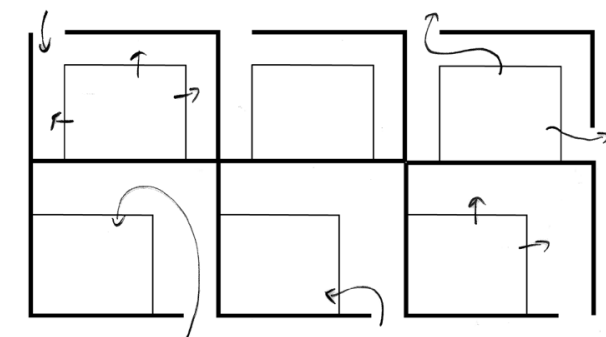

Figure 4.4: Private outdoor space for each dwelling with entrances beginning to be considered.
While this exploration is successful in testing different ideas and the permeability, context is key to solidifying whether or not each will work. The next step is to test out a range of appropriate floor plans that range in size and number of rooms.

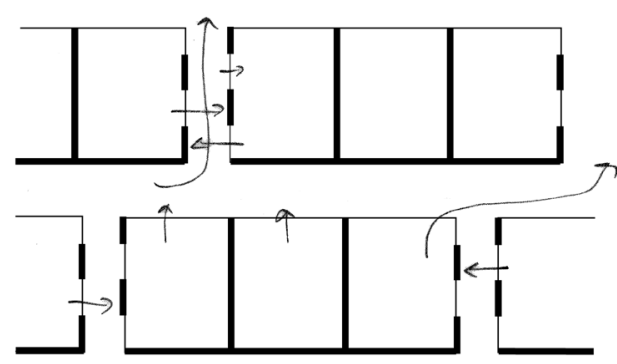

Figure 4.5: Alternating windows and entrances for greater privacy. Fences could be added to increase privacy.

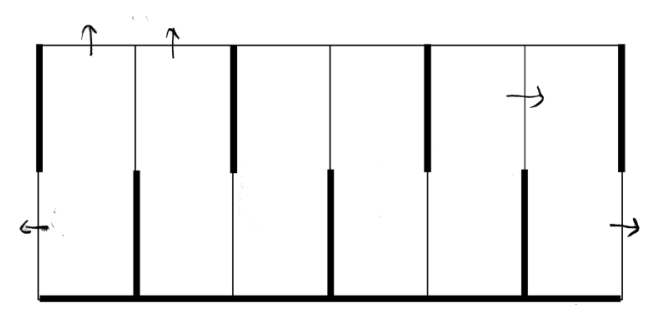

Figure 4.7: Flexible dwellings where thinner walls could be kept up or taken down as the needs of potential occupants
change.

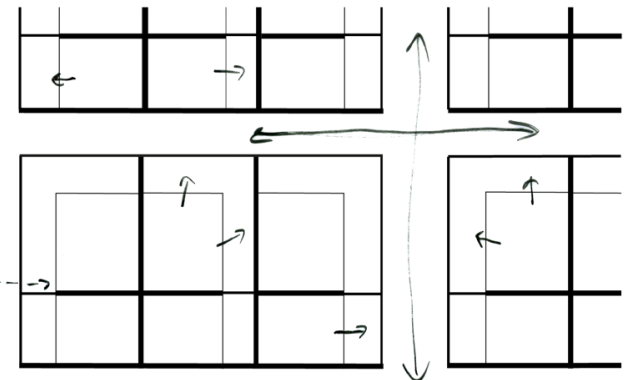

Figure 4.6: Increased privacy through total isolation of each dwelling via fencing/walls.

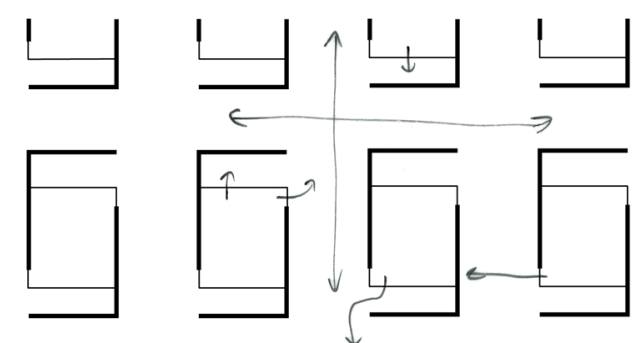

Figure 4.8: Multiple entries to each block for access with privacy 


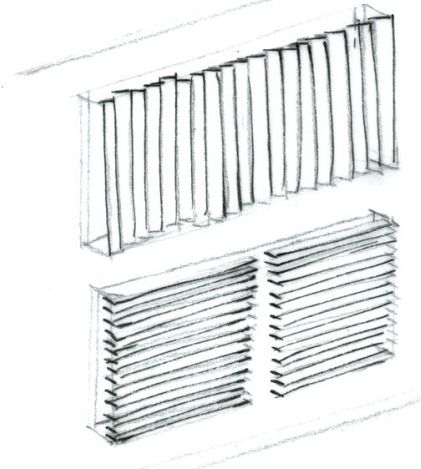

Figure 4.9: Shutters/screening for
privacy while still allowing light.

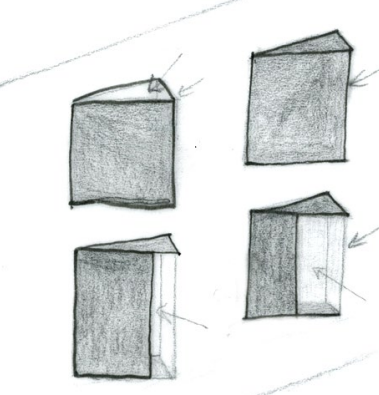

4.11: Variations of windows which are north facing, variations in ligh
being allowed in

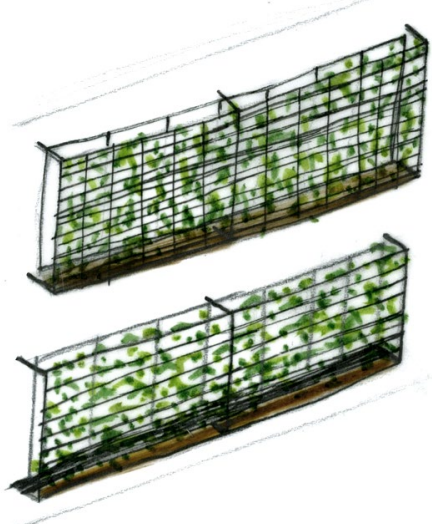

Figure 4.10: Thick and thin foliage screens. Accessiblor or hot, these may not be Residents with accessibility concerns will be unable to take care of their foliage and tha would require extra costs by Housing NZ

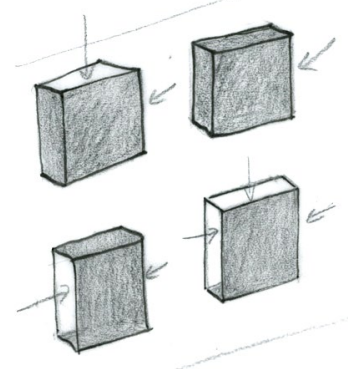

Figure 4.12: Boxed windows to allow light but maintain privacy. Different faces will provide different light. Also dependant on it could be poor at providing privacy.

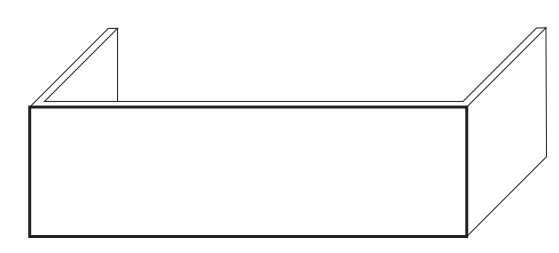

Figure 4.13: Beginning balcony form. Will block view into the interior from above, however
horizontal view is unobstructed

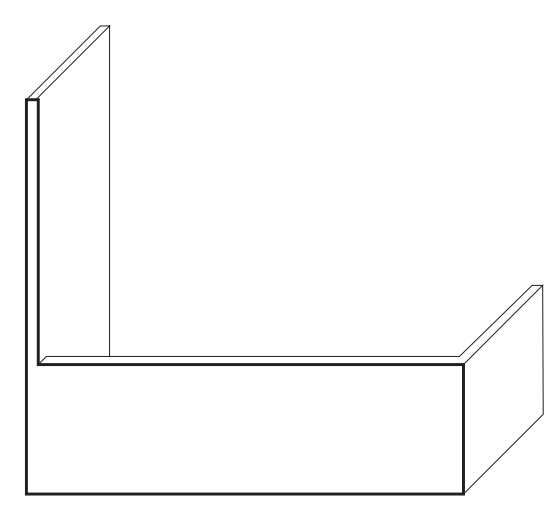

Figure 4.15: Visual barrier added. Can be utilised on either side of a balcony depending on surroundings

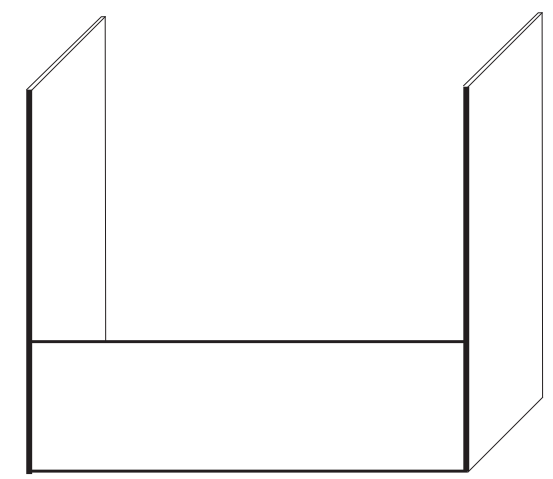

Figure 4.17; Isolated balcony. View mostly
obstructed

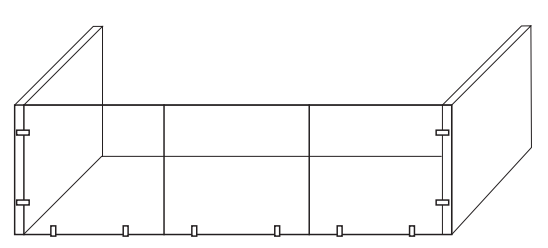

Figure 4.14. Glazed balcony. Frosted material could distort view but still allow light

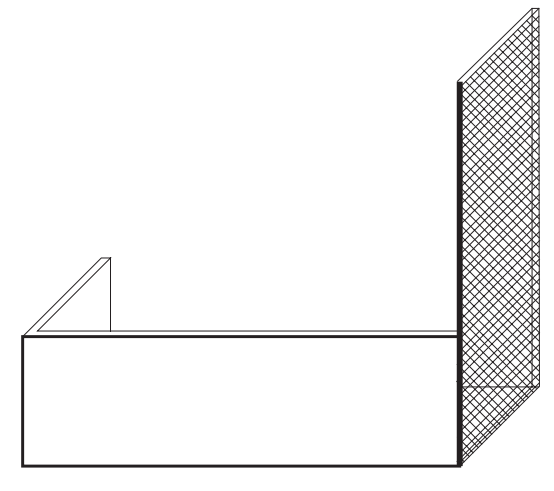

Figure 4.16: Semi-perforated barrier, this will obstruct view but still allow light

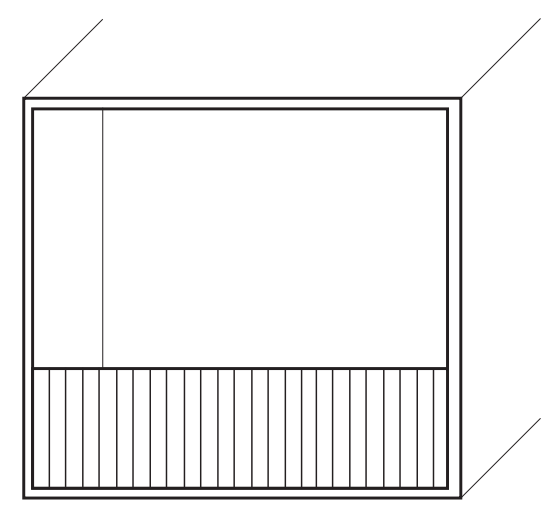

Figure 4.18: Built-in balcony. This can sit within
the facade to maximise privacy. 
Plan Exploration

These floor plans range from one-six room dwellings. Bedrooms are not defined as rooms to not imply a fixed use. A family could utilise

a four-room dwelling as three bedrooms and

n extra living or study space depending on their needs. These dwellings must meet the accessibility and cultural criteria, simplified in these diagrams:

Cultural Requirements:

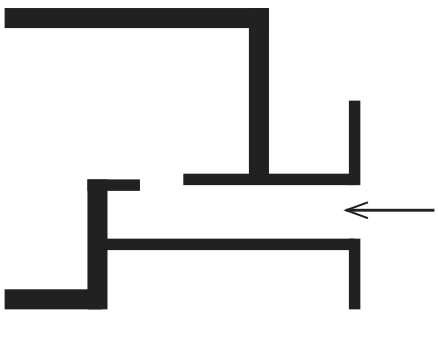

Isolated entrance
Good spatial
relationships

$=-5$

$\sqrt{---}+\sqrt{\pi} \pi \mathrm{H}$

$\Gamma+\Gamma$

$\mathrm{h} \pi \mathrm{H}+\square$

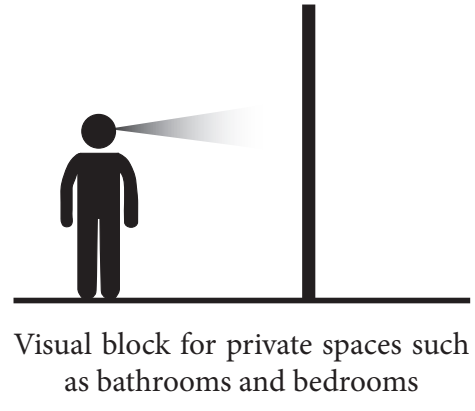

Bad spatial

relationship

$\times \square$

$\therefore \mathrm{r}+\mathrm{H}$

$x$

$\times \square$
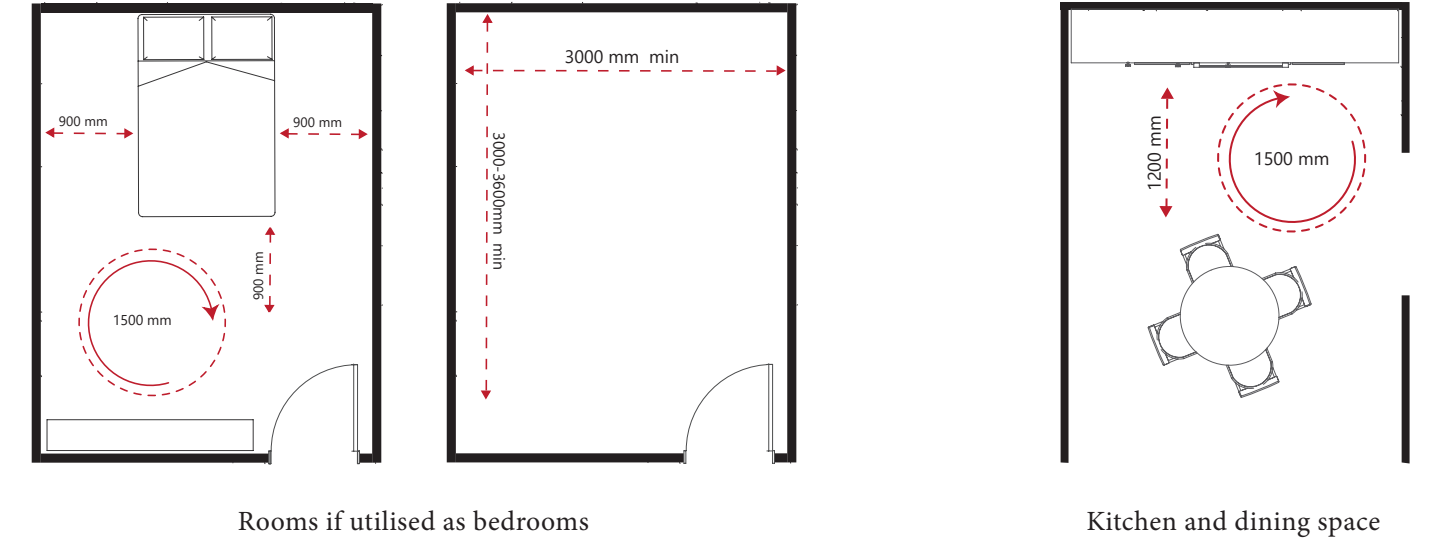

Kitchen and dining space

Rooms if utilised as bedrooms

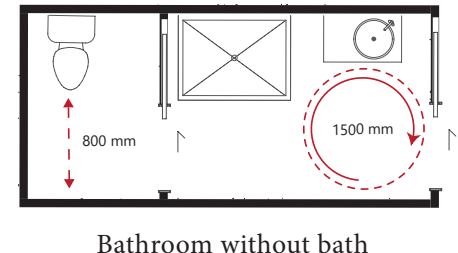

Bathroom without bath

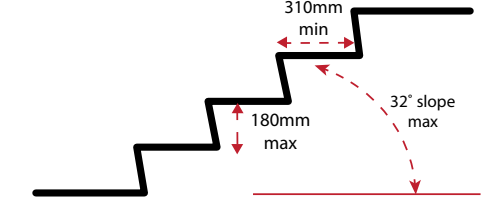

Accessible stairs
Bathroom with

Figure 4.20: Key accessibility requirements to accommodate a range of
abilities. Taken from Lifemark Design Guide and through cultural analysis 

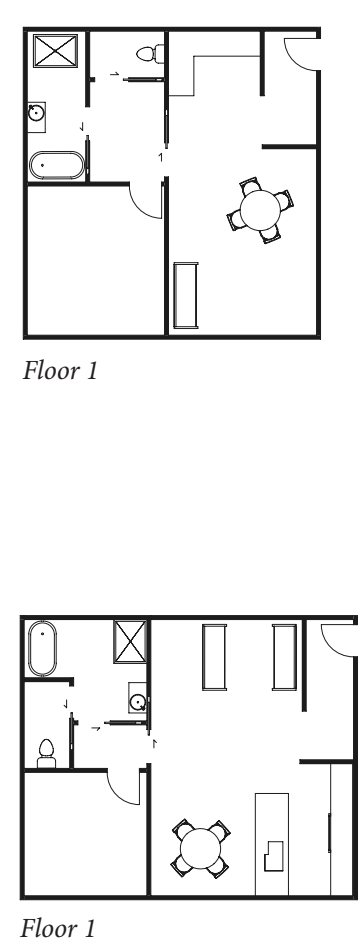

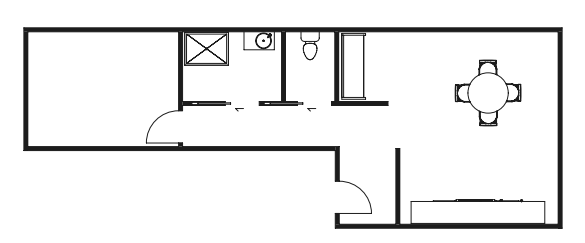

Floor

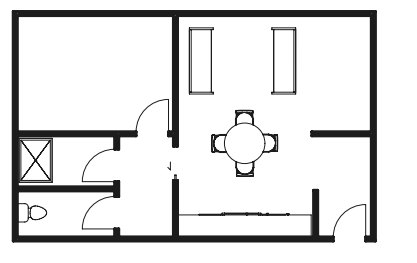

Floor 1
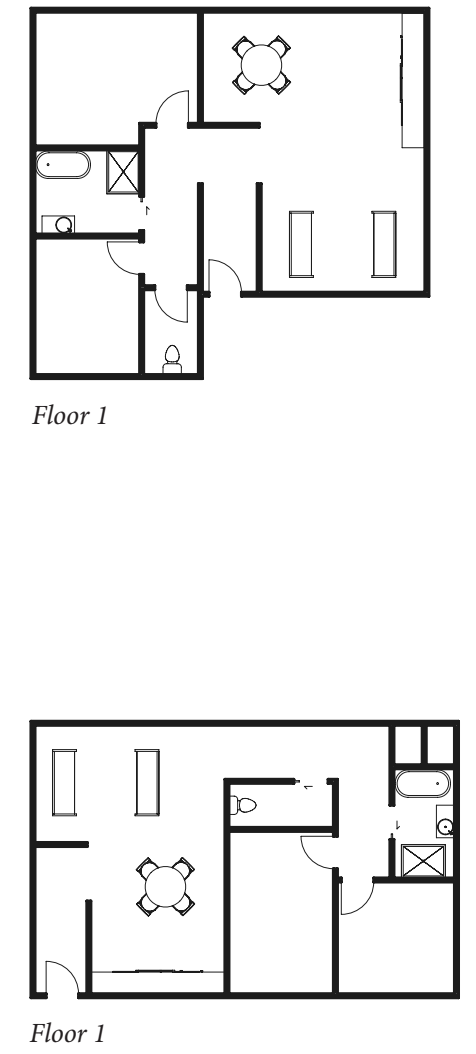

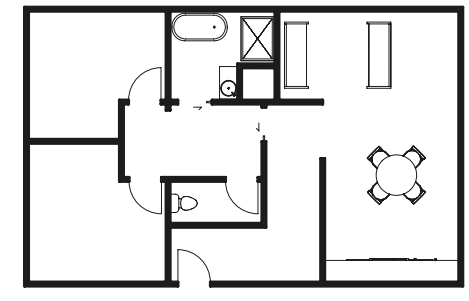

Floor 1
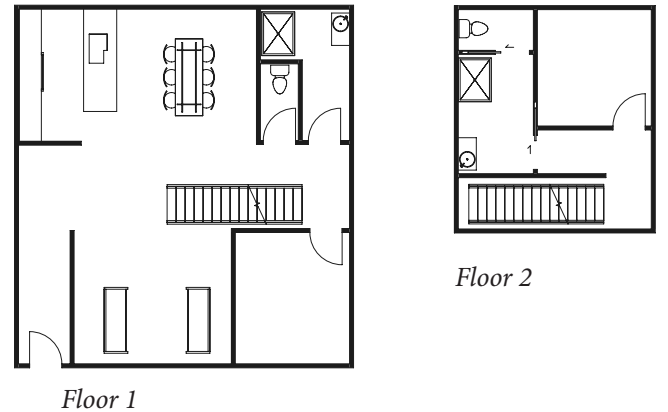

Figure 4.22: A range of culturally acceptable and inclusive 2 room dwellings

$1+\quad \mid$ 

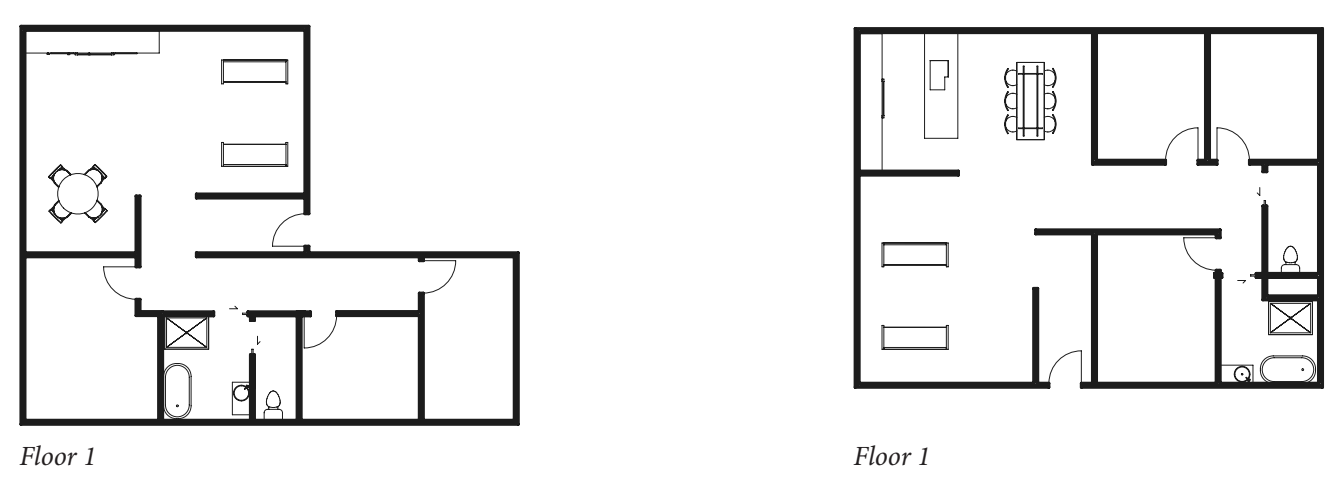

Floor
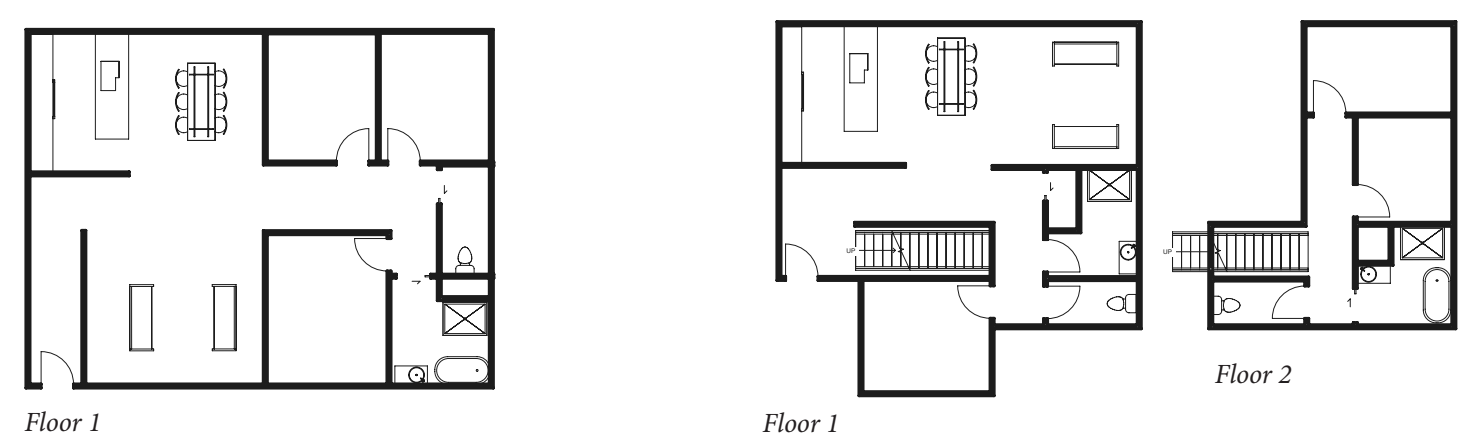

Figure 4.23: A range of culturally acceptable and inclusive 3 room dwellings
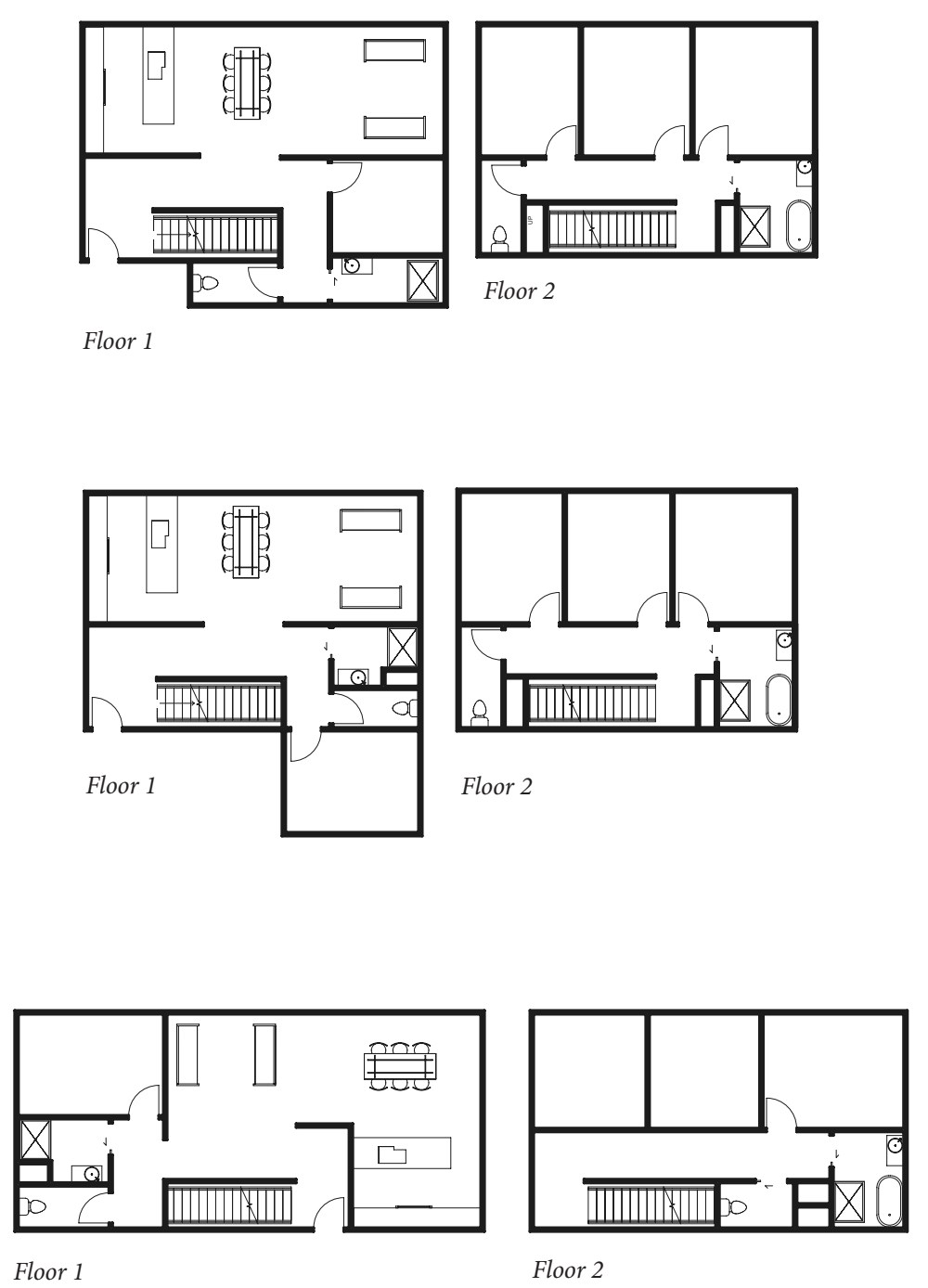

Figure 4.24: A range of culturally acceptable and inclusive 4 room dwellings 

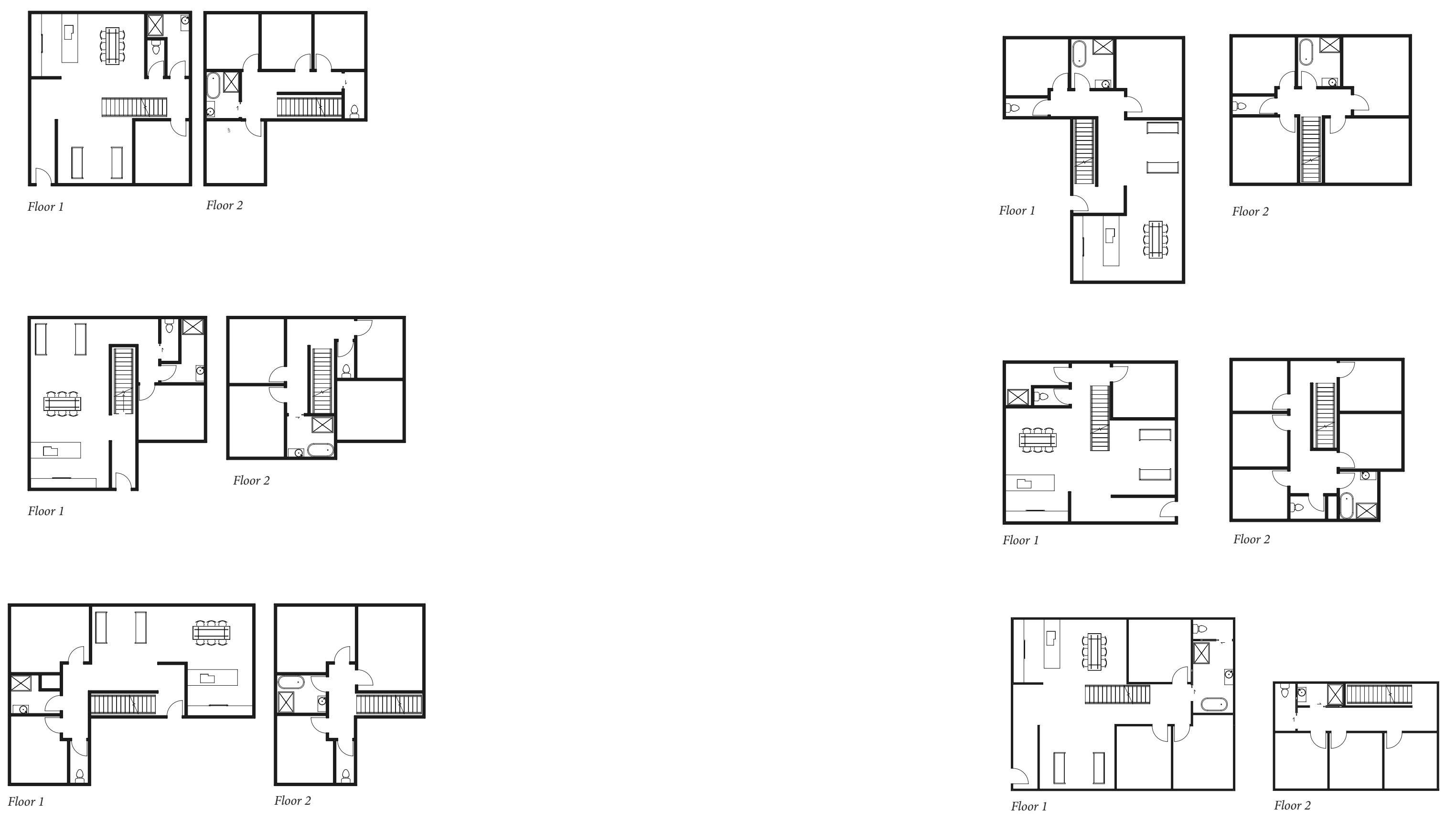
Urban Scale

Arlington's original design prioritised pedestrian movement at a cost to the sense of security in the development. It seemed that the topography determined the circulation around the development. This resulted in many steps and narrow access ways which can make navigating around the area uncomfortable and unsafe for residents.

To be appropriate, the development itself needs to be accessible and inclusive. However, by breaking up each building more, there is greater opportunity for buildings/units to look into one another which is not appropriate as it reduces privacy. In turn, the larger or taller the building is, the more it will block out access around the development, along with the light into each building surrounding and the green space below.

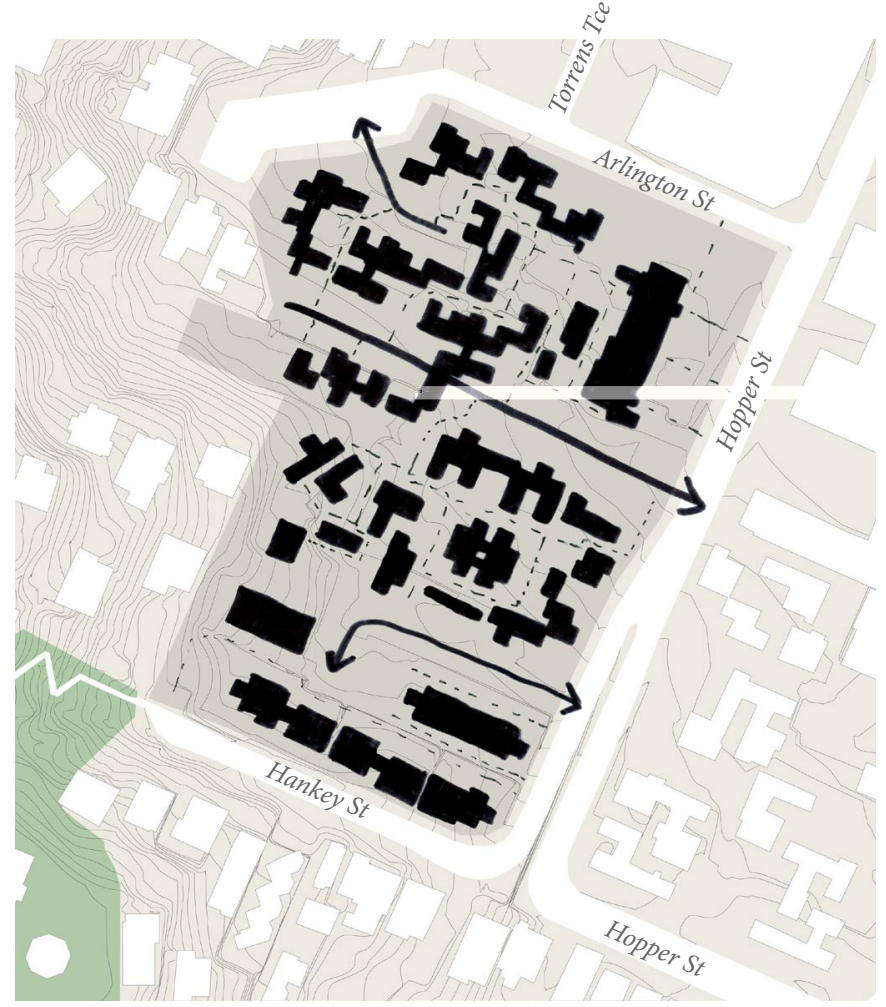

$\longrightarrow$ main vehicle access $\sim$ main pedestrian access ... secondary pedestrian access

Figure 4.27: Current Arlington masterplan 

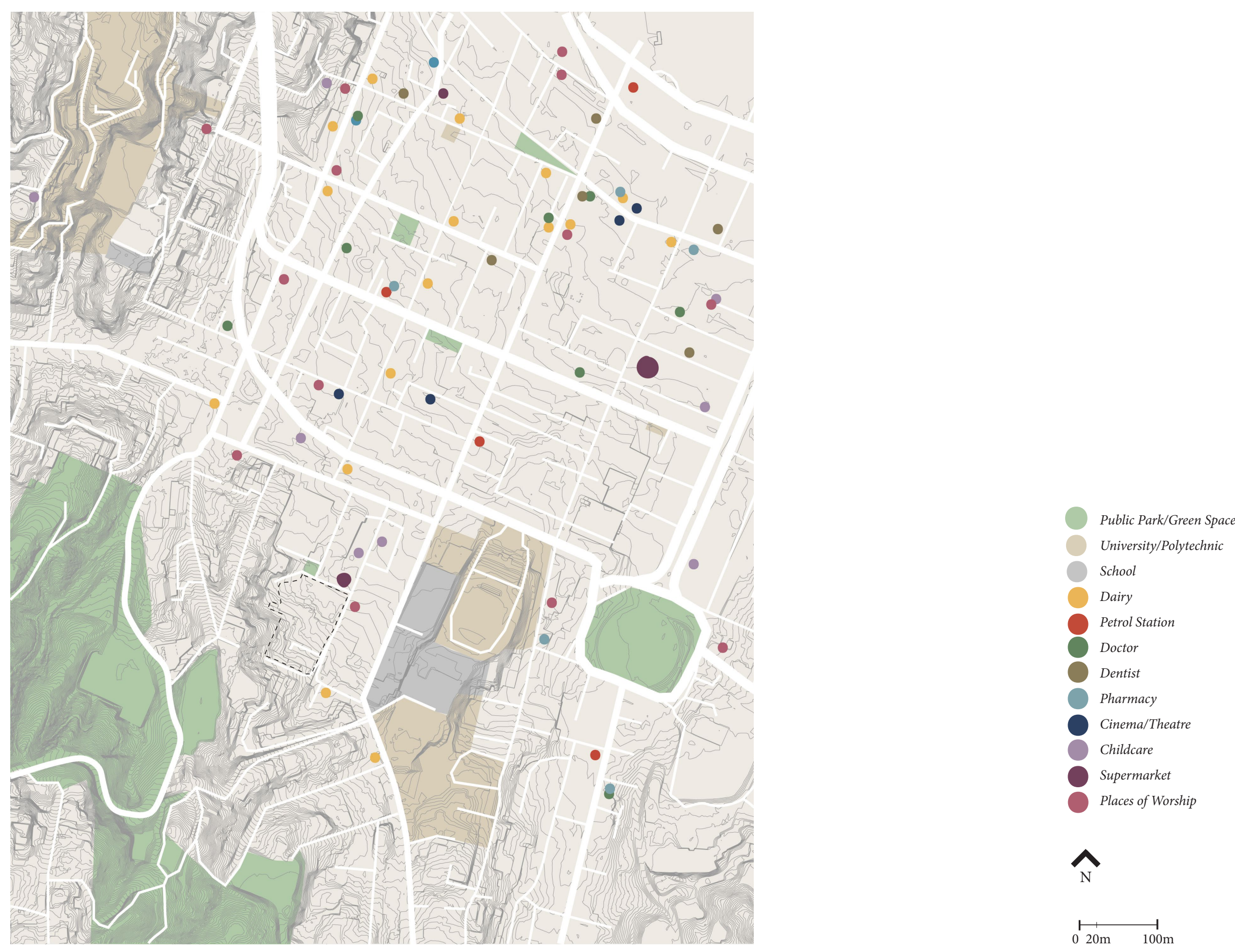

Figure 4.28: Map exploring surrounding amenities to Arlington 

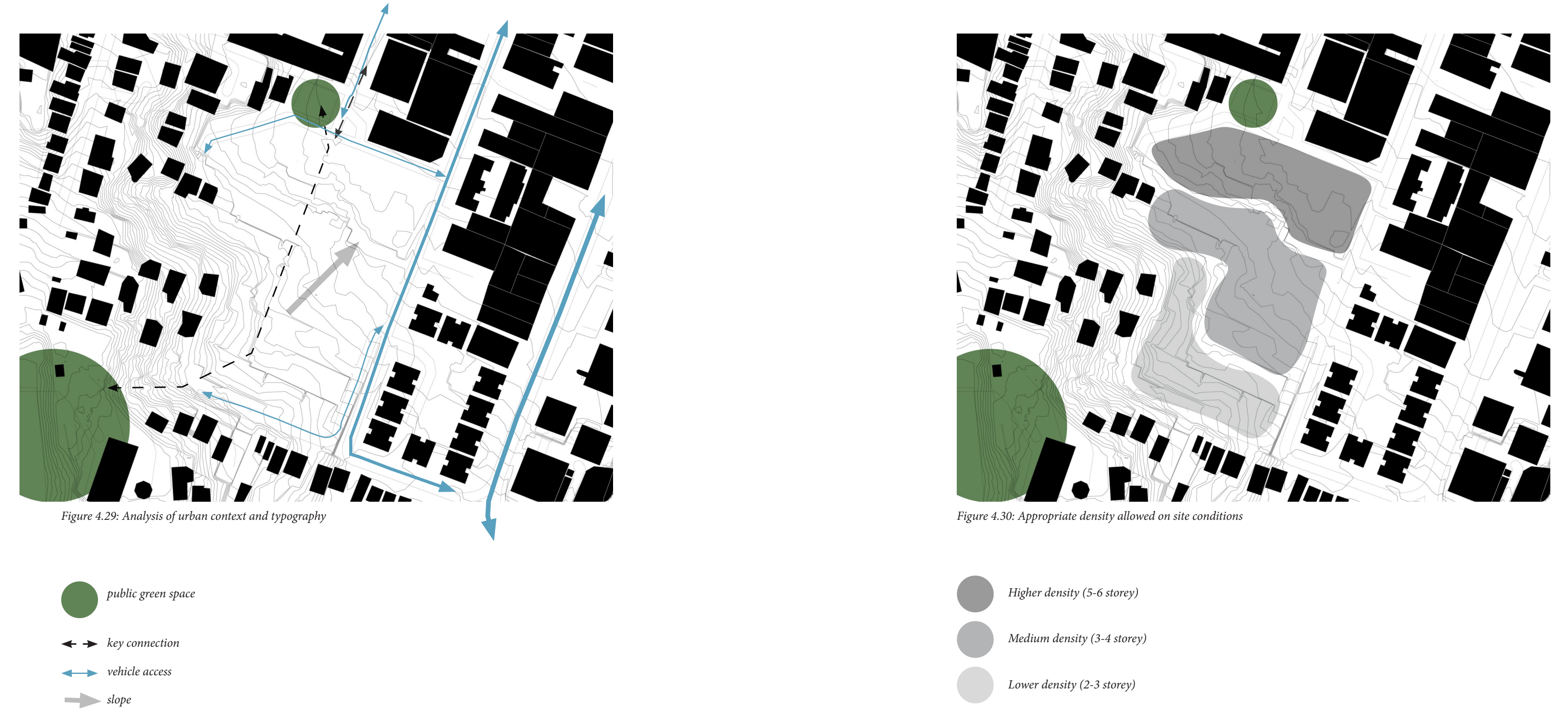
Initial Planning

Arlington's masterplan had the following issues:

stairs and small winding routes throughout

Lack of adequate visual and physical connection throughout the site

Lack of perceived security due to blind corners

These four maps suggest different methods of addressing these issues along with adding:

Range of green space which can be accessed throughout site

Connection with Torrens Terrace and Brooklyn Park to encourage easy movement throughout site and link to public parks.

Increased density while still appropriate in surroundings

Safe, accessible and visible circulation

routes throughout the site
Proposal 1

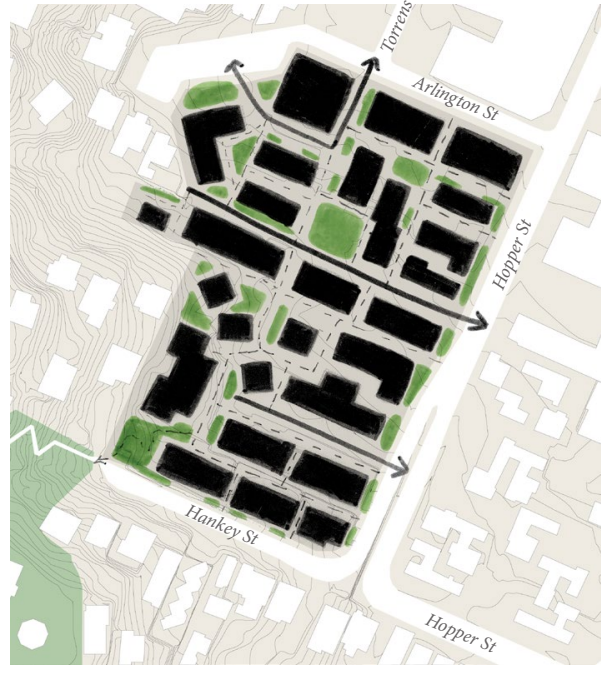

Proposal 2

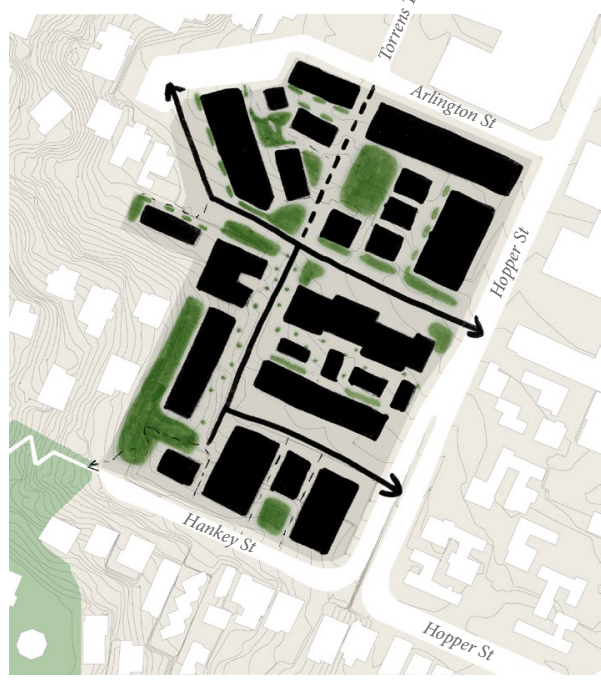

Proposal 3

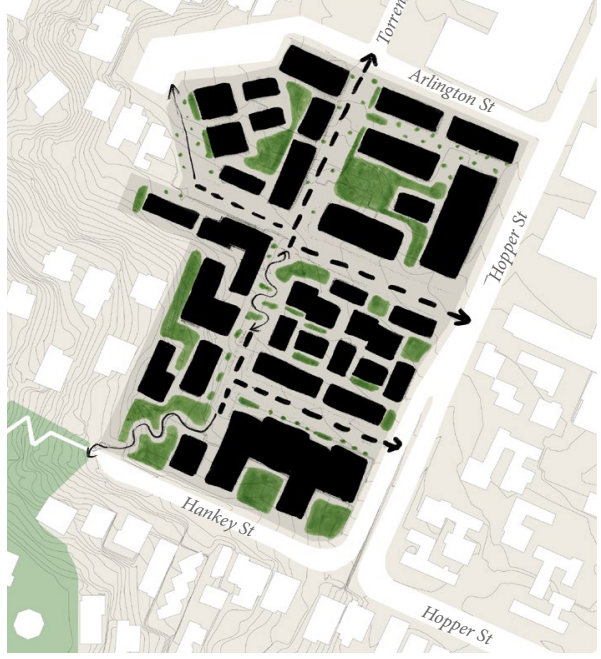

Proposal 4

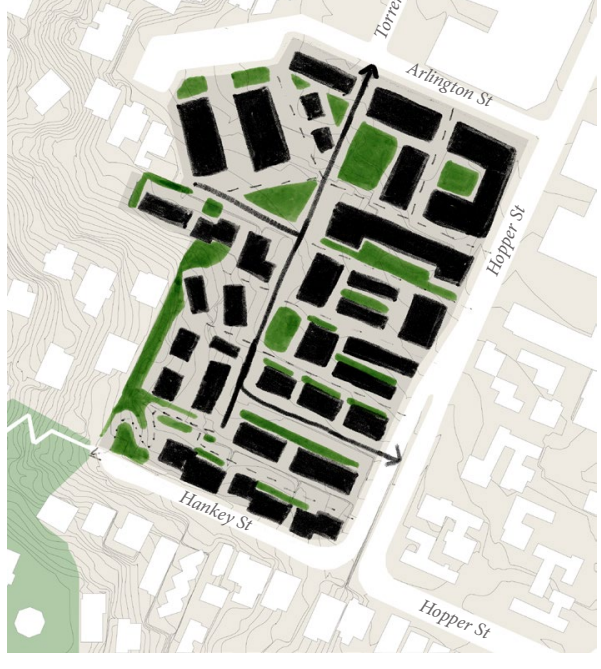

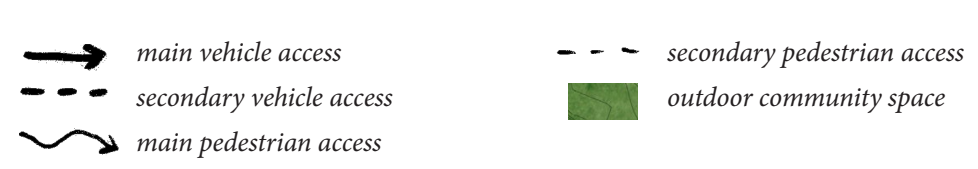

Figure 4.31: Four initial planning possibilities aimed at correcting the problems of the current design and providing for the needs of contemporary social housing tenants 


\section{Communal Space}

The main cultural concern for "appropriateness" is privacy. However, increased privacy can decrease community connection, particularly when one-two room dwellings will be prioritised.

The more residents stick to their dwellings, the larger the risk of isolation. A diverse range of indoor and outdoor spaces that will allow for a range of connections between residents to occur can combat this. There are many ways to explore this in design, however sloping, ramping and shared streets are good ways to combat accessibility in a development, while also providing opportunities for residents to interact.

Arlington originally had a court which residents utilised, however, there was minimal green space
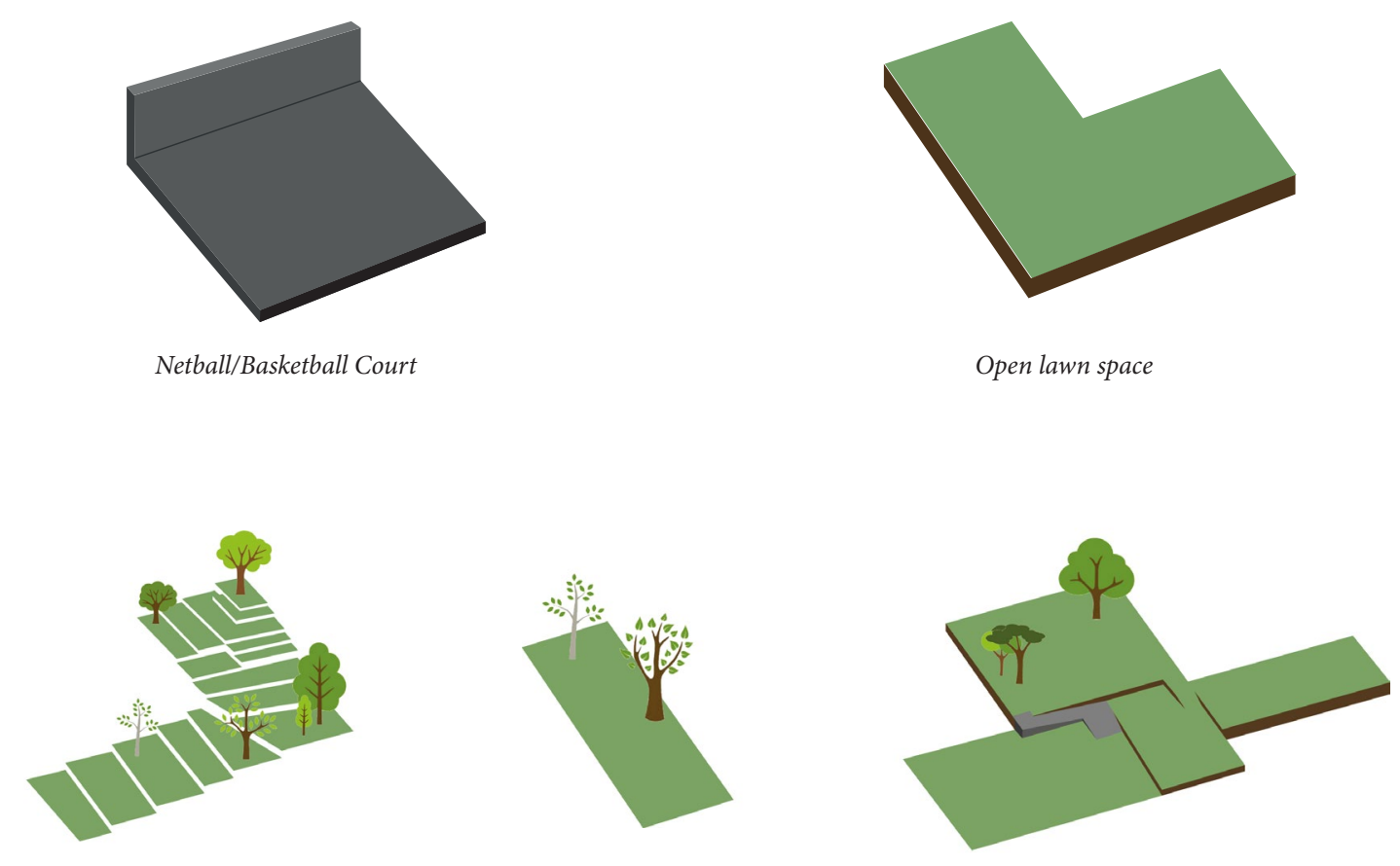

throughout the development which upset some residents (Novak \& Rangiwhetu, 2019). This is because the closest park is Brooklyn Park, which is up a steep set of stairs to the south-west of the site. Providing green space which can be occupied, or greenery which is visible from each dwelling will improve the mental and physical wellbeing of the residents (Barton \& Rogerson, 2017) (Braubach et al., 2017).

Although the access routes can become informal community space, a range of diverse public spaces which are more formal/ designed solely for community use would also benefit the users.

Potential spaces are:

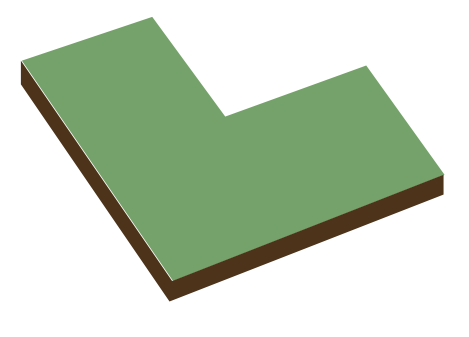

open lawn space

Community Gardens / Park / Hangi area
Accessible and inclusive streets:

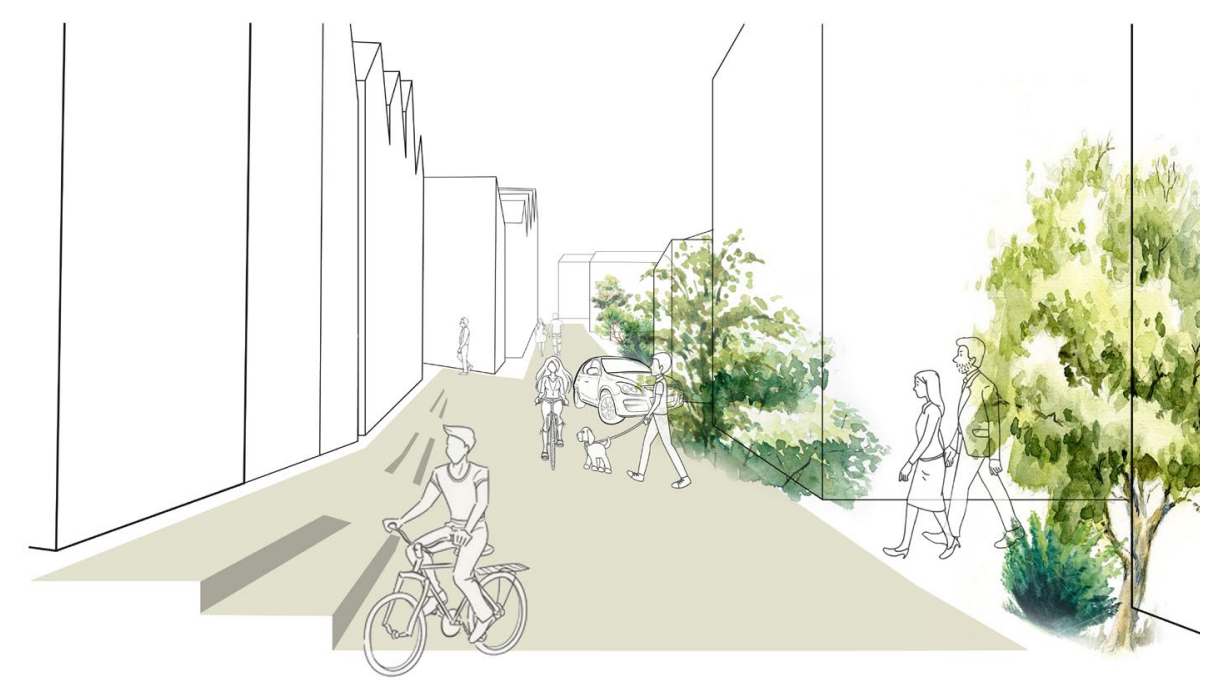

Figure 4.33: Shared street to encourage connection throughout the community using universal design principles

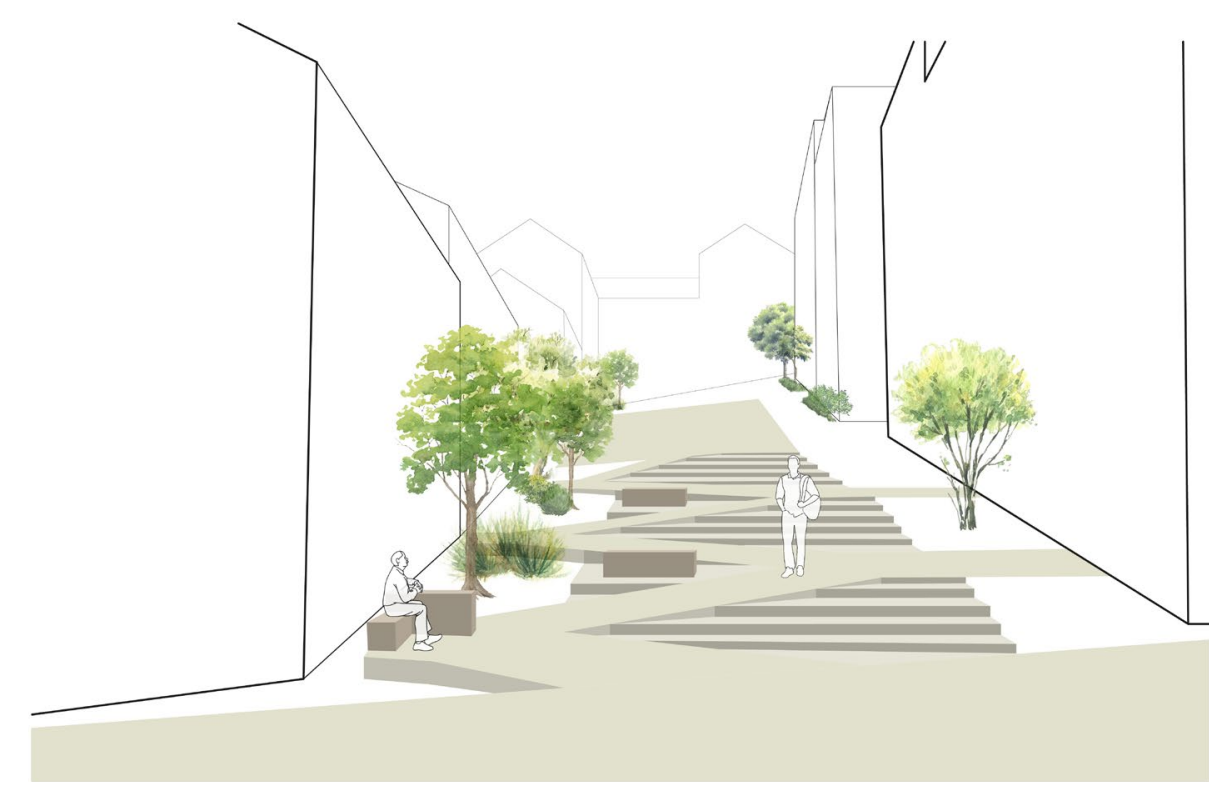

Figure 4.34: Accessible pedestrian street with areas to pause and connect with surroundings and Figure 4.34: Accessib
residents and nature

Figure 4.32: Outdoor community space options which could be implemented on site 


\section{Interior Communal Space}

Places for connection are not excluded to the exterior spaces within the development. Interior spaces are also essential to allow connection between residents, but can also support larger gatherings. Upon cultural analysis, it was found that many groups prefer to have more than one living space to accommodate large gatherings that would fluctuate in size. While a simple solution to this would be to provide multiple living spaces in larger dwellings, these would not be used frequently. Alternatively, a solution which Station R utilised is to have a communal space that residents can book out a use for these occasions.
Station R located in Auckland is comprised of two-three bedroom apartments, however, to fit as many into the building as possible, living space was compact (Ockham, 2017). To allow for larger gatherings, communal event space which is the same size as an entire apartment was set aside on the top floor of the building (Figure 4.32). This same concept could be utilised at Arlington, with communal spaces provided in a range of location throughout the development. They will be comprised of a large kitchen, dining area and multiple living spaces which meet the cultural criteria se previously.
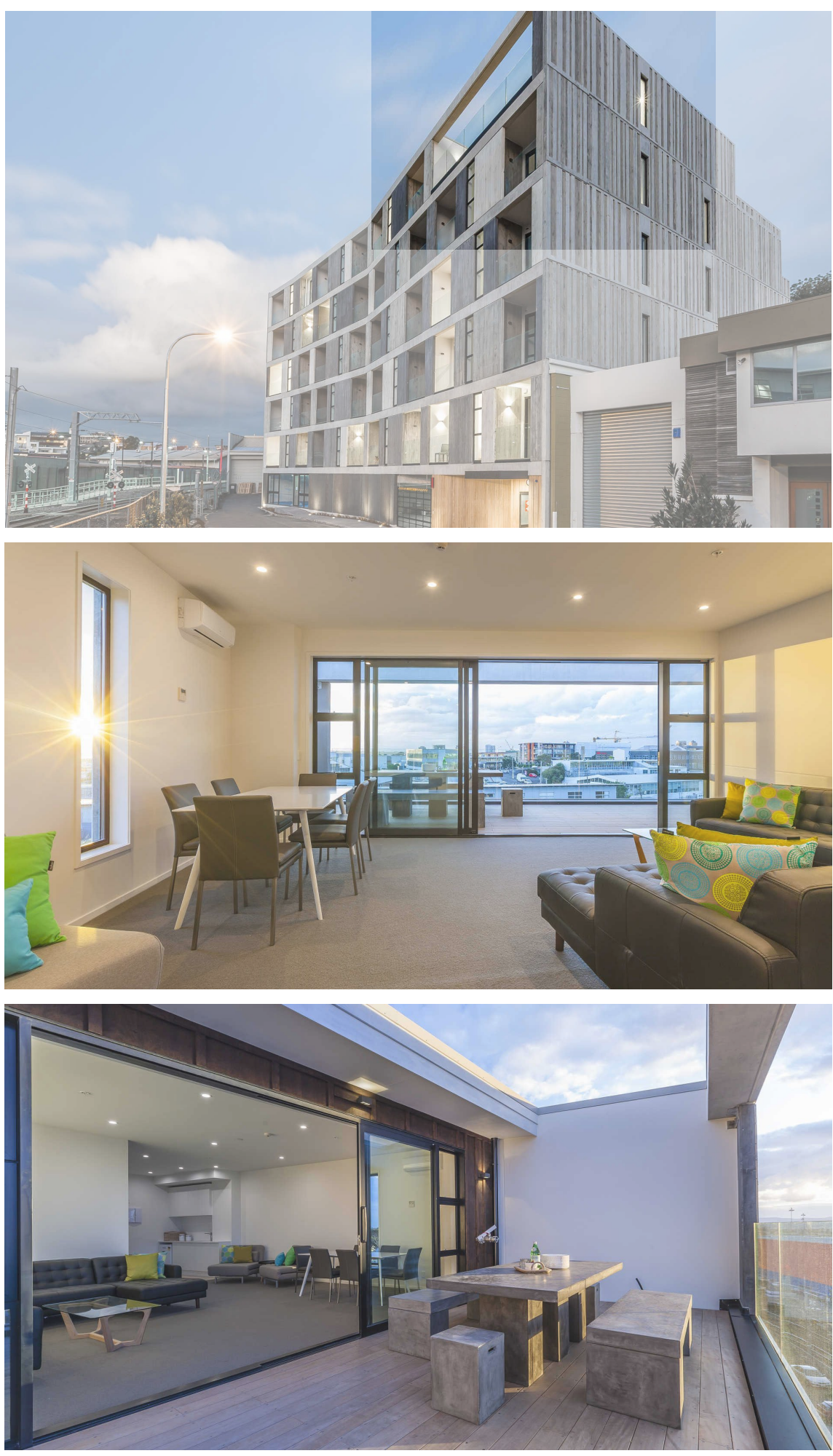

Figure 4.35: Top to bottom: Apartments from Fenton St with communal apartment highlighted, Living

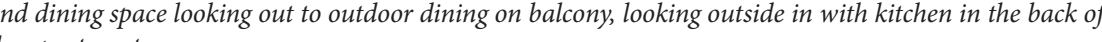
and dining spanclo
the apartment. 


\section{Reflection}

The proposed design will respond to the questions outlined in chapter three based on the findings of the design analysis carried out in this chapter. These findings are discussed in detail here:

At what size does a dwelling require an extra living? Is this required in every large home?

Dwellings are designed and defined by the number of rooms rather than bedrooms to allow flexible use of each dwelling based upon the occupant's needs. This can mean that families who wish to have multiple living spaces could opt for a higher occupancy of a bedroom depending on their preference and utilise the extra room as a secondary living space. Along with this, case study analysis provided an additional solution to this issue. Large living/dining/kitchen spaces can be provided throughout the development to allow those even in one-two room dwellings to have larger gatherings than what would fit in their units. These will be booked out as needed and avoid the potential cost of excess living space that will not be utilised frequently in each unit. These living/dining/kitchen spaces will meet the cultural requirements defined through Chapter 2 and be easily accessible.

\section{What kind of dwelling is appropriate?}

The initial design is yet to define this question definitively. Social housing design should be appropriate to the context, therefore different density buildings have been explored in the initial design which can be further defined in the developed design. As New Zealand's population grows, a greater use of space, particularly in urban centres should be considered when proposing any housing solution. The standalone dwelling that was appropriate in the 1950 s is no longer appropriate in an inner-city suburb such as Mt Cook where Arlington is located. That said, a five-six storey building may also not be appropriate in the context and will be defined specifically to Arlington in Chapter 5 .

While each scale considered accessibility and cultural requirements, the next stage is to further develop how all three scales relate to one another. Many of the building envelope tests ignore that maintaining natural light and density will most likely result in needing windows on almost every side of each block. Having internal bedrooms does not meet New Zealand's building code and would be a poor design decision when there is no restriction on layout, orientation etc. These tests were helpful to propose ways that privacy can be increased. However, they are void of scale and may only apply to individual units or multiunit blocks. They could be re-introduced in the developed design phase in response to the way the building envelopes and masterplan has changed.

Currently, each scale is acting in isolation and only the masterplan considers the context of the design. The building envelope cannot be accurately designed without considering the interior and the exterior. The masterplan also needs to be further developed to acknowledge the needs of each building, while also acknowledging the placement of community spaces to support the residents. Along with this, maintaining natural light and density while also preserving privacy at each scale will be essential to a successful design. Addressing all of these requirements throughout the entire development would be well outside of the scope of this thesis, therefore only the internal street and one area of the development will be focused on. 

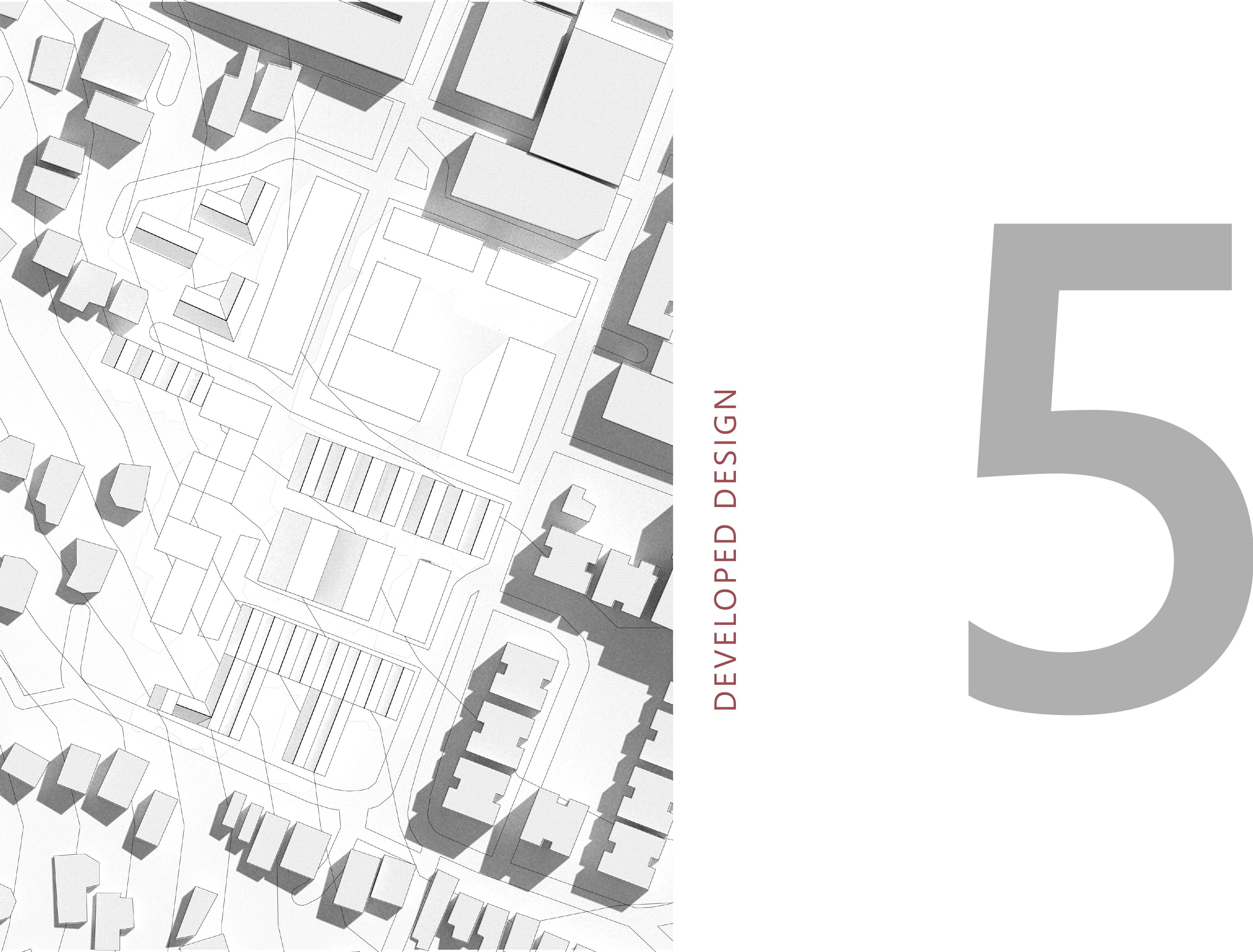
Developing state housing

The developed design defines how all three scales will relate to one another with the universal design criteria as a backbone. The building envelope will relate to the site conditions and the designed urban space, while also connecting to the interior units.

CPTED (Crime Prevention Through Environmental Design) principles will also directly inform design decisions as this was a significant issue for the residents of Arlington

(Novak \& Rangiwhetu, 2019).

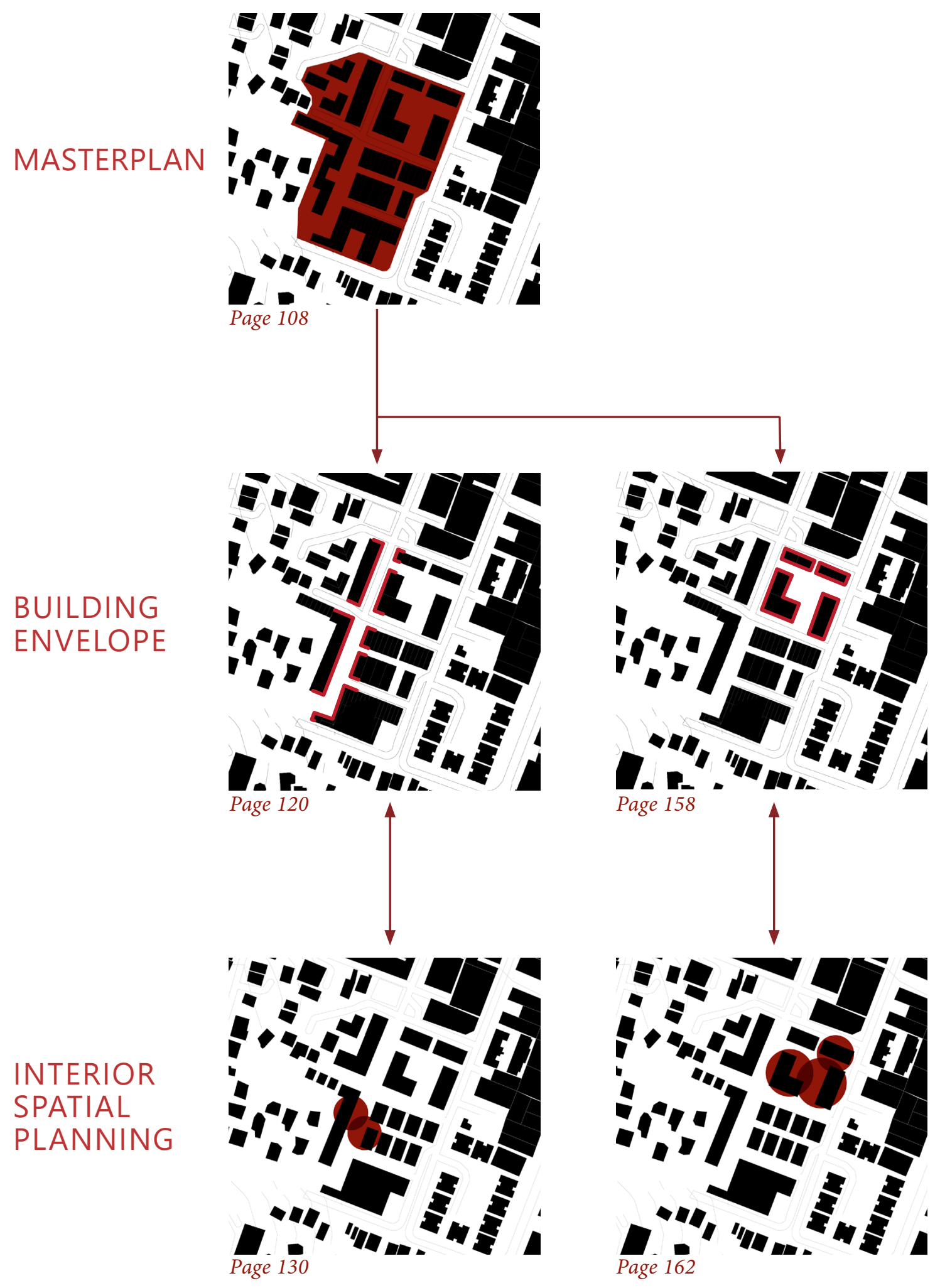




\section{MASTERPLAN}

In order to develop the masterplan design,

massing will be developed further to consider

shading, building heights and width of access

ways. CPTED design highlights the importance

of passive surveillance (eyes on the street),

which is only successful when buildings are

a sufficient distance apart and there are clear

lines of sight. This will also allow for a greater

level of sunlight to reach the entire site. This

will benefit both the individual dwellings and

the community spaces.

The accessibility and cultural criteria that will

\section{be explored in masterplan design is:}

Appropriate height and scale of buildings in relation to surroundings

Accessibility around development considered

Light/shading balanced with appropriate

density of units in the development

Communal spaces provided throughout to

support residents

Emphasis on the connection between

Torrens Terrace to Brooklyn Park.

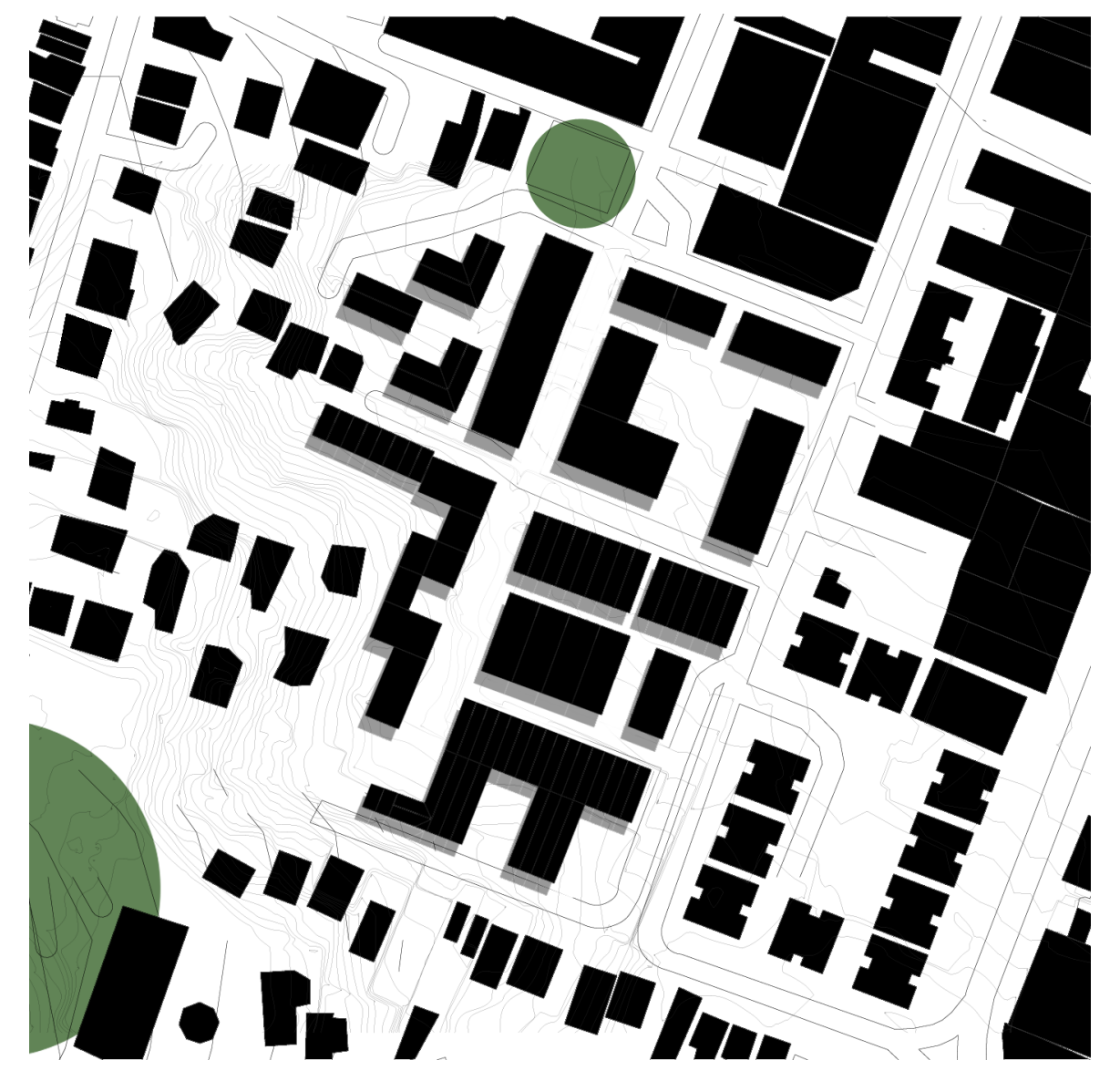




\section{Appropriate Building Height/Scale}

Arlington is located on the edge of Wellington City in Mt Cook. This presents a unique design opportunity as towards the south are residential homes, elevated by the land, and

toward the north are commercial buildings that

range between four-seven storeys high. Much

of the social housing in New Zealand that is being replaced, has been doubled in density at minimum. This is in response to the standalone homes which have been provided in the last 60 years due to the poor use of space, particularly in urban centres.
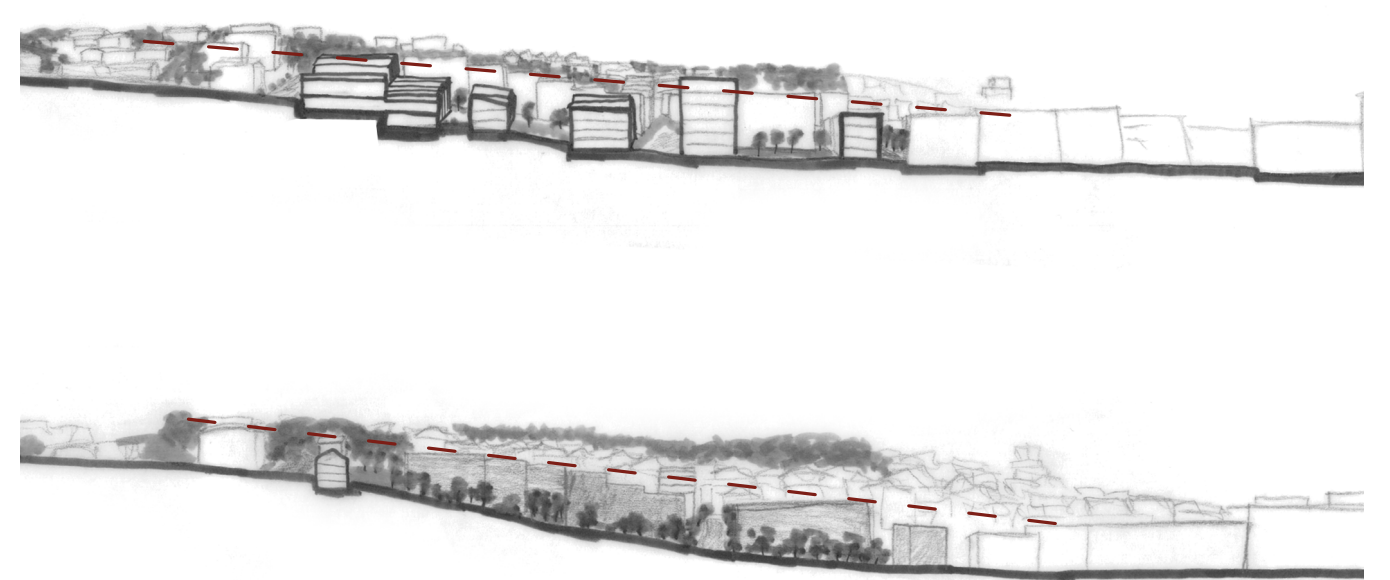

Figure 5.2: North South sections exploring appropriate height

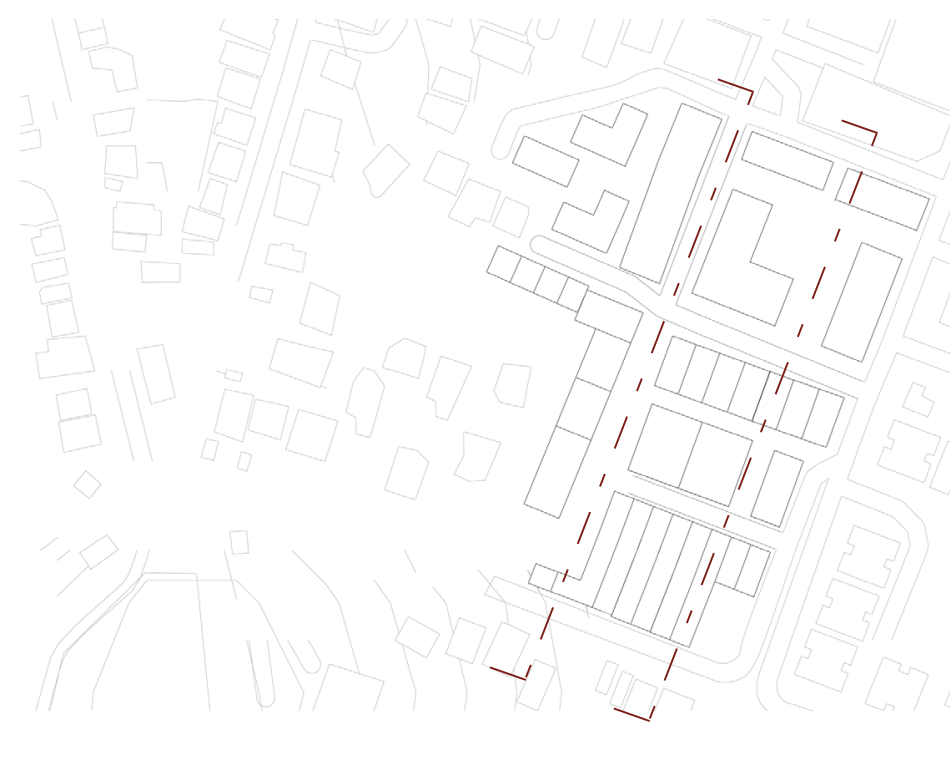

When redesigning Arlington, density in comparison to its surroundings is important. Initial mapping of the site demonstrated the restriction of height on steeper areas of the sight. Sections through the site demonstrate the
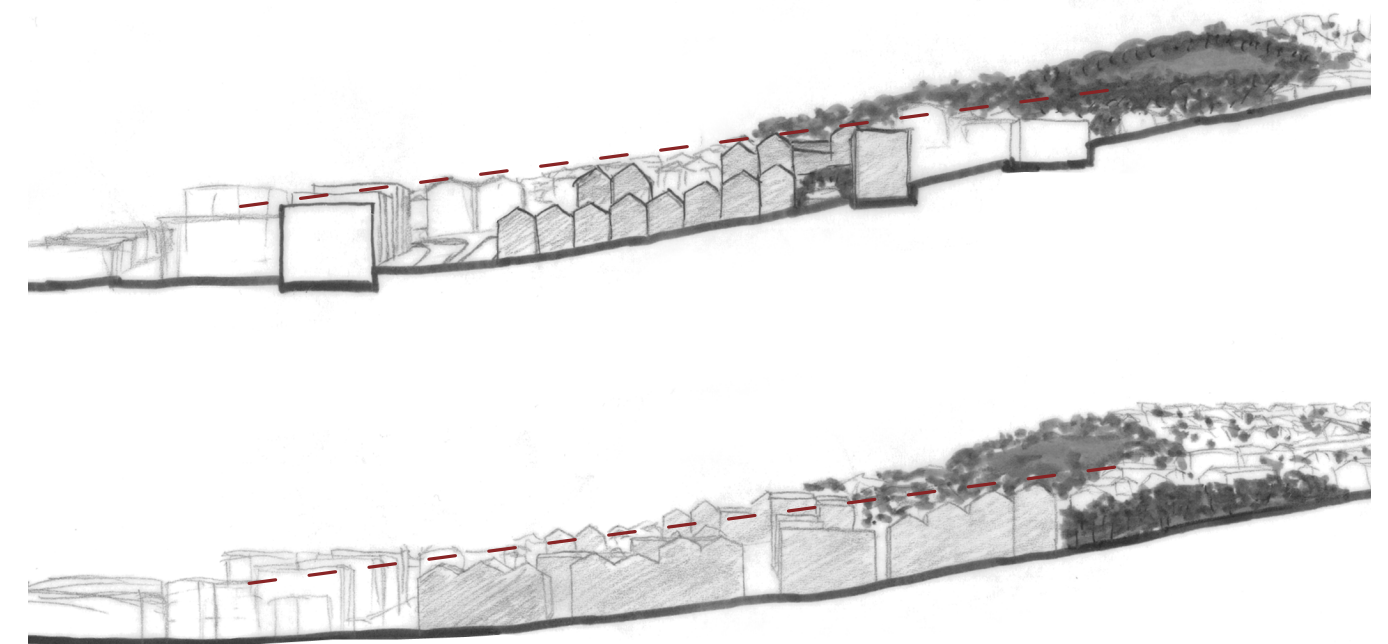

possibility of the dwellings be able to be higher as they currently sit at an appropriate height. Shading will also need to be considered if the height of the development is to be changed.

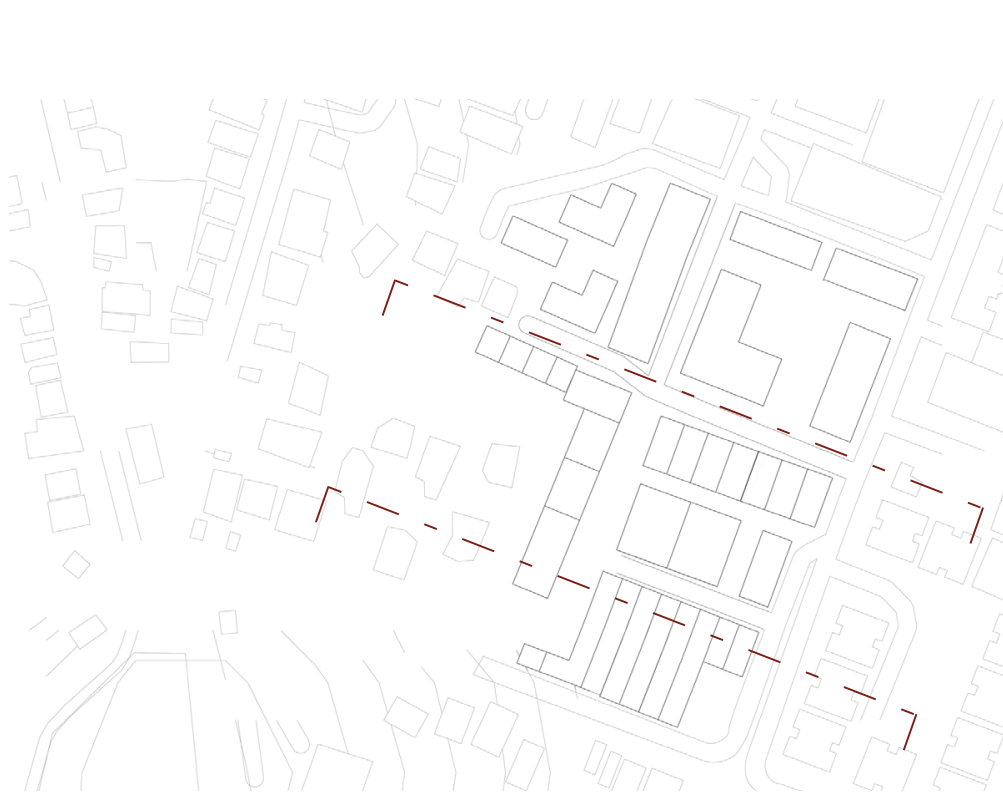

Figure 5.3: East West sections exploring appropriate height 


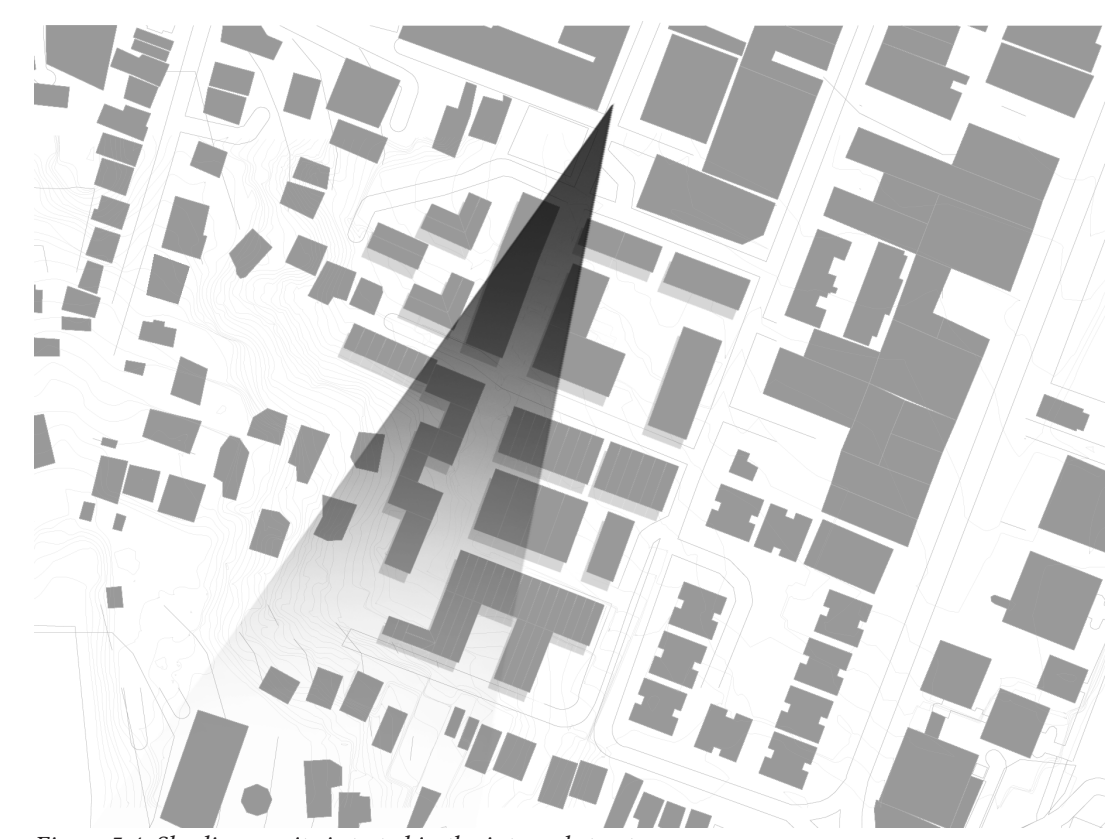

The internal street is a significant feature to the entire development as it provides access throughout the site, but also connections to internal and outdoor communal spaces in and surrounding the buildings. Currently, sunlight, accessibility between, in and around buildings, CPTED principles and the building envelop all need to be addressed in the developed design phase. The internal street is designed from an outside-in approach, meaning the surrounding landscape determines the heights of the buildings, how many levels and where the entries to each building will be. This allows the building envelop to inform the community spaces and the internal units simultaneously while ensuring accessibility in and out of each building is met.

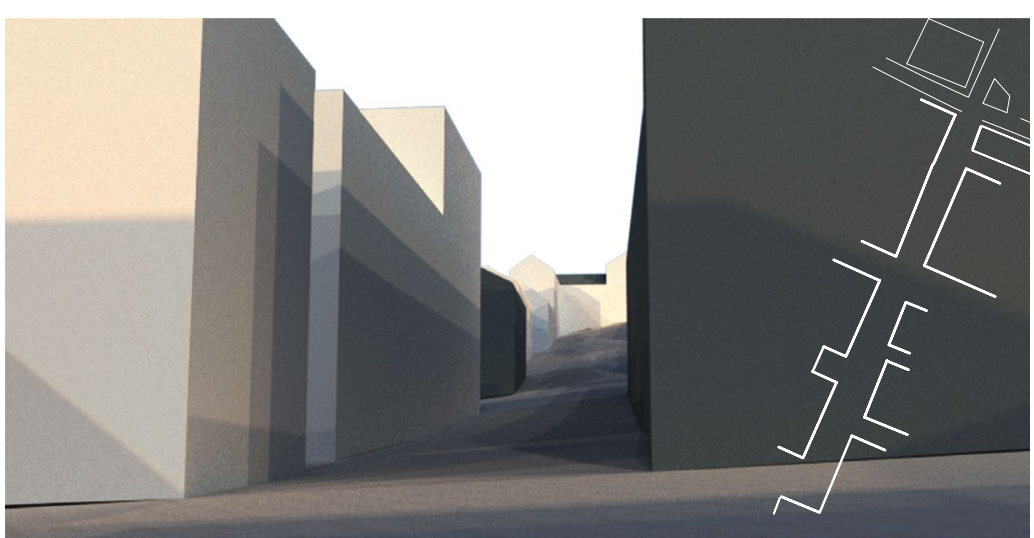

Figure 5.5: Current Proposal: Front apartment buildings at 4 stories climbing to 5 and 6 Significant shadowing throughout the street

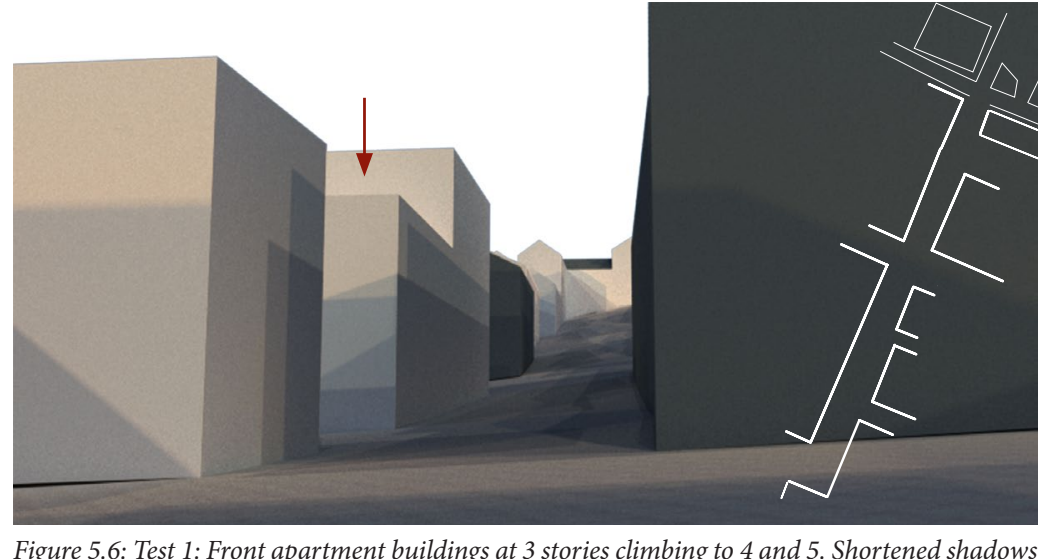

Figure 5.6: Test 1: Front apartment buildings at 3 stories climbing to 4 and 5 . Shortened shadows
present, greater daylight. Rear Western building facade flattened to avoid hidden corners

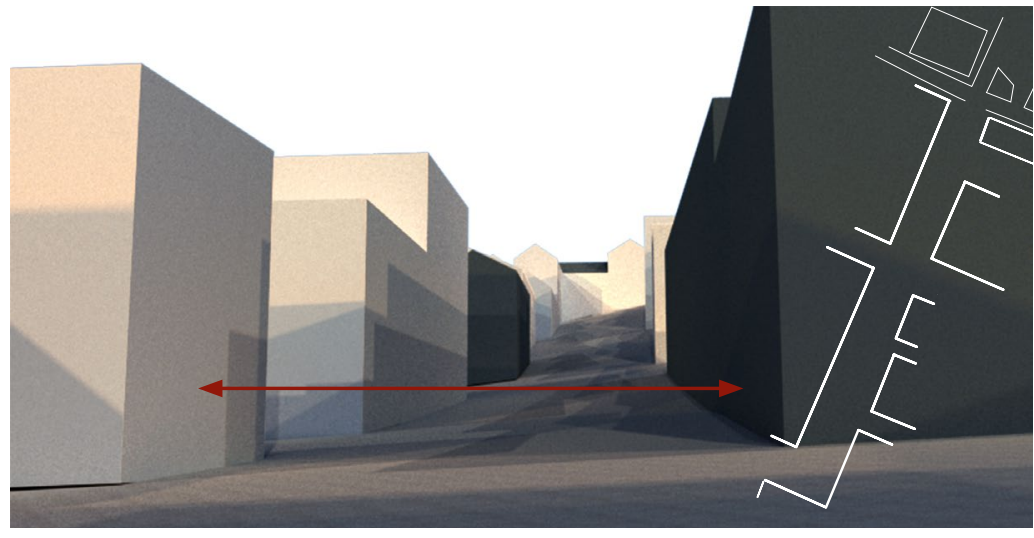

Figure 5.7 Test 2: Internal street is shifted from $10 \mathrm{~m}$ to $15 \mathrm{~m}$ wide. Improved lighting however the

scale of the street is large and no longer has an intimate sense of space 

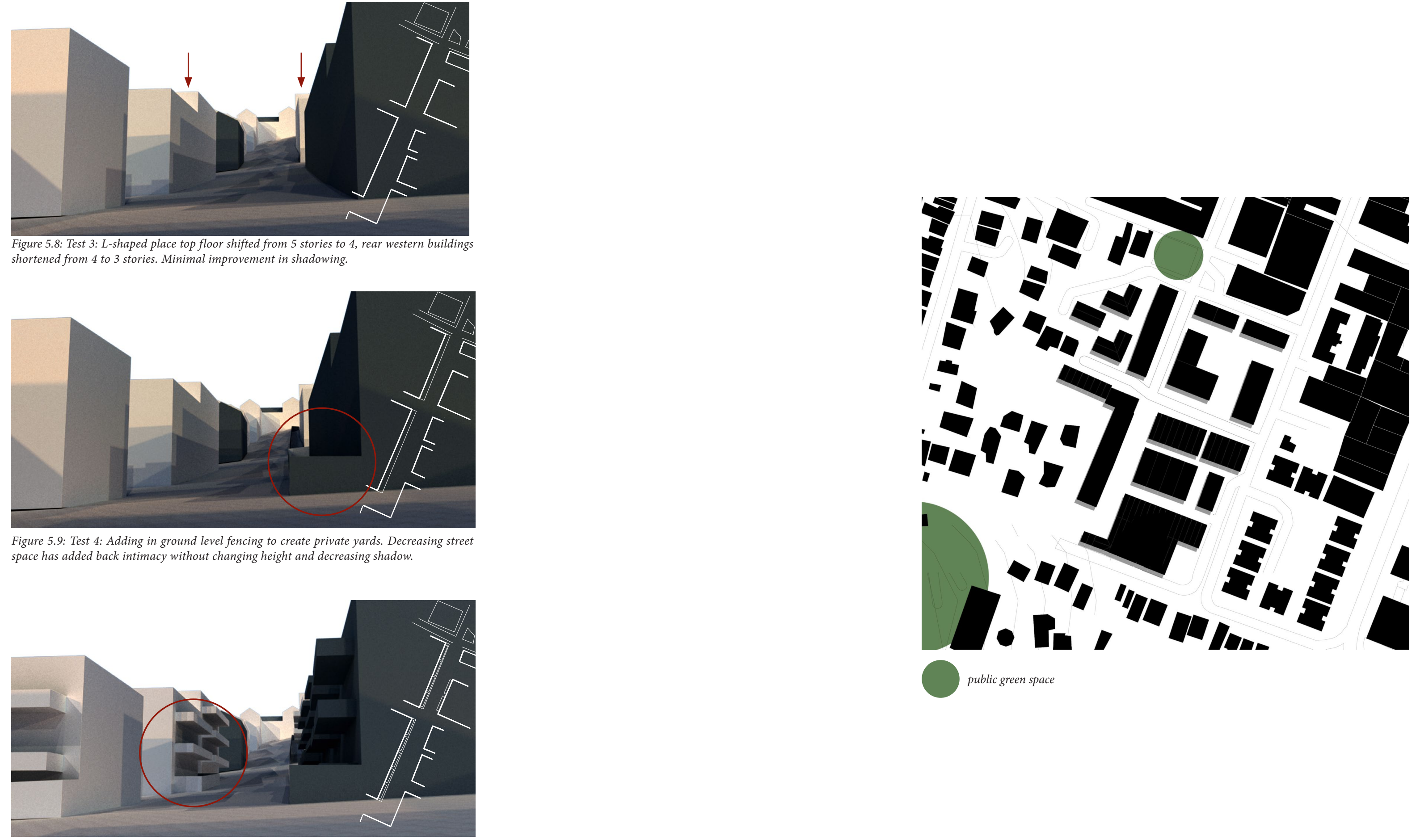

public green space

Figure 5.10: Test 5: Balconies added to dwellings on all levels. Has again improved the
intimacy of the street without shifting shadows greatly 
Connection Space

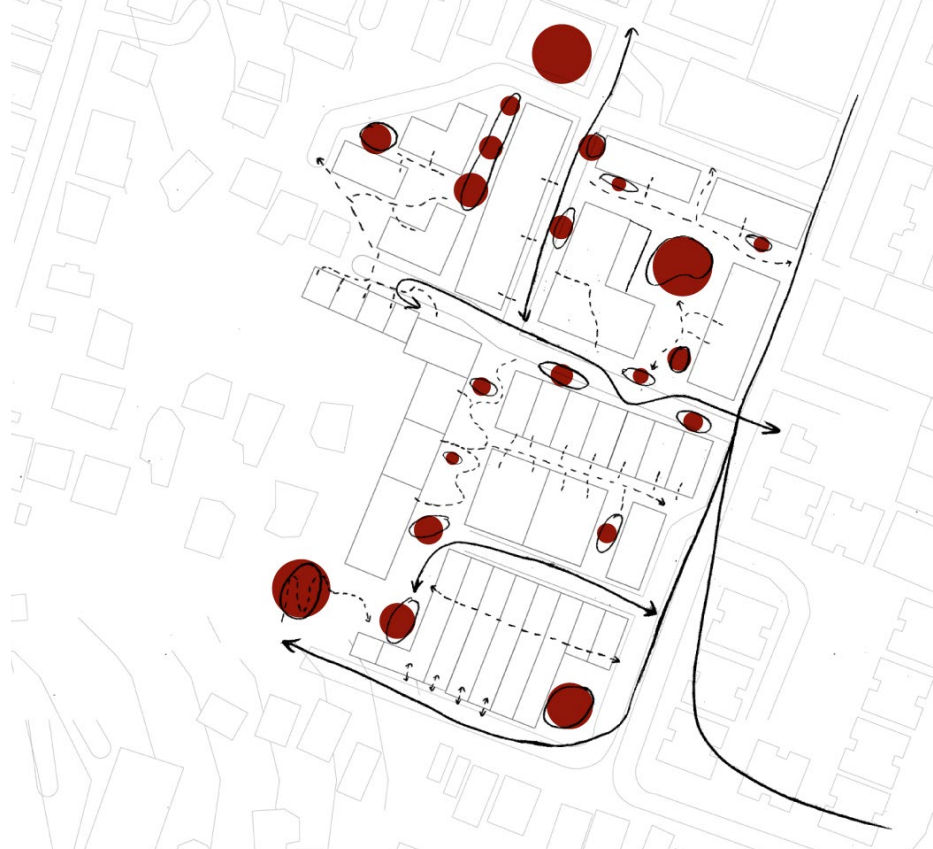

Figure 5.12: Test 1: Exterior communal spaces mapped with possible circulation shown. Main alle access routes are too obstructed.

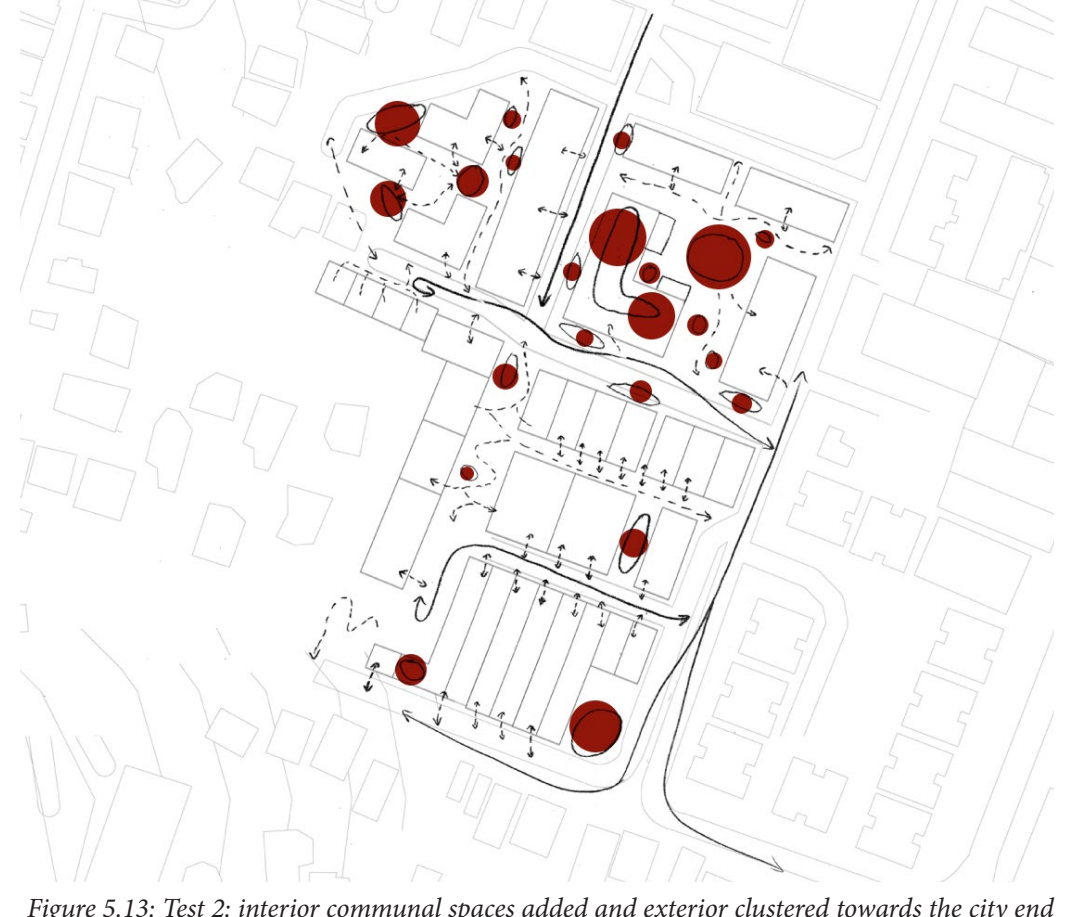

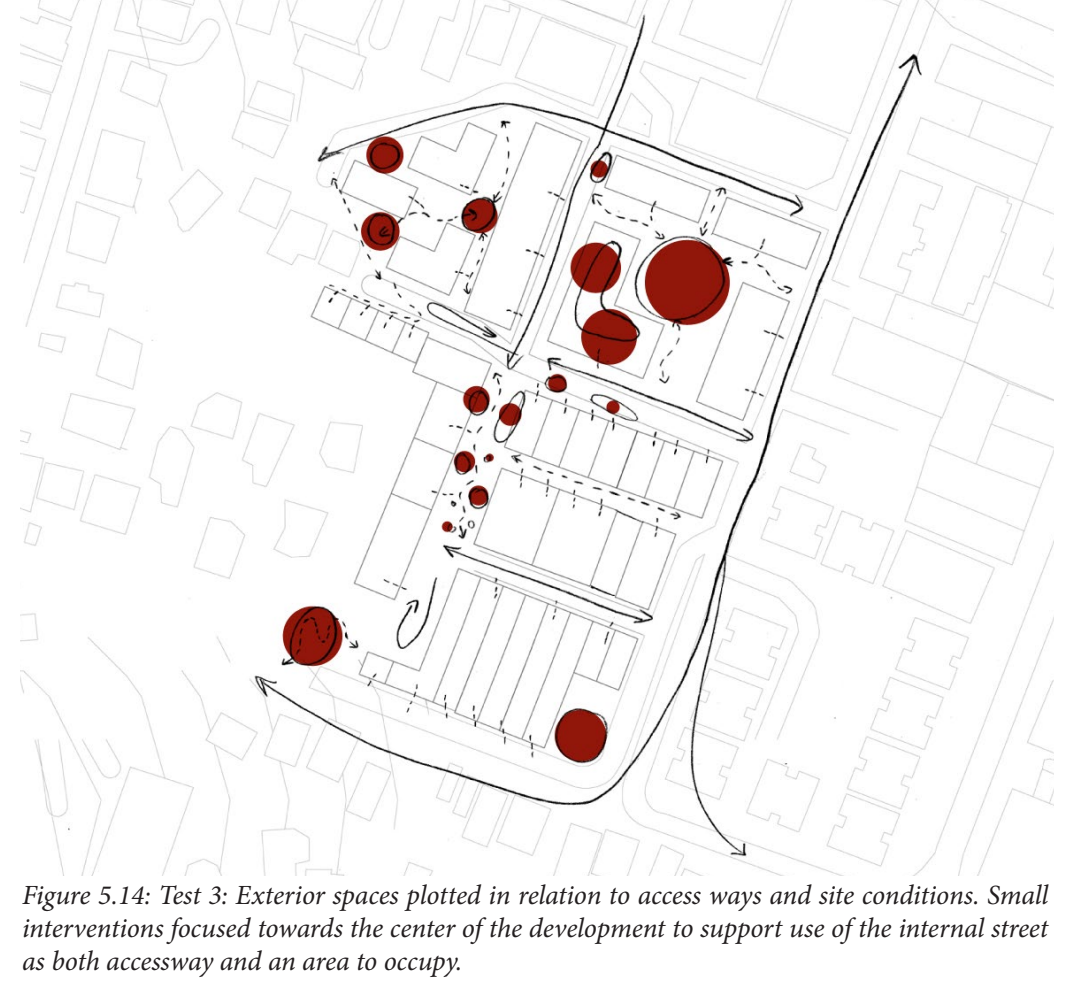

pedestrian movement 


\section{Laundry Proposals}

Laundries involve cleansing, an activity that needs to be kept separate from kitchens, dining spaces and toilets. A cupboard would be an easy way to separate this activity from any room. However, washing machines and dryers need adequate ventilation which is typically underestimated in the home. They are also an appliance that is treated by some as a necessity

but in actuality should be used occasionally

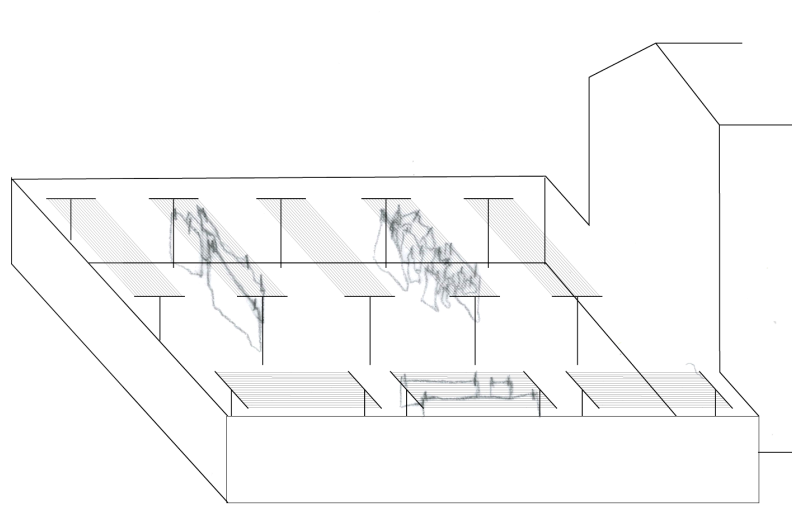

Figure5.15: Arlington's laundry yards

Te Mara Apartments has individual washing machines in each unit with a folding clothesline on each balcony which is visible to the street. This is not culturally appropriate and the

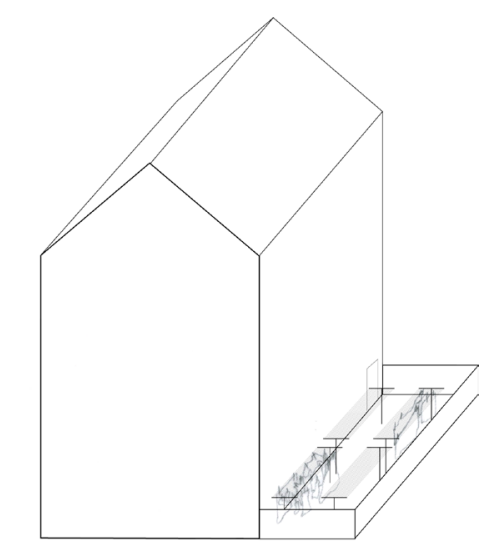

Figure 5.17: Outdoor shared laundry which connets into a block that has multiple units. This will still be relatively private, only a residents neighbours tan when clothes cannot be dried in the air.

Arlington had a series of shared laundrie throughout the development. While this was

hidden from those on the street, it takes up valuable ground area that could be used for more housing or social space that can be used more frequently.

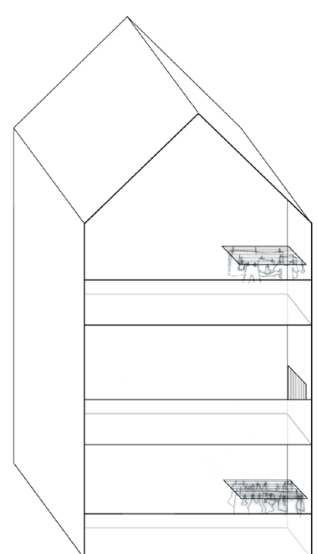

Figure 5.16: Te Mara balcony washing lines

following two solutions can be utilised in the design to maintain laundry space as private communal space, only accessible and visible to residents of the development.

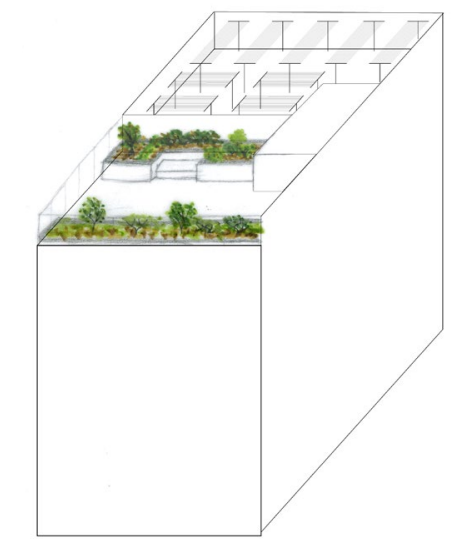

igure 5.18: Rooftop Laundry is private from There is also an opportunity to uttilise extra rooftop space as sscial space that could be us
while waiting for a washing load to finish

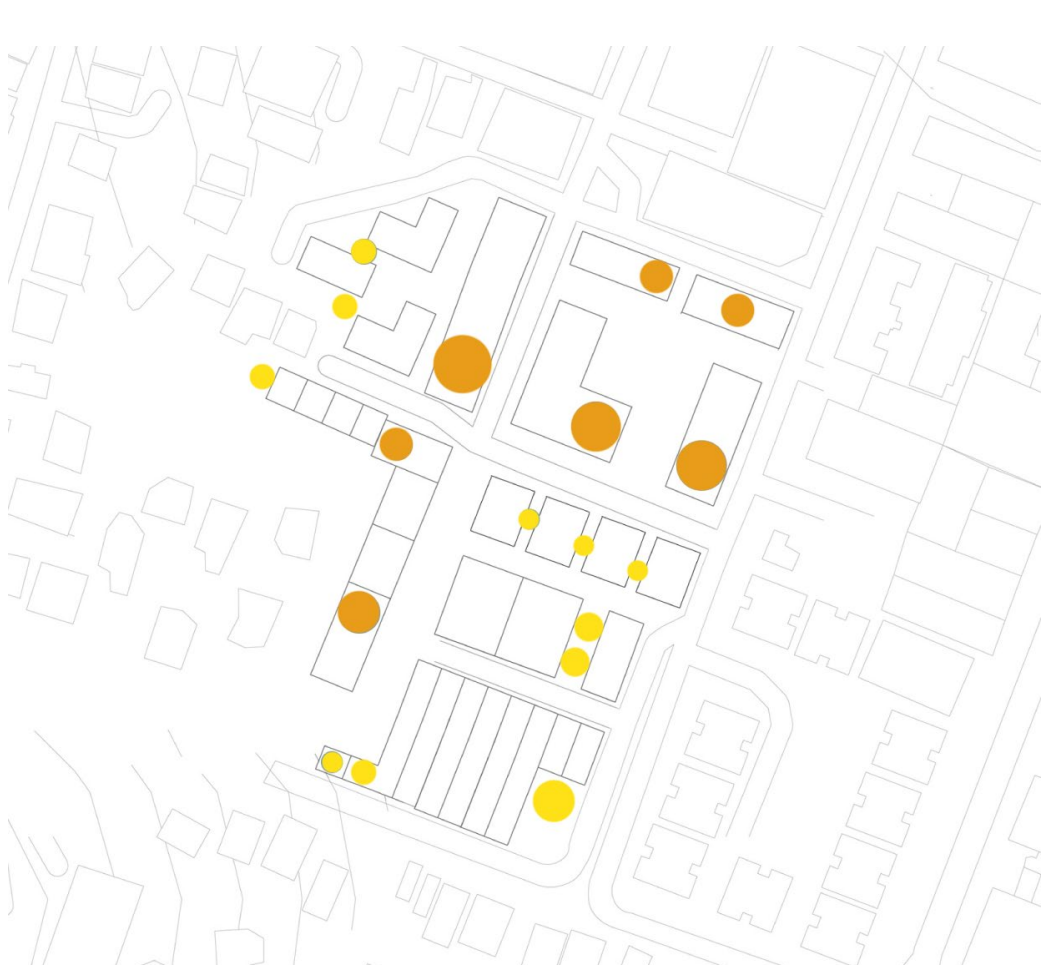

Rooftop Laundry

Outdoor Laundry 


\section{INTERNAL STREET}

The masterplan identifies where key spaces are located and where buildings may be placed for appropriate density and access around the site.

However, to further develop the entire scheme

the building envelope and interior needs to be

detailed to inform the masterplan. This is first

done in the internal street area as indicated in

the map adjacent.

The criteria that will define this design

exploration in both the building envelope and

the interior units is:

Maintaining privacy in and around

dwellings

Providing safe and open access ways

through passive surveillance

Creating accessible dwellings, buildings

and access ways throughout

Meeting key cultural criteria through the

separation and connection of spaces.

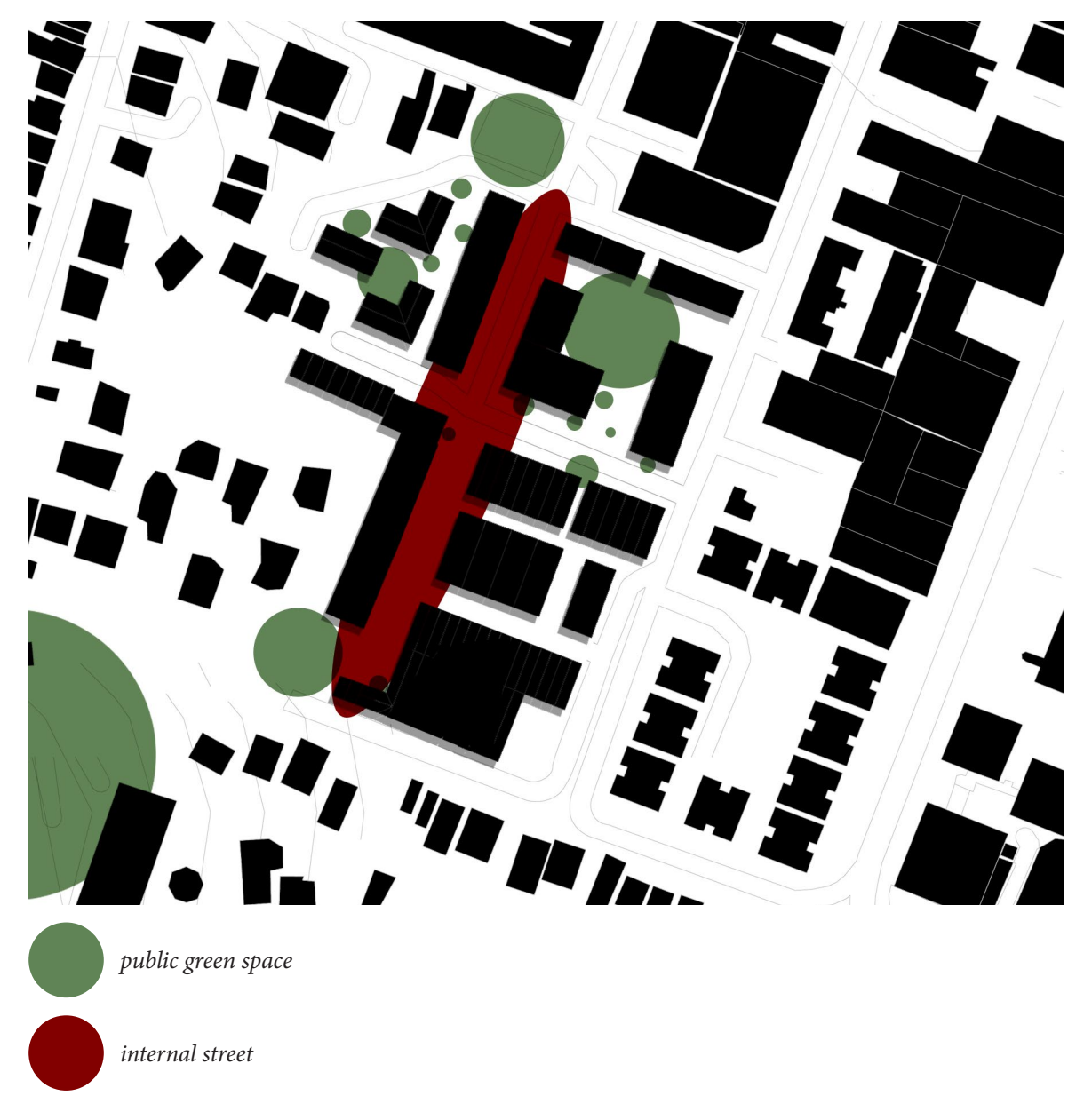




\section{Foliage Testing}

Foliage provides shade, privacy, colour and four tests explore the way foliage can enhance encourage movement throughout the site. privacy, create communal space and provide Along with this, green space will benefit the shade in relationship to the surrounding wellbeing of the development's residents. These buildings.

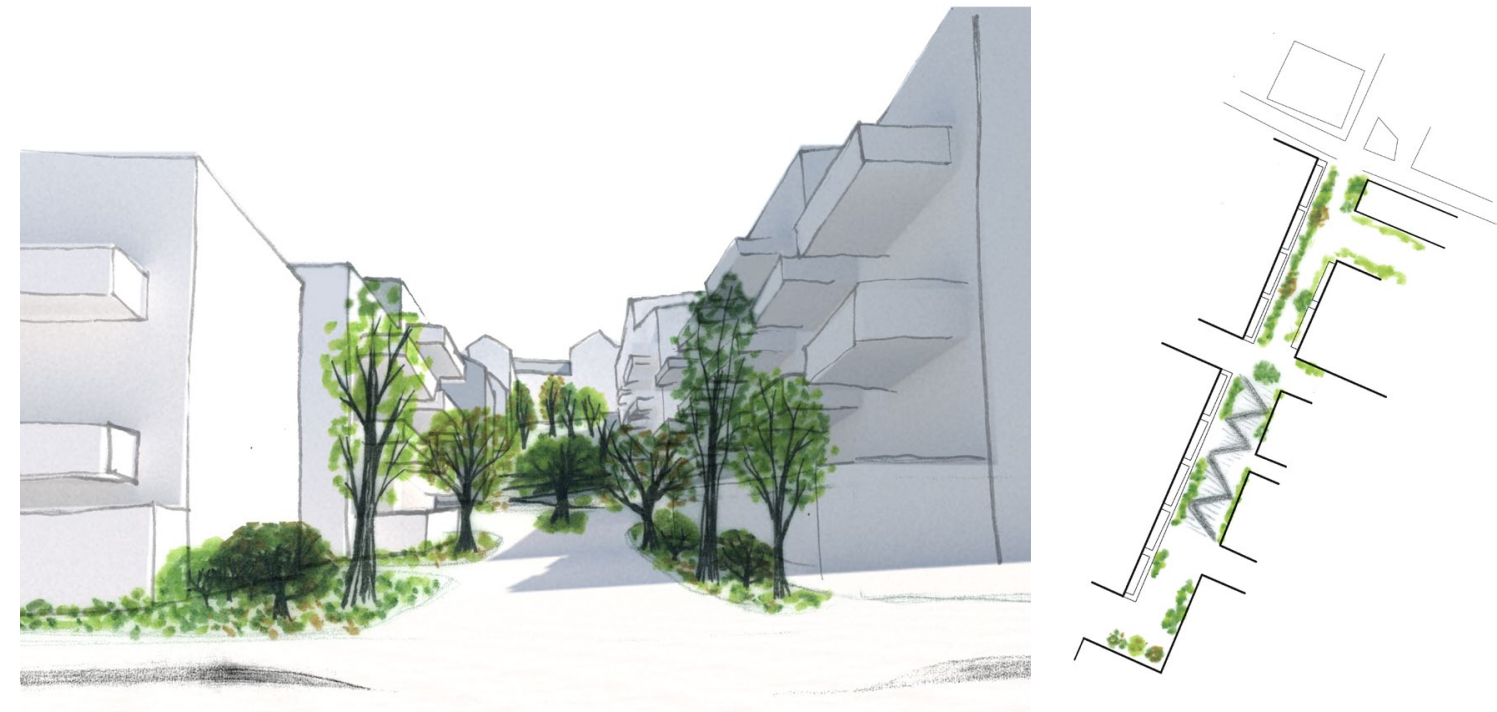

Figure 5.21: Test 1: An excess of foliage is added to condense the street and disperse view. Higher level of privacy the further in a dwelling is into the development.
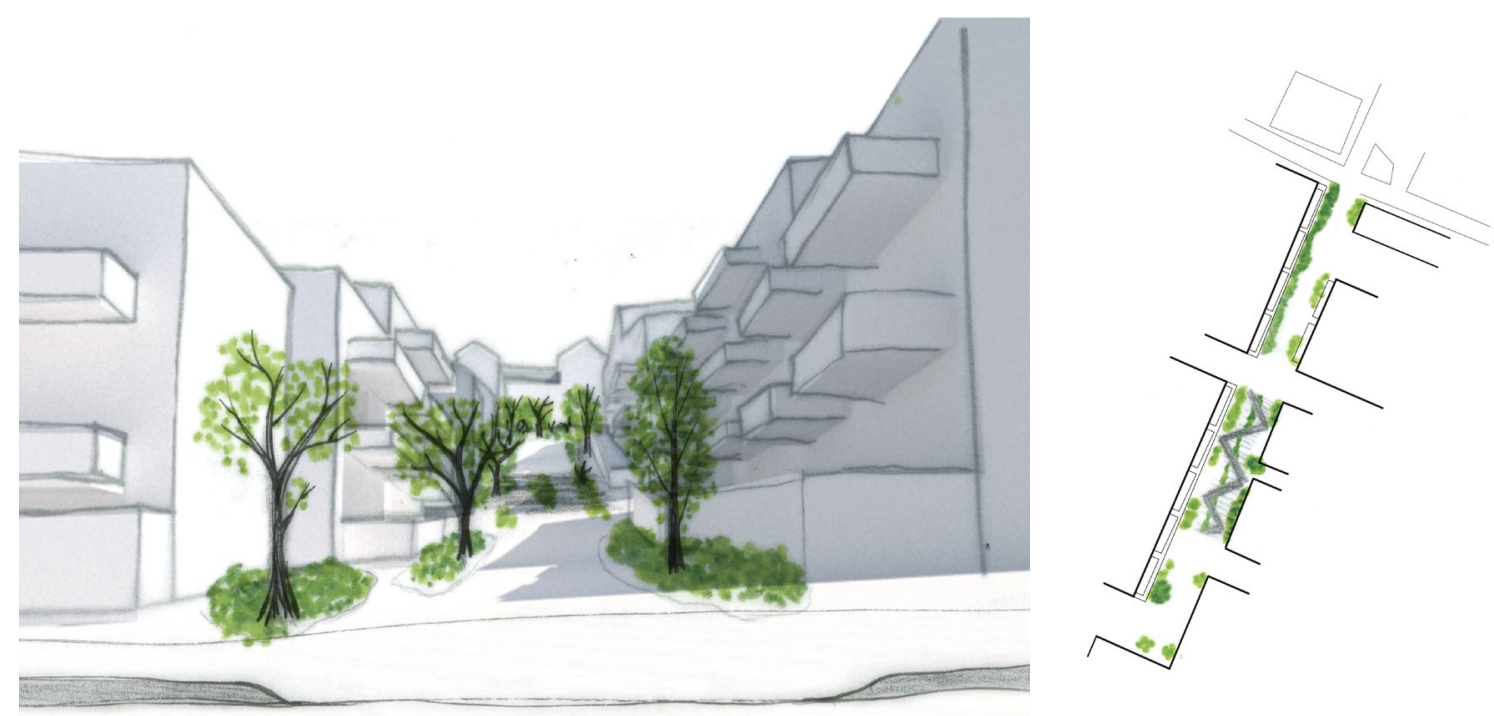

Figure 5.22: Test 2: Tall trees to line the street and lead visitors along, while providing small amounts of shade and privacy.

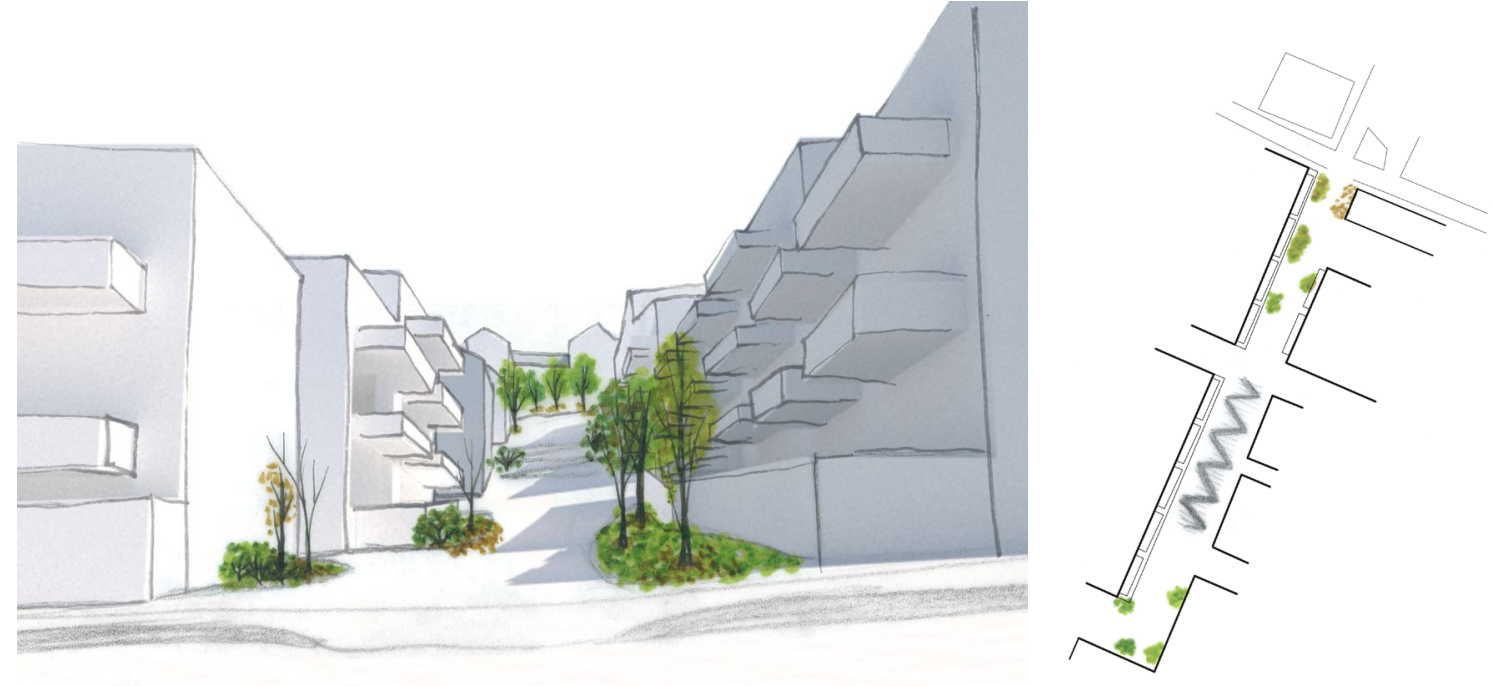

Figure 5.23: Test 3: The eastern side of the street had the greatest amount of sunlight throughout the day, therefore deciduous trees on that side of the street are appropriate and evergreen on the west

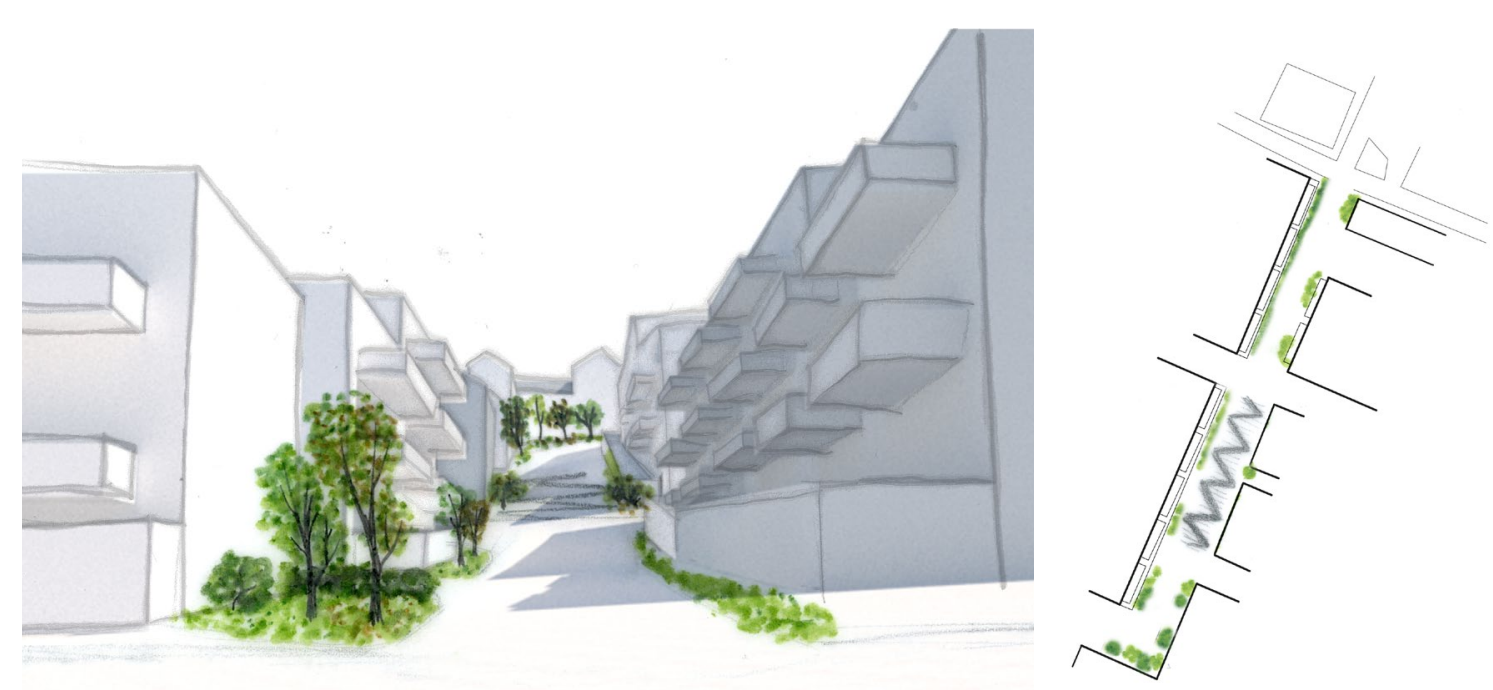

Figure 5.24: Test 4: Trees to sunnier side of street to provide shade in summer and provide privacy between buildings. 


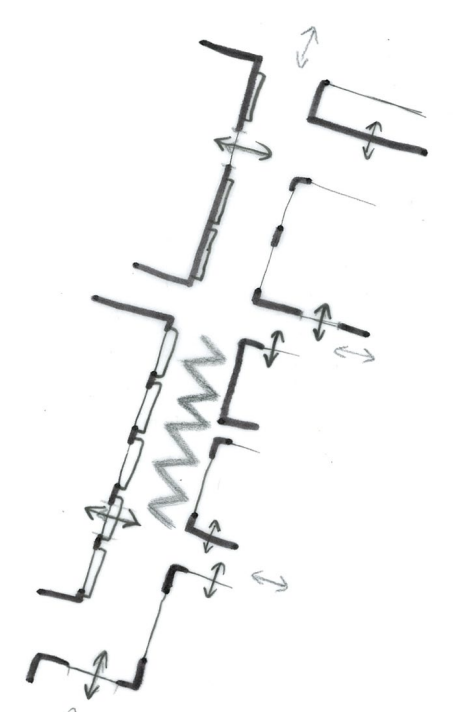

Figure 5.25: Test 1: Balconies vs solid walls across from each other. This will not provide adequate light into each building Community space
of development

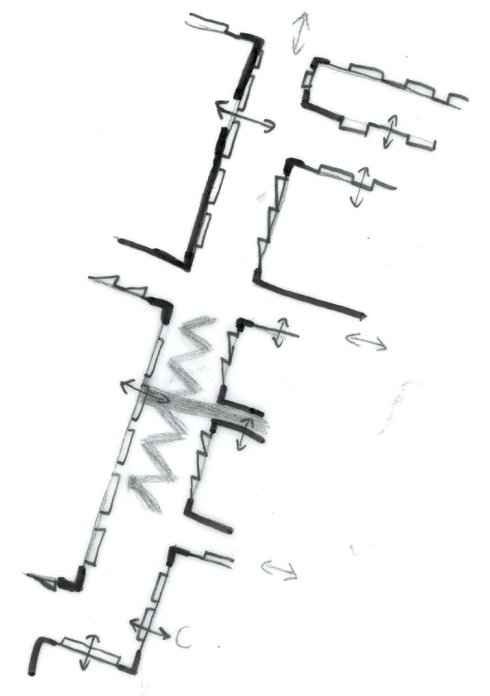

Figure 5.27: Test 3: Angled windows on smaller entrances with access ways to respond to site contours. Community space shiffed to look
towards green space in the south-west conner

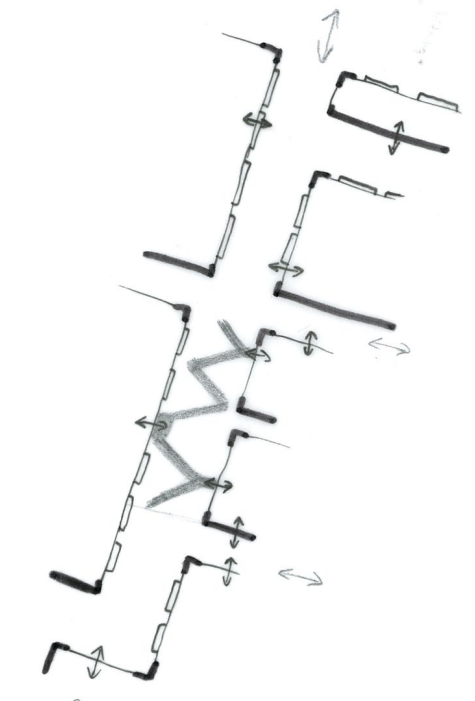

Higure 5.26: Test 2: Different openings and so that northern views will not be into any into opposing apartments

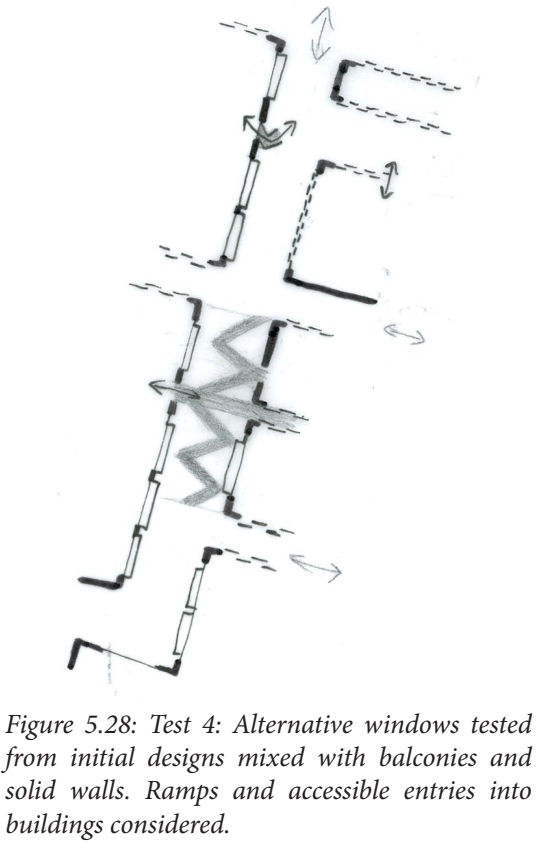

The building envelope tests utilise window and balcony designs proposed in the initial design phase. This test allows the building footprint

be simplified to focus solely on the

street and how the internal street would need to

be laid out to align with building entrances.

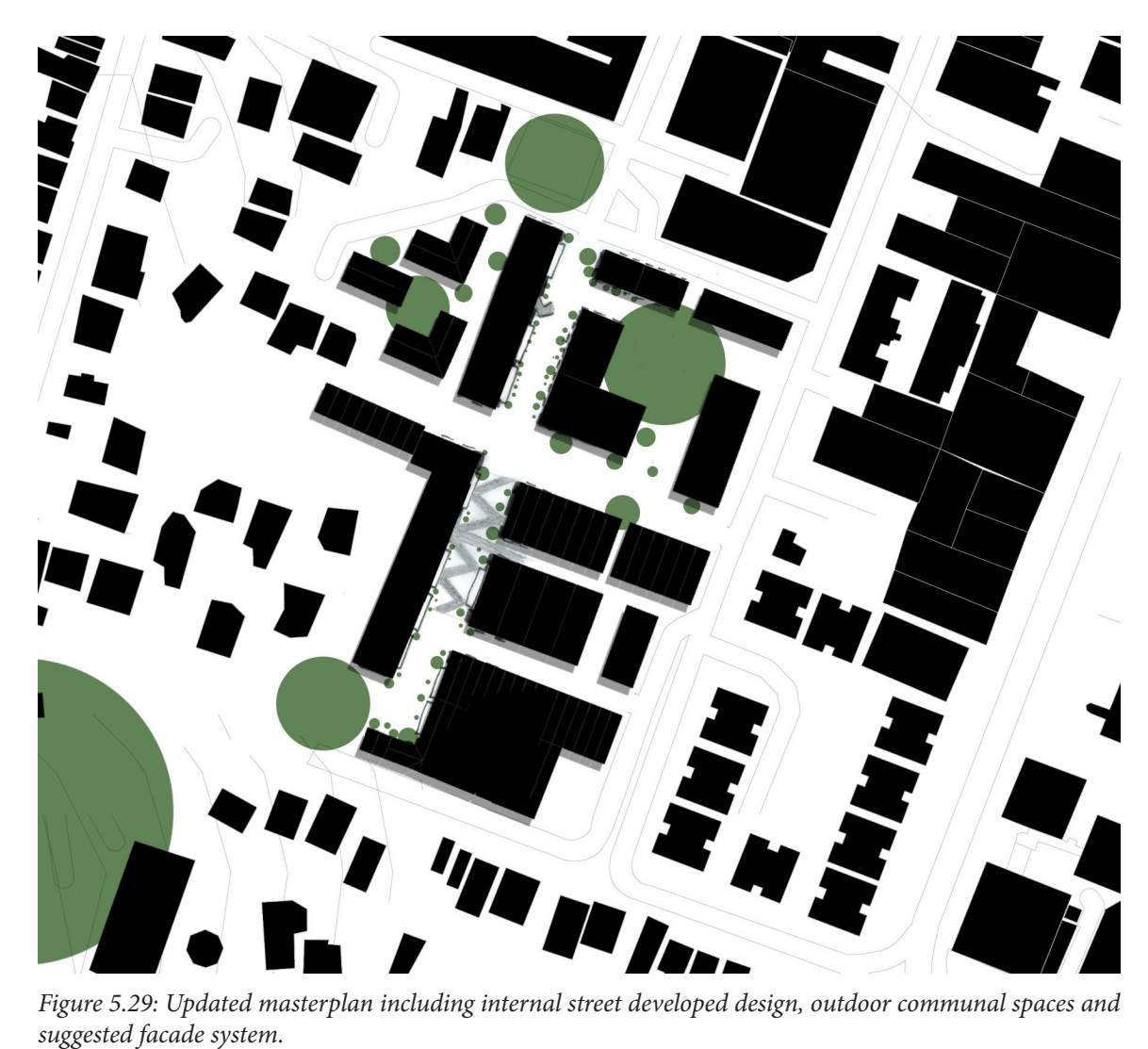




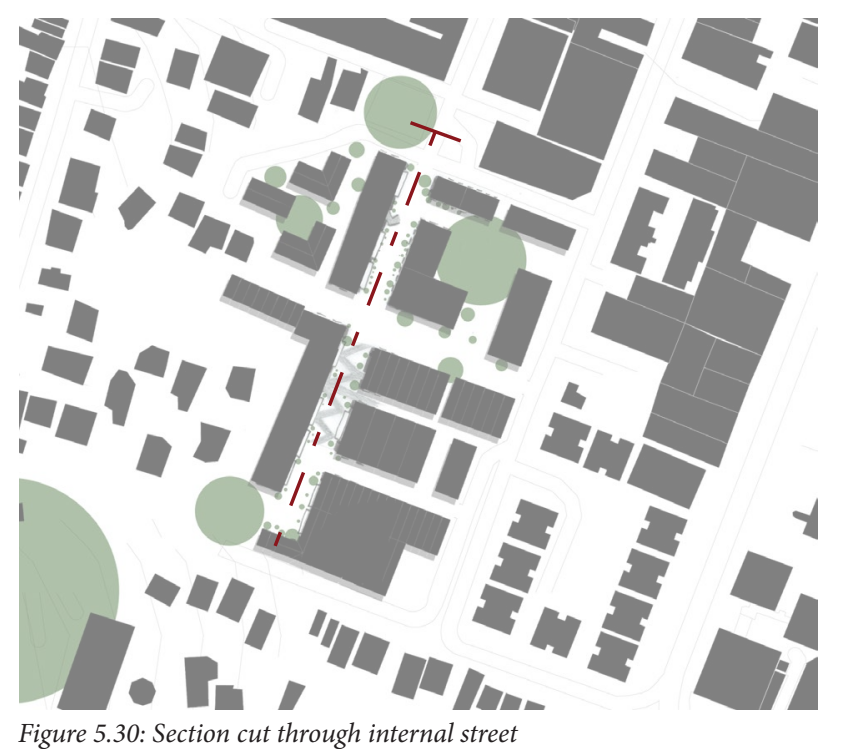

Figure 5.30: Section cut through internal street
These section/plan tests of the facade begin to address the connection between interior and exterior. The relationships between buildings can be understood clearly in plan and section to consider green space, façade systems and access ways as individual features and their relationship to one another.

The communal stair and ramp space still requires further development to make sure it is 1:12 to be accessible. The interior of two units also needs to be developed to work with this system and the surrounding buildings.

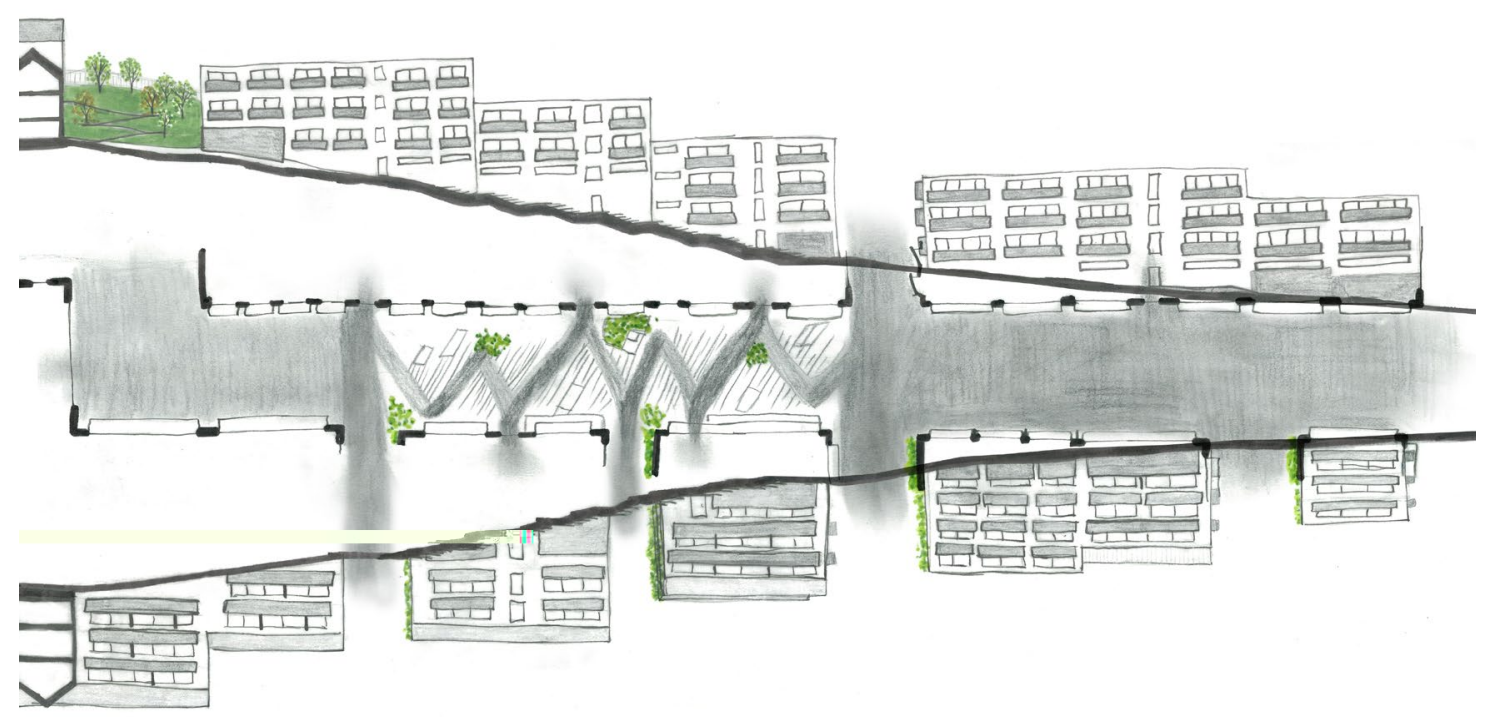
Figure 5.31: Test 1: Simple balconies tested with greenery on solid facades and seating placed into ramp/stair area. Entryways into
buildings considered in relation to the stair/ramp route. Entrances are note accurate and awkward, as ground floors are underutilised.

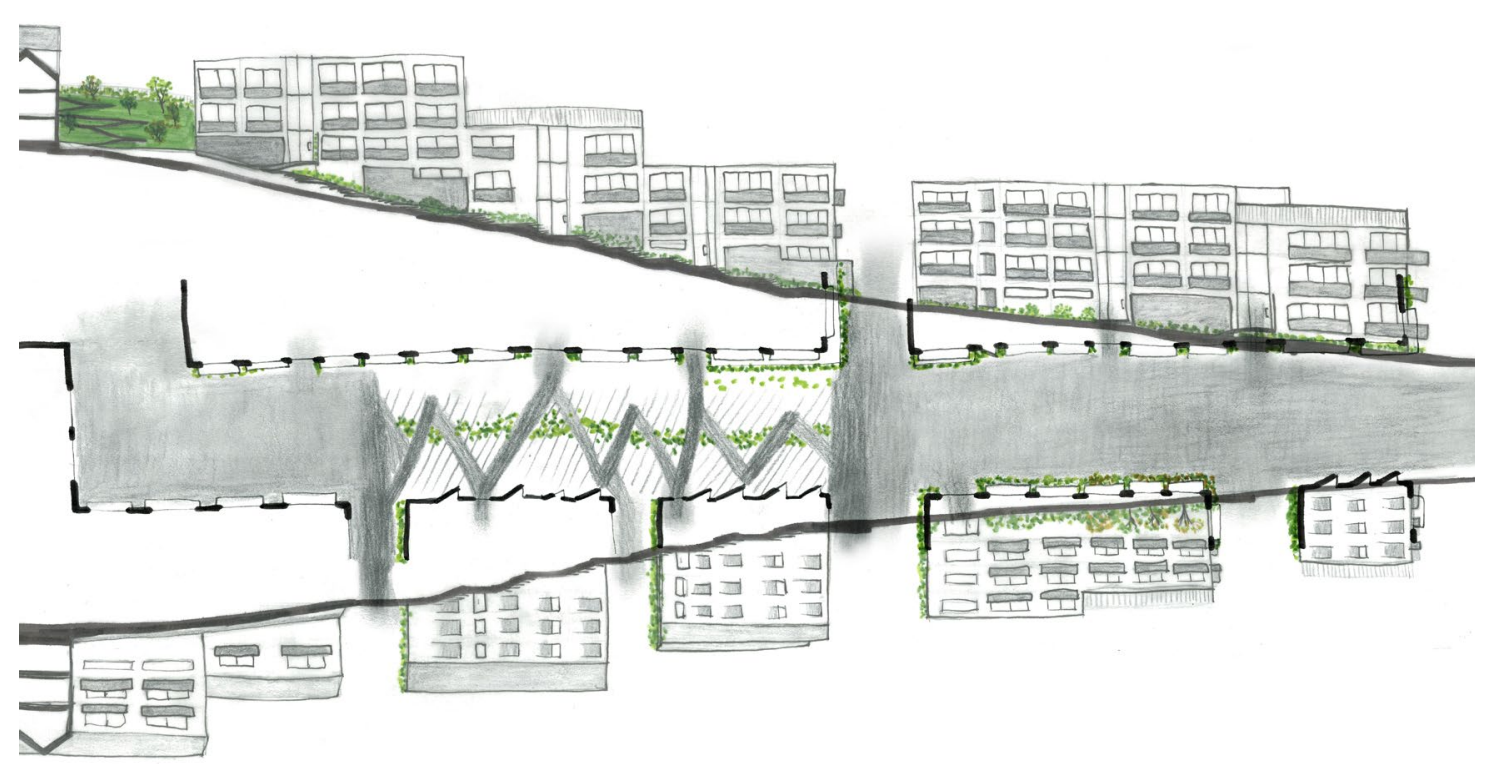

Figure 5.32: Test 2: Potential rooftops added which can hold laundries without adding more height to buildings. Central greenery to divide the stair ramp space is unsuccessful as it should enhance, not restrict the

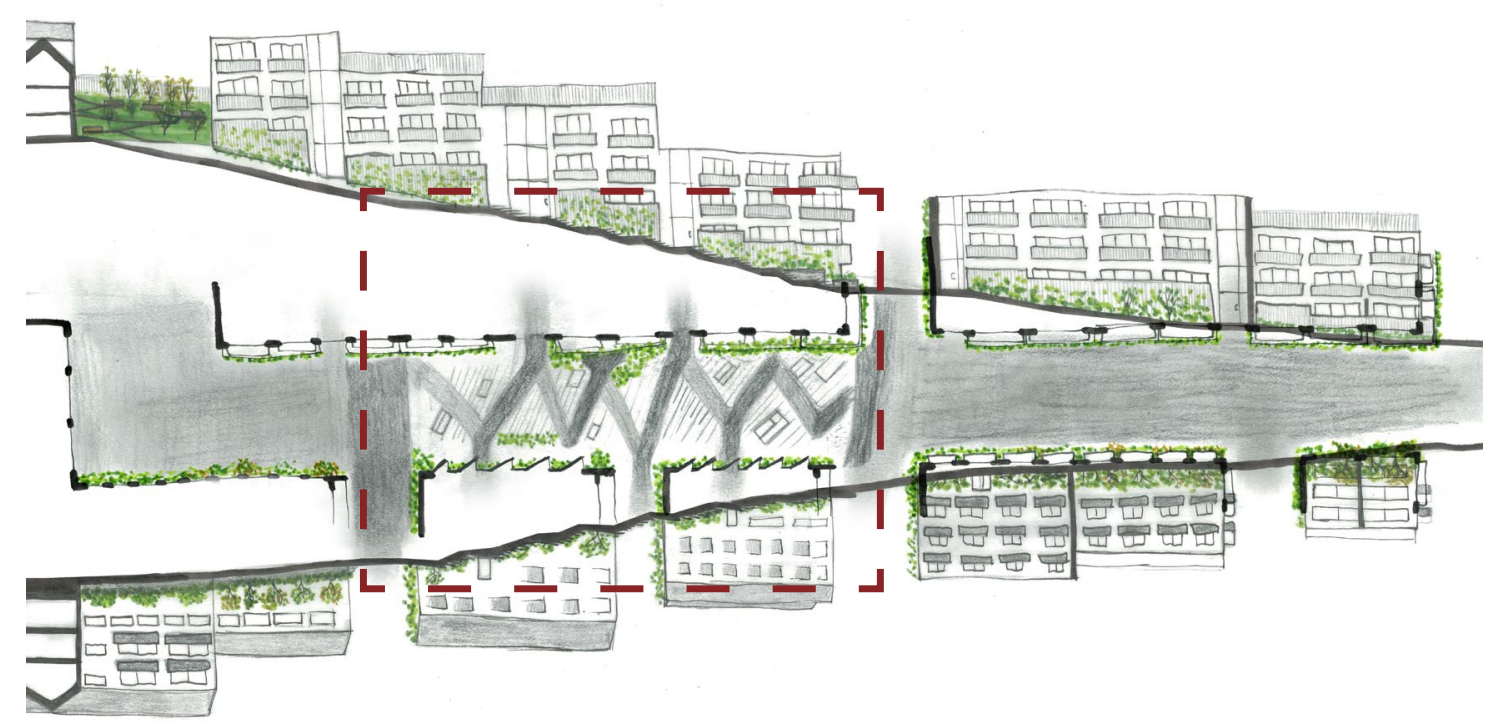

Figure 5.33: Test 3: Greenery planned earlier is added and reassigned to compliment the facade systems in this iteration. Mix of high or and access ways better connected Stair and ramp system highlighted as it will be further developed 
As highlighted in Figure 5.33, the stair/ramp system requires further development to ensure it is accessible with a fall of 1:12 and sufficient landings. Building pads for each building have

been placed and the site has been adjusted

to ensure accessibility around the site and at

entrances to each building. Figure 5.34 shows

the accurate topography of the internal street and where the landscape requires this stair/ wo ensure accessibility.

Landings, ramps and steps can reach a resolved form, however the buildings surrounding the space will be developed and can then inform the design furthe
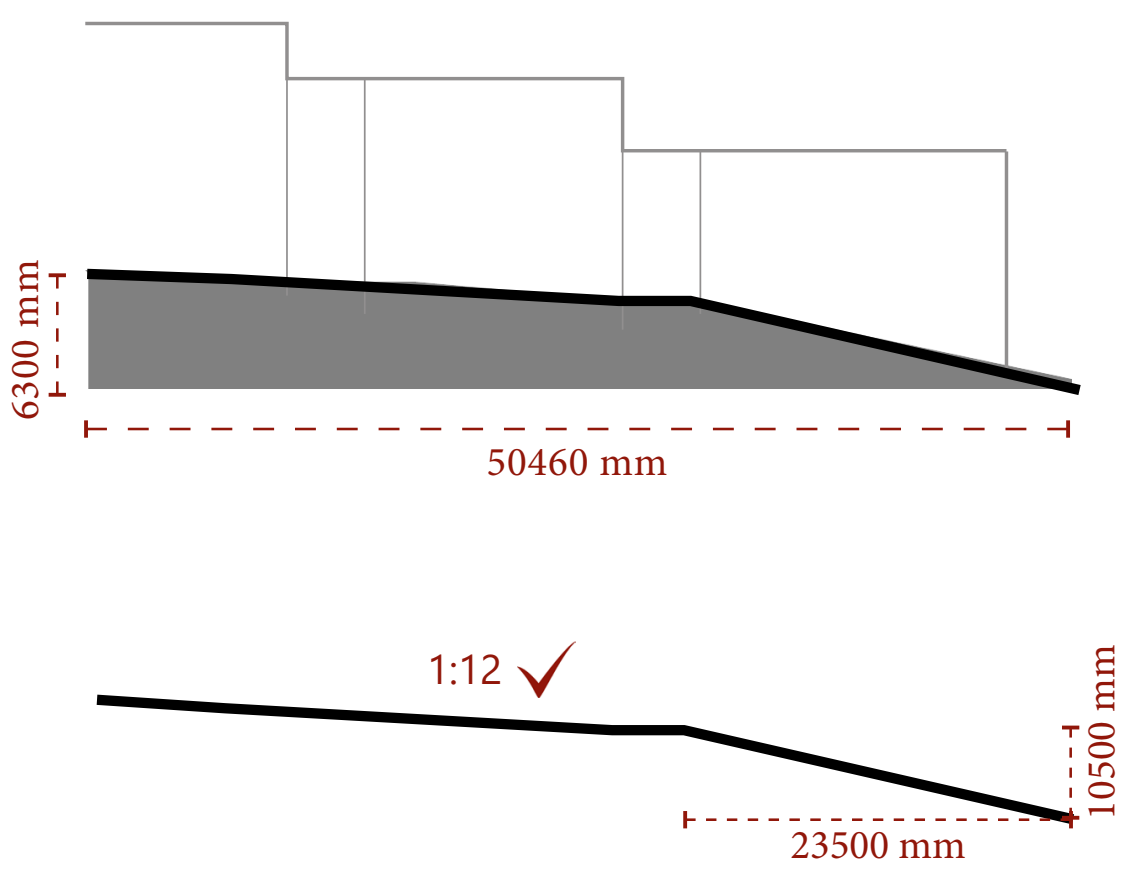

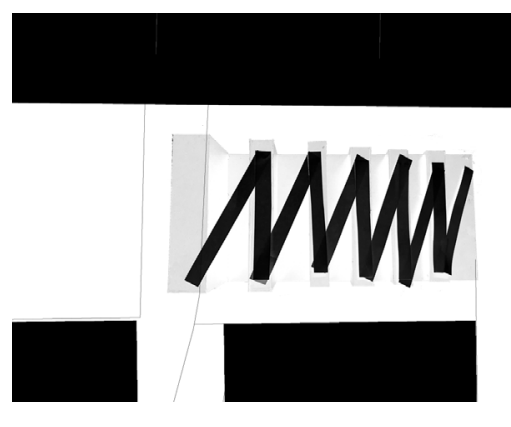

Figure 5.35: Simple repetition of 1:12 ramps, with
straight pieces being flat landings.

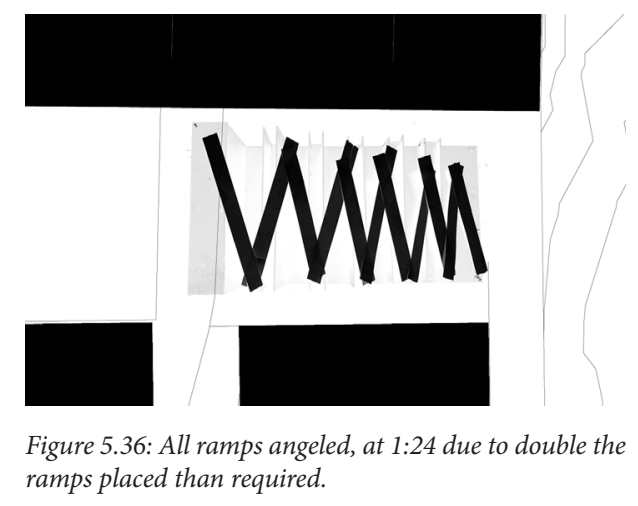

ramps slaced than required.

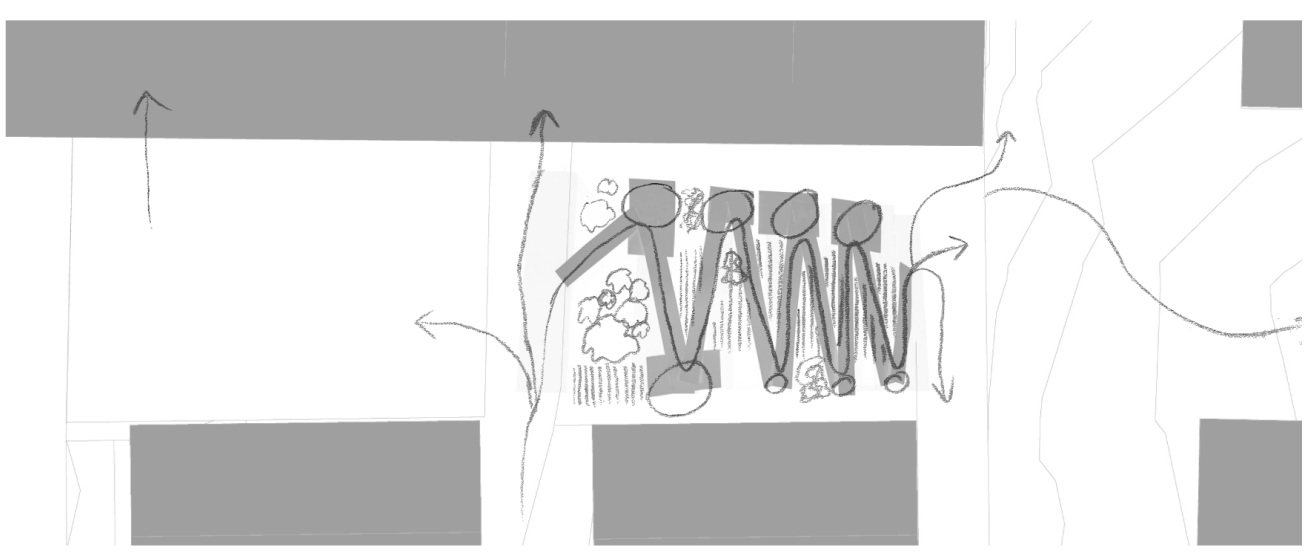

Figure 537. Only necessary 1:12 ramps to equally distribute distance. Landings added and an indication of movement vs pause shown Green space also added in to reflect back wpon previous design tests

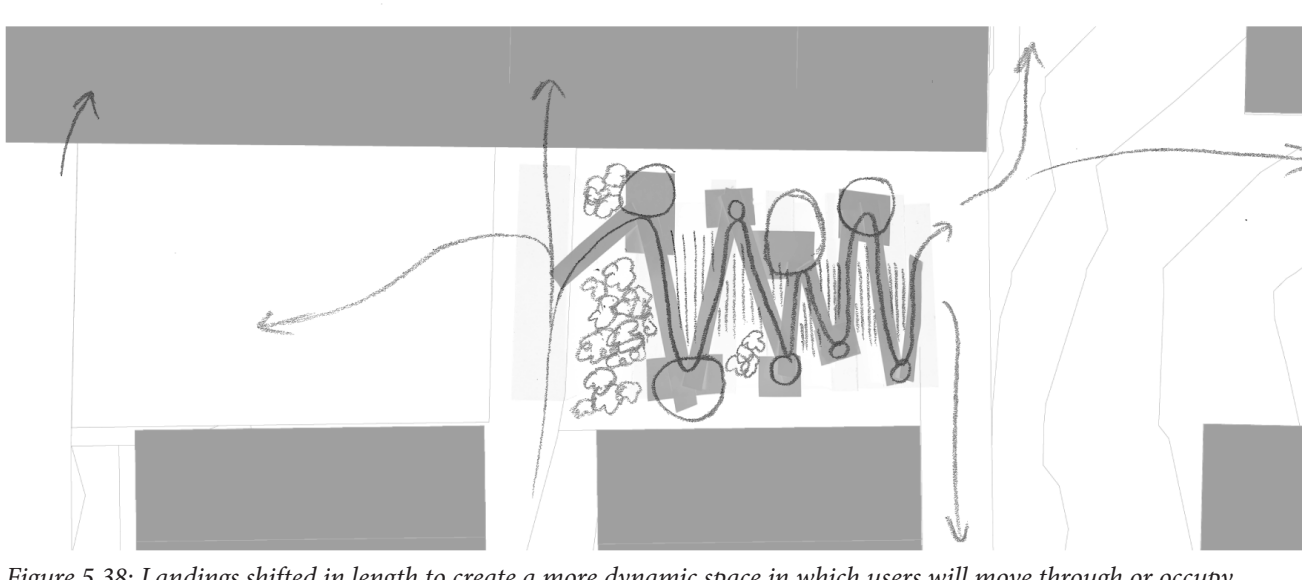

Figure 5.38: Landings shifted in length to create a more dynamic space in which users will move through or occupy. 
INTERNAL STREET UNITS

In order to further define the building envelope, two building typologies which define the internal street are designed. Due to the site being neighboured by residential dwellings to the south west and commercial building to the north east, the site will have a mix of apartments and "house" dwellings. These dwellings will meet the cultural and

accessibility criteria set out in Chapter 2 and 3 ,

but also still consider CPTED principles. This means interior dwellings are kept private, while access ways inside and out have clear lines of sight.

The masterplan has been simplified to reflect the ideas discussed earlier, particularly acknowledging potential space adjacent to buildings for laundries and minimising unwanted corners. This is reflected below.

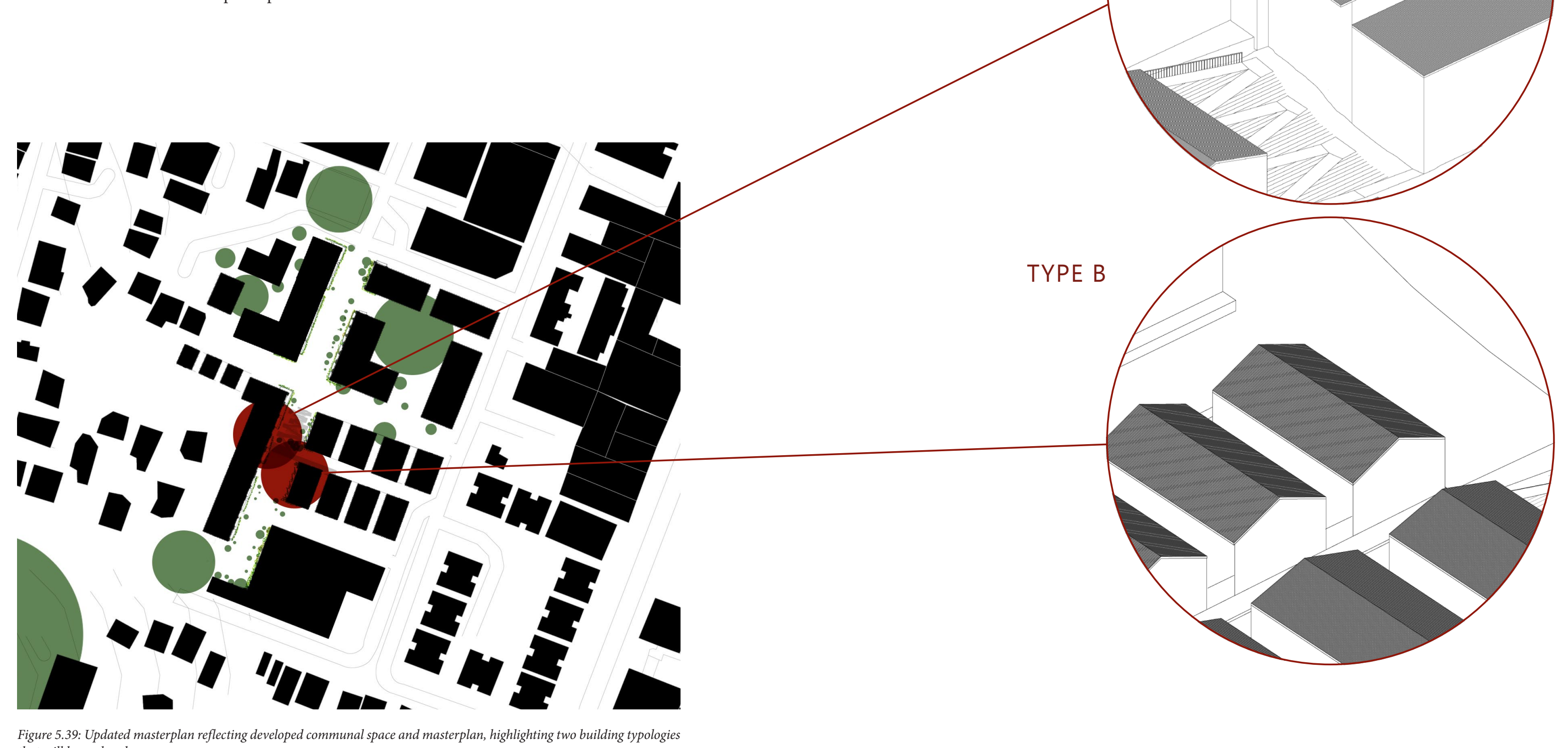




\section{TYPE A}

Type A is a compact, three storey apartment building which has an open glazed entrance and has a direct link to the ramp \& stair system. Glazing can only be on two sides of this type as it is repeated on either side. The criteria which will define these units is:

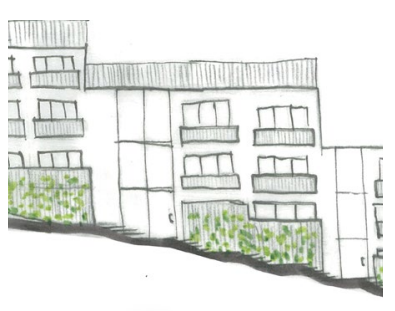

Accessible hallways, doorways and rooms according to NZS4121 \& Universal Design Guides

Culturally appropriate spatial layout which balances Tapu \& Noa, along with maintaining a separation between public, semi private and private space

Access ways into the building and each unit should have clear lines of sight and utilise CPTED principle

Dwellings should have visual connection to the exterior, but still maintain privacy.
The following design solutions from the initial design phase will be tested on Type A

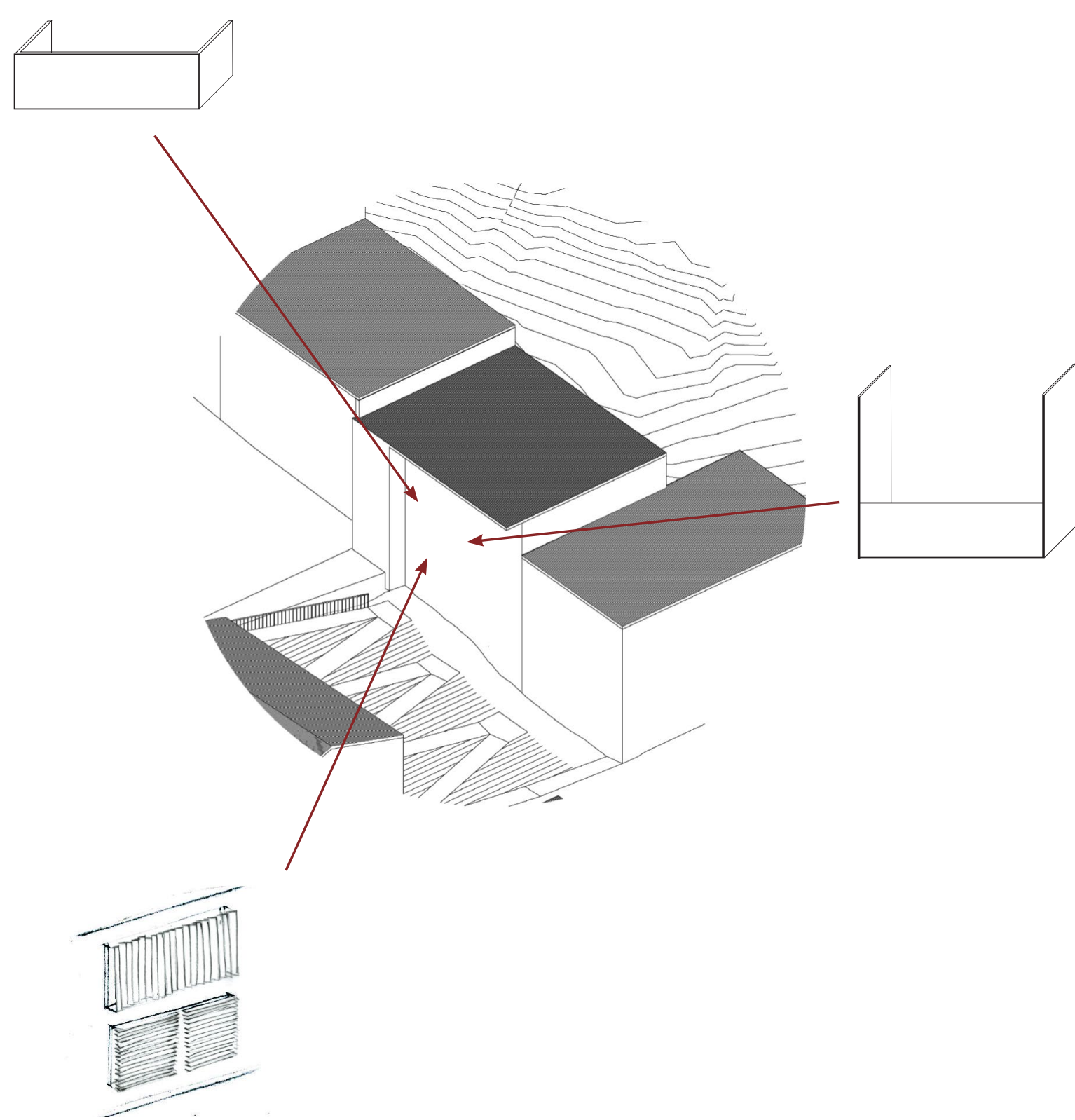


TYPE A - ITERATION 1

BALCONIES AND WINDOWS

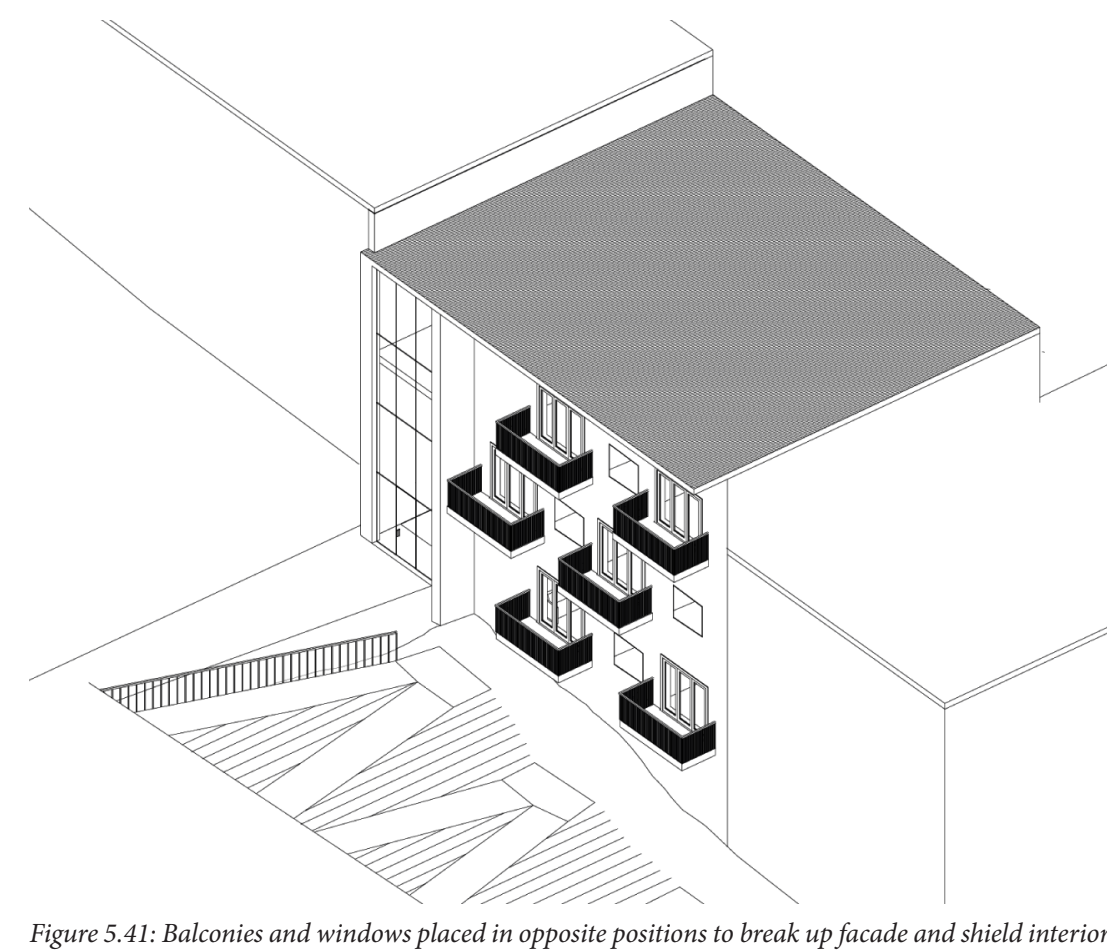

from street view.

Iteration one is comprised of one-two room

dwellings, however an entire floor could be

reconfigured to provide for a larger household.

Windows should be adjusted for privacy.
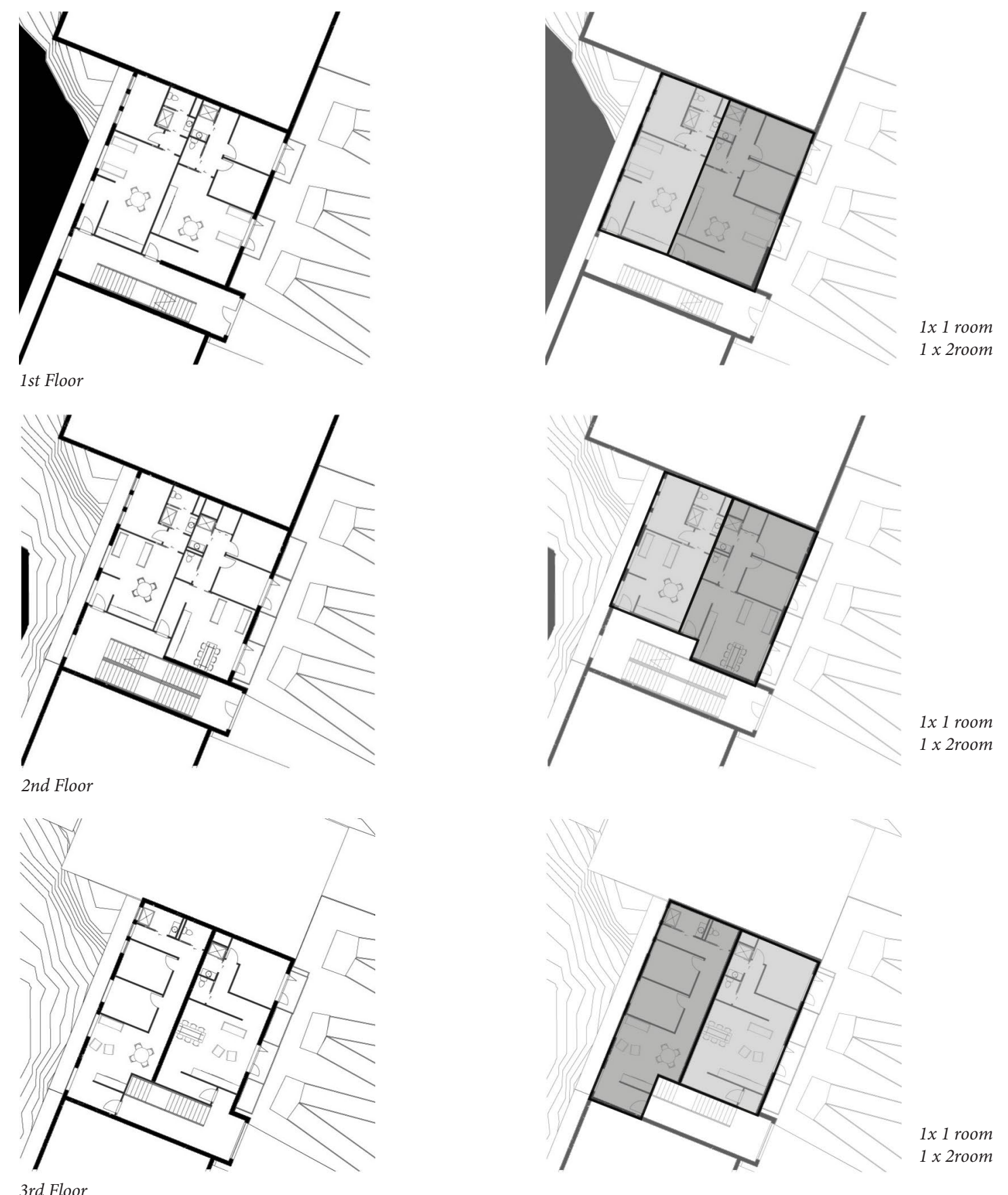


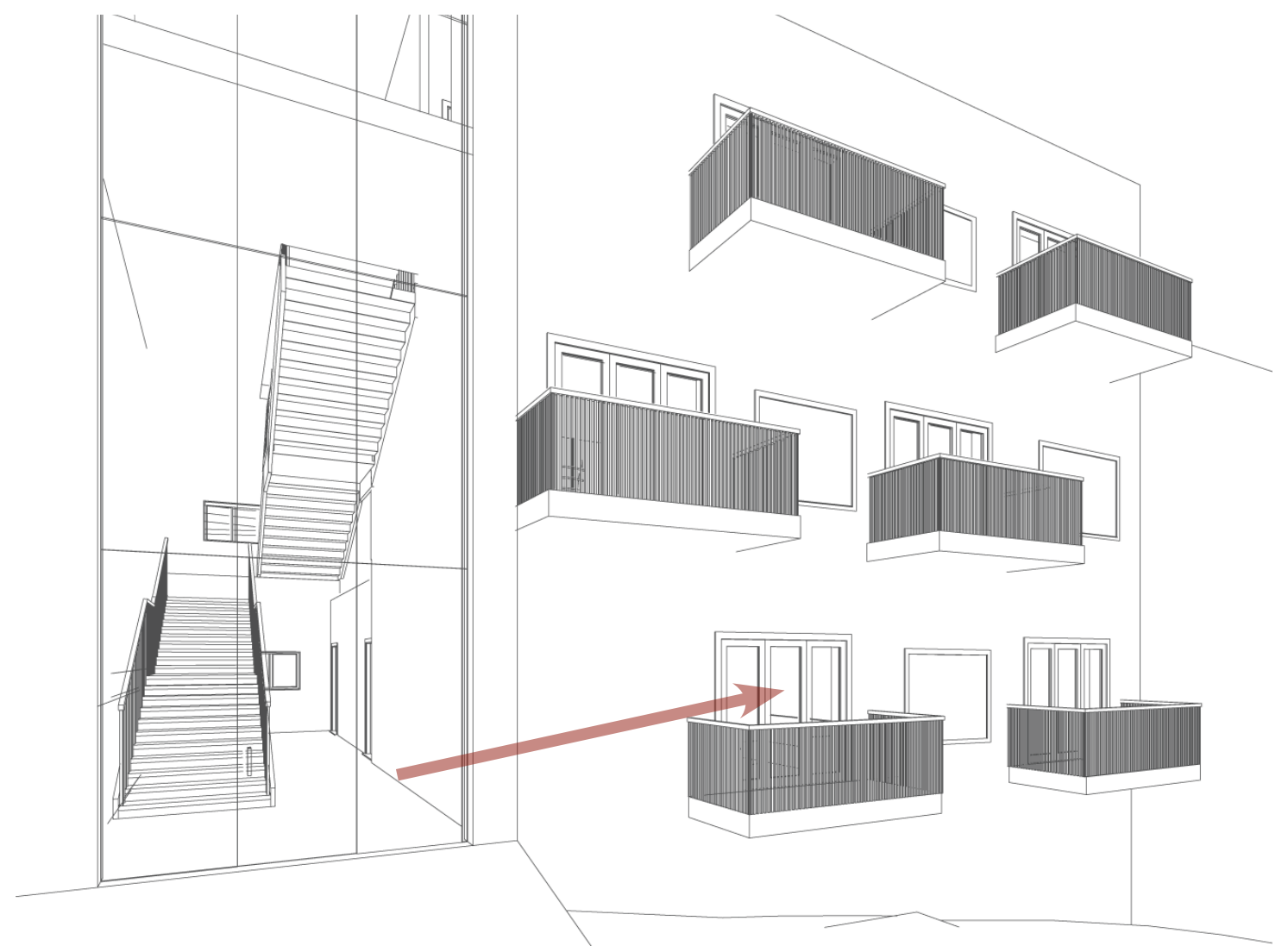

Figure 5.43: View from Entryway to Type A. Interior of the ground floor apartments is highly visible.

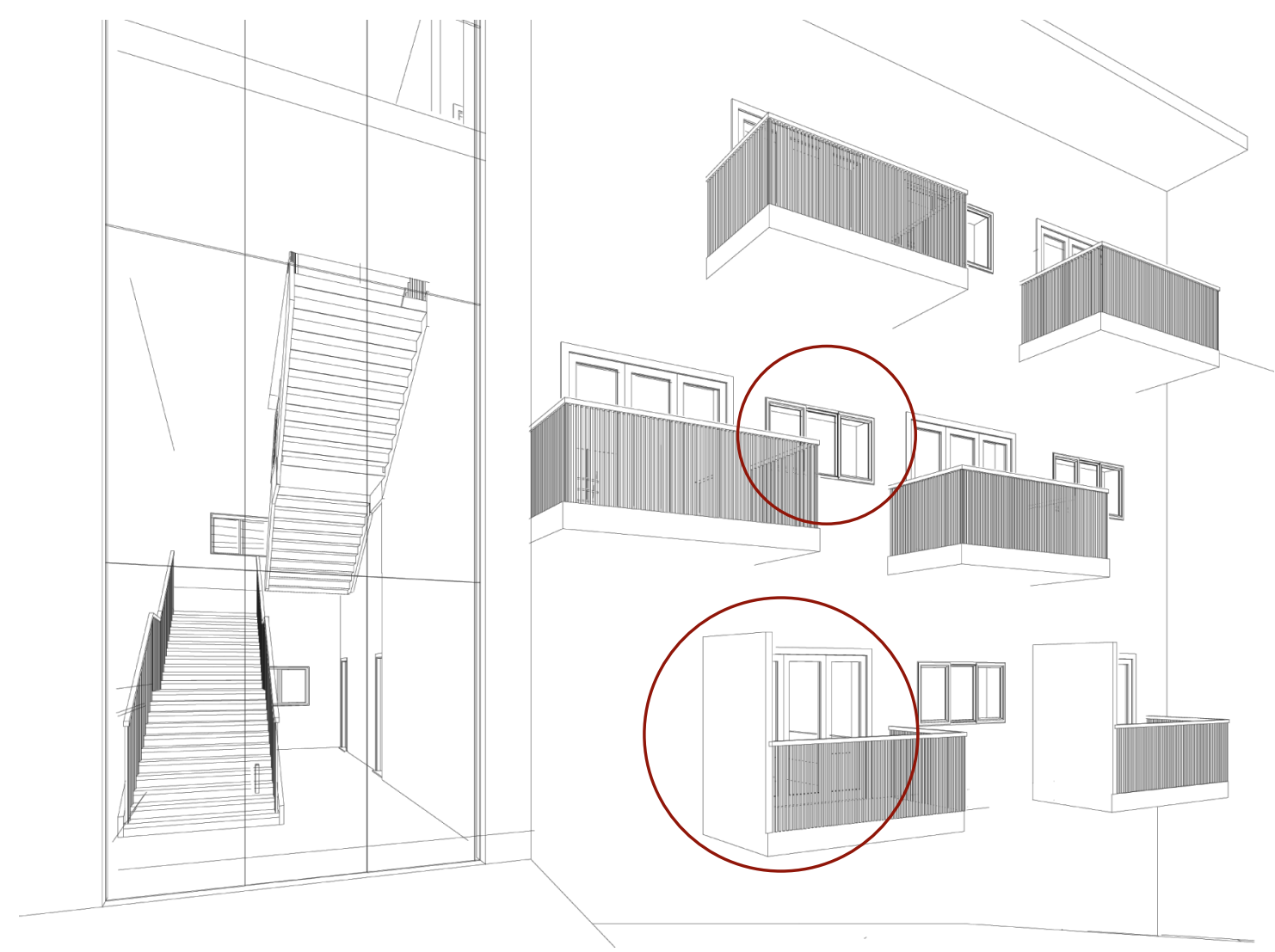

Figure 5.44: Window height and size adjusted. Partitions added to balconies to privatise the ground floor

Balconies successfully hide the interior of the second and third floor, however most of the first floor is still visible. The windows could be smaller or higher to block view into the interior on all floors. Entryway is highly visible, therefore will be more secure through passive surveillance. 
TYPE A - ITERATION 2

FACADE SCREENING

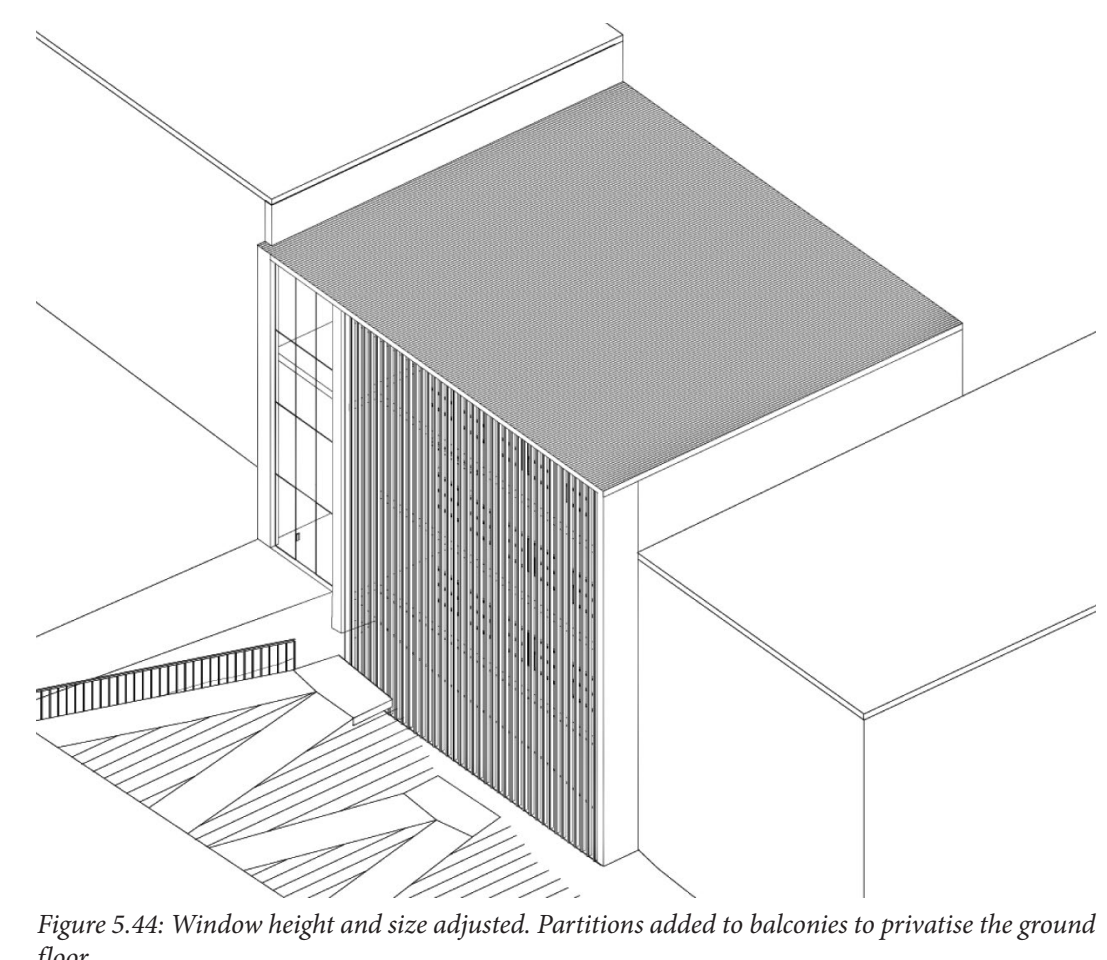

Figure 5 .4
floor
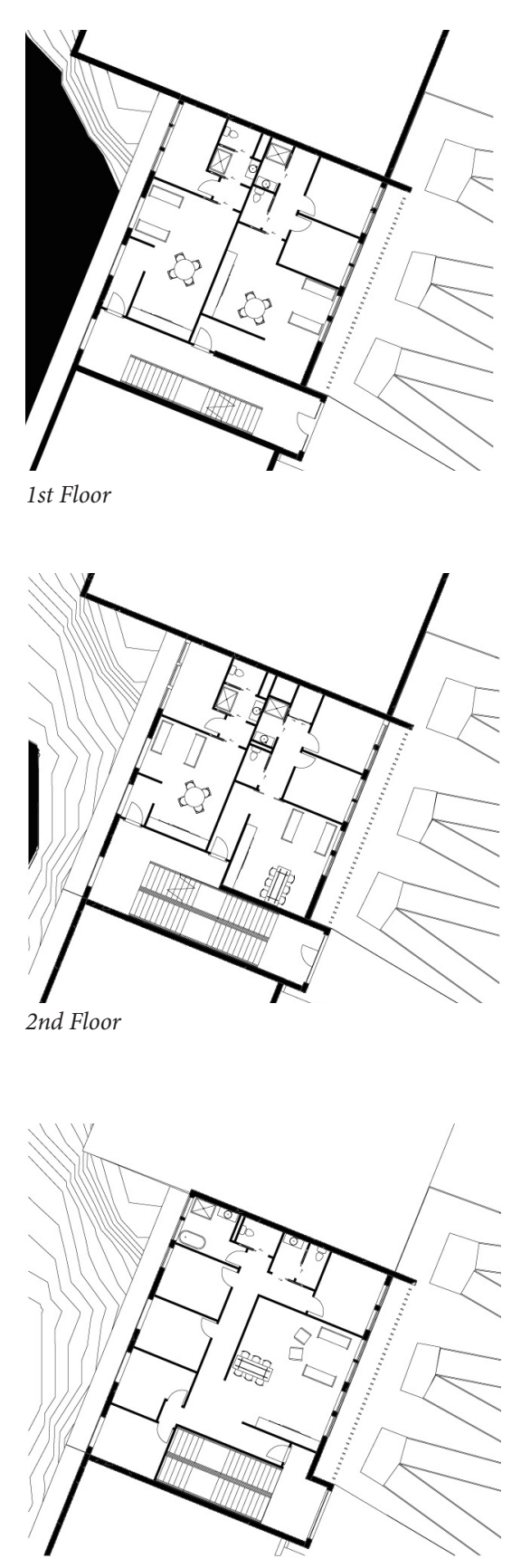

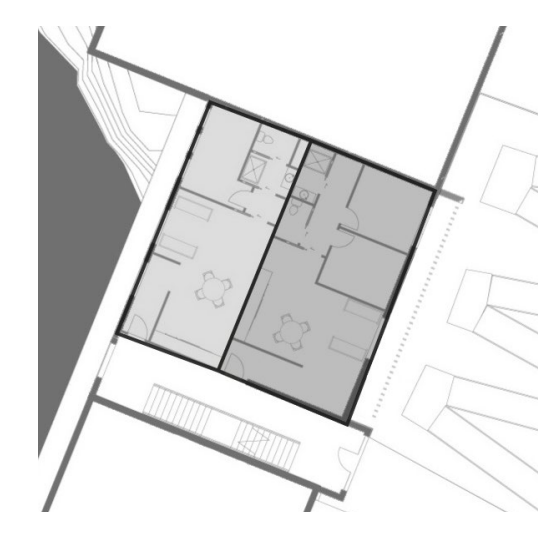

$1 \times 1$ room

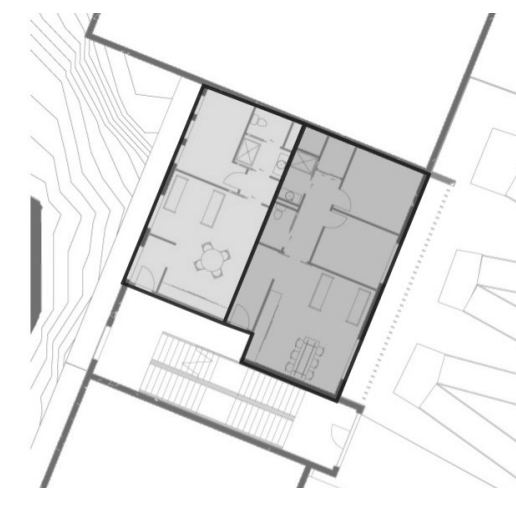

$1 \times 1$ room
$1 \times 2$ room

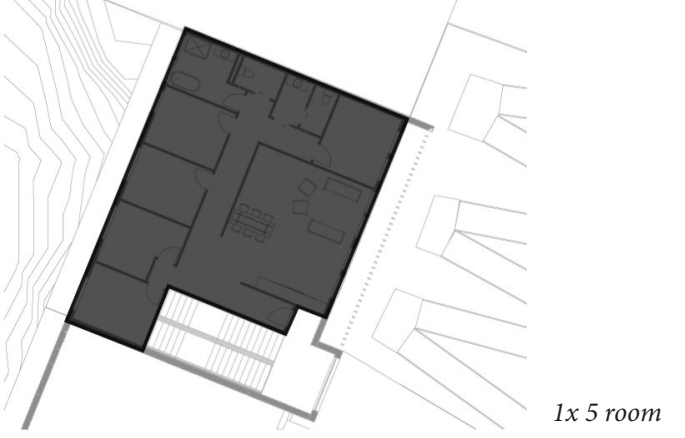

As an alternative, as excess of screening is

proposed. Timber will tie into the planned

landscaping for the site. Third floor unit holds

five rooms for a large household. 


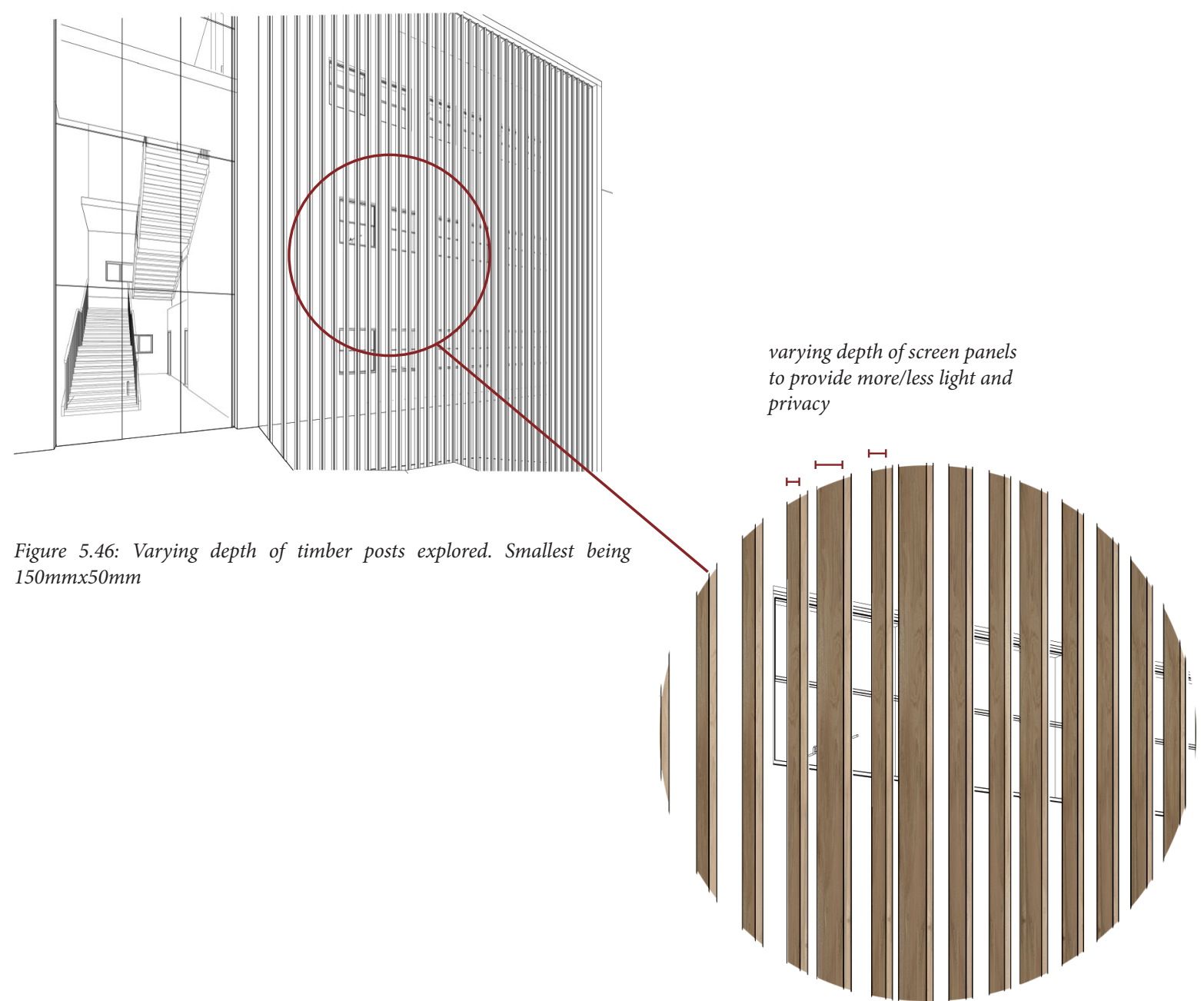

Varying depth of timber screening allows for greater privacy. Spacing between timber posts can be increased when the depth is increased to

allow greater light while maximising privacy as

main view of concern is from the side.
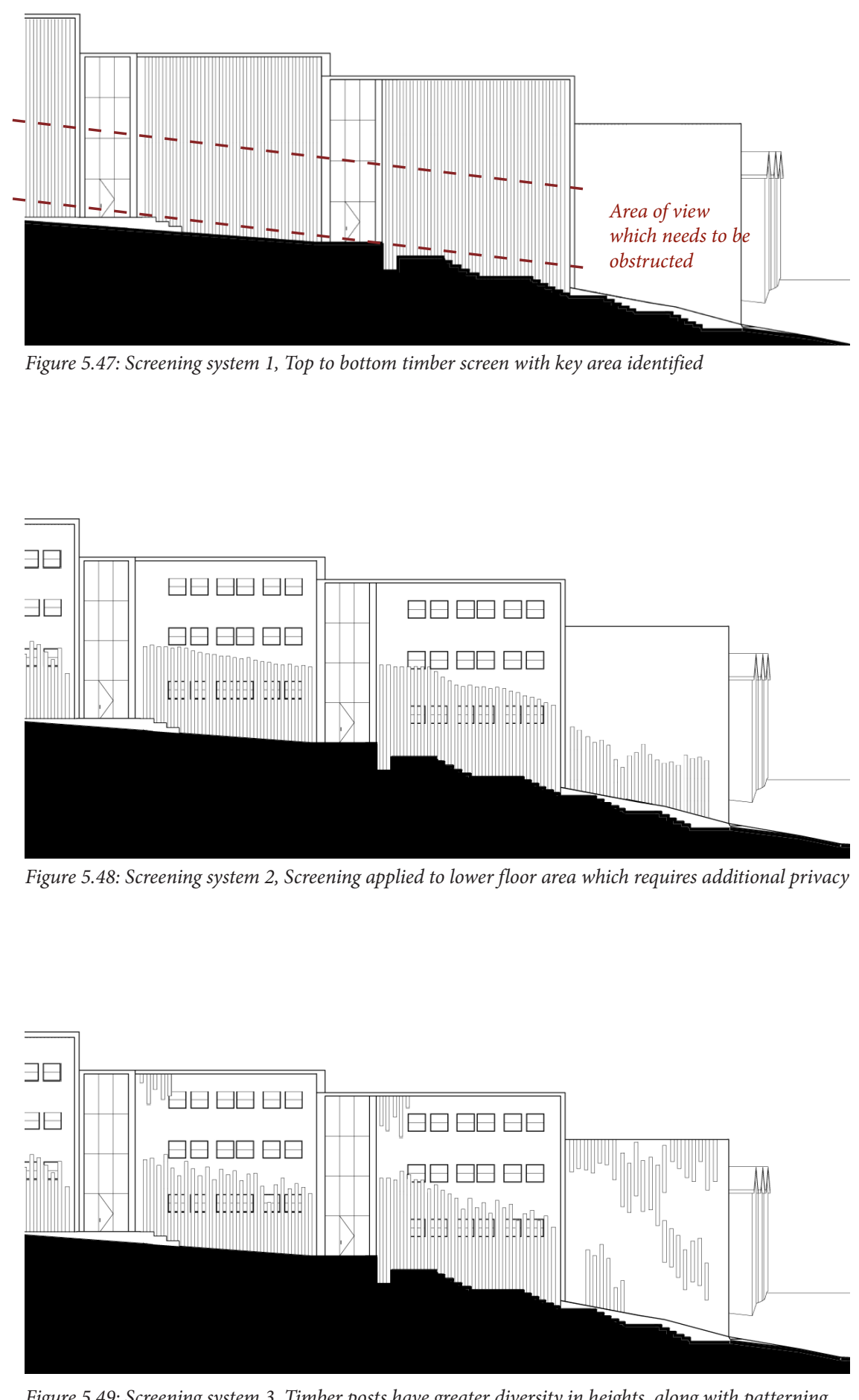

Figure 5.49: Screening system 3, Timber posts have greater diversity in heights, along with patterning being reflected onto the upper facade and surrounding buildings 
TYPE A - ITERATION 3

BALCONIES AND FACADE
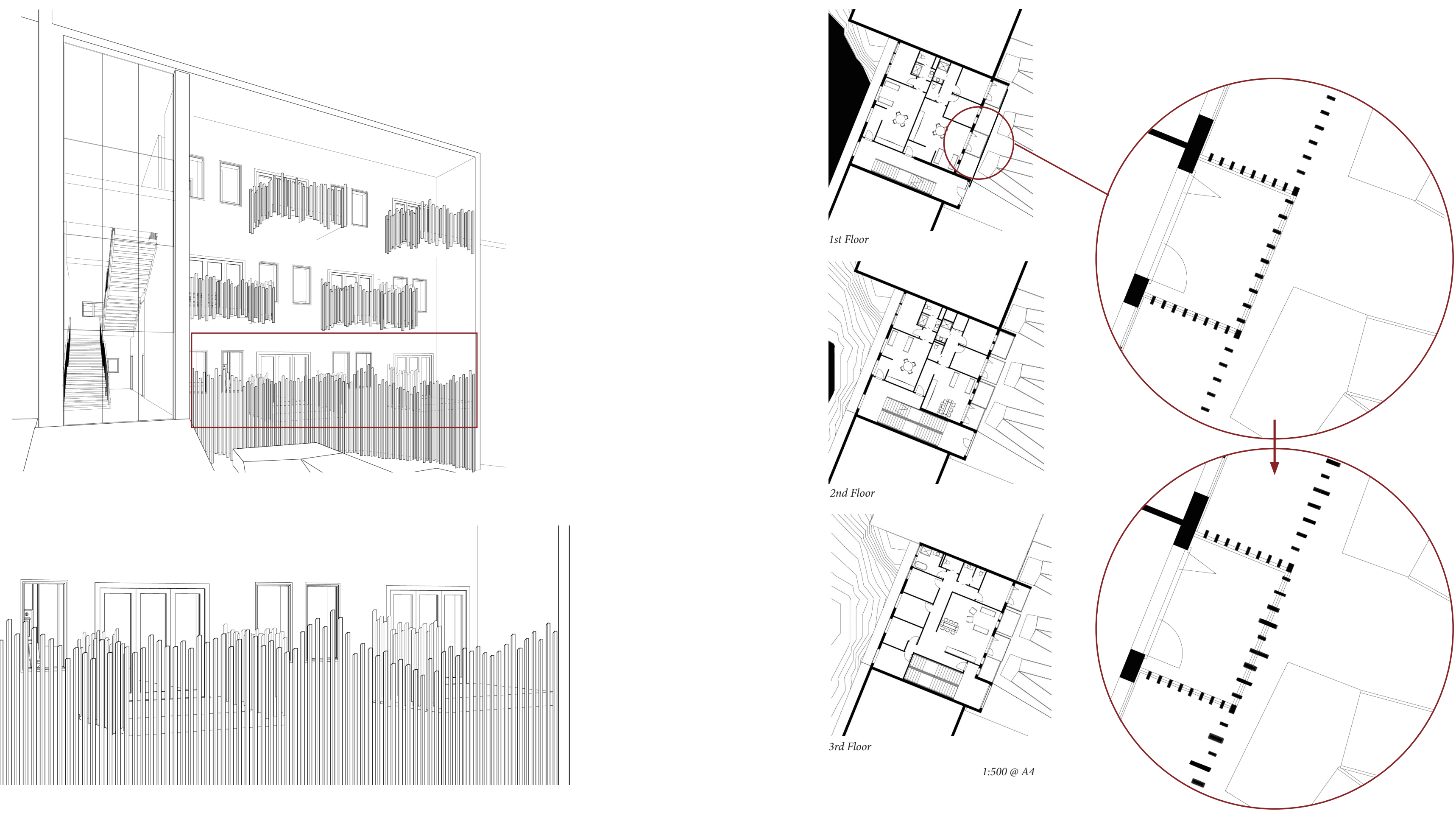


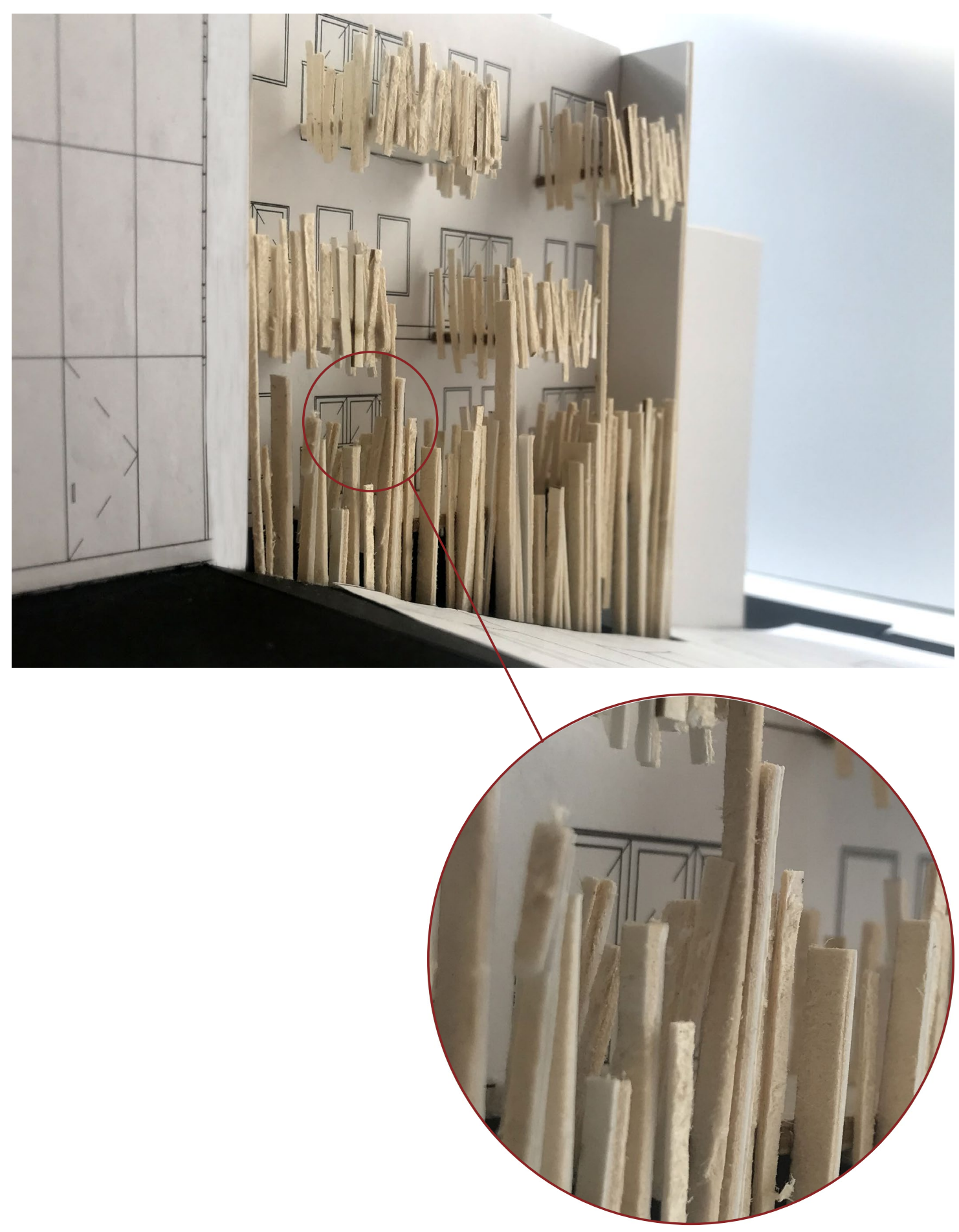

Figure 5.52: Test model created to understand height and width in 3D. Highlighted view of ground floor unit through screening.
Iteration 3 is successful in being inclusive and accessible on the interior and exterior. Balconies are flush with interior floor for reasonable access. Accessible stairs are utilised on the interior, however those with greater accessibility concerns can utilise lower floor apartments or many of the other accessible units throughout the development.

Larger windows on upper floors may be frosted or made even smaller. In order to maximise light into units, the screening system should not be higher than necessary. 


\section{TYPE B}

Type B is a compact, two storey apartment building which is domestic in scale. A gable roof has been utilised to match with surrounding dwellings, however Type B will include two-three different apartments within the building. A laundry area is located adjacent to the building, and washing machines and dryers will be place on the ground floor for ease of access. The criteria which will define these units is:

Accessible hallways, doorways and rooms according to NZS4121 \& Universal Design Guides

Culturally appropriate spatial layout which balances Tapu \& Noa, along with maintaining a separation between public, semi private and private space

Access ways into the building and each unit should have clear lines of sight and utilise CPTED principles

Dwellings should have visual connection to the exterior, but still maintain privacy.

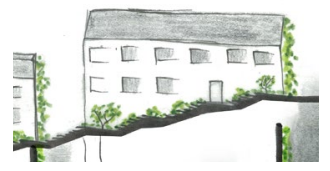

The following design solutions from the initial design phase will be tested on Type $B$

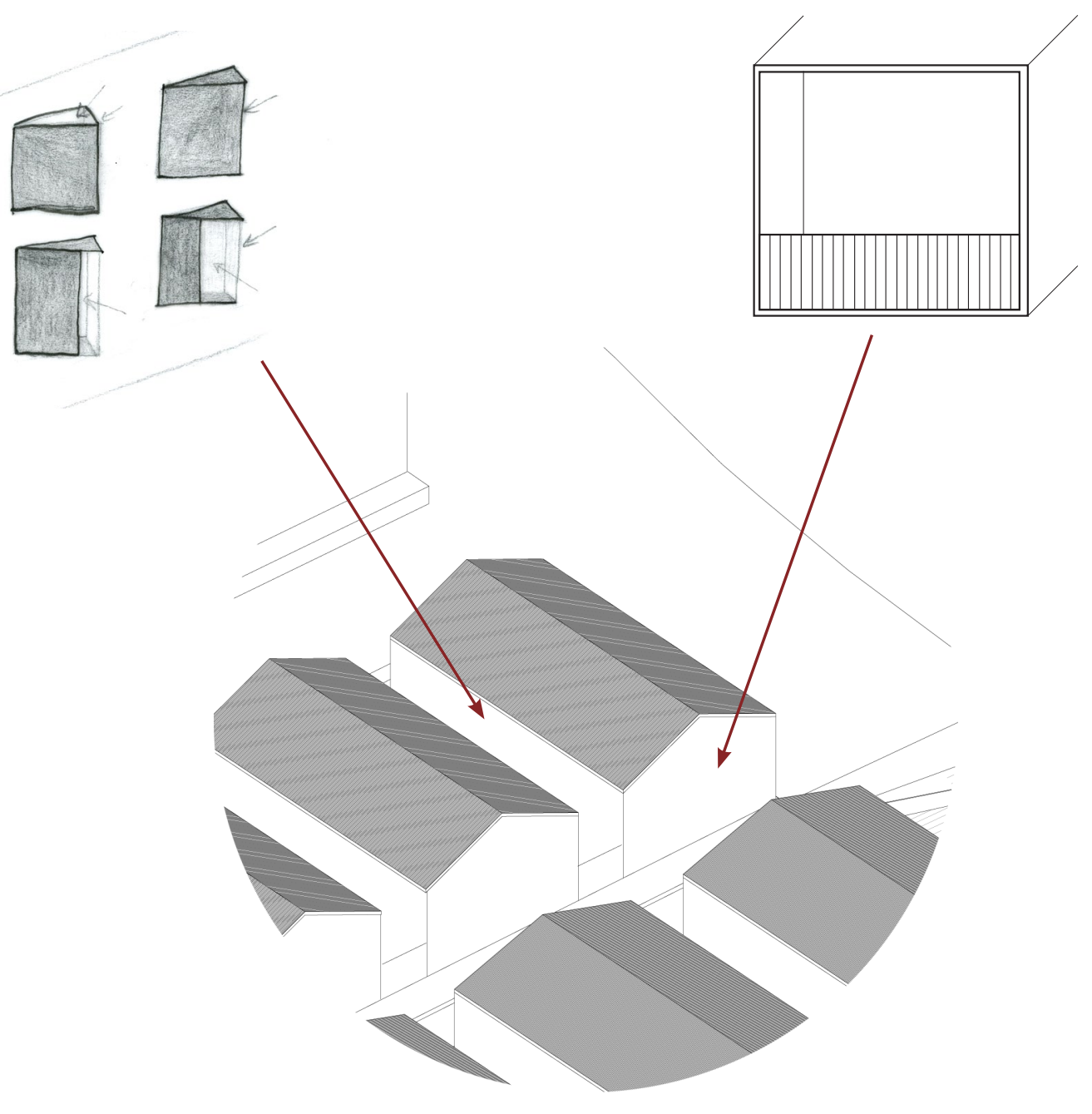


TYPE B - ITERATION 1

HIDDEN BALCONY AND ANGLED WINDOWS

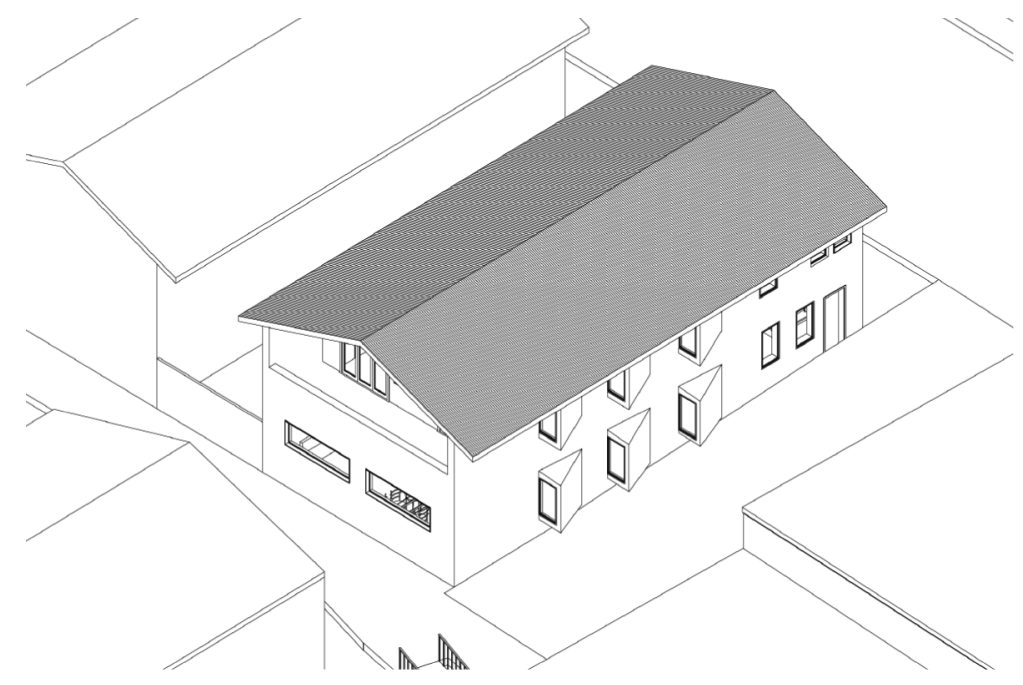

Figure 5.54: Top: Isometric view, Bottom: Perspective of Type B from street

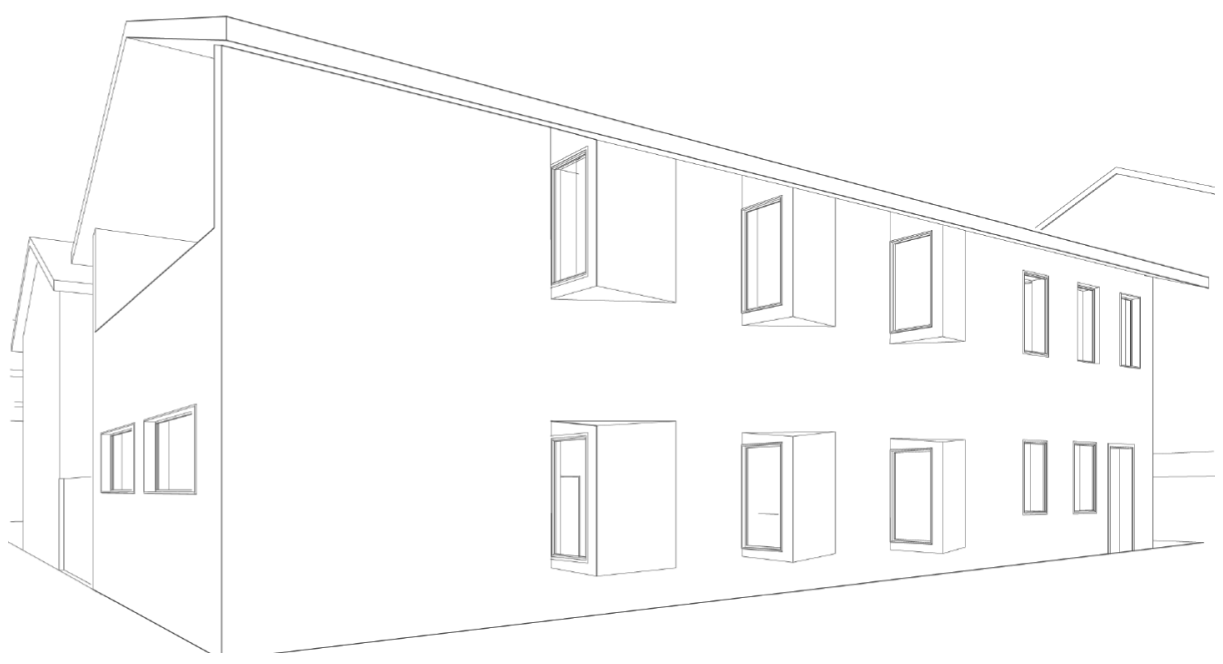

Windows disrupt the facade and create tricky junctions in the facade without significant benefit to privacy. Hidden balcony is very

effective in shielding second floor, however

lower unit has a lack of outlook. Higher

windows on ground floor are effective and may be a better alternative than slanted windows.
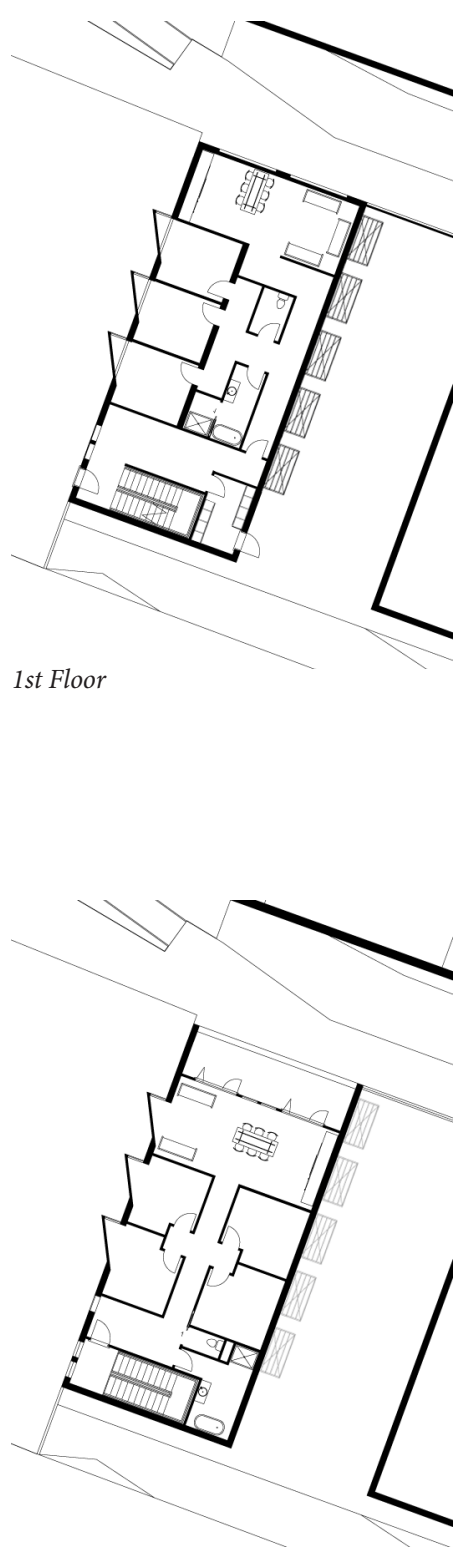

2nd Floor
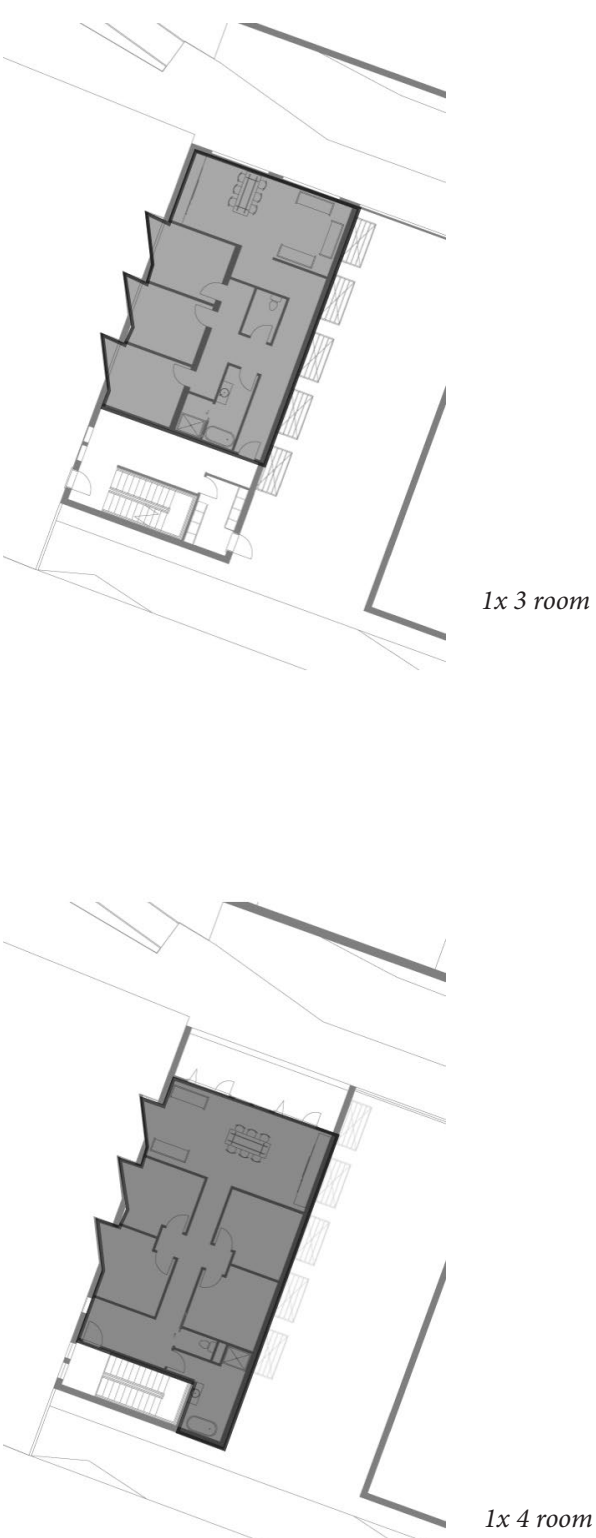

1:500@ A4 
TYPE B - ITERATION 2

ANGLED AND HIGH WINDOWS

Building has been widened by $5 \mathrm{~m}$ to allow for

greater density. Peeling back the exterior wall

to reveal snippets of light has greater success

aesthetically, while still providing privacy
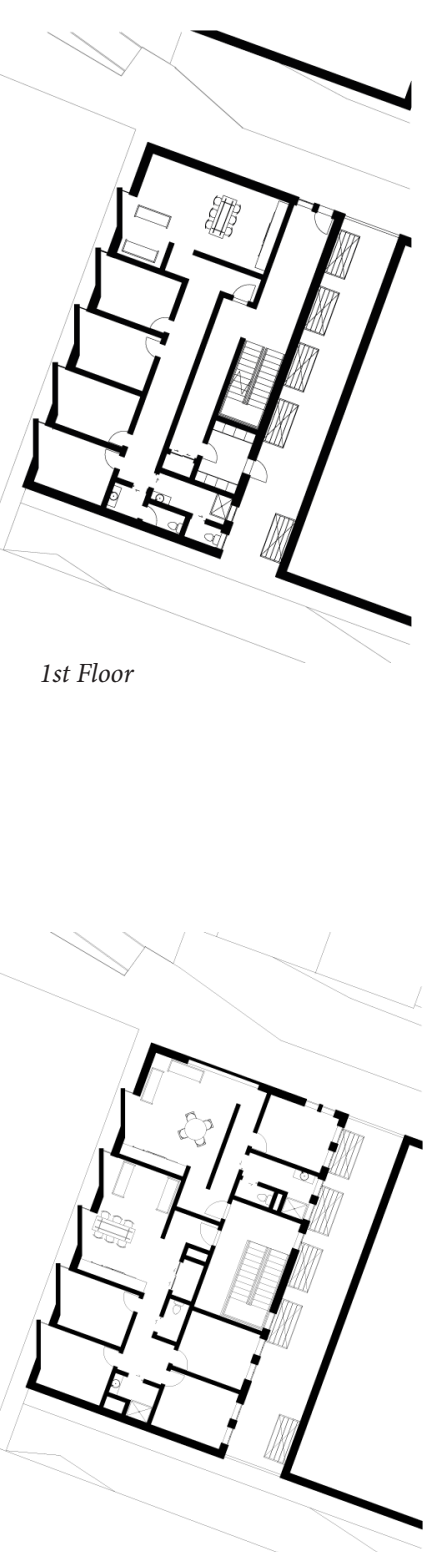

2nd Floo
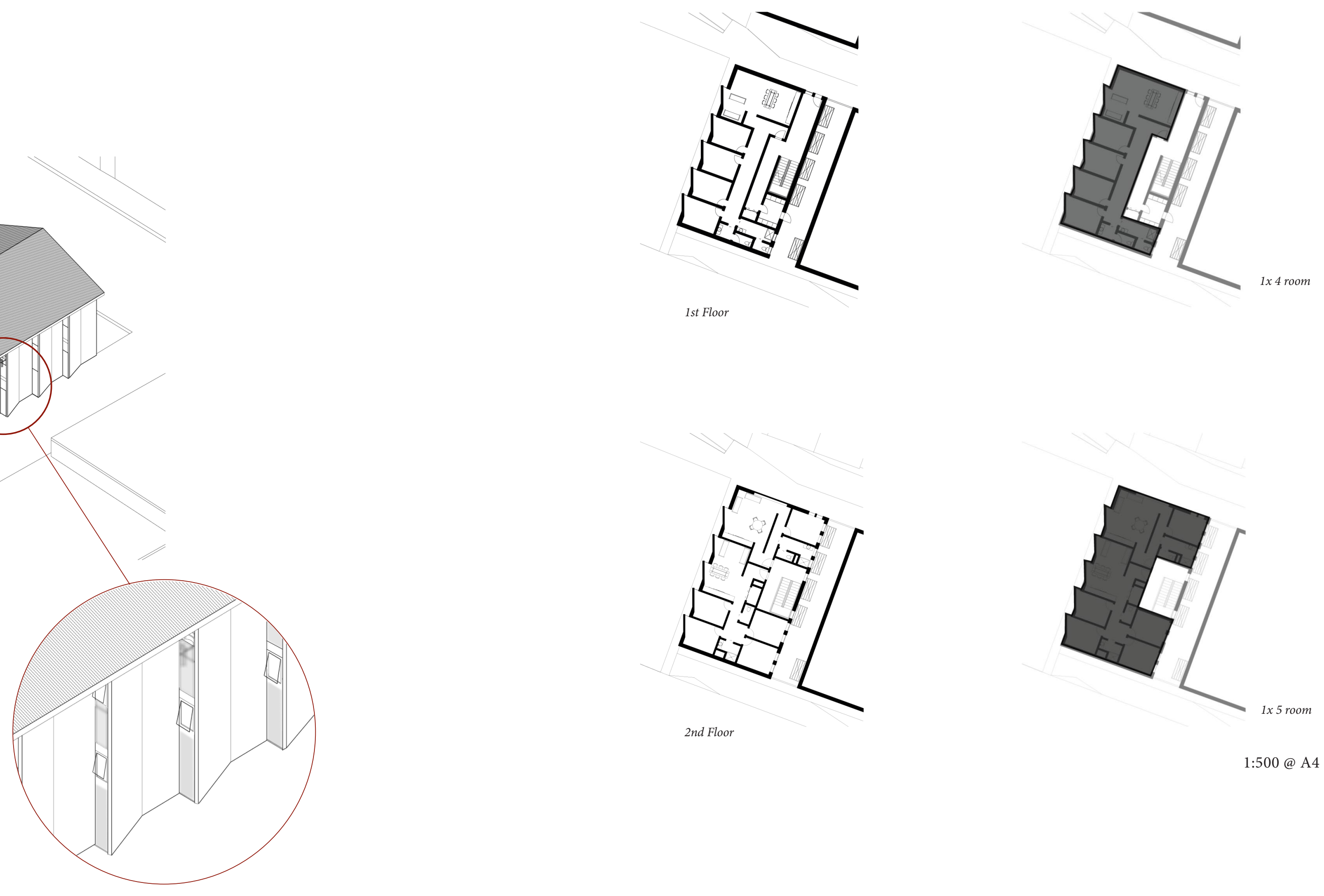

1:500@A4 


\section{TYPE B - ITERATION}

HIDDEN BALCONY AND HIGH WINDOWS

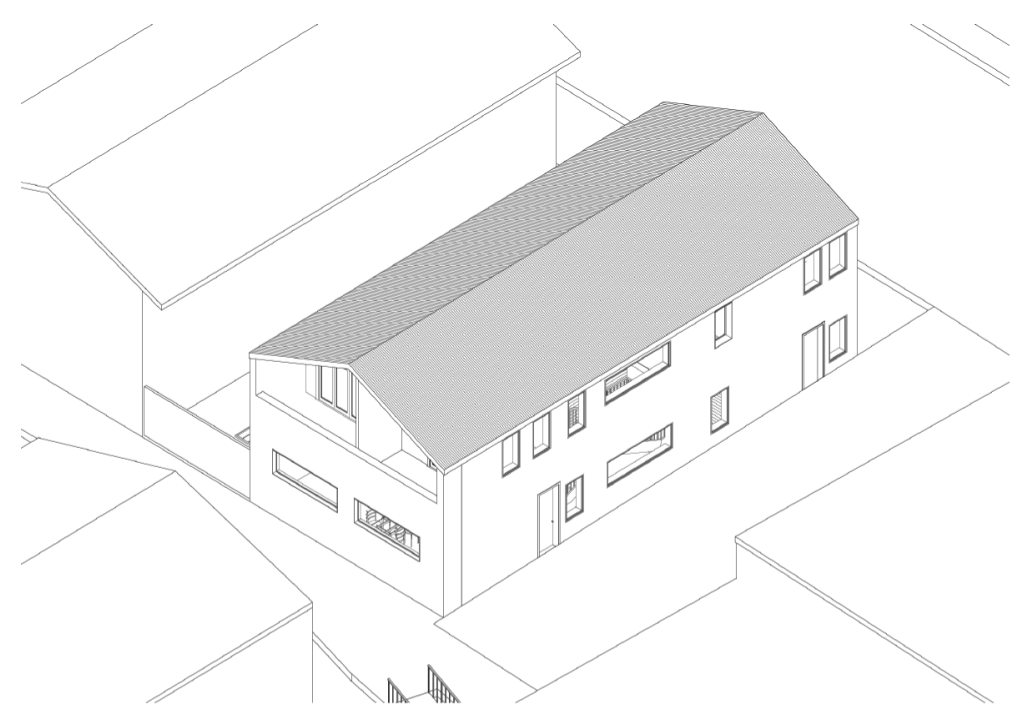

Figure 5.58: Top: Isometric view, Bottom: Perspective of Type B from street

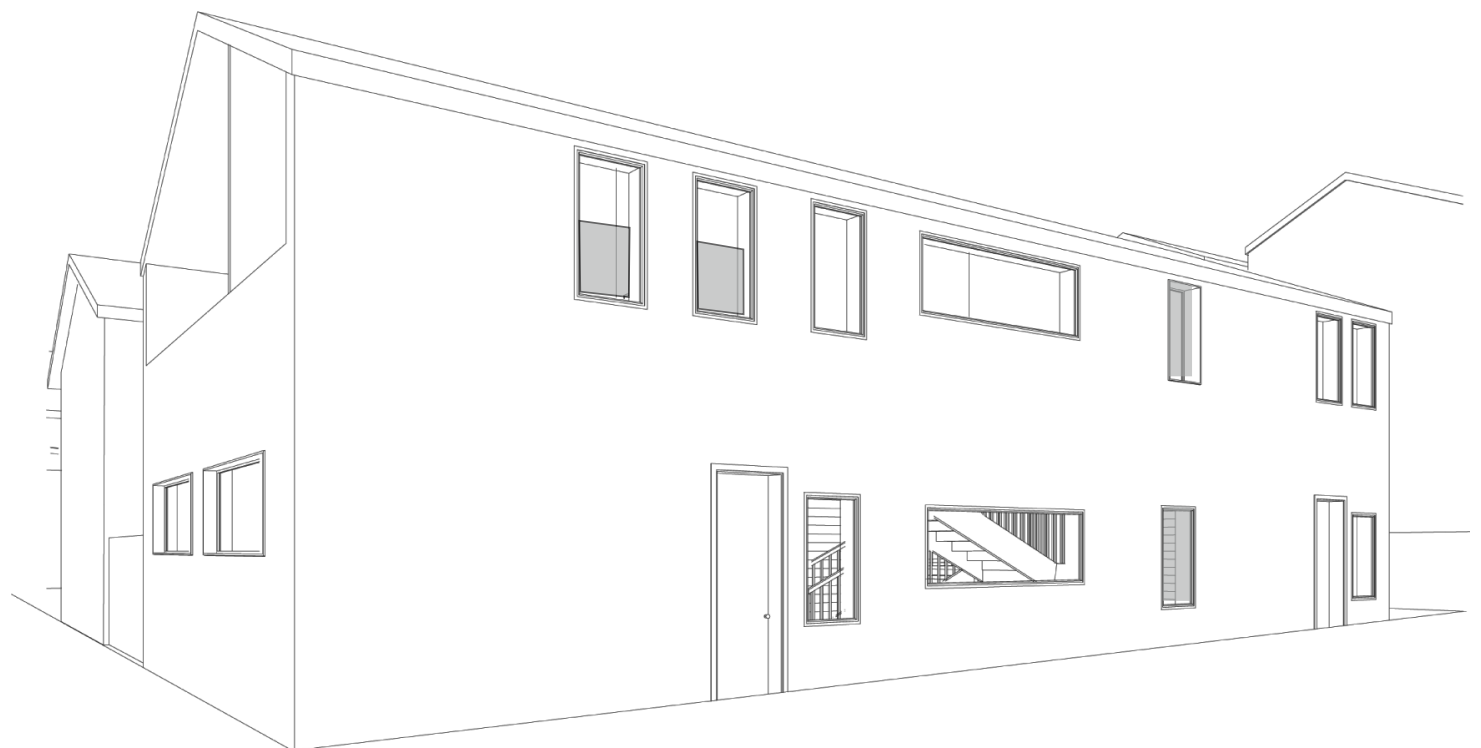

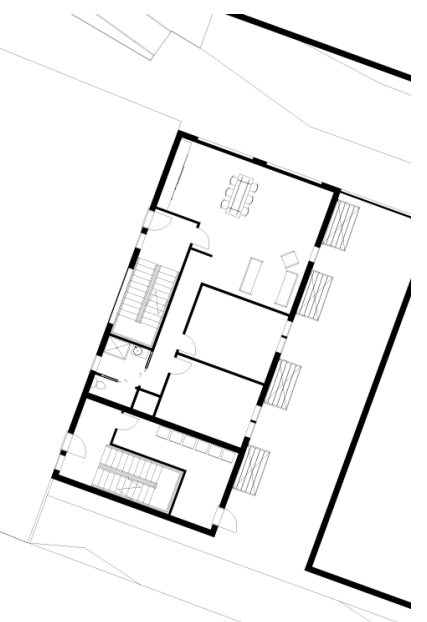

1st Floor

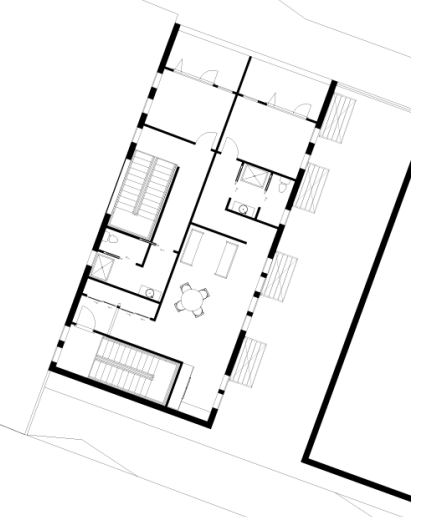

2nd Floor
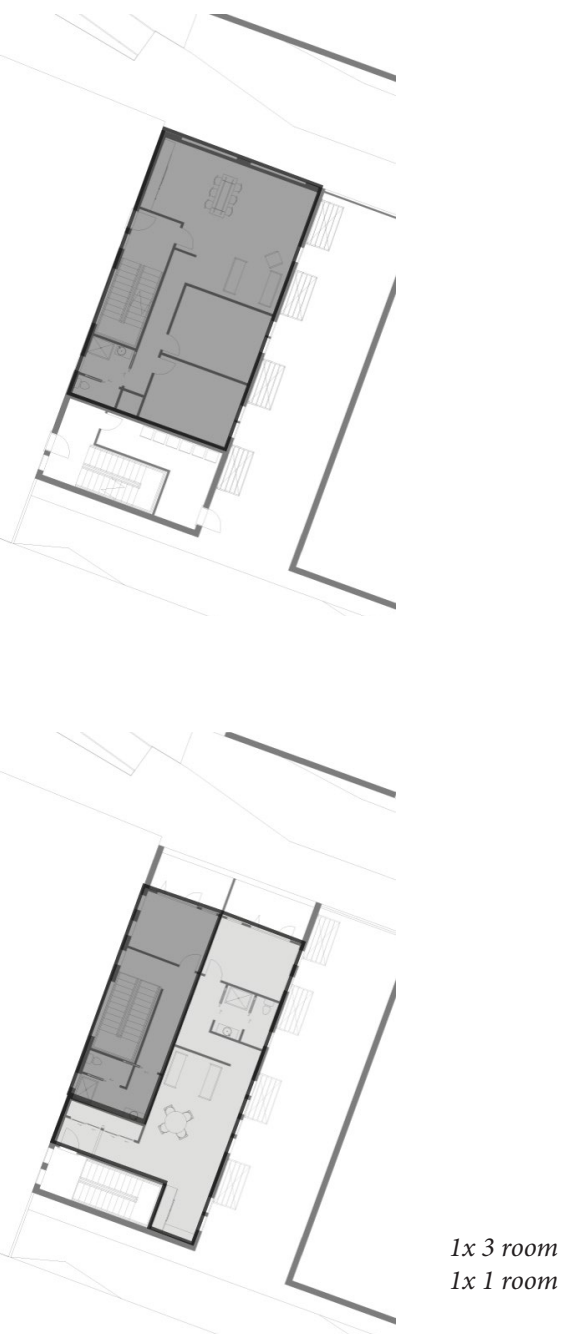

1:500@ A4

High windows with 50\% frosting where spaces

are more private e.g. bedrooms. Non-frosted in

access spaces (accessible stairs). High windows

on ground floor for maximum light into living/

kitchen/dining while maintaining privacy. 
TYPE B - ITERATION 4

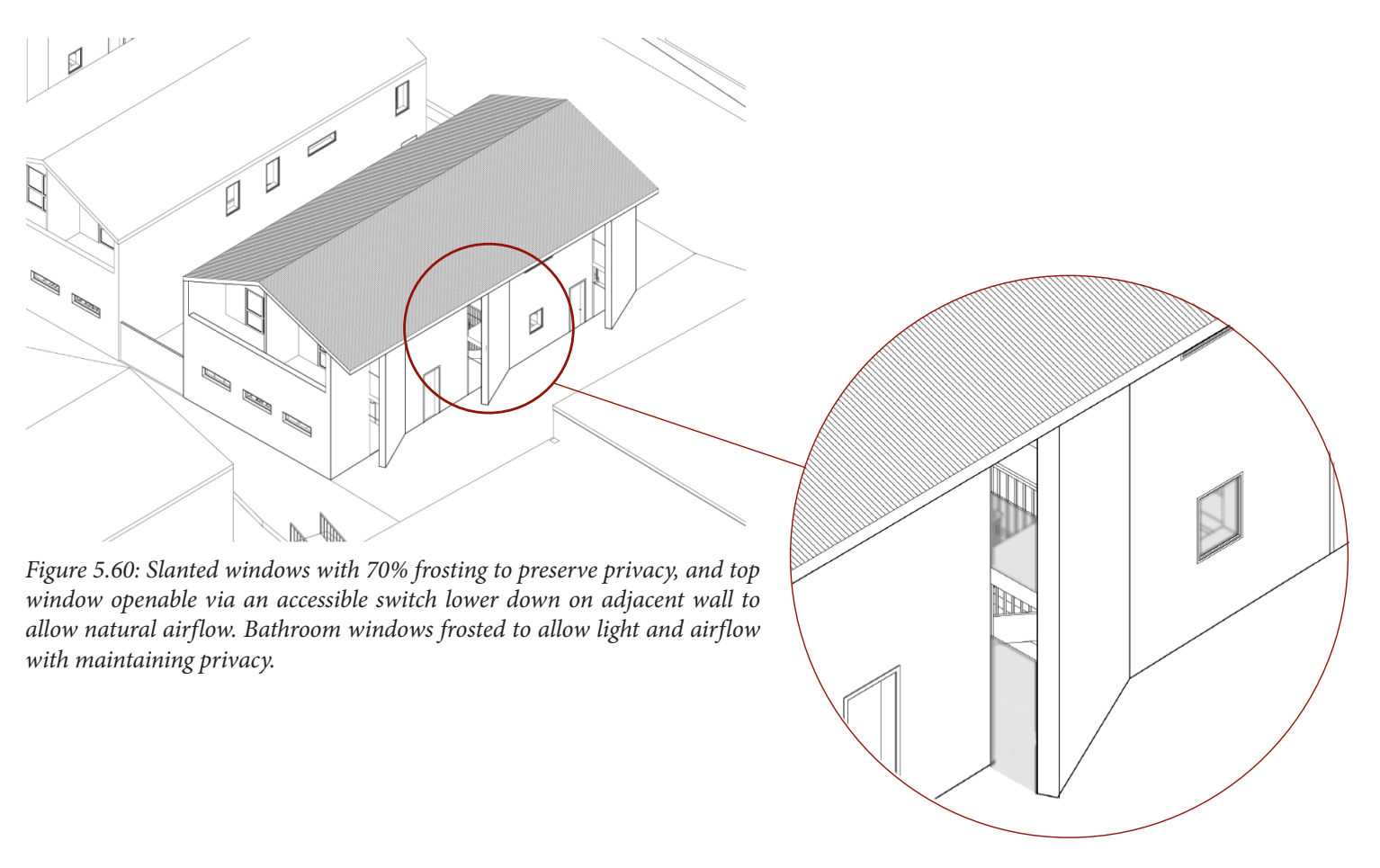

Final iteration successfully balances natural

light, self-adjustable airflow and privacy

through careful consideration of windows

Accessibility and cultural inclusivity is glazing. maintained through spatial planning and managing privacy.

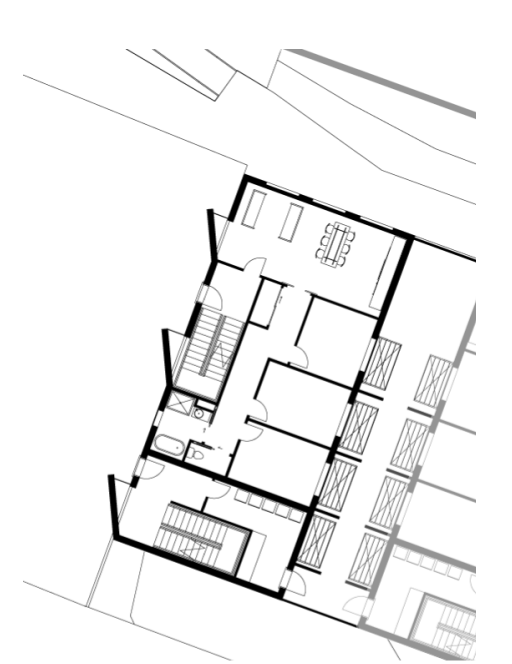

1st Floor

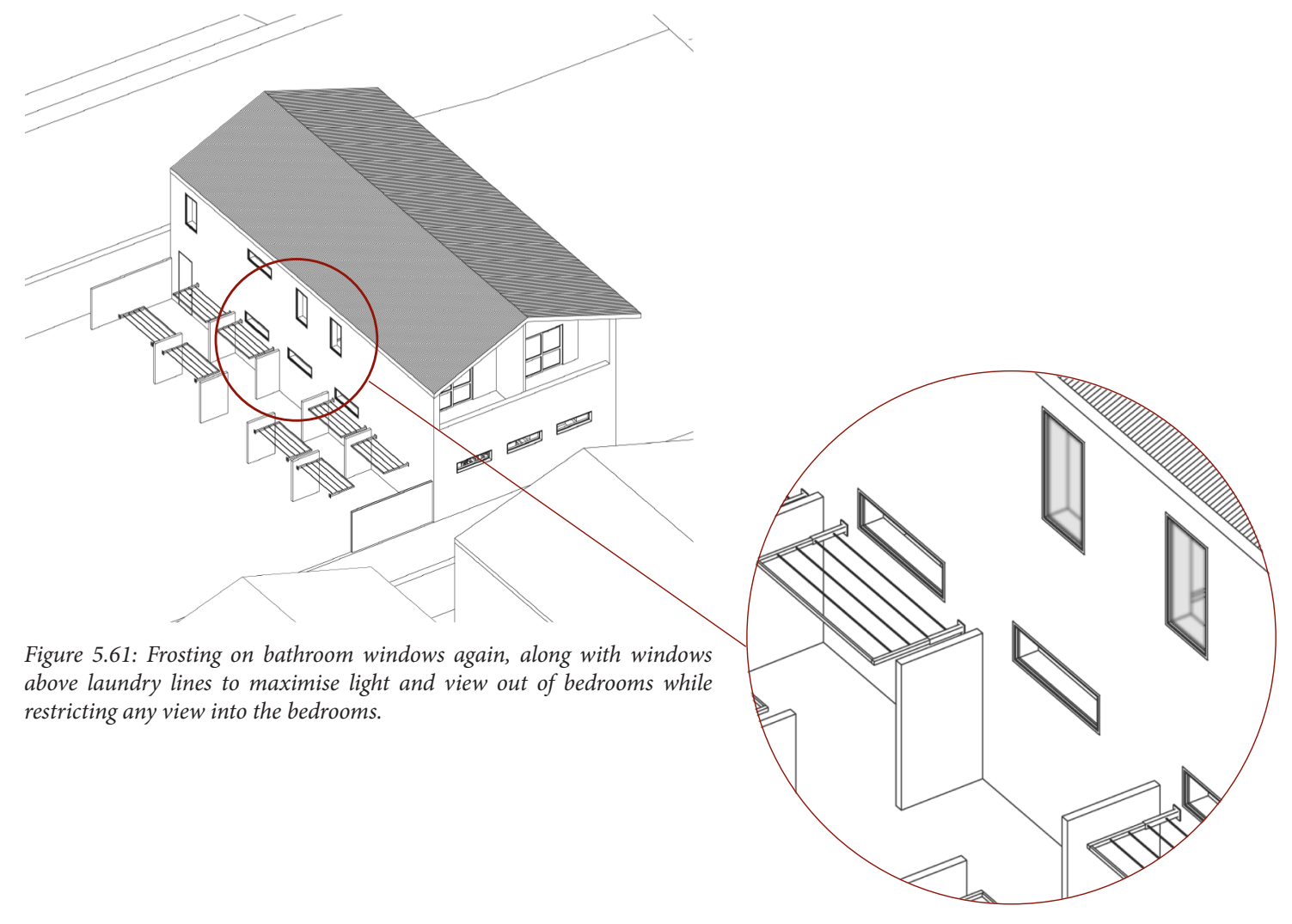

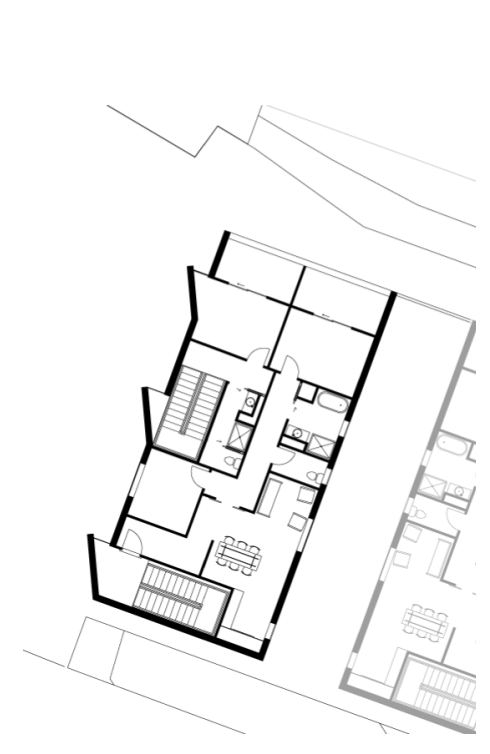

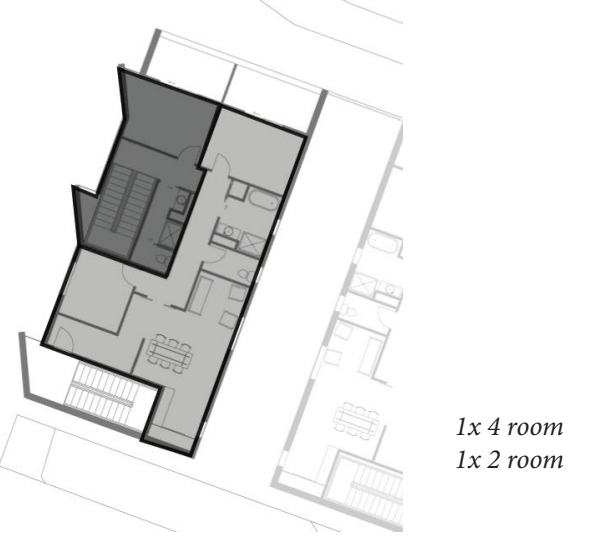

1:500@A4 
Internal Street Overall

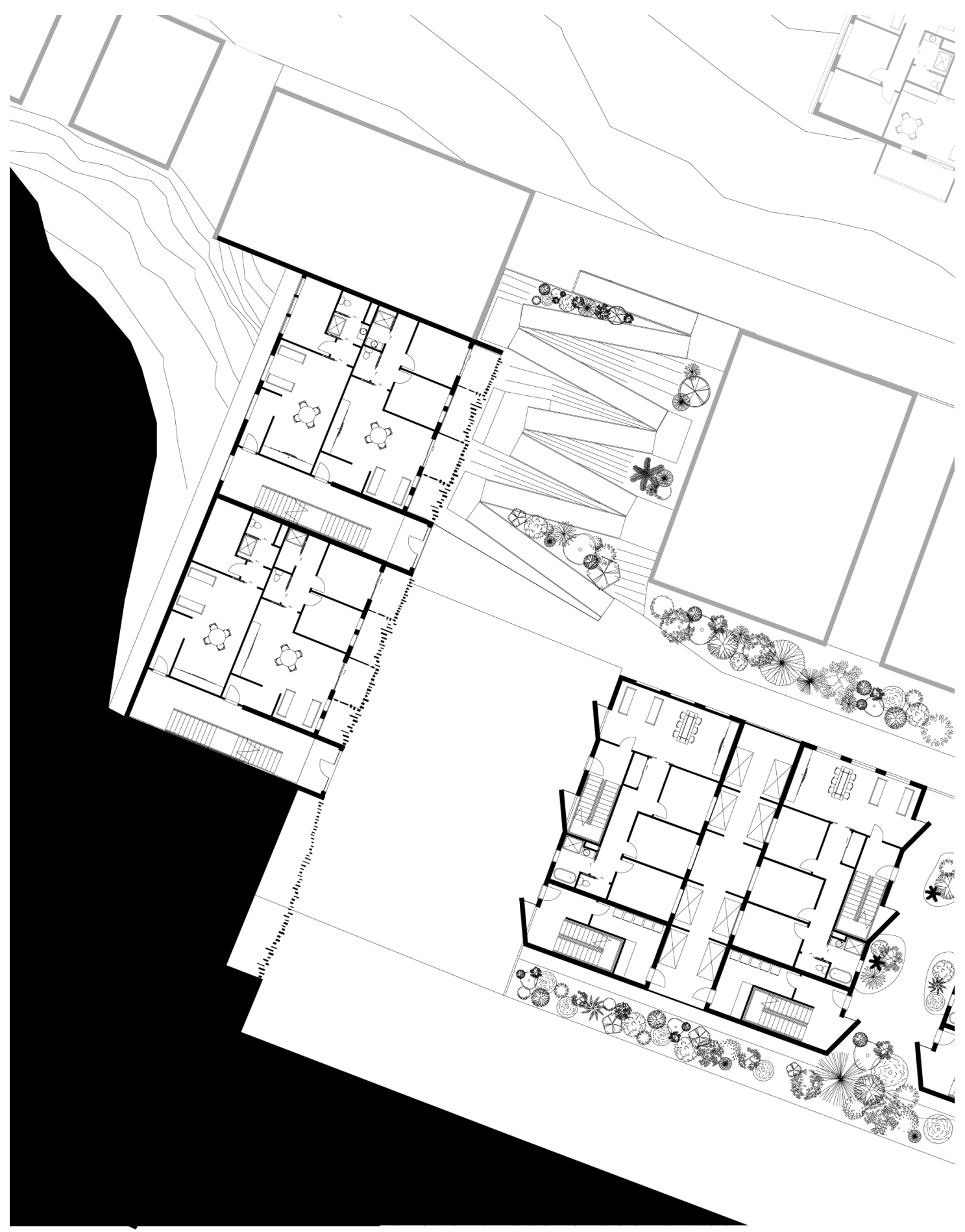

The internal street provides an accessible link between the upper and lower area of the development, along with providing a space for residents to connect. Within the internal street, an apartm defined (Type five room dwellings and shared laundries. Type $\mathrm{A}$ and $\mathrm{B}$ are to be repeated where appropriate along the internal street, with access to each dwelling considered. Wide connections between Hankey St and the internal street are designed to provide safe access routes for residents through passive surveillance techniques. This is also utilised in the glazed entrances and internal walkways in each building.

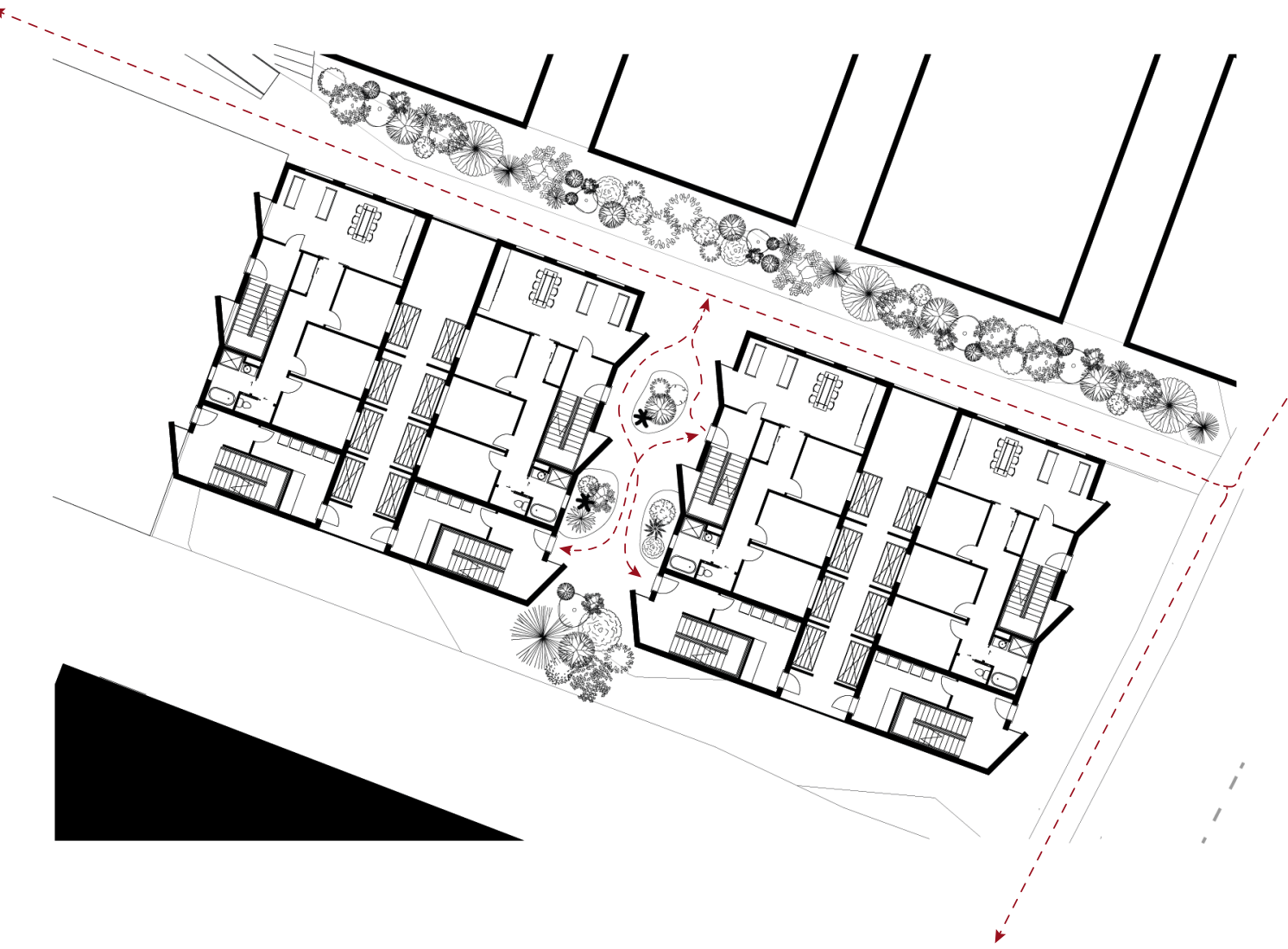


North East Courtyard

The North East Courtyard will be designed similar to a European Piazza, where people will gather and be overlooked by the surrounding buildings. Due its less sloping topography and direct connection to the city side of the development, majority of the interior communal facilities will be located here. This is also for ease of access for Te Mara residents. The proximity to the street is a challenge for all 4 of the buildings. In order to make the most of the courtyard space and maximise privacy, the buildings are either elevated from the ground or the ground floor is utilised for non-residential

space as shown below.
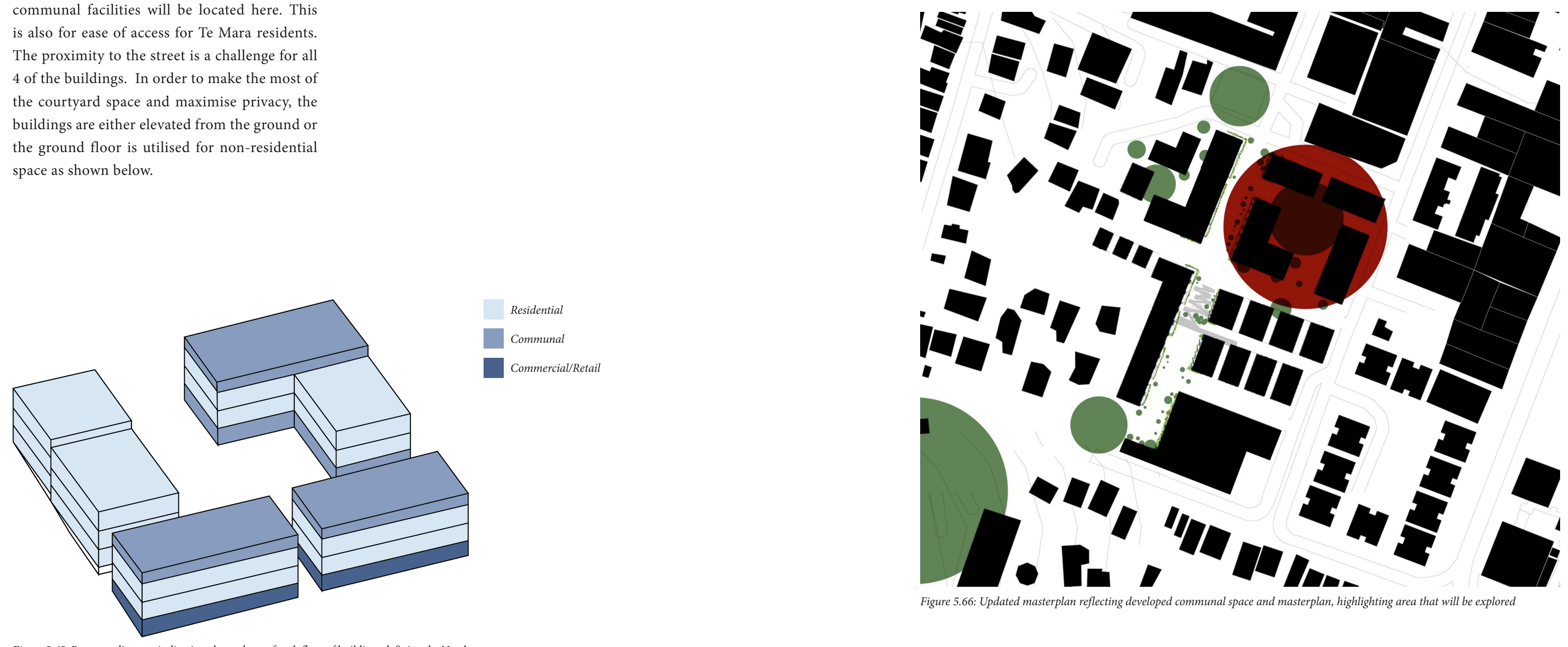


\section{Piazza Design Options}

The North East Courtyard may be designed in a

variety of ways as these tests indicate, however

the surrounding buildings should define the use

in greater detail as they hide and reveal space.
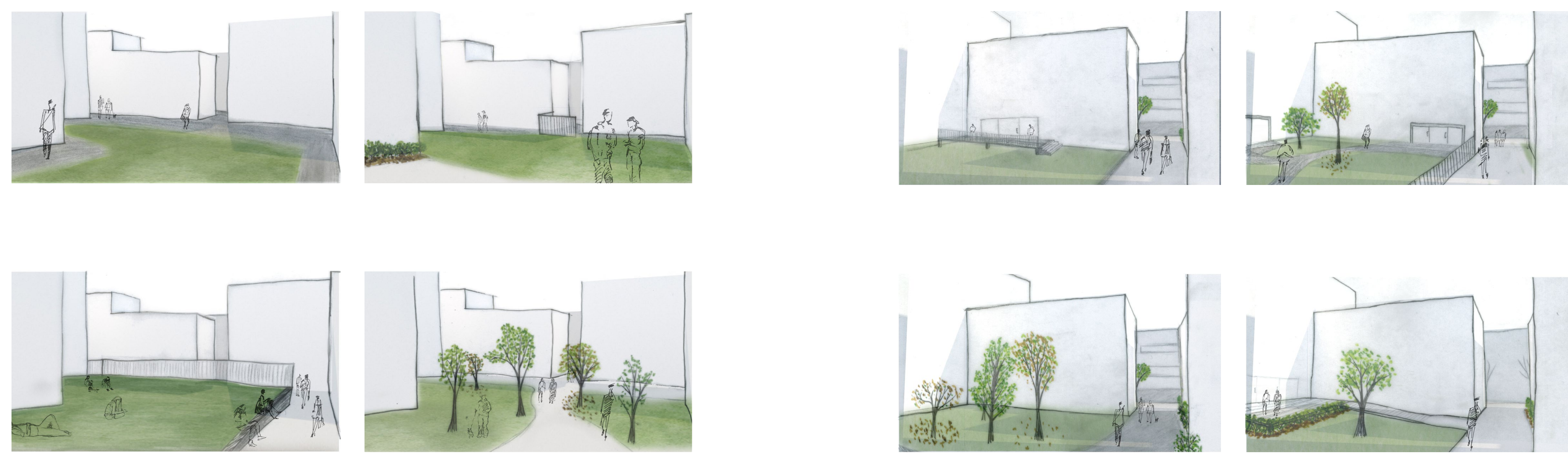
NORTH EAST COURTYARD UNITS

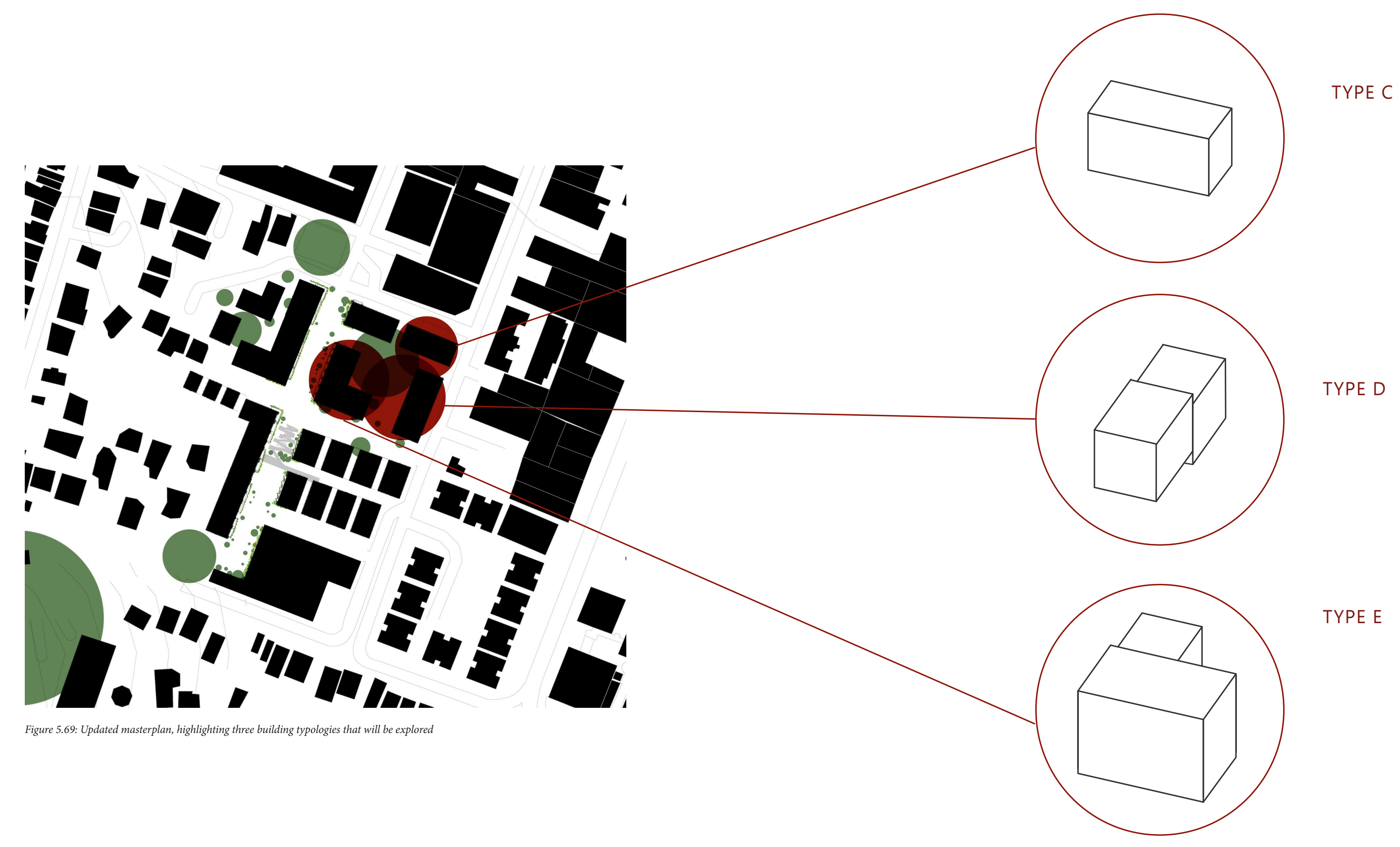




\section{TYPE C}

Type $\mathrm{C}$ is a four storey mixed-use apartment block. Being on the flatest area of the site, the ground is to be utilsied as retail/commercial space in order for the two residential floors

to be more private. The top level is used for residential and holds a laundry and drying space. to be used by the buildings residents.

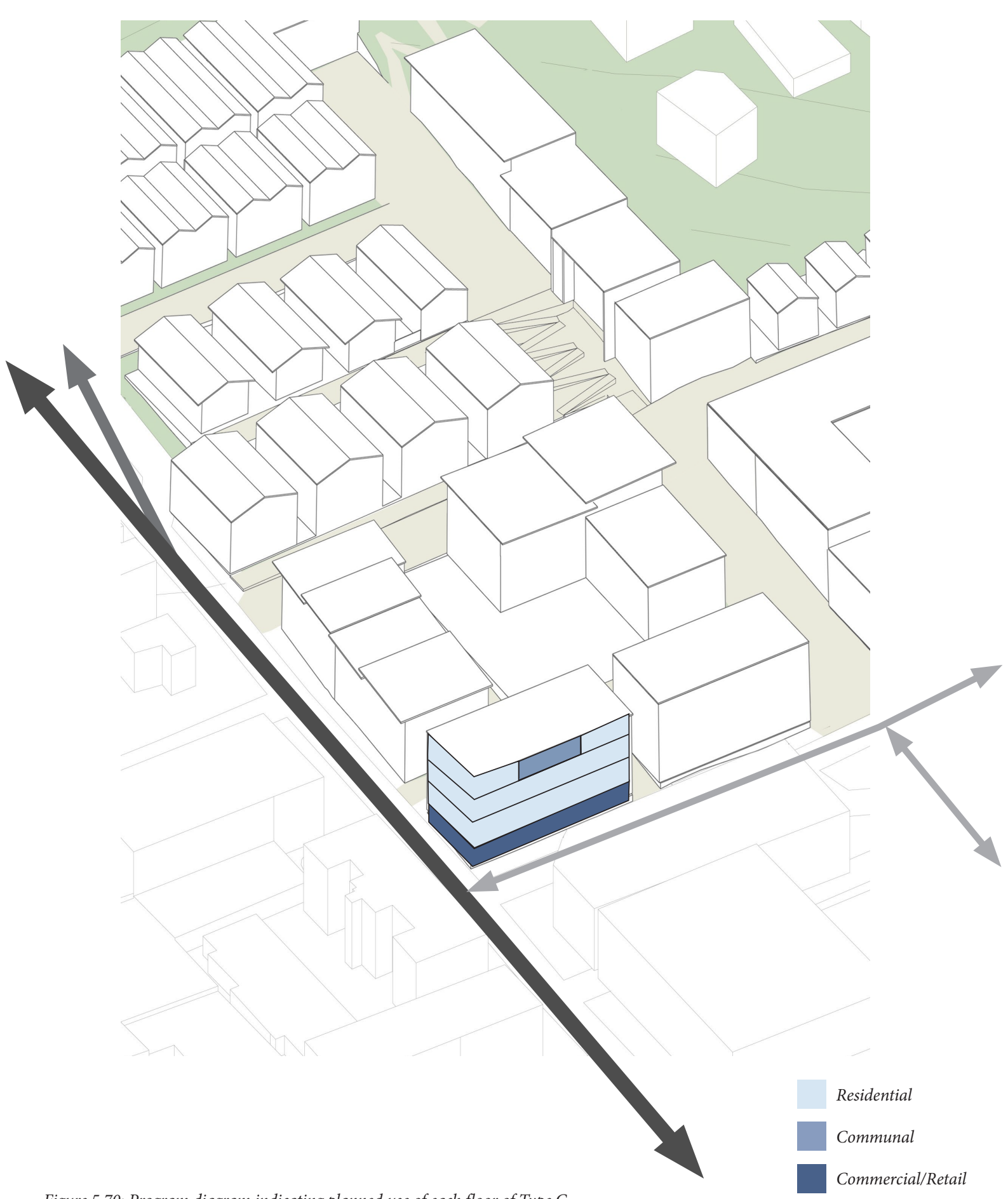


Reside n tia I Options
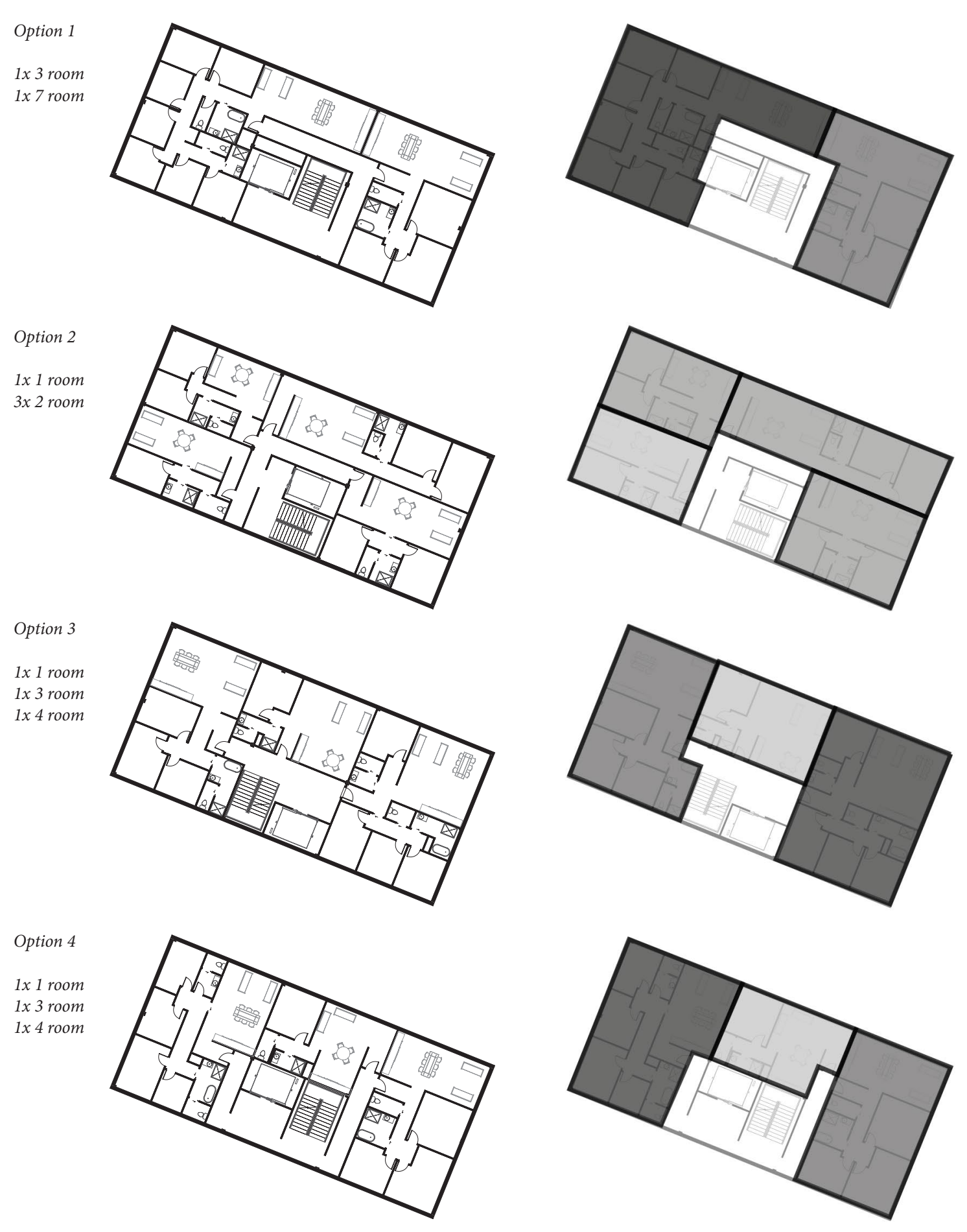

Figure 5.71: Type C spatial layout options ranging from one-seven room units

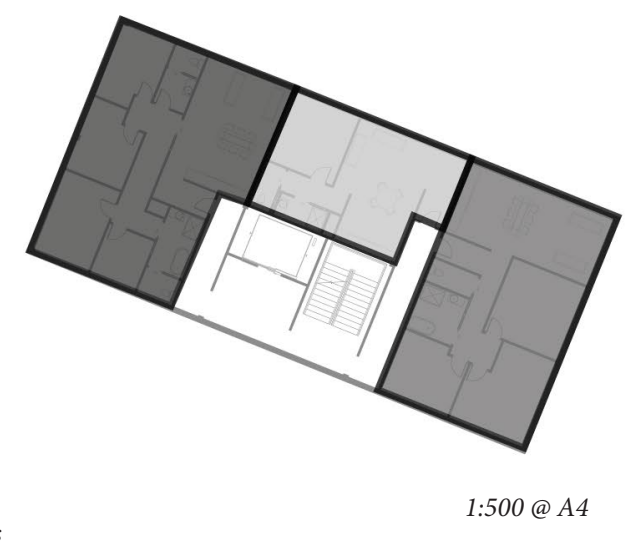

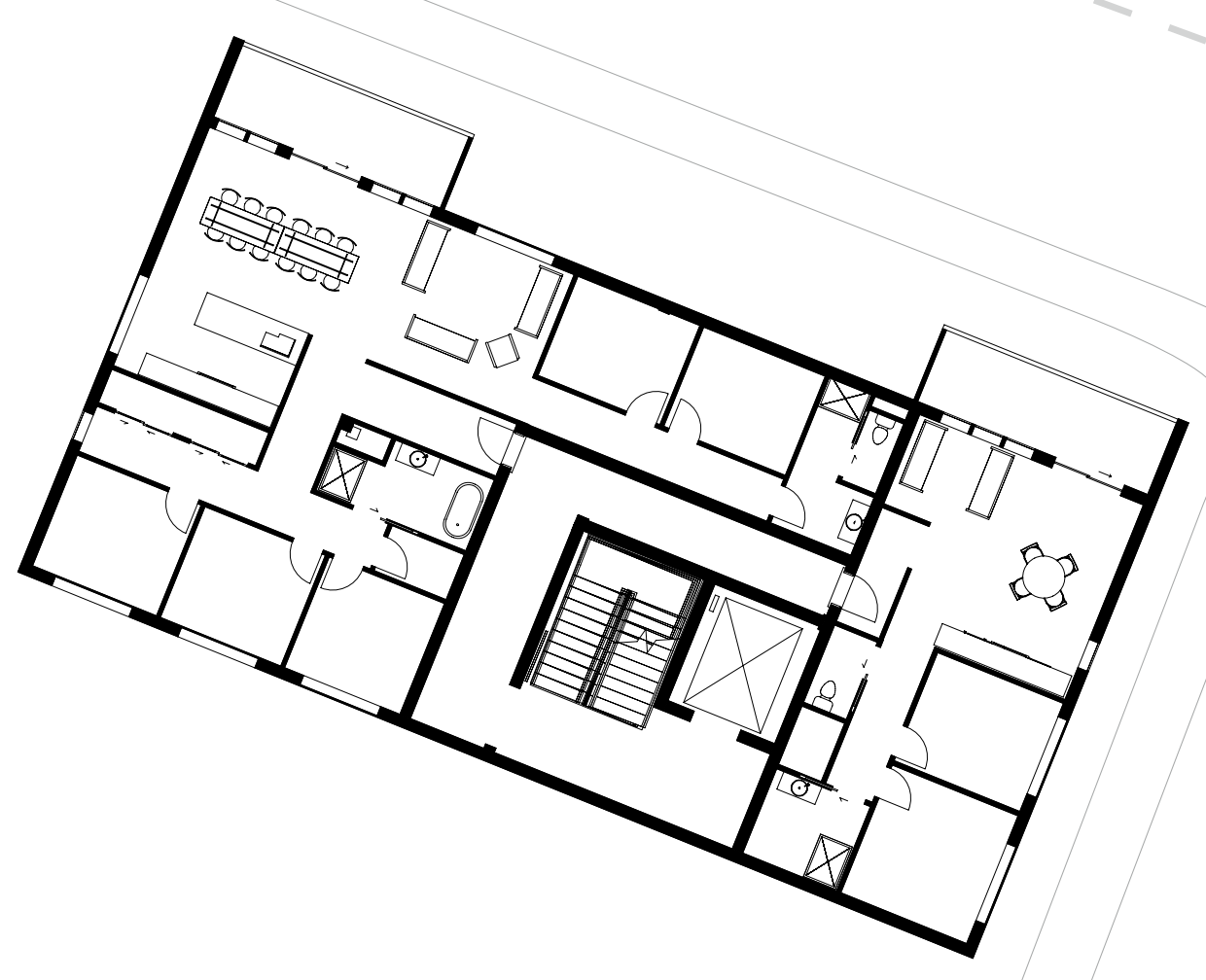

1:300@A4

Figure 5.72: Resolved Type C spatial layout with balconies and windows considered. Facade design consistent with initial design tests and
lessons learnt from Type A and B. 
Retail Layout

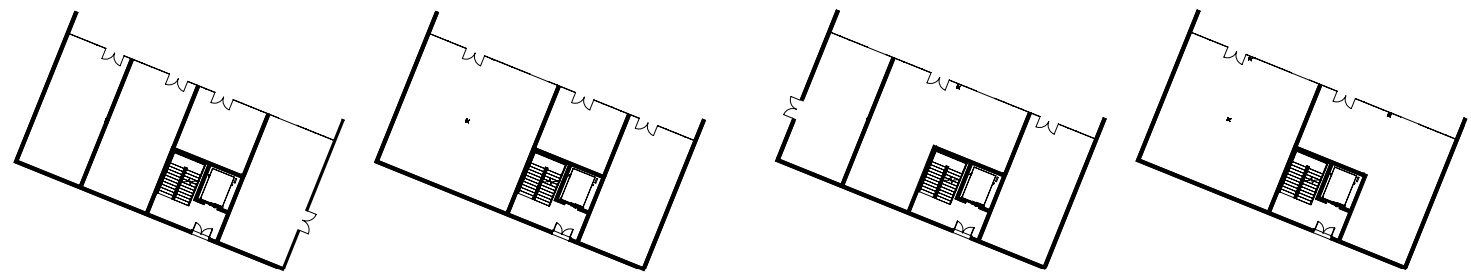

Figure 5.73: Range of ways to define retail/commercial spaces with constraints of structural grid.

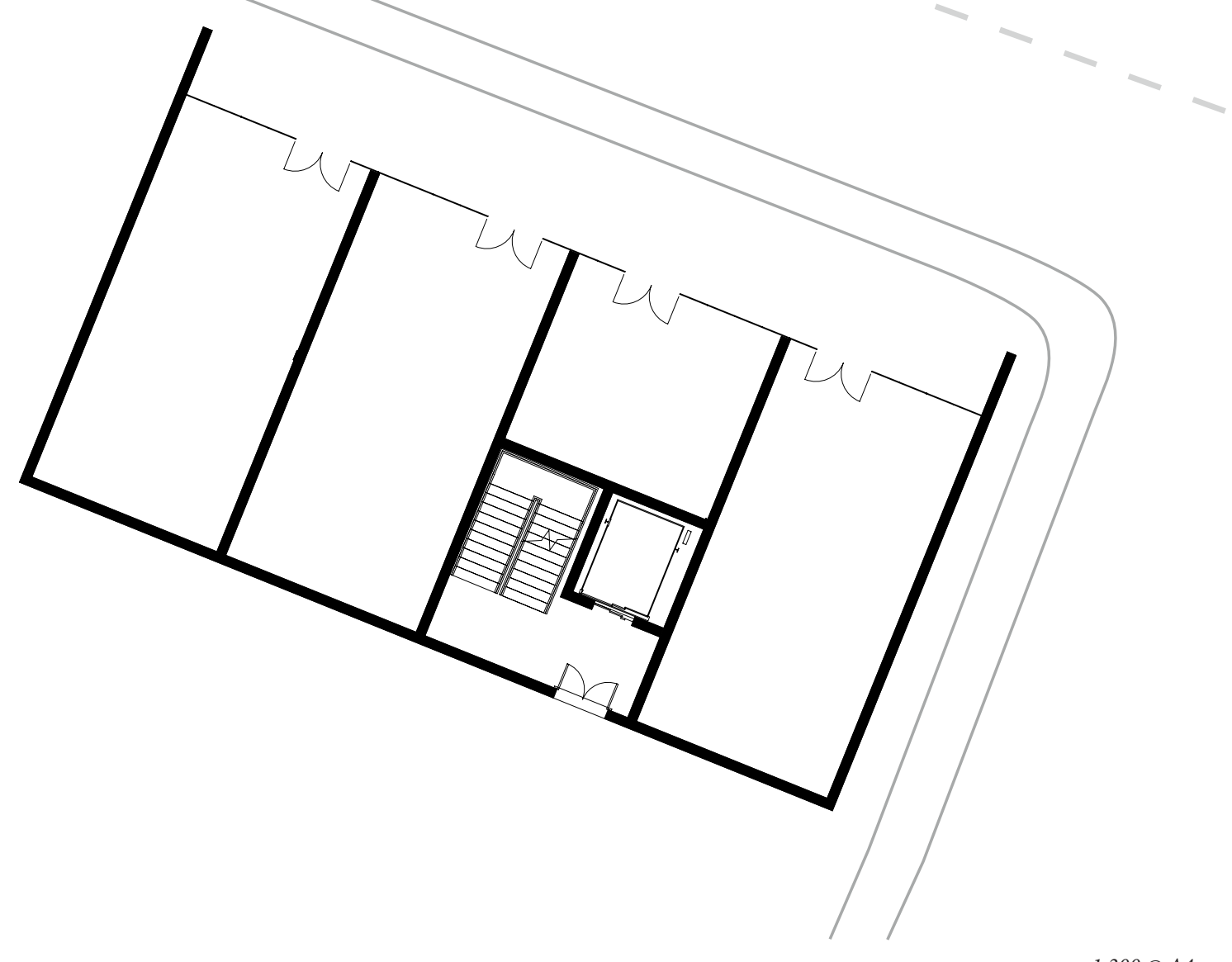

Top Floor Layout:

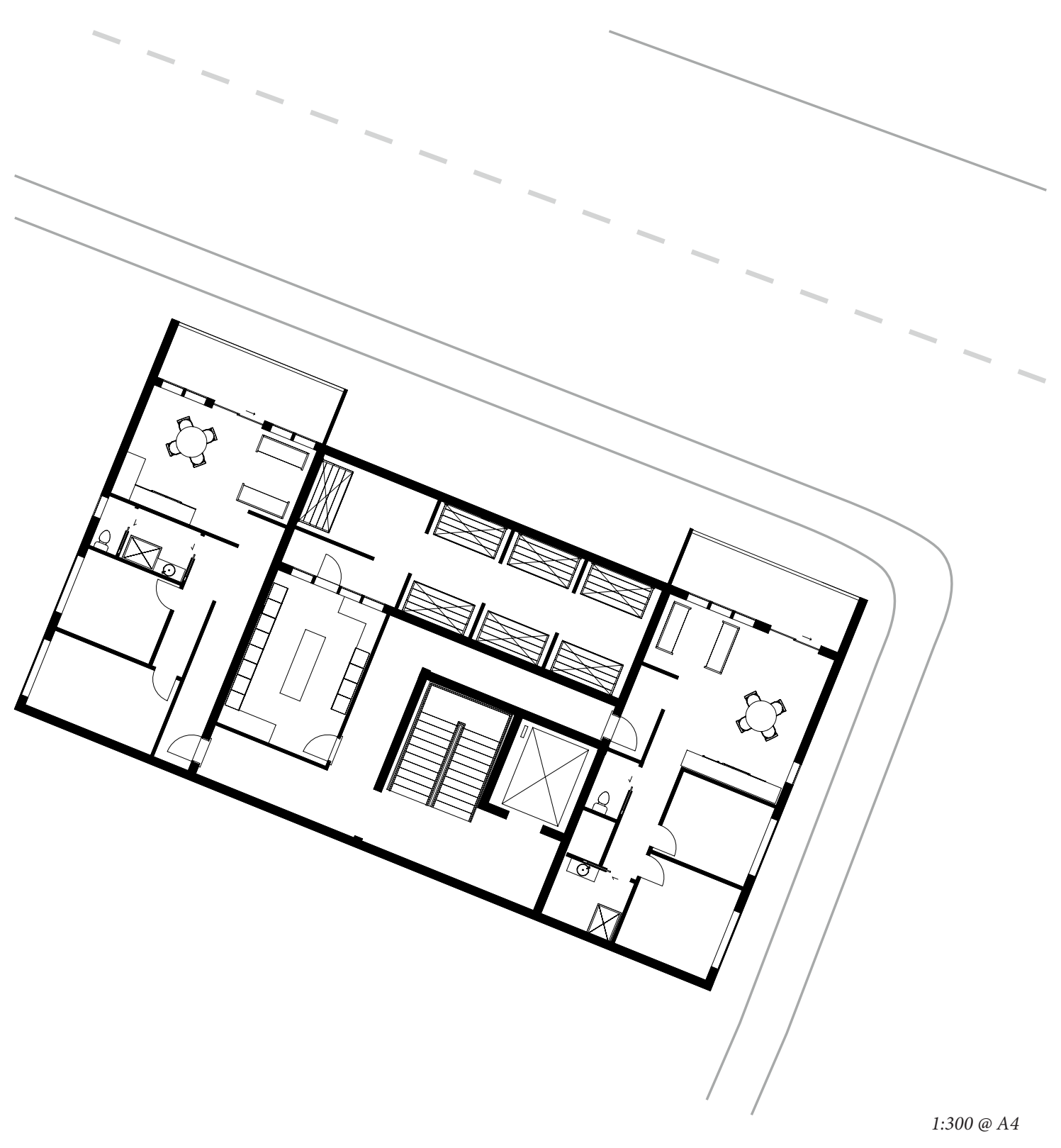


TYPE D

Type D is a three storey apartment building split into two sue to the topography of the site. To maximise privacy of the dwelligns from the street, both buildings within Type D have been elevated from the street. A broken up roof will also make the building read as less of a single mass from the street. This design is also a response to Te Mara Apartments on the other side of Hankey Street.

The use of enclosed balconies and high windows will also provide significant privacy to each dwelling.

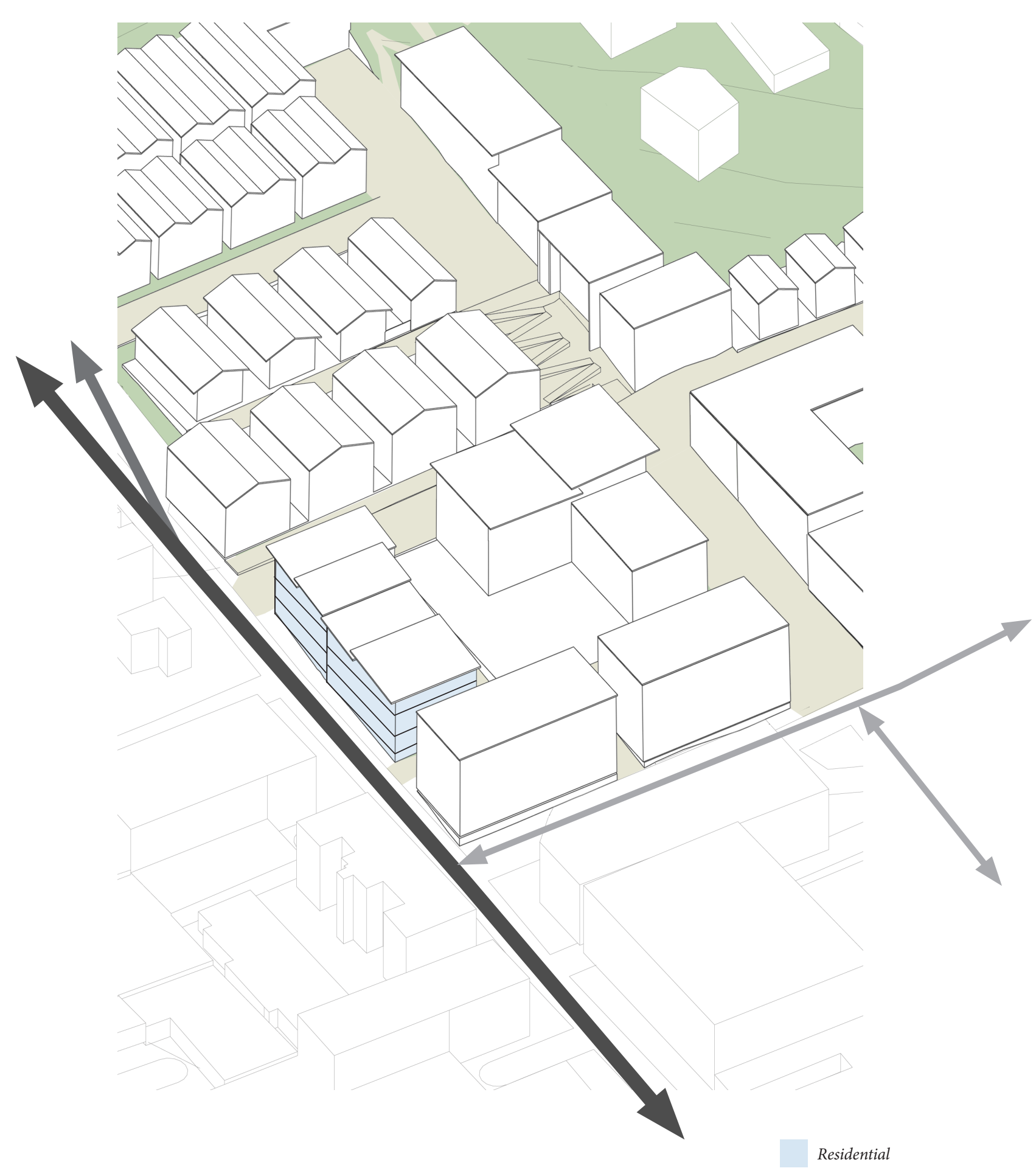

Figure 5.76: Program diagram indicating planned use of each floor of Type D 
Option 1

$1 \times 2$ room
$1 \times 3$ room

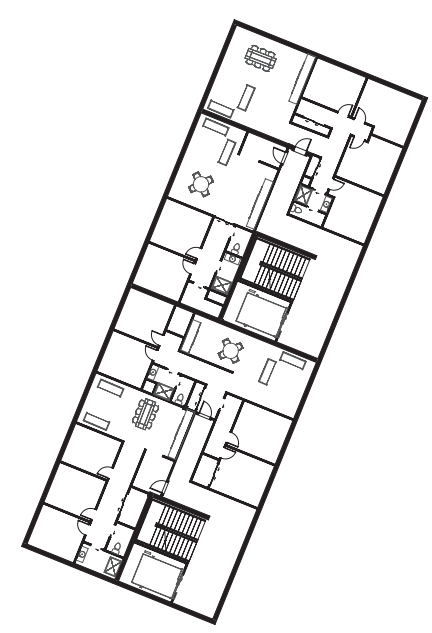

Option 2

$5 \times 1$ room
$1 \times 4$ room

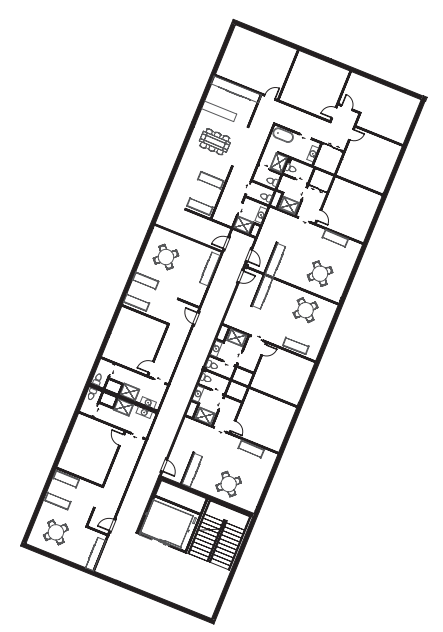

Option 3

$1 \times 1$ room

$1 \times 2$ room
$2 \times 5$
room

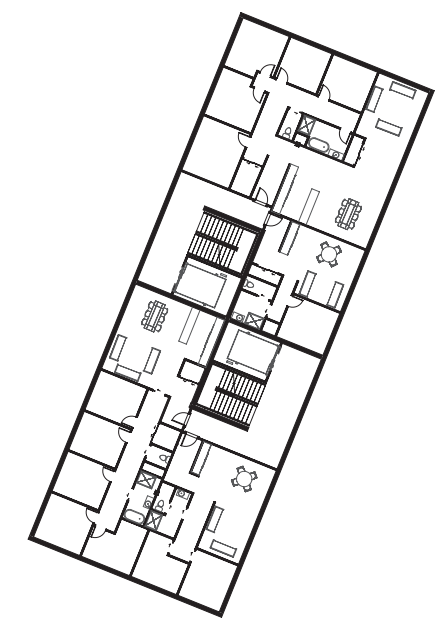

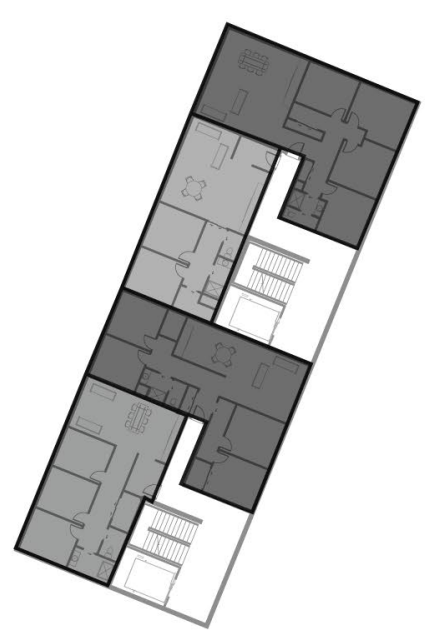
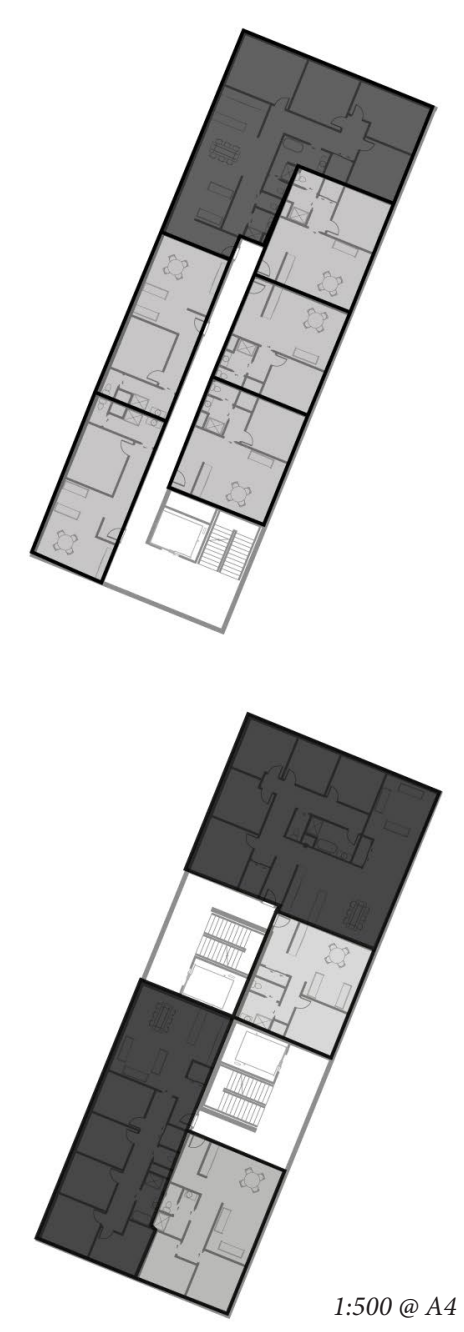

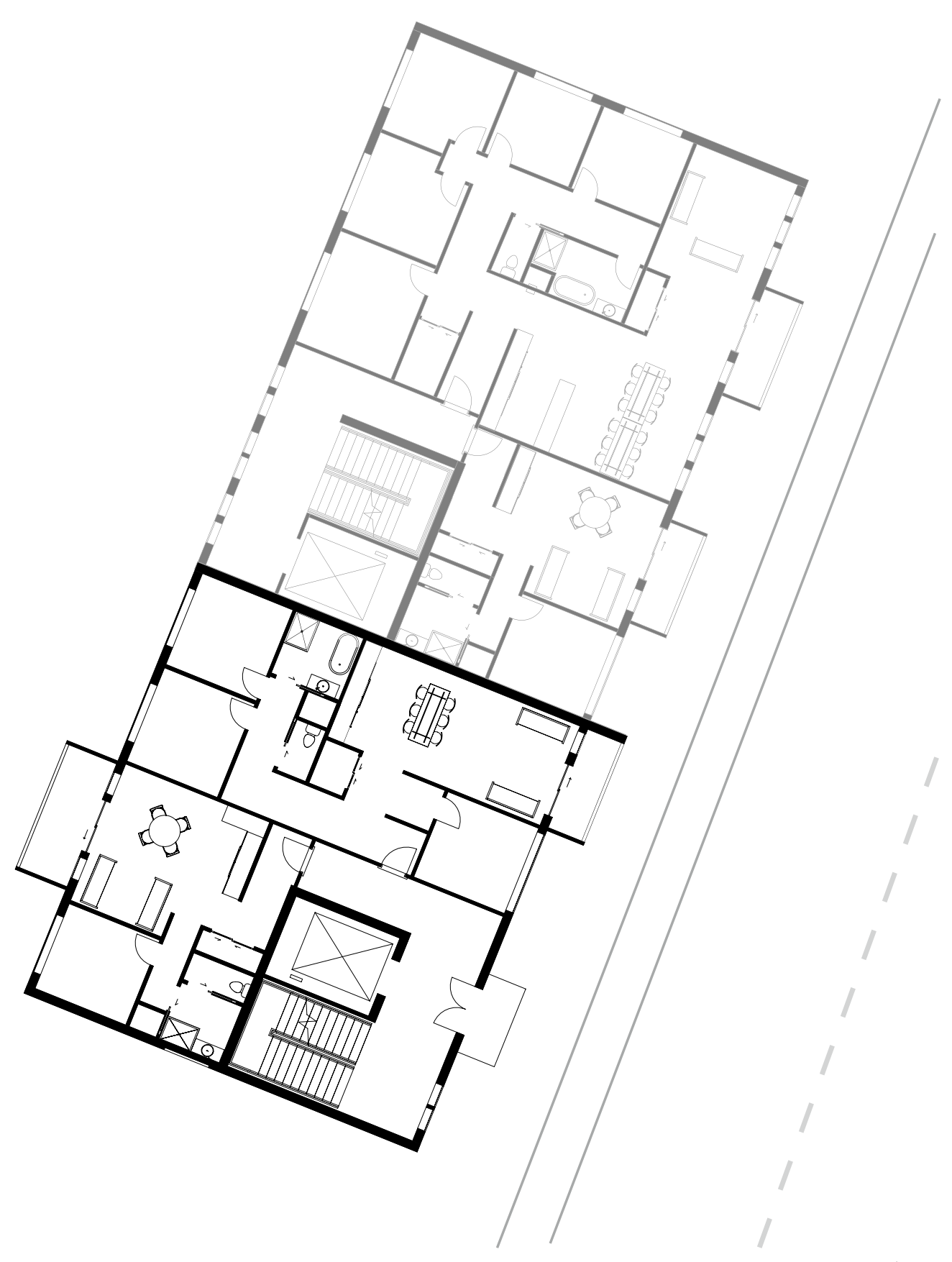

$: 300 @ A 4$ 


\section{TYPE E}

Type $\mathrm{E}$ is the largest of the typologies explored. The ground floor is comprised entirely of communal spaces which to support the development's residents, along with Te Mara Apartments adjacent to Arlington. Middle floors are entirely residential with closed balconies and higher windows to increase privacy. The top floor has an elevated roof to allow airflow into the laundries and communal rooftop.

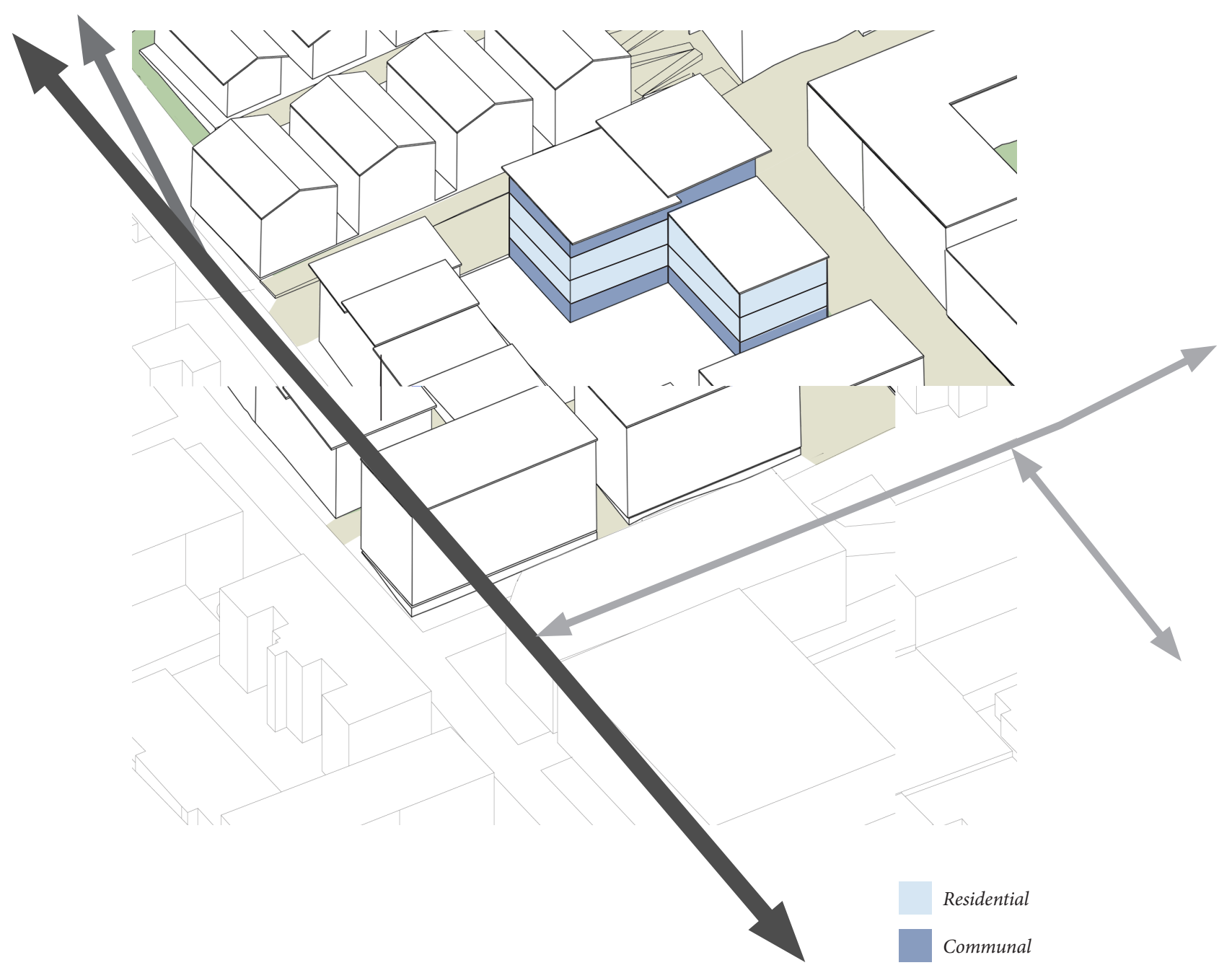

Figure 5.79: Program diagram indicating planned use of each floor of Type $E$ 

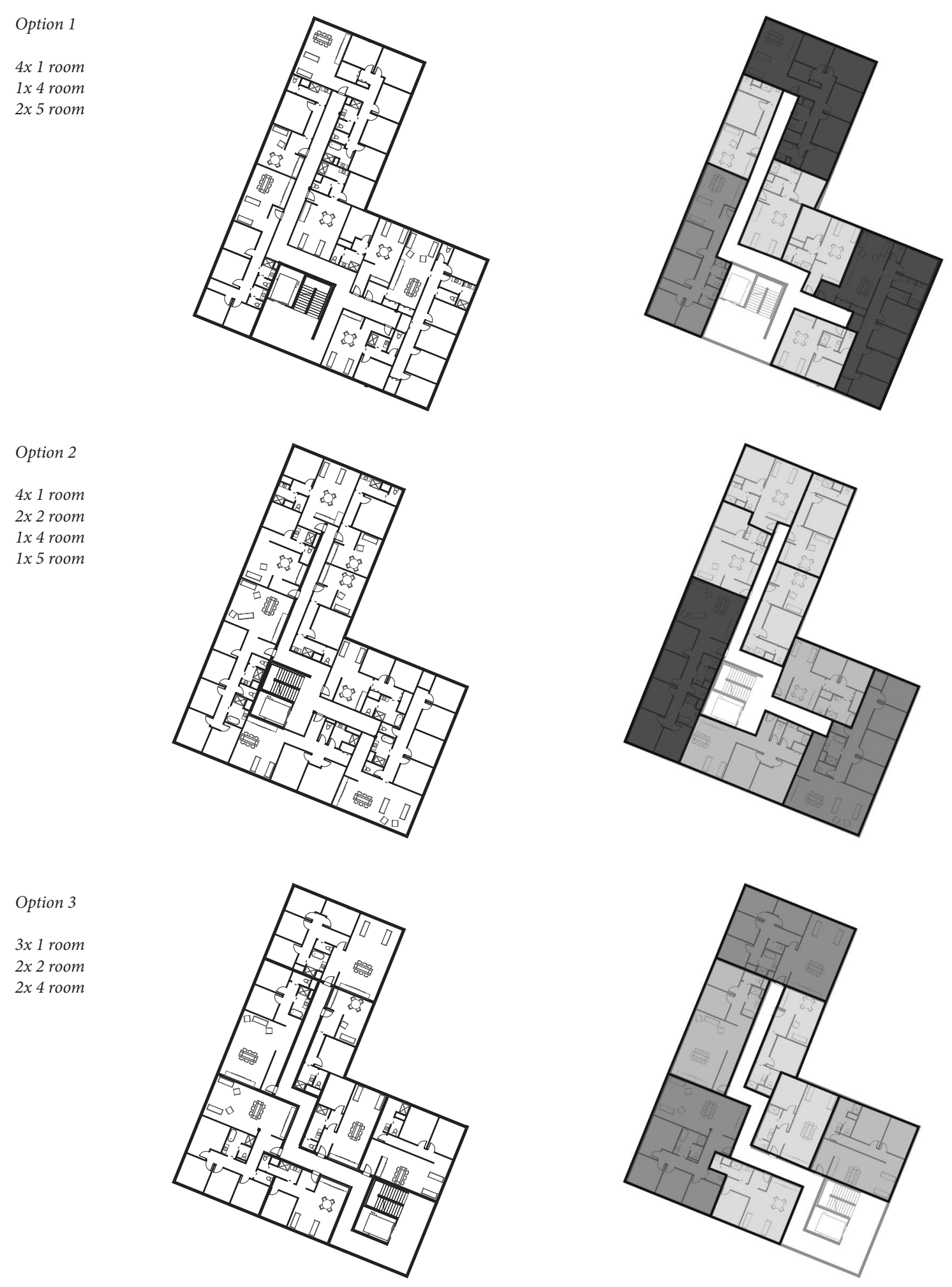

Figure 5.80: Type E residential unit layout options

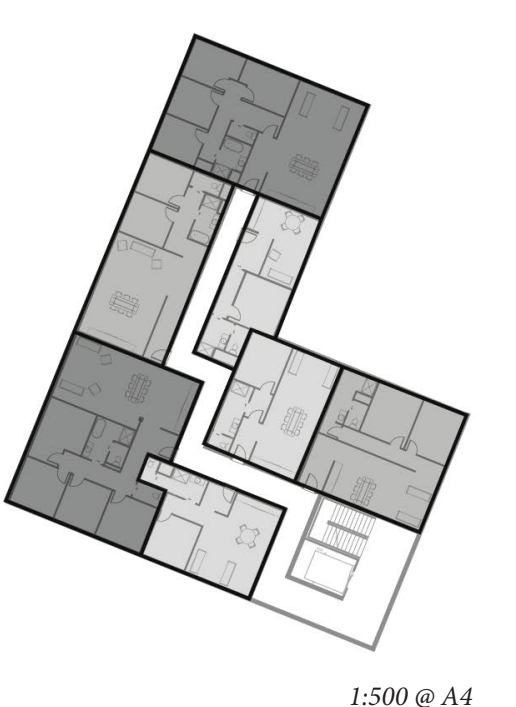

1:500@A4

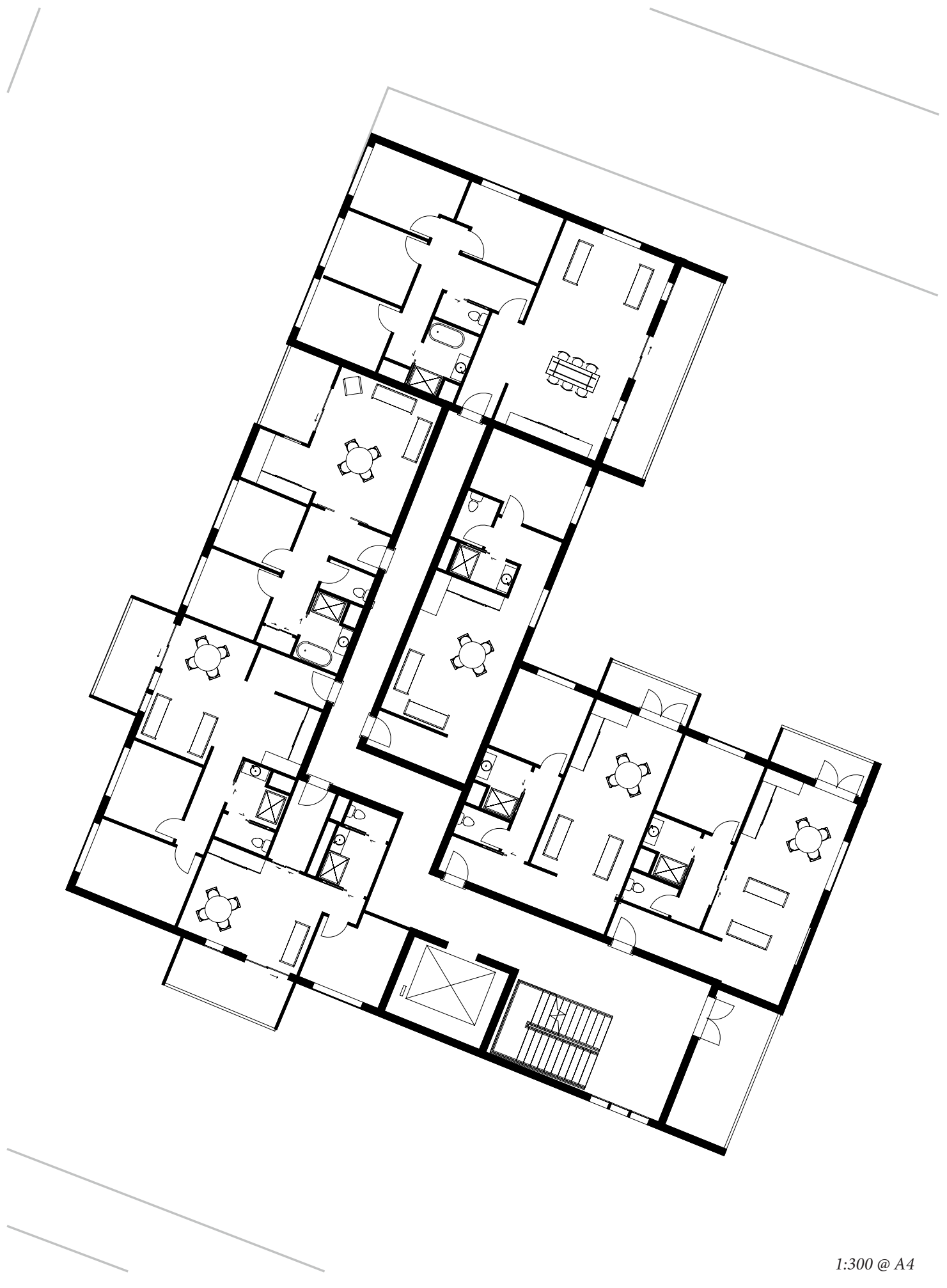

Figure 5.81: Resolved Type E spatial layout with balconies and windows considered. Option 3 adapted to provide one-four room units 
Internal Community Space

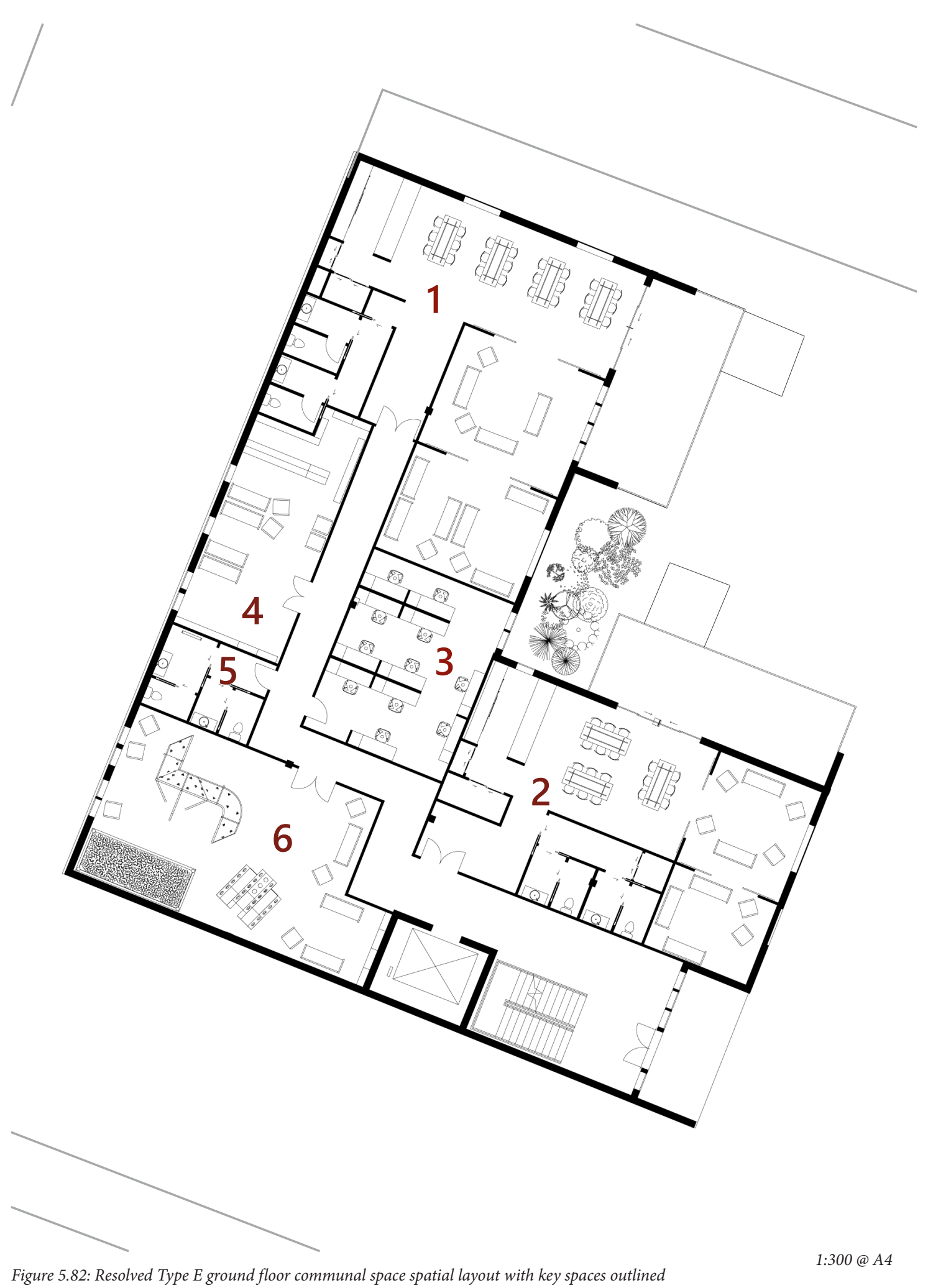

1. Largest Communal Space

Kitchen large enough for three to four to work. Dining space allows for 32 occupants conservatively. Two living areas able to be opened up or closed based on user preference. Outdoor deck to overlook open lawn space

2. Medium Communal Space

Smaller configuration as the large communal space with the dining area accommodating 24 persons.

3. Workspace

At minimum capacity can fit 11 desks, however can be configured differently based upon needs of residents.

4. Library/Reading Room

Alternative space to read or study which is quiet

5. Communal Bathrooms

For use of library, workspace and softplay occupants

6. Softplay

Space for parents with children to connect with neighbours and provide alternative space for play and learning

7. Courtyard

Flat large lawn for flexible use. 
Laundry \& Rooftop Garden

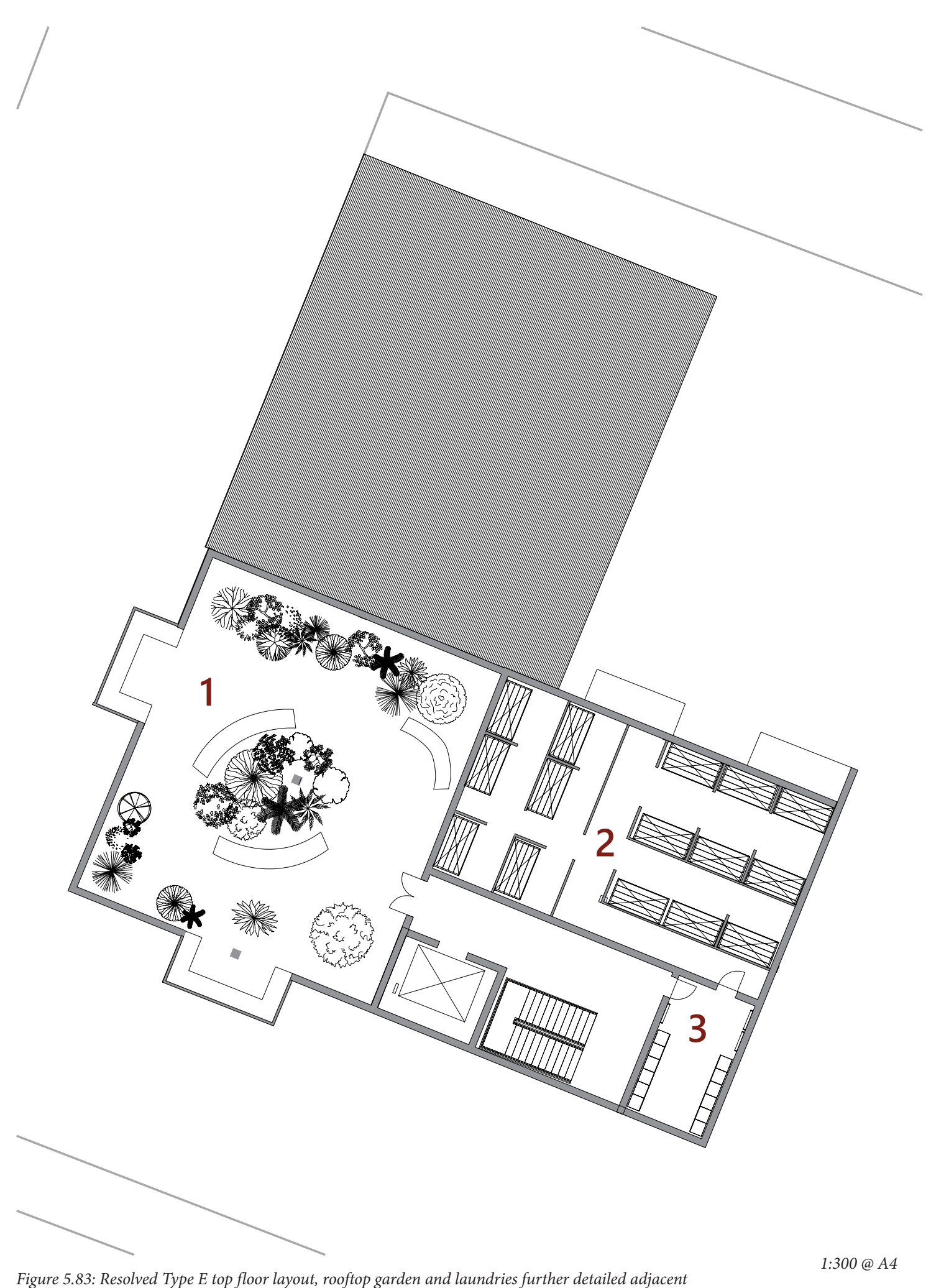

1. Rooftop Garden

Foliage both on ground level and raised up is able to be planted and taken care of and enjoyed by residents while they wait for laundry or as an alternative space to relax or connect. Covered and open to air

2. Drying Room

15 Drying racks, roof elevated for weather cover with natural ventilation

3. Laundry

Washing machines and dryers provided, free of use for all residents 
Courtyard Scheme Overall

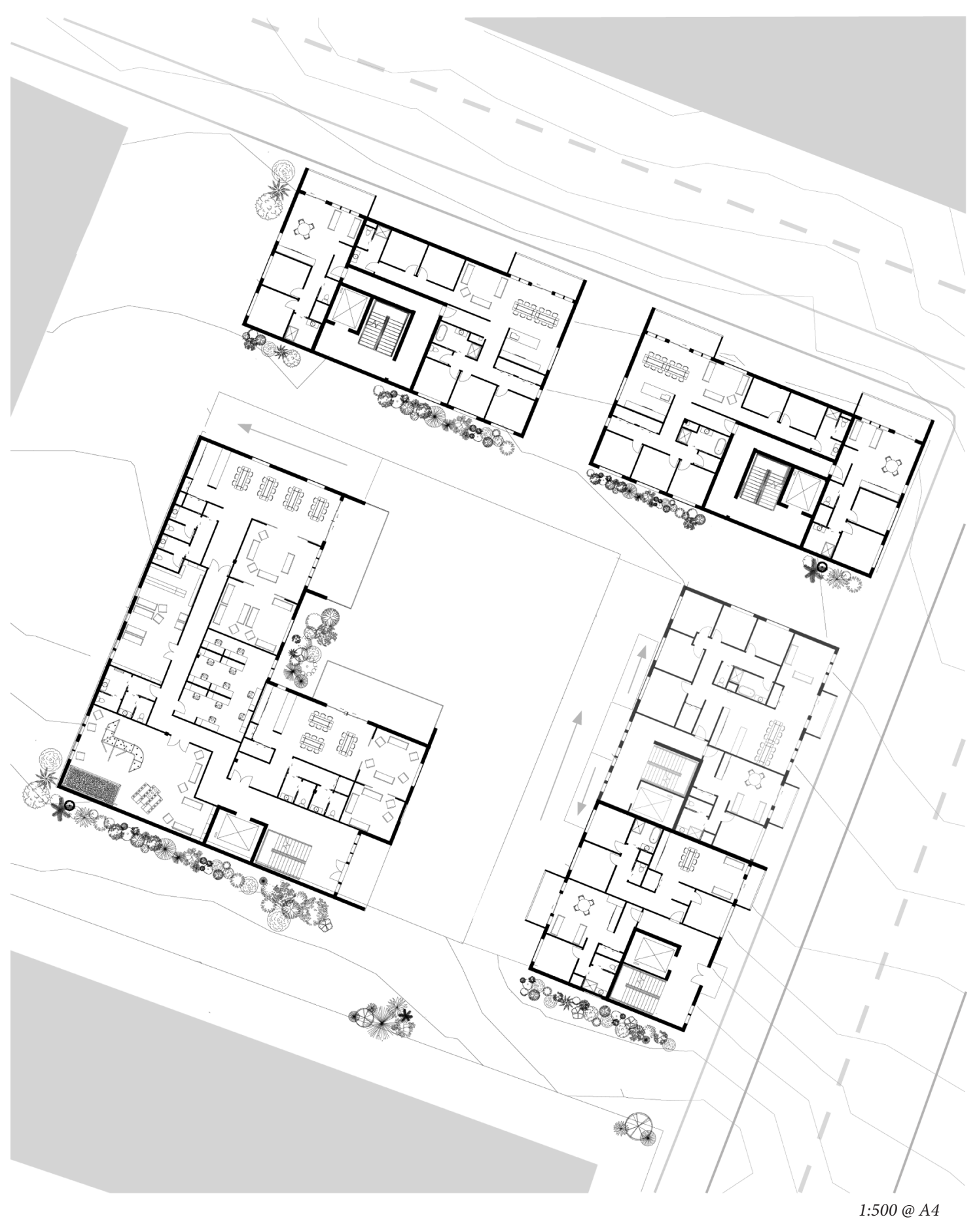

The North East courtyard provides four accessible and inclusive apartment blocks comprised of one to six room units, a range of indoor communal spaces for all residents, appropriate laundry space, rooftop garden and open outdoor lawn. These units meet the criteria outlined in this thesis and consider the wellbeing of their residents by designing for passive surveillance. 

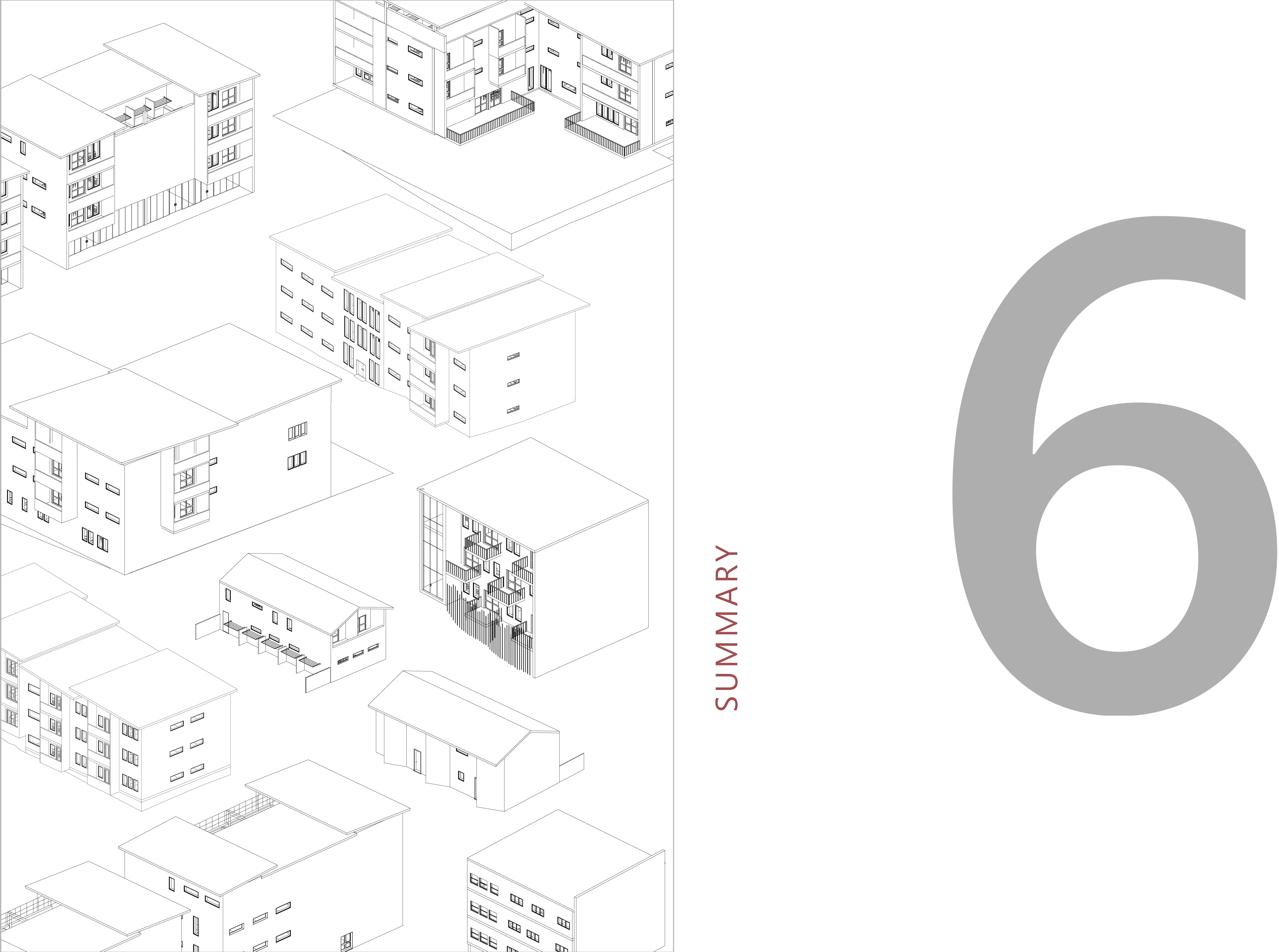


\section{Conclusion}

This thesis explored contemporary social housing in New Zealand and identified that Social housing is failing to meet the spatial needs of its diverse inhabitants. Although New Zealand was once an example of successful, popular social housing, the lack of consistent consideration of the diversity that comprises a household in today's society has resulted in a housing crisis. The housing crisis to date has been a discussion that focused predominantly on housing shortage and building performance. This thesis however identifies how social housing design has fallen below modern living standards and is not meeting the needs of its diverse range of occupants. By examining design methods and guidelines through research, this thesis outlines a more appropriate definition of for an inclusive social housing model in New Zealand.

An evaluation of a small sample of the existing housing stock, both international and domestic, has shown that there are a variety of ways appropriate social housing can be provided. Moreover, this evaluation highlights the importance of contextual analysis in order for any dwelling to be appropriate. These findings suggest that failing to test design proposals through this integral research approach will mean such a proposal will fail to meet the needs of its residents.

To better understand these needs a contextual analysis examining age, ethnicity, ability, family size and dwelling preferences within New Zealand's housing register was conducted. This analysis identified groups which had spatial requirements which were not consistent with the standard social housing model. These requirements were combined into criteria to which contemporary state houses could be compared against. Although the state housing case studies examined in this thesis failed to meet all criteria, this test established that designing for multiple cultures and needs is possible. Arlington Apartments in Wellington was chosen as a suitable site to explore these concepts as it is both suburban and urban, allowing a range of appropriate housing typologies to be proposed. Appropriate social housing was explored at three scales; the masterplan, the building envelope and thresholds, and the interior spatial planning. Each scale was developed individually, comprehensively incorporating the spatial criteria. The developed design focused on two areas of the scheme to bring together successful components of the initial design and to explore how the three scales could be dynamically altered to increase suitability. Five housing typologies in total were defined, made up of two-five storey buildings with interior and exterior communal space provided throughout the site.

By scrutinizing and developing the design intervention proposed against design methods and guidelines examined in this thesis, the design proposal of the five housing typologies has been specifically detailed to align with the occupant needs that make social housing more appropriate. An evaluation of the scheme, and the contextual analysis carried out for this, suggests that the designs proposed are more appropriate and inclusive.

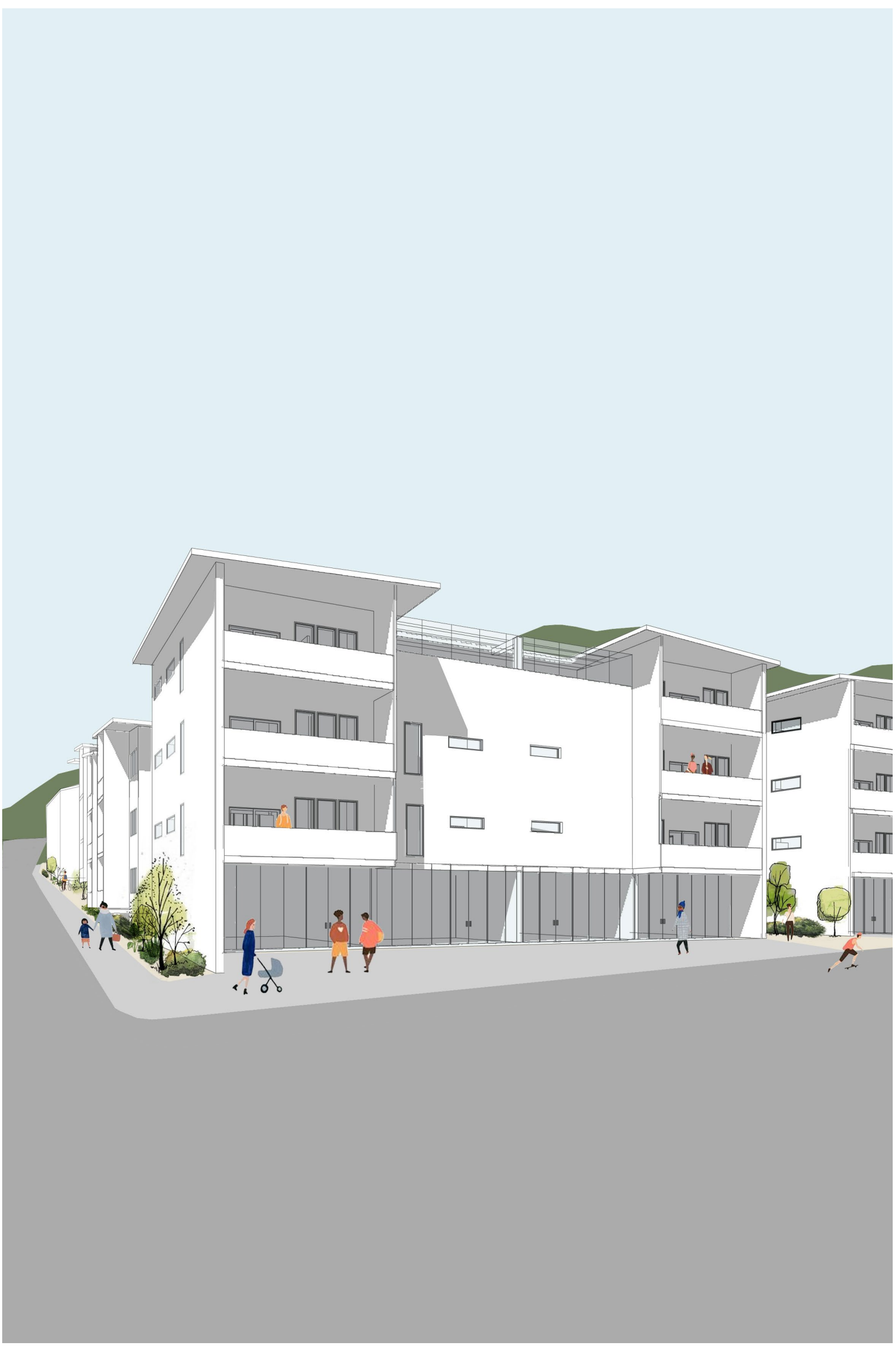

Figure 6.1: Standing on the corner of Hopper St and Arlington St 

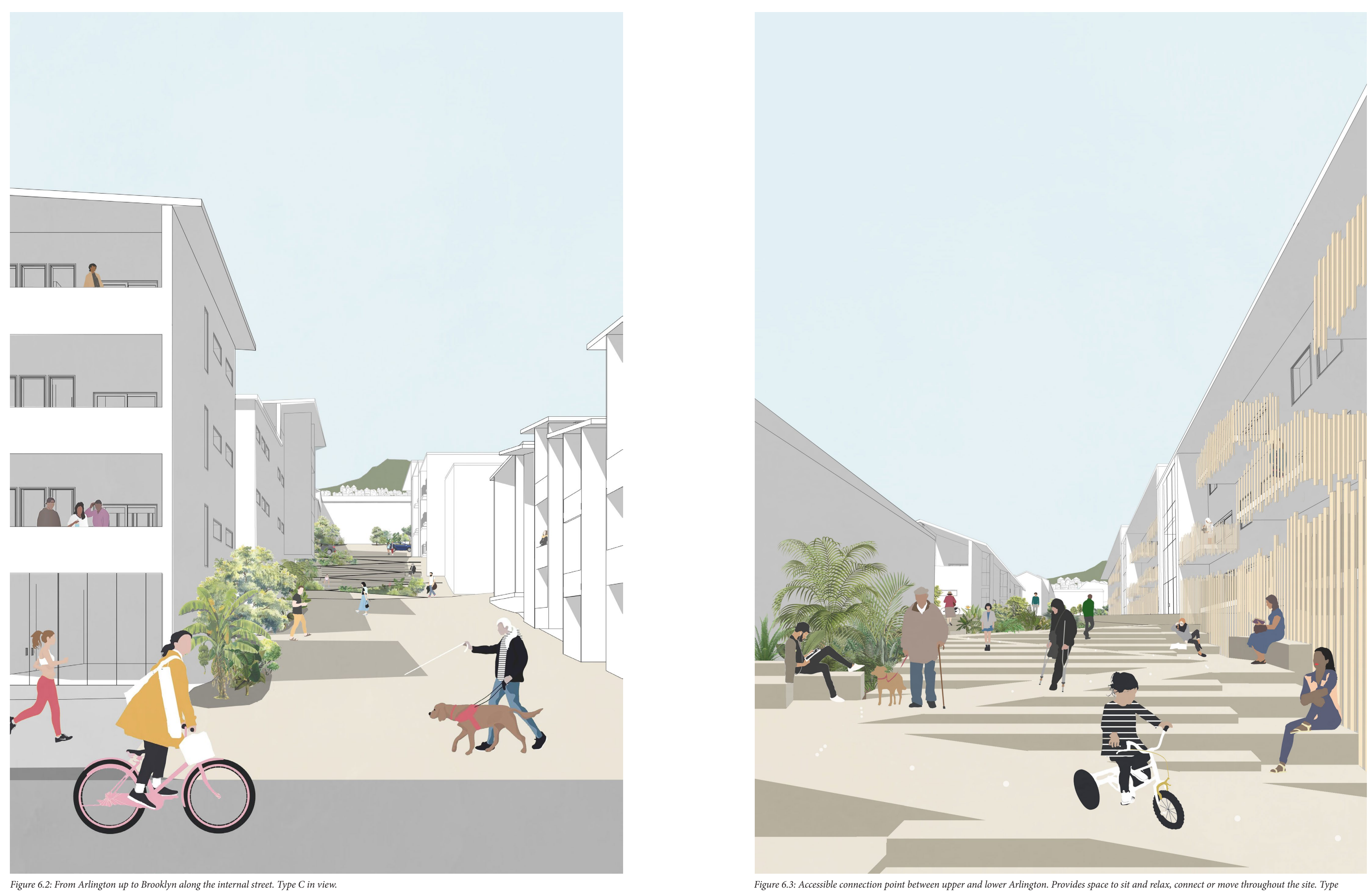


\section{Future Research}

This thesis carried out design-led research to define more appropriate and inclusive social housing in New Zealand. However, it should be noted that this research is not without limitations and there are plenty of practical steps further research can take to expand on this design outcome:

First, the design tests were site-specific, because this was essential to defining an appropriate social housing solution. However, this has meant that the design solution is appropriate to Arlington and could not be reproduced elsewhere without modification in response to the site. The initial design responses are not particularly context-specific and a similar process as the one presented in this thesis could be used to develop a design specific to any selected site. Any further research would need to apply this design approach in a wider context or another site. This would require an analysis including density, building use, building height and topography, and with a continual consideration of the inclusive/appropriate criteria outlined in this thesis.

Second, the scope of this thesis was limited to developing five-building typologies in two areas. These typologies cover a majority of the site, however, there are still inclusive spaces, both inside and out, which could not be defined without also responding to the specific building envelope. Further research could aim to improve and developed the entire scheme in greater detail.

Third, the criteria for appropriateness were developed by means of a review of relevant literature. This could be further enhanced by conducting an occupant based study to gage feedback from the resident, with particular focus to those on the housing register. A phenomenological approach to this research could result in a richer design response as it would be directly informed by those who are occupying state housing. Although this would not necessarily be statistically representative, especially considering the ever-changing diversity of the New Zealand population, it would allow for suggestions from potential residents of these homes to inform the overall design.

Finally, testing at three scales made it possible comprehensively develop a housing model. It was found that while the masterplan and building envelope would be designed in a variety of ways, the interior scale requirements could be met through spatial planning. Universal design guides and Lifemark provide detailed interior design solutions for accessible dwellings. This could be further supplemented with New Zealand's unique cultural requirements. While they are not outlined in the literature, this is where a phenomenological approach could also supplement this research. 


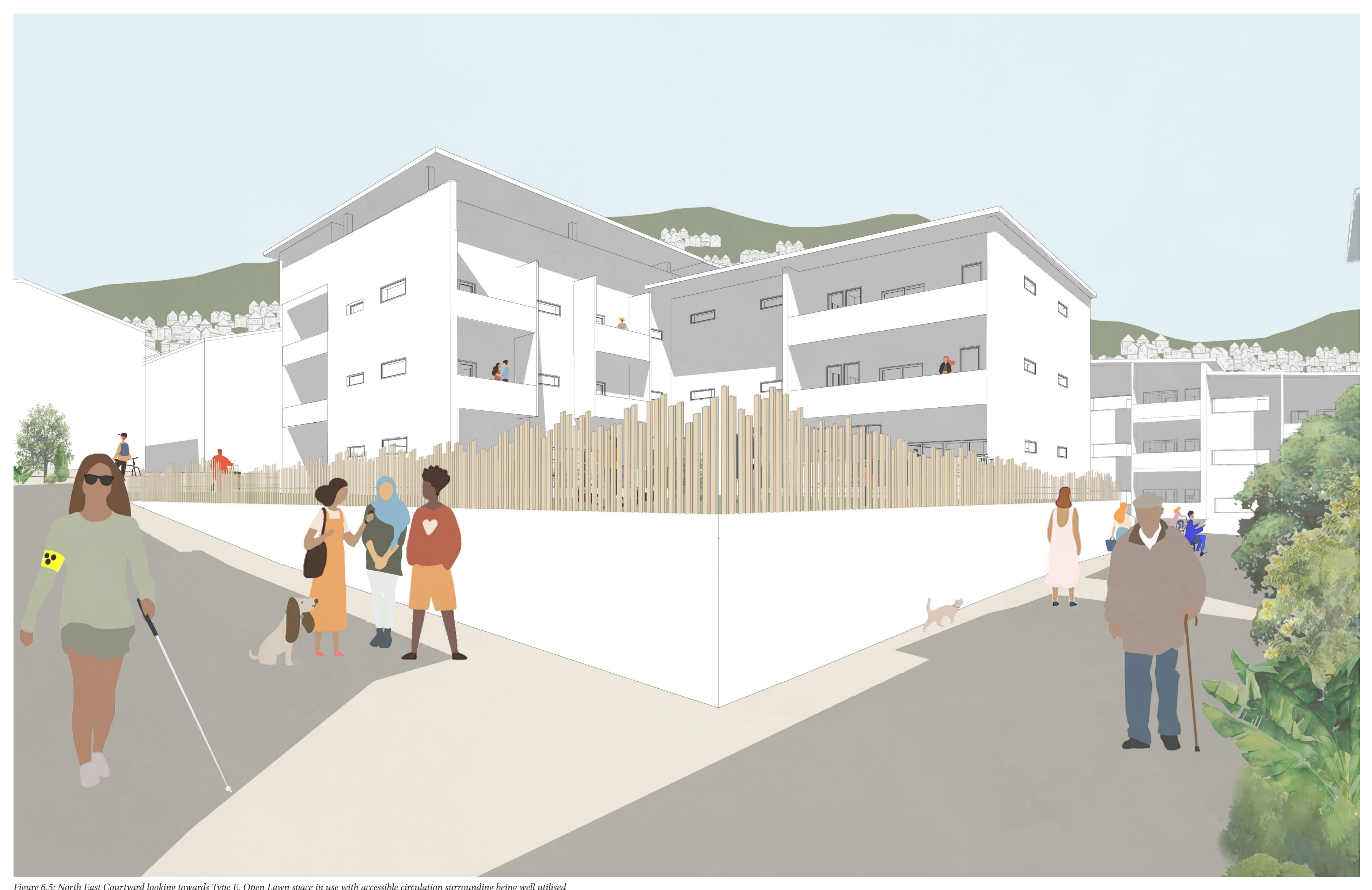




\section{Final Remarks}

The requirements of social housing have changed dramatically since it was first built in New Zealand in the 1890s. Planners, architects and designers must recognise the specific needs of the diverse community for whom they are designing for. The criteria established and tested through this design-led research thesis are intended to advance the capability of the profession to meet the needs of the current and future tenants of social housing. This thesis defined a more appropriate and inclusive social housing model, along with design solutions which could be implemented into existing state housing, or in future developments at a range of scales. From this research, social housing in New Zealand can provide for its diverse residents and be flexible in the way they may live in the future.

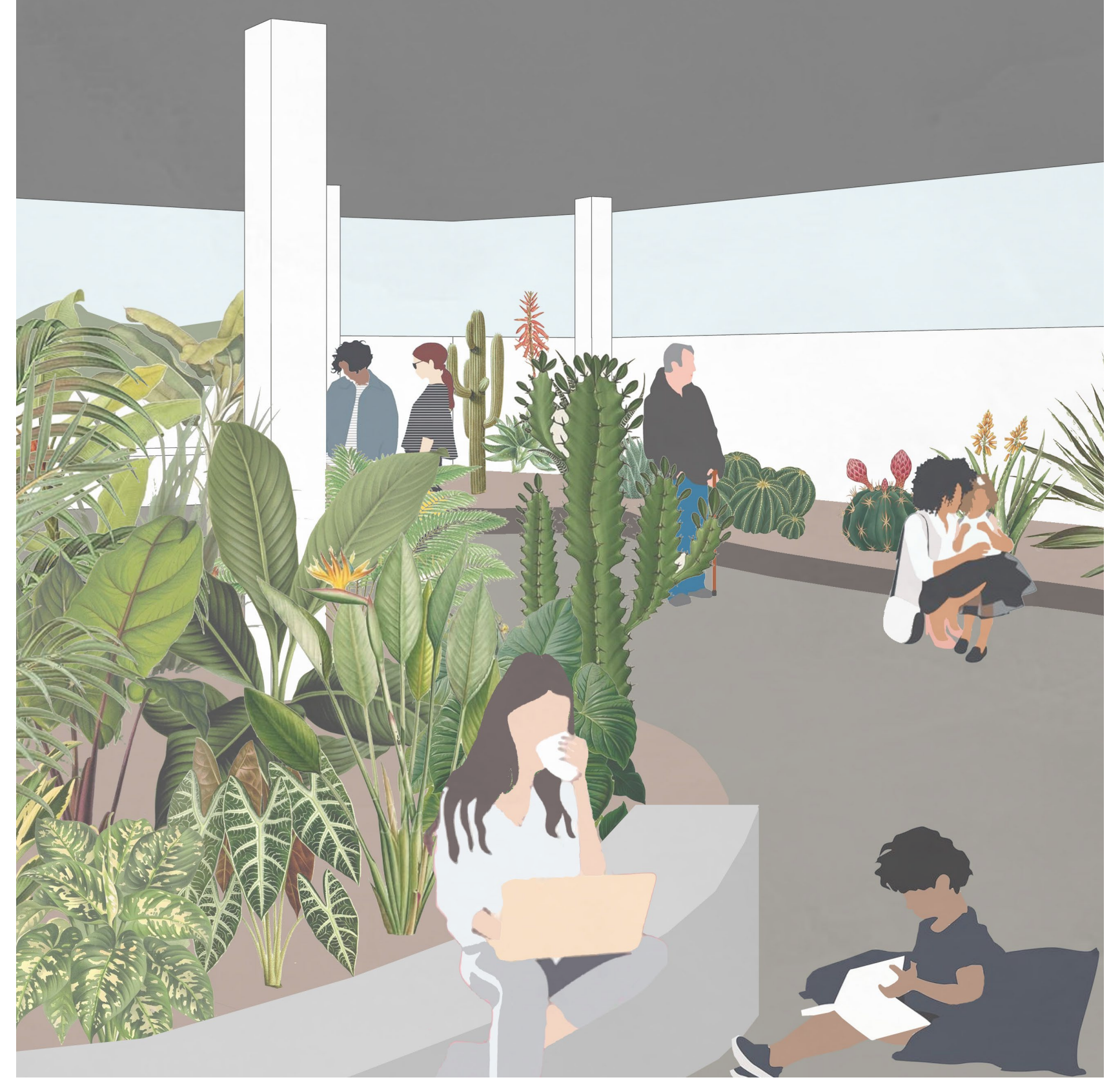

Figure 6.6: Rooftop Garden located in Type E. To be used by all residents to relax, take a break, or wait for their washing. 


\section{Bibliography}

Arrigoitia, M., Scanlon, K., Whitehead, C. (Ed.) (2014). Social housing in Europe. John Wiley \& Sons, Oxford. Retrieved from https://ebookcentral.proquest.com/lib/vuw/reader.action?docID=1676649

Auckland Council (2018). CPTED Principles. Auckland Design Manual. Retrieved from http://www. aucklanddesignmanual.co.nz/design-subjects/design-safety/perceptions/guidance/CPTEDintro\#/ design-subjects/design-safety/perceptions/guidance/CPTEDintro/CPTEDprinciples

Barton, J., Rogerson, M. (2017). The importance of greenspace for mental health. BJPsych International 14(4), 79-81. Retrieved from https://www.ncbi.nlm.nih.gov/pmc/articles/PMC5663018/

Beltrán, W., (2011). Descripción cuantitativa de la pluralización religiosa en Colombia. IHEAL Paris III Sorbonne Nouvelle. Colombia, Retrieved from http://www.bdigital.unal.edu.co/8486/1/ williammauriciobeltran.2011.pdf

Bertram, B. (Prod. \& Dir.), Blenkov, M. (Prod.) (2018). Human Shelter [DVD]. Denmark: Creative Alliance.

Boyce, S. A. (2009). Only the Houses Remain - The Demise of the State Housing Scheme in New Zealand. Kapiti, NZ: Wayside Press.

Braubach, M., Egorov, A., Mudu, P., Wolf T., Ward Thompson, C., Martuzzi, M. (2017) Effects of Urban Green Space on Environmental Health, Equity and Resilience. In: Kabisch N., Korn H., Stadler J., Bonn A. (eds) Nature-Based Solutions to Climate Change Adaptation in Urban Areas (pp. 187-205). doi:10.1007/978-3-319-56091-5_1

Bureau of Democracy, Human Rights and Labor, (2017). International Religious Freedom Report for 2017 (Burma). United States of America, Retrieved from https://www.state.gov/documents/ organization/281054.pdf

Cahill, N. (2017). Our Place - Public + Private Balance in a State Housing Community (Masters Thesis). Victoria University of Wellington, New Zealand.

Campo, J. E. (1991). The Other Sides of Paradise: Explorations into the Religious Meanings of Domestic Space in Islam. University of South Carolina Press, South Carolina.

Department of Census \& Statistics. (2012). Census of Population and Housing of Sri Lanka, 2012 [PDF, Table A4: Population by district, religion and sex]. Retrieved from http://www.statistics.gov.lk/ PopHouSat/CPH2011/Pages/Activities/Reports/FinalReport/Population/Table\%20A4.pdf
Enable. (2018). ACC-funded housing modifications for injured people. Retrieved from https://www. enable.co.nz/services/housing-modifications-for-disabled-people/acc-housing-modifications/

Ewans, M. (2004). Conflict in Afghanistan: Studies in Asymetric Warfare. London: Routledge

Faumina \& Associates. (2002). The Pacific Housing Design Guide. Retrieved from https://www.hnzc. co.nz/assets/Uploads/pacific-housing-design-guide.pdf

Gatley, J. (2008) Arlington Housing. Long Live the Modern. Ed. Julia Gatley. Auckland: Auckland University Press.

Gatley, J. (2013). Counterculture Themes in the Growth and Development of Athfield Architects. Proceedings of the Society of Architectural Historians, Australia and New Zealand, 2(30), 583-594.

Gellner, D., Gombrich R. (2015). Buddhism. International Encyclopaedia of the Social \& Behavioural Sciences, 886-893. http://dx.doi.org/10.1016/B978-0-08-097086-8.84001-5

Harvey, J. (007). Gentrification in the Sky? Community Care, 1674, 8. Retrieved from https://search. proquest.com/docview/223279677?rfr_id=info\%3Axri\%2Fsid\%3Aprimo

Herrle, P. (2017). Tibetan house: Vernacular architecture of the himalayas and environs. Retrieved from https://ebookcentral.proquest.com

Hoekstra, J. (2013). Social Housing in the Nertherlands: the development of the Dutch Social housing model. Delft, OTB Research Institute for the Built Environment.

Holmes, C. (2012). The Adaptable Dwelling (Masters Thesis). Victoria University of Wellington, New Zealand.

Hoskins, R. (2014). Ki te Hau Kainga, New Perspectives on Maori Housing Solutions. Retrieved from https://staticl.squarespace.com/static/57176f9f20c6478937696378/t/57da453715d5db41c38b6 dd1/1473922385746/KitehauKainga-August2014.pd

Howden-Chapman, P. (2015). Home Truths: Confronting New Zealand's Housing Crisis. Auckland: BWB Texts.

Housing New Zealand (2017). Accessible dwellings. Retrieved from https://www.hnzc.co.nz/housingdevelopments-and-programmes/our-developments/wellington-region-developments/view/hansonstreet 
Huynh, V. (2017). Secondhand Architecture - Finding Value in the Existing (Masters Thesis). Victoria University of Wellington, New Zealand.

International Commission of Jurists. (2012, April). International Commission of Jurists (ICJ) Submission to the Universal Periodic Review of Sri Lanka. Reviewed at 14th Session of the Working Group on the Universal Periodic Review at the United Nations Human Rights Council, Geneva, Switzerland. Retrieved from https://www.webcitation.org/6CR9h4Bvo?url=http://documents.icj.org/ICJ-UPR14SriLanka.pdf

Johnson, A. (2017). The Demand for Social Housing in New Zealand. Retrieved from https://www. salvationarmy.org.nz/sites/default/files/uploads/20170814spputakingstockreport.pdf

Karim, S., Khalid, S., Rana, M., Mubbashar, M., Jenkins, R. (2004) Pakistan mental health country profile. International Review of Psychiatry, 16(1-2), 83-92, DOI: 10.1080/0954026031000163513

Lal, B. (1992). Pacific Islands History: Journeys and transformations. Australian National University, Canberra.

Lifemark. (2012). Lifemark Design Standards Handbook. Retrieved from https://docs.tcdc.govt.nz/ store/default/3219847.pdf

Mace, R. (1985). Universal design, barrier-free environments for everyone. Designers West 33(1), 147152. Los Angeles.

McKay, B., Stevens, A., \& Devitt, S. (2014). Beyond the state: New Zealand state houses from modest to modern. Penguin Group, Auckland.

Mendell, M., Mirer, A., Cheung, K., Tong, M., Douwes, J. (2011). Respiratory and Allergic Health Effects of Dampness, Mold, and Dampness-Related Agents: A Review of the Epidemiologic Evidence. Environmental Health Perspectives, 119(6), 748-56. DOI: 10.1289/ehp.1002410

Ministry of Business, Innovation \& Employment (2017). Migration Trends. Retrieved from https:// www.mbie.govt.nz/assets/Uploads/c22ab0c547/migration-trends-2016-17.pdf

Ministry of Social Development (2018). Housing Quarterly Report - December 2018. Retrieved from https://www.hud.govt.nz/assets/Community-and-Public-Housing/Follow-our-progress/ December-2018/Housing-Quarterly-Report-December-2018-accessible-web.pdf
Ministry of Housing and Urban Development (2019). Housing Quarterly Report - June 2019 Retrieved from https://www.hud.govt.nz/assets/Community-and-Public-Housing/Follow-ourprogress/June-2019/cae7aaceaf/Housing-Quarterly-Report-June-2019.pdf

Ministry of Social Development (2017). Who can get public housing. Retrieved from http://housing. msd.govt.nz/housing-options/social-housing/who-can-get-social-housing.html

Ministry of Housing and Local Government (1961). Homes for today and tomorrow. HMSO,

London. Retrieved from https://archive.org/details/op1266209-1001/page/n3

Modi, S. (2014). Improving the Social Sustainability of High-Rises. Council on Tall Buildings and Urban Habitat, 1, 24-30. Retrieved from http://global.ctbuh.org/resources/papers/download/828improving-the-social-sustainability-of-high-rises.pdf

National Housing Commission. (1988). Housing New Zealand - Provision and Policy Crossroads. Five Yearly Report, March 1988.

Newman, O. (1973). Defensible Space - Crime Prevention Through Urban Design. New York, USA: The MacMillan Company.

Novak, S., Rangiwhetu, L. (2019, September). Making Social Housing Healthy \& Sustainable. Seminar presented at the meeting of the New Zealand Centre for Sustainable Cities, Wellington.

Omer, S. (2004). Islamic Values in House Design. Studies in the Islamic Built Environment, 140-186.

Parsloe, T. (2017). Appropriating buildings to house refugees: Berlin Tempelhof. Forced Migration review, 55, 35-36. Retrieved from http://web.b.ebscohost.com/ehost/pdfviewer/ pdfviewer?vid=0\&sid=b2af79fb-ea56-457a-a562-03e 180 c7515b\%40pdc-v-sessmgr0

Pearson, A., Griffin, E., Davies, A., Kingham, S. (2013). An ecological study of the relationship between socioeconomic isolation and mental health in the most deprived areas in Auckland, New Zealand. Health \& Place, 19, 159-166

Prorok C.V. (2015) The Diasporic Hindu Home Temple. In: Brunn S. (Ed.) The Changing World Religion Map. Springer, Dordrecht

Refugee Council USA, (2011). Living on the Edge: Columbian Refugees in Panama and Ecuador. Washington, DC: Retrieved from https://reliefweb.int/sites/reliefweb.int/files/resources/1F0F566B 5231BD649257862001BC934-Full_Report.pdf 


\section{List of Figures}

Sahney, P. (2010). Hindu Domestic Mandirs: Home Temples in Greater New York. Voices, 36(3), 3944. Retrieved from https://search.proquest.com/docview/818562038?accountid=14782

Schrader, B. (2007). State Housing. New Zealand Geographic, July/August(86). Retrieved from https://www.nzgeo.com/stories/state-housing/

Soper A. (1978). The evolution of Buddhist architecture in Japan. New York: Hacker Art Books.

Statistics New Zealand (2014). Disability Survey. Retrieved from http://archive.stats.govt.nz/ /media/Statistics/Browse\%20for\%20stats/DisabilitySurvey/HOTP2013/DisabilitySurvey2013HOTP.pdf

Stewart, M. (2014). Tower tenants 'living in fear' on inner city housing block. Stuff. Retrieved from http://www.stuff.co.nz/dominion-post/news/10506671/Tower-tenants-living-in-fear-on-inner-cityhousing-block

Takaoka, Y., Yamao, D., Hamanaka, S., Suechika, K., Nishikida, A., Aoyama, H., (2017). Report of Simple Tally of "Middle East Public Opinion Survey (Syria 2017) (Report No. 8). Japan: Retrieved from https://cmeps-j.net/wp-content/uploads/2017/07/report_syria2017_eng.pdf

Towers, G. (2000). Shelter is not enough - Transforming multi-storey housing. Bristol, UK: Policy Press.

United States Department of State. (2017). 2016 Report on International Religious Freedom: China (Includes Tibet, Hong Kong, and Macau). Retrieved from https://www.state.gov/j/drl/rls/irf/2016/ eap/268724.htm

Urban, F. (2012). Slab and Tower - Histories of Global Mass Housing. USA: Routledge.

Walden, R. (1981). The Rise of the Personal in New Zealand Architecture: Complexity and Contradiction in Athfield, Walker and Others, New Zealand Architect 4,30 .

Wellington City Council (2018). Our 10-Year Plan - Housing Strategy. Retrieved from https://wellington.govt.nz/ /media/your-council/plans-policies-and-bylaws/plans-and-policies/a-

to-z/housingstrategy/housing-strategy-j006215.pdf?la=en
All images unless stated are Author's own.

Figure 1.1: Sourced from Archives New Zealand \& Housing New Zealand

Figure 1.2: Sourced from Stuff, Data from MHUD (2018) \& MSD (2019)

Figure 1.3: Sourced from https://vanilla-square.co.uk/history-glasgows-tenements/

Figure 1.4: Sourced from https://news.stlpublicradio.org/post/design-competition-aims-revive-pruitt-igoe-site\#stream/0

Figure 1.5: Sourced from https://www.architectsjournal.co.uk/news/domesday-book-to-recordevery-tower-block-in-the-uk/8678535.article

Figure 1.6: https://www.archdaily.com/572616/pushed-slab-mvrdv

Figure 1.7: Sourced from http://www.spatialagency.net/database/meyer

Figure 1.8: Sourced from https://New Zealandhistory.govt.New Zealand/media/photo/state-housesin-porirua-east-1950s

Figure 1.9: Courtesy of Jason Mann and https://www.New Zealandia.co.New Zealand/awards/national/award-detail/3239\#Central\%20Park\%20Apartments

Figure 2.1-2.4: Data sourced from MSD Quarterly Report (December 2018)

Figure 2.8: Sourced from https://www.urbanclap.com/blog/interiors/mandir-designs-indian-homes/

Figure 2.9: Infographics adapted from: Irish Wheelchair Association (2014). Best Practice Access Guidelines Designing Accessible Environments (Edition 3). Retrieved from https://www.iwa.ie/ downloads/about/iwa-access-guidelines.pd

Figure 3.1: Courtesy of Studio Pacific Architecture

Figure 3.2: Courtesy of Designgroup Stapleton Elliott, Paul McCredie

Figure 3.3: Courtesy of Designgroup Stapleton Elliott, Paul McCredie

Figure 3.4: Courtesy of Andy Spain

Figure 3.5: Housing New Zealand https://www.hNew Zealandc.co.New Zealand/housing-developments-and-programmes/greys-ave/

Figure 3.10: Image given by Studio Pacific Architecture

Figure 3.11: Plans soured from Studio Pacific Architecture 
Figure 3.12: Wellington City Council. https://wellington.govt.New Zealand/your-council/projects/ arlington-apartments-redevelopment

Figure 3.13: Housing New Zealand \& HLC. https://owairakadevelopment.co.New Zealand/

Figure 3.14: Mana News. http://mananews.co.New Zealand/wp/?p=4791

Figure 3.16: King \& Dawson Architects via Wellington City Archives.

Figure 3.20-3.22: Original plans sourced King \& Dawson Architects via Wellington City Archives. Diagrams overlaid are Author's Own.

thank you. 